U.S. Department

of Transportation

National Highway

Traffic Safety

Administration

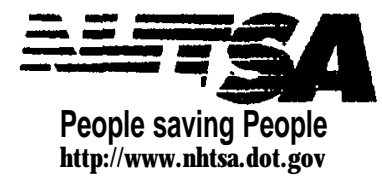

DOT HS 808467

October 1996

Final Report Supplement

\title{
Heavy Vehicle Driver Workload Assessment Task 6: Baseline Data Study
}

This document is available to the public from the National Technical Information Service, Springfield, Virginia 22161. 
This research was supported (in part) by the $\mathrm{National} \mathrm{Highway} \mathrm{Traffic} \mathrm{Safety} \mathrm{Administration}$ (NHTSA), U.S. D epartment of Transportation, U nder Contract N o. DTNH22-91-C-07003, The opinions, findings and recommendations contained herein are those of the authors, and do not necessarily represent those of the NHTSA. 
Technical Report Documentation Page

\begin{tabular}{|c|c|c|}
\hline 1. Report No. & $\begin{array}{l}\text { 2. Government Accession No. } \\
\text { DOT HS } 808467 \quad \text { (6) }\end{array}$ & 3. Recipient's Catalog No. \\
\hline \multirow{2}{*}{\multicolumn{2}{|c|}{$\begin{array}{l}\text { 4. Title and Subtitle } \\
\text { Final Report Supplement -- Task 6: Baseline Data Study }\end{array}$}} & $\begin{array}{l}\text { 5. Report Date } \\
\text { September, } 1995\end{array}$ \\
\hline & & 6. Performing Organization Code \\
\hline \multicolumn{2}{|c|}{ 7. Author(s) $\quad$ L. Tijerina, S. Kiger, T. Rockwell, C. Tomow, J. Kinateder, F. Kokkotos } & 5. Performing Organization Report No. \\
\hline \multirow{2}{*}{\multicolumn{2}{|c|}{$\begin{array}{l}\text { 9. Performing Organization Name and Address } \\
\text { Battelle Memorial Institute } \\
505 \text { King Avenue } \\
\text { Columbus, OH } 43201-2693\end{array}$}} & 10. Work Unit No. (TRAIS) \\
\hline & & $\begin{array}{l}\text { 11. Contract or Grant No. } \\
\text { DTNH22-91-C-07003 }\end{array}$ \\
\hline & & 13. Type of Report and Period Covered \\
\hline \multirow[t]{2}{*}{ 12. Sponsoring Agency Name and Address } & \multirow{2}{*}{$\begin{array}{l}\text { Office of Crash Avoidance Research } \\
\text { National Highway Traffic Safety } \\
\text { Administration } \\
4007 \text { th Street, NRD-50 } \\
\text { Washington, DC } 20590\end{array}$} & $\begin{array}{l}\text { Final Report } \\
\text { July, } 1991 \text {-September, } 1995\end{array}$ \\
\hline & & 14. Sponsoring Agency Code \\
\hline
\end{tabular}

\section{Supplementary Notes}

Contracting officer's Technical Representative: Dr. Michael J. Goodman (NRD-50)

\section{Abstract}

This report consists of an empirical establishment of heavy vehicle driver baseline performance data. Researchers interested in highway safety have called out the need for rudimentary workload data so that they might have a basis for comparison of workload associated with particular in-cab high technology devices. Thirty (30) professional drivers participated and were asked to perform a series of tasks during over-the-road drives involving both open road driving and close car following in both day and night conditions. The requested tasks included looking at right and left mirrors, adjusting $\mathrm{CB}$ volume, changing $\mathrm{CB}$ frequency, manually tuning the radio, adjusting radio volume, reading clock, reading air pressure, adjusting the heating or air conditioning, and calculating available driving hours. Drivers were measured with respect to visual allocation; steering, accelerator, and brake inputs; speed and headway maintenance; and lanekeeping. Results indicated that, to a varying degree, visual allocation measures, several steering measures, speed variance, and several lane position measures are preferable measures for further workload assessment.

\section{Key Words}

18. Distribution Statement

human factors, heavy vehicle, workload, driving tasks, baseline data, normal driving

\footnotetext{
19. Security Classif. (of this report)
}

20. Security Classif. (of this Page)

21. No. of Pages

22. Price 132 


\section{TABLE OF CONTENTS}

Page

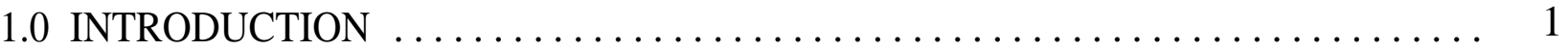

$1.1 \quad$ Background $\ldots \ldots \ldots \ldots \ldots \ldots \ldots \ldots \ldots \ldots \ldots \ldots \ldots \ldots \ldots \ldots \ldots \ldots \ldots, 1$

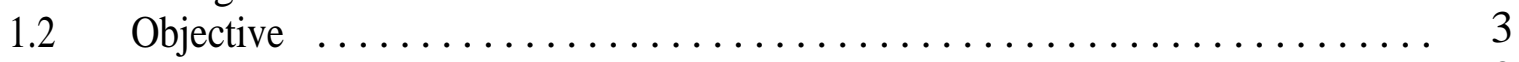

$1.3 \quad$ Organization of the Report $\ldots \ldots \ldots \ldots \ldots \ldots \ldots \ldots \ldots \ldots \ldots \ldots \ldots \ldots$

2.0 METHODOLOGY........................................ 5

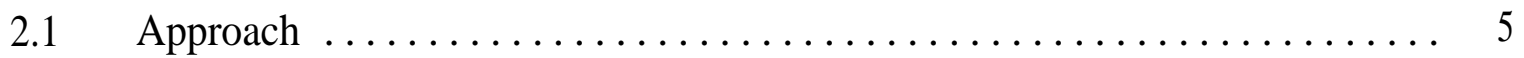

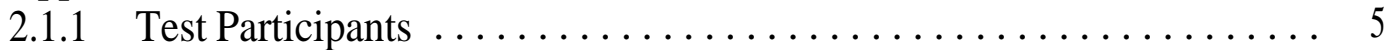

2.1.2 Test Vehicle ................................ 5

2.2 Instrumentation: Video Recording System, Sensors, and Data Capture System . 5

$2.2 .1 \quad$ Video Recording System .......................... 6

2.2.2 Engineering Data Capture System $\ldots \ldots \ldots \ldots \ldots \ldots \ldots \ldots \ldots \ldots$

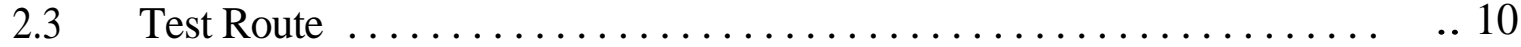

2.4 Driving Scenarios and Requested Tasks $\ldots \ldots \ldots \ldots \ldots \ldots \ldots \ldots \ldots \ldots \ldots \ldots \ldots \ldots \ldots$

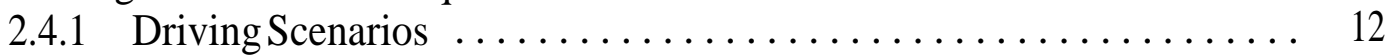

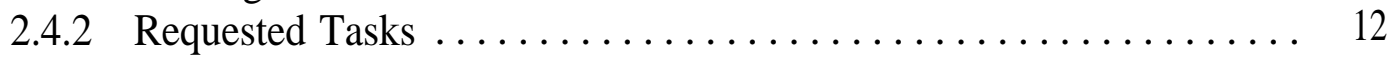

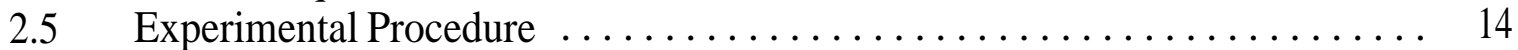

2.5.1 Pre-Trip Procedure $\ldots \ldots \ldots \ldots \ldots \ldots \ldots \ldots \ldots \ldots \ldots \ldots \ldots \ldots$

2.5.2 Over-the-Road Procedure $\ldots \ldots \ldots \ldots \ldots \ldots \ldots \ldots \ldots \ldots \ldots$

2.5.3 Post-Run Participant Debriefing $\ldots \ldots \ldots \ldots \ldots \ldots \ldots \ldots \ldots \ldots \ldots$

2.6 Statistical Analysis Approach ............................. 15

2.6.1 Outliers and Transformations $\ldots \ldots \ldots \ldots \ldots \ldots \ldots \ldots \ldots \ldots \ldots \ldots$

2.6.2 Standardization and Weighting $\ldots \ldots \ldots \ldots \ldots \ldots \ldots \ldots \ldots \ldots \ldots$

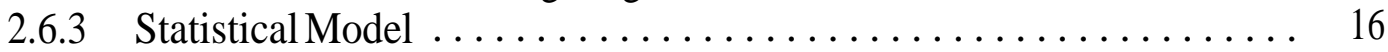

$2.7 \quad$ Dependent Measures $\ldots \ldots \ldots \ldots \ldots \ldots \ldots \ldots \ldots \ldots \ldots \ldots \ldots . \ldots \ldots$

3.0 RESULTS: VISUAL ALLOCATION DATA $\ldots \ldots \ldots \ldots \ldots \ldots \ldots \ldots \ldots \ldots$

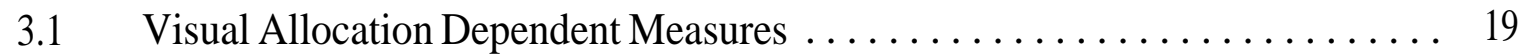

3.2 Results for Visual Allocation Measures in Open Road Driving . . . . . . . . . 20

3.2.1 Road Type Effects on Visual Allocation in Open Road Driving ....... 20

3.2.2 Lighting Effects on Visual Allocation in Open Road Driving ........ 22

3.2.3 Interaction of Road Type and Light on Visual Allocation in Open Road

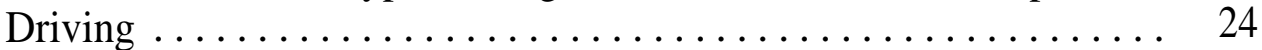

3.3 Results for Visual Allocation in Car Following .................. 24

3.3.1 Road Type Effects on Visual Allocation in Car Following .......... 26

3.3.2 Lighting Effects on Visual Allocation Measures During Car Following . 26 


\section{TABLE OF CONTENTS (Continued)}

$\underline{\text { Page }}$

3.4 Results of a Comparison of Open Road Driving and Car Following Scenario Effects on Visual Allocation ......................... 26

3.4.1 Driving Scenario (Open Road Driving versus Car Following) Effects on Visual Allocation Measures . . . . . . . . . . . . . . . . . . . . . . 29

3.4.2 Results of the Interaction Between Road Type x Driving Scenario on Visual Allocation Measures .........................29

3.5 Results of Requested Task Execution During Open-Road Driving on Visual Allocation Requested ..................................... .29

3.5.1 Effects of Requested Task on Visual Allocation Measure .......... 32

3.5.2 Effects of Road Type on Visual Allocation Measures During Requested Device Use in Open Road Driving . . . . . . . . . . . . . . . . . .35

3.5.3 Effects of Requested Task x Road Type Interactions on Visual Allocation Measures in Open Road Driving ..................... - 35

3.6 Discussion . . . . . . . . . . . . . . . . . . . . . . . . . . . . . . . . . ... 39

4.0 RESULTS: STEERING, ACCELERATOR, AND BRAKE MEASURES . . . . . . . . . . 42

$4.1 \quad$ Steering, Accelerator, and Brake Dependent Measures .............. 42

4.2 Results: Steering, Accelerator, and Brake Effects in Open Road Driving ..... 43

4.2.1 Effects of Road Type on Steering, Accelerator, and Brake Measures in

Open Road Driving ........................... .43

4.2.2 Effects of Light on Steering, Accelerator and Brake Measures in Open Road Driving .............................. 45

4.3 Results: Steering, Accelerator, and Brake Measures in Car Following . . . . . 45

4.3.1 Effects of Road Type on Steering, Accelerator, and Brake Measures in Car Following ............................. 45

4.3.2 Effects of Light on Steering, Accelerator and Brake Measures in Car Following ............................. 48

4.4 Results: Steering, Accelerator, and Brake Measures in Comparison of Driving Scenarios (Open Road Driving versus Car Following) . . . . . . . . . . .48

4.4.1 Effects of Driving Scenario on Steering, Accelerator, and Brake Measures

4.4.2 Effects of Driving Scenario x Road Type Interactions on Steering, Accelerator, and Brake Measures $\ldots \ldots \ldots \ldots \ldots \ldots \ldots . \ldots$

4.4.3 Effects of Driving Scenario x Light Interaction on Steering, Accelerator, and Brake Measures $\ldots \ldots \ldots \ldots \ldots \ldots \ldots \ldots \ldots \ldots$

4.5 Results: Steering, Accelerator, and Brake Measures During Requested Task Execution ............................. 54

4.5.1 Effects of Road Type on Steering, Accelerator, and Brake Measures During Requested Task Execution $\ldots \ldots \ldots \ldots \ldots \ldots \ldots \ldots$ 


\section{TABLE OF CONTENTS (Continued)}

$\underline{\text { Paee }}$

4.5.2 Effects of Light on Steering, Accelerator, and Brake Measures During Requested Task Execution . ., ...................... 54

4.5.3 Effects of Requested Task on Steering, Accelerator, and Brake Measures During Requested Task Execution .................. 54

4.5.4 Effects of Road Type x Requested Task Interaction on Steering, Accelerator, and Brake Measures During Requested Task Execution . . 58 4.5.5 Effects of Road Type x Light Interaction on Steering, Accelerator, and Brake Measures During Requested Task Execution ............ 58

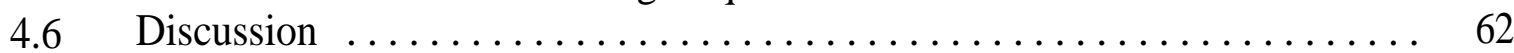

5.0 RESULTS: SPEED AND HEADWAY AND DATA $\ldots \ldots \ldots \ldots \ldots \ldots \ldots \ldots \ldots . .64$

$5.1 \quad$ Longitudinal Control Dependent Measures ....................... 64

5.2 Results for Speed Measures During Open Road Driving . . . . . . . . . . . . 64

5.3 Results for Speed and Headway Measures in Car Following . . . . . . . . . . 65

5.4 Results of Comparison of Open Road Driving and Car Following Driving Scenario Effects on Speed Measures ........................... .67

5.5 Effects on Requested Task Execution During Open Road Driving on Speed Measures ..................................... . 70

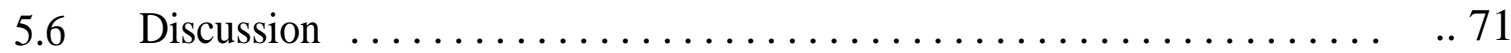

6.0 RESULTS: ANALYSIS OF LANEKEEPINGMEASURES $\ldots \ldots \ldots \ldots \ldots \ldots, 74$

$6.1 \quad$ Lanekeeping Dependent Measures $\ldots \ldots \ldots \ldots \ldots \ldots \ldots \ldots \ldots \ldots \ldots \ldots$

6.2 Results of Lanekeeping Measures during Open Road Driving . . . . . . . . . 74

6.3 Results of Lanekeeping Measures during Car Following . . . . . . . . . . . . 75

6.4 Results of Comparison between Driving Scenarios (Open Road Driving, Car Following) on Lanekeeping Measures $\ldots \ldots \ldots \ldots \ldots \ldots \ldots \ldots \ldots . \ldots 1$

6.5 Results of Lanekeeping Measures during Requested Task Execution $\ldots \ldots .81$

6.6 Discussion $\ldots \ldots \ldots \ldots \ldots \ldots \ldots \ldots \ldots \ldots \ldots \ldots \ldots \ldots . \ldots . \ldots \ldots$

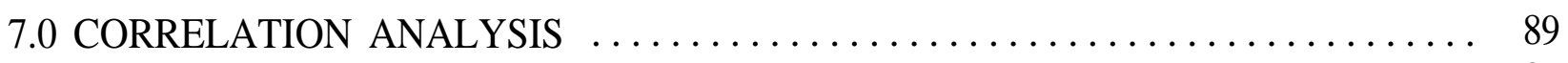

7.1 Correlations: Open Road Driving ......................... 89

7.2 Correlations: Car Following .......................... 100

7.3 Correlations: Requested Tasks ....................... 109

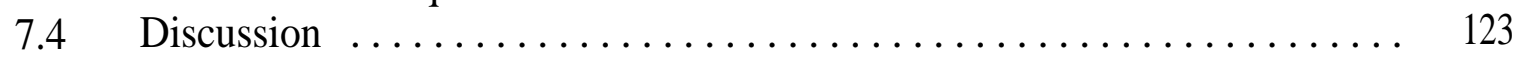

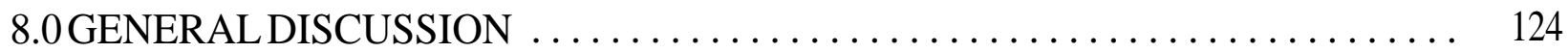

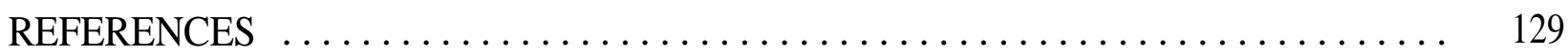

Appendix A: Subject Biographical Data Summary $\ldots \ldots \ldots \ldots \ldots \ldots \ldots \ldots \ldots$ A-1 


\section{TABLE OF CONTENTS (Continued)}

$\underline{\text { Paee }}$

Appendix B: Subject Instructions $\ldots \ldots, \ldots, \ldots \ldots \ldots \ldots \ldots \ldots \ldots \ldots \ldots \ldots$ B-1

Appendix C: Informed Consent Form $\ldots \ldots \ldots \ldots \ldots \ldots \ldots \ldots \ldots \ldots \ldots \ldots \ldots \ldots \ldots \ldots \ldots$

Appendix D: Checklist for Tasks and Naturally Occurring Maneuvers .............. D-1

Appendix E: Summary of Subject Debriefing $\ldots \ldots \ldots \ldots \ldots \ldots \ldots \ldots \ldots \ldots \ldots \ldots \ldots \ldots$ 


\section{LIST OF FIGURES}

Page

Figure 2-1. Schematic Diagram of the Video Recording System ............... 7

Figure 2-2. Schematic of Video Data Reduction System ..................... 8 


\section{LIST OF TABLES}

Page

Table 3.2.1 Means of Visual Allocation Measures that Significantly Differed as a Function of Road Type in Open Road Driving . . . . . . . . . . . . .21

Table 3.2.2 Means of Visual Allocation Measures that Significantly Differed as a Function of Light Level in Open Road Driving ................., 23

Table 3.2.3 Interaction of Road Type and Light Level in Terms of Mean On-road Glance Duration (MORT) .................................... .

Table 3.3.1 Significant Road Type Effects on Visual Allocation Measures During Car

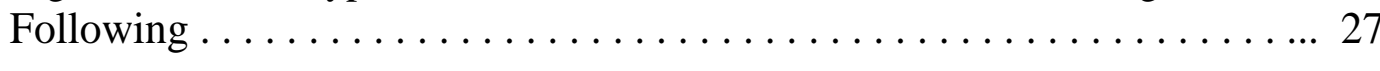

Table 3.32 Visual Allocation Measures that Significantly Differed by Lighting During Car

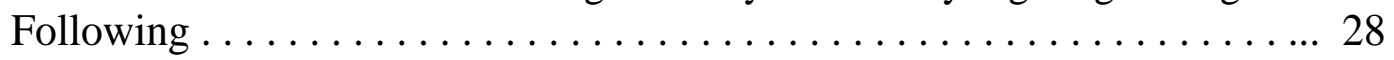

Table 3.4.1 Driving Scenario (Open Road Driving Versus Car Following) Effects on Visual Allocation...

Table 3.4.2 Significant Interaction Effects of Road Type x Driving Scenario (Open Road Driving Versus Car Following) on Visual Allocation Measures ........... 31

Table 3.5.1 Effects of Requested Task on Visual Allocation Measures in Open Road Driving33

Table 3.52 Effects of Road Type on Visual Allocation Measures During Requested Task Execution in Open Road Driving ......................... 36

Table 3.5.3 Effects of Requested Task x Road Interactions on Visual Allocation Measures During Open Road Driving . . . . . . . . . . . . . . . . . . . 37

Table 3.6.1 Visual Allocation of Heavy Vehicle Drivers by Location . . . . . . . . . . . . 40

Table 4.2.1 Significant Effects of Road Type on Steering, Accelerator, and Brake Measures in Open Road Driving . . . . . . . . . . . . . . . . . . . . . . . . 44

Table 4.2.2 Significant Effects of Light on Steering, Accelerator, and Brake Measures in Open Road Driving ................................... 46 


\section{LIST OF TABLES}

$\underline{\text { Page }}$

Table 4.3.1 Significant Effects of Road Type on Steering, Accelerator, and Brake Measures in

CarFollowing................................... 47

Table 4.3.2 Significant Effects of Light on Steering, Accelerator, and Brake Measures in CarFollowing..................................... 49

Table 4.4.1 Significant Effects of Driving Scenario on Steering, Accelerator, and Brake Measures in Car Following ......................... 51

Table 4.4.2 Significant Effects of Driving Scenario x Road Type Interaction on Steering, Accelerator, and Brake Measures . . . . . . . . . . . . . . . . . 52

Table 4.4.3 Effects of Driving Scenario x Light Interaction on Steering, Accelerator, and Brake Measures .........................., .... 53

Table 4.5.1 Significant Effects of Road Type on Steering, Accelerator, and Brake Measures During Requested Task Execution . . . . . . . . . . . . . . . . . . . . 55

Table 4.5.2 Significant Effects of Light on Steering, Accelerator, and Brake Measures During Requested Task Execution ............, ......., . ., . . 56

Table 4.5.3 Significant Effects of Requested Task on Steering, Accelerator, and Brake Measures During Requested Task Execution ................... 57

Table 4.5.4 Significant Effects of the Interaction Between Requested Task and Road Type on Steering, Accelerator, and Brake Measures During Requested Task Execution . 59

Table 4.5.5 Significant Effects of the Interaction Between Road Type and Light on Steering, Accelerator, and Brake Measures During Requested Task Execution . . . . . . . . 61

Table 5.2.1 Effects of Road Type on Speed Measures During Open Road Driving . . . . . 66

Table 5.3.1 Headway Measures that Significantly Differed by Road Type (Urban Versus Rural Freeway) Under Car Following Conditions ................ 68

Table 5.3.2 Headway Measures that Significantly Differed by Light Level (Day Versus Night) Under Car Following Conditions . . . . . . . , . . . . . . . . . . . 69 


\section{LIST OF TABLES}

$\underline{\text { Page }}$

Table 5.5.1 The Interaction Between Requested Task and Light on Speed Variance in Open Road Driving. ............................. 72

Table 6.2.1 Significant Effects of Road Type on Lanekeeping Measures in Open Road Driving ................................. 76

Table 6.2.2 Significant Effects of Light on Lanekeeping Measures in Open Road Driving . 77

Table 6.3.1 Significant Effects of Road Type on Lanekeeping Measures During Car

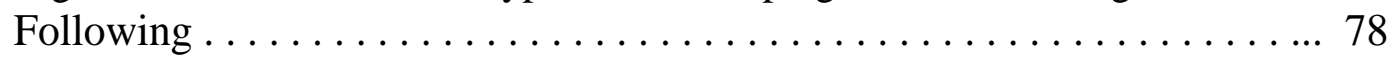

Table 6.3.2 Significant Effects of Light on Lanekeeping Measures in Car Following . . . . . 79

Table 6.3.3 Significant Effects of Road Type x Light Interaction on Lanekeeping Measures During Car Following . . . . . . . . . . . . . . . . . . . 80

Table 6.4.1 Significant Effects of Road Type x Driving Scenario Interactions on Lanekeeping Measures ...................................8 82

Table 6.5.1 Statistically Significant Effects of Requested Task on Lanekeeping Measures in Open Road Driving. ............................... 83

Table 6.5.2 Significant Effects of Road Type on Lanekeeping Measures During Requested Task Execution. ................................. 84

Table 6.5.3 Statistically Significant Effects of Requested Task x Road Type Interactions on Lanekeeping Measures . . . . . . . . . . . . . . . . . . . 86

Table 7.1.1 Correlations Among Visual Allocation Measures and Steering, Accelerator, and Brake Measures in Open Road Driving . . . . . . . . . . . . . . -90

Table 7.1.2 Correlations Among Visual Allocation Measures and Speed Measures in Open Road Driving.. . . . . . . . . . . . . . . . . . . . . . 93

Table 7.1.3 Correlations Among Visual Allocation Measures and Lanekeeping Measures Collected During Open Road Driving ......................... .95

Table 7.1.4 Correlations Among Lanekeeping Measures and Steering, Accelerator, and Brake Measures . . . . . . . . . . . . . . . . . . . . . . . 96 


\section{LIST OF TABLES}

\section{Page}

Table 7.1.5 Correlations Among Various Lanekeeping Measures and Speed Measures

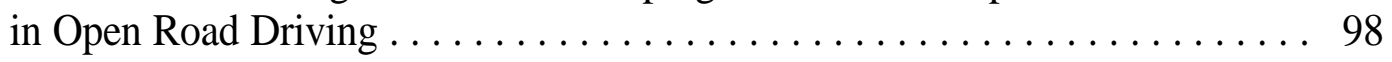

Table 7.1.6 Correlations Among Steering, Accelerator, and Brake Measures and Speed Measures .............................. 99

Table 7.2.1 Correlations Among Visual Allocation Measures and Steering, Accelerator, and Brake Application Dependent Measures During Car Following ....... 101

Table 7.2.2 Correlations Among Visual Allocation, Speed, and Headway Measuring During Car Following.

Table 7.2.3 Correlations Among Visual Allocation Measures and Lanekeeping Measures During Car Following ............................ 105

Table 7.2.4 Correlations Among Lanekeeping and Steering, Accelerator, and Brake Measures During Car Following ....................... 106

Table 7.2.5 Correlations Among Pairs of Lanekeeping Measures, Speed Measures, and Headway Measures During Car Following ................... 108

Table 7.2.6 Correlations Among Speed and Headway Measures and Steering, Accelerator and Steering Measures During Car Following ................. 110

Table 7.3.1 Correlations Among the Visual Allocation Measures and Steering, Accelerator, and Brake Measures Taken During Requested Task Execution ........., . 112

Table 7.3.2 Correlations Among Visual Allocation and Speed Measures During Requested Task Execution ............................ 115

Table 7.3.3 Correlations Among Visual Allocation Measures and Lanekeeping Measures During Requested Task Execution .., . . . . . . . . . . . . . . . . . 117

Table 7.3.4 Correlations Among Steering, Accelerator, and Brake Measures and Speed Measures During Requested Task Execution ................... 118

Table 7.3.5 Correlations Among Lanekeeping Measures and Speed Measure Taken During Requested Task Execution ............................ 120 


\section{LIST OF TABLES}

\section{Page}

Table 7.3.6 Correlations Among Lanekeeping Measures and Steering, Accelerator, and Brake Measures During Requested Task Execution .................. 121 


\subsection{INTRODUCTION}

\subsection{Background}

For drivers in general, and heavy vehicle drivers in particular, highway safety depends in large part on attending to the primary task of safely controlling the vehicle at all times. In recent years, a wide variety of products have been proposed and developed for use in heavy trucks. With the advent of the Intelligent Transportation Systems (ITS) initiative, the proliferation of high technology, in-cab devices is expected to increase. Examples of such systems include the following:

- Driver information and route guidance systems

- $\quad$ Text displays (e.g., pick-up address, package type)

- Vehicle subsystem monitoring and warning systems (e.g., tire pressure, oil pressure, brake failure, load shifting)

- $\quad$ Computerized trip recorders (e.g., automatic record of speed, RPM, stops; driver entry of fuel purchase; state-line crossings)

- $\quad$ Sophisticated voice communication links (e.g., cellular phone systems)

- $\quad$ Crash Avoidance Systems (e.g., infra-red and TV systems, perspective displays)

- $\quad$ Changes to existing control and display systems (e.g., head-up displays).

Many of these high technology devices may introduce subsidiary tasks which may compete with the primary task of driving. This competition is what is referred to by the phrase "driver workload" in this report. Some of these devices can probably be used concurrently with the primary driving task without competition, but others may not. It is reasonable to assume that the inventors and manufacturers of these systems intend for these systems to enhance commercial vehicle operations efficiency and effectiveness, to help the driver in doing the job at hand, and to be safe. However, without an assessment of the driver workload associated with a high technology device, the safety of the system remains largely unknown.

What is needed is a set of workload assessment techniques with which to assess the safety implications of a device from the driver's perspective. In response to this need to assess the safety implications, the National Highway Traffic Safety Administration (NHTSA) has funded research and development of a workload assessment protocol (Tijerina, Kiger, Rockwell, and Wierwille, 1995). It is intended that the workload assessment protocol can 
serve as a basis for standard practice in the field of driver workload test and evaluation. In industry, there exist Good Laboratory Practices (GLP), Good Manufacturing Practices (GMP), and ISO 9000 standards and certification. The field of driver-oriented test and evaluation of devices also benefits from similarly promulgated good "evaluation" practices. The Workload Assessment Protocol can serve as a draft for such a standard.

This report covers the sixth in a series of tasks involving the assessment of driver workload in heavy vehicle operation associated with in-cab devices or systems. A review of the overall study was provided by Tijerina, Kantowitz, Kiger, and Rockwell (1994). This phase of the work had as its chief objective the development of a baseline of driver visual allocation, in-cab behaviors, and driver-vehicle performance under different driving conditions, driving tasks, and in-cab tasks while on the road.

In an earlier interim report, Wierwille, Tijerina, Kiger, Rockwell, and Bittner (1992) reviewed research that indicated many factors influence driver workload. For this reason, there is a need to collect data under realistic driving conditions to determine "normal" or societally accepted variations in driver visual allocation, in-cab behavior, and driver-vehicle performance. Based on other research reported in Kiger, Rockwell, Niswonger, Tijerina, Myers, and Nygren (1992), driving condition variables that can influence the demand of driving include traffic density, road type, lighting (day, night), traction, and visibility. It has also been determined that driving tasks or driving scenarios (e.g., car following, lane changes, etc.), can also change the demand of the primary task of driving. There is also evidence that in-cab tasks differ in the visual demand they place on the driver (Rockwell, 1988; Dingus et al., 1989). It is clear that virtually any in-cab task will demand greater attention away from the driving task than driving without in-cab device use (Dingus \& Hulse, 1993). Furthermore, the current state-of-the-art in highway safety and driver workload research is such that relative workload assessments are quite feasible but absolute predictive safety assessments are difficult if not impossible in most cases. Thus, there is a need for baseline data against which to compare the results associated with particular in-cab tasks.

There is frequently a need to understand baseline driving performance and behavior for highway safety research and workload assessment. In the realm of crash avoidance, for example, there have been repeated instances where modeling crash countermeasures would be materially enhanced with baseline data on driver performance and behavior. Examples include lane change time and lane change distance (Chovan, Tijerina, Alexander, and Hendricks, 1994), backing accelerations and speeds (Tijerina, Hendricks, Pierowicz, Everson, and Kiger, 1993), left-turn across path trajectories (Chovan, Tijerina, Everson, Pierowicz, and Hendricks, 1994), and others. Note that this paucity of data refers specifically to passenger car drivers. The paucity of data on heavy vehicle drivers is even more severe. In terms of data collected on the road, no studies were uncovered that provided heavy vehicle driver visual allocation, in-cab driver behavior, or drivervehicle performance data. This task and this report had as the chief objective to begin to alleviate this data gap and thus begin the process of characterizing heavy vehicle driver baseline performance data for use in subsequent tasks, future projects, and future in-cab device or system evaluations. 


\subsection{Objective}

The objective of this task was to develop baseline data on heavy vehicle driver visual allocation, in-cab driver behaviors, and driver-vehicle performance while driving a standard configuration heavy vehicle (Turanski and Tijerina, 1992). In particular, this research involved data capture under variations in roadway type, lighting conditions, driving scenarios, and in-cab conventional tasks. The results are provided in terms of the following:

- $\quad$ variations in candidate workload measures within the various conditions evaluated;

- $\quad$ variations in candidate workload measures between the various conditions evaluated;

- $\quad$ the relationships between the various measures used in terms of the covariance for the various conditions evaluated.

\subsection{Organization of the Report}

The remainder of this report is organized in the following way. Section 2.0 provides a detailed description of the protocol used, including test participants, test vehicle, driving condition (e.g., lighting condition, road type), driving task, in-cab task conditions and statistical analyses carried out on dependent measures. Subsequent sections provide a description of the dependent measures, statistical analyses carried out on those dependent measures, and the statistically significant results obtained. There are separate results sections for visual allocation measures, incab driver behaviors as measured by steering accelerator and brake inputs, longitudinal control assessed via measures of speed and headway, and lateral control measures assessed via measures of lane position and lane exceedences. The report concludes with discussion of the results as a whole. Appendices are provided that contain additional details of the procedures and materials used, as well as additional details of the results obtained.

The reader is forewarned that a great deal of data analysis is reported in this document. This results from several factors. First, many measures were collected concurrently and each of the reported measures underwent analysis. Second, there were many observations taken and this led to relatively powerful statistical tests. Thus, there were often more statistically significant results, reported for completeness, than there were practically significant results. Third, this study provided an opportunity to screen many dependent measures for possible use in future workload assessment research. This process of screening measures demanded a thorough review of all the results obtained.

This study was an attempt to get baseline data for normal driving using candidate workload measures. It is an original contribution to the literature in that it represents the driver visual allocation, in-cab driver behavior, and driver-vehicle performance of professional heavy vehicle drivers, on real roads, driving a conventional tractor-trailer rig with a 76,000-lb payload. 
Commonly executed tasks were "requested" of the driver in order to develop baselines against which new technologies might be compared. However, there was no attempt in this study to introduce workload beyond that associated with driving condition effects on normal driving and the execution of common tasks. 


\subsection{METHODOLOGY}

\subsection{Approach}

\subsubsection{Test Participants}

Thirty professional truck drivers participated in this study. The participants were active, line-haul drivers employed by two trucking companies in Columbus, Ohio. The participants were volunteers and were paid $\$ 138.00$ for their time. All participants held a Class A Commercial Driver's License (CDL). The participants had no more than three moving violations and/or one "at fault" accident within the last three years. In addition, no participant had a Driving Under the Influence (DUI)) citation within the last three years.

Twenty-seven of the participants were male (90\%) and three were female (10\%). The participants ranged in age from 32 to 60 years with a mean age of 47 years. As a group, the participants averaged 17.3 years of truck driving experience and averaged 109,000 miles of truck operation per year. About half of the drivers wore glasses. All but two drivers regularly used CB radios while operating their trucks. Three-fourths of the participants used AM/FM radios while driving. All participants had prior experience in driving trucks with long trailers (i.e., trailers at least 48 feet long). A biographical data summary is found in Appendix A.

\subsubsection{Test Vehicle}

The truck used in this study consisted of a 1992 Volvo/White GMC conventional tractor with sleeper compartment and a 1993 Fruehauf dry freight van semi-trailer. The trailer was 53 feet long and was loaded with ballast to bring the gross vehicle weight to 76,300 pounds. The tractor was equipped with standard engine gauges, tachometer, speedometer, digital clock, CB radio and an AM/FM stereo radio.

\subsection{Instrumentation: Video Recording System, Sensors, and Data Capture System}

The truck used in this study was instrumented with a variety of equipment to capture driver behavior and driver-vehicle performance. The captured data was in two different forms: video data and engineering data. These two forms provide a convenient means to organize the instrumentation description. 


\subsubsection{Video Recording System}

The tractor was equipped with a video system to record the events of the run for post-run data reduction. This recording system is depicted in Figure 2-1. The recording system consisted of four video cameras, two video cassette recorders (VCRs), monitor, video switcher, infrared illuminator, time code generator, a four-into-one video "splitter," and two lapel microphones.

One camera was mounted to the ceiling of the cab and directed toward the driver's face. This view of the driver was used to record the participant's visual glances during the run. Two cameras were mounted on the front fenders of the truck (one on each side) and directed toward the road ahead of the truck. These two cameras were used to monitor traffic and road conditions as well as to record the lane selection of the participant throughout the run. A fourth camera was mounted inside the cab and aimed to record distance headway information displayed by a headway measurement device or the hand activity on the steering wheel as desired. The infrared illuminator was used to provide supplemental lighting for the driver's gaze camera for nighttime data recording.

A time base for post run data analysis was provided using a video time code generator. The time information output by this device was superimposed on the view of the participant's face prior to recording on the VCRs. This device provided a high-speed elapsed time clock with resolution to 1/30 second (i.e., one video frame).

The scenes from the four cameras were recorded on two video cassette recorders. One recorder contained the view of the participant's face. The second VCR contained a split-screen view of the scenes from all four cameras. Since the time code information was superimposed on the view of the participant's face, a common time base was established on the recordings for both VCRS.

The participant and experimenter each wore a microphone to permit recording of the incab conversation on an audio track of the video tape. The video monitor and switcher permitted the experimenter to periodically view each video recording to ensure proper camera aim following in-route seat adjustments or postural changes made by the participant.

Visual allocation data were obtained through a post-run examination of the video tapes by a data reducer. A video data reduction system, depicted in Figure 2-2, was used to extract information from the tapes. The system consisted of a VCR, time base corrector, time code reader, video genlock, an Amiga 1200 computer and a computer monitor with built-in speakers. The audio signal containing the in-cab conversation from the run was routed directly from the VCR to the speakers built into the computer monitor. The VCR was used by the data reducer to playback the tape and locate the beginning and ending of the participant's glances. The conventional front panel controls on the VCR were used to search the tape. The video signal from the VCR was routed through a time base corrector, which corrected sync timing 


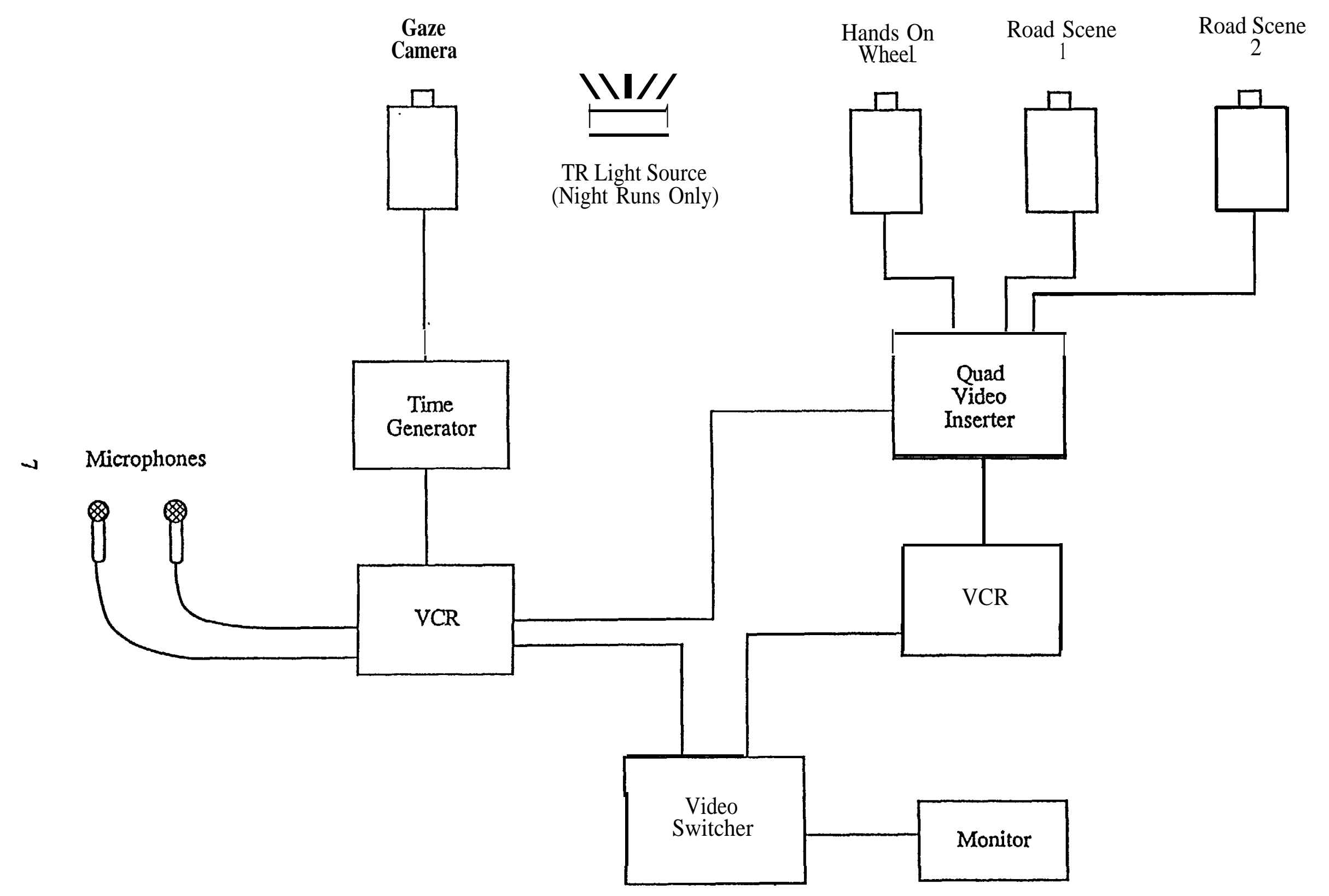

Figure 2-1. Schematic Diagram of the Video Recording System 


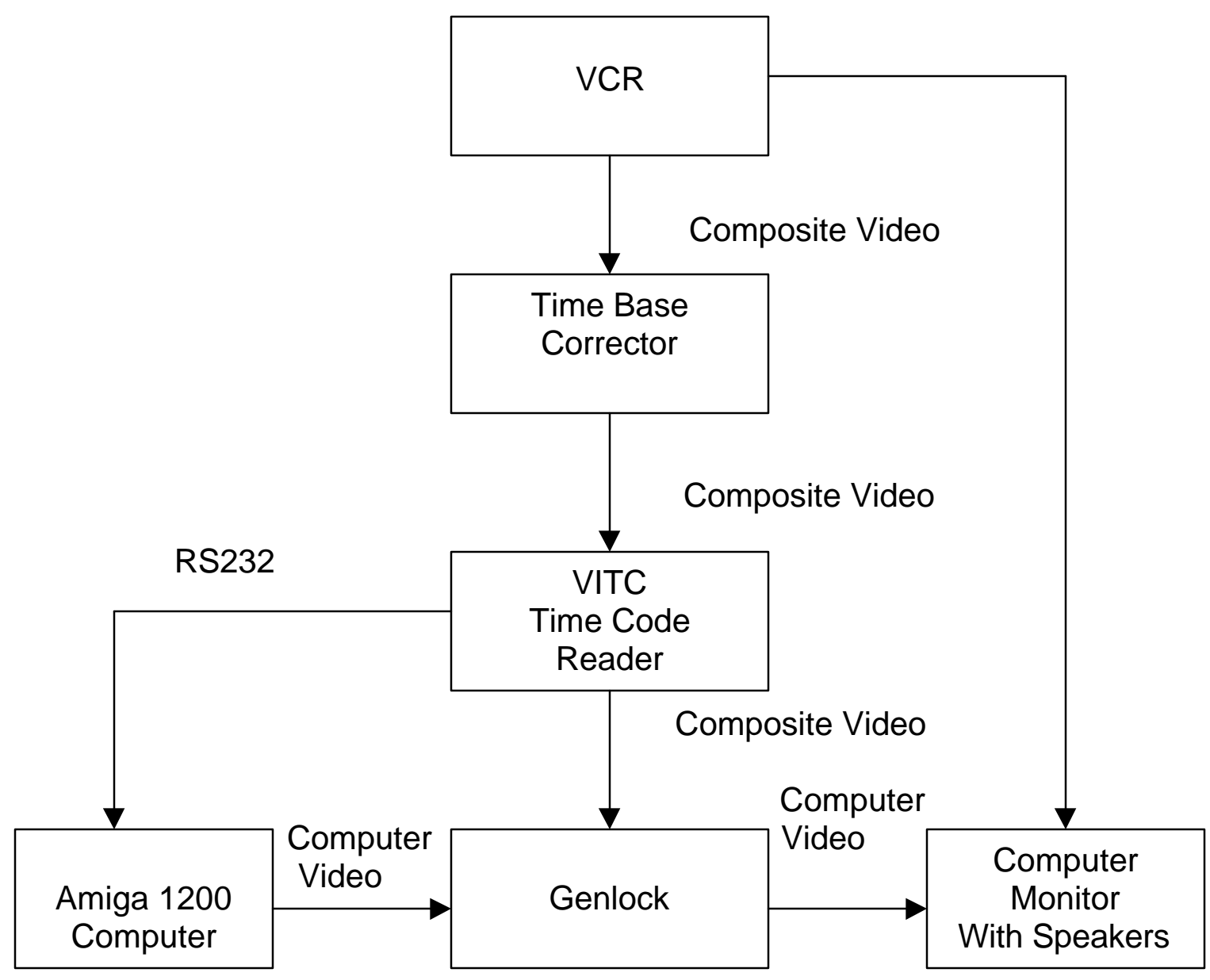

Figure 2-2. Schematic of Video Data Reduction System 
errors generated during playback. This enhancement to the signal improved the stability of the video and aided in reading the time code data stored on the video tape. The time code data stored on the tape were the vertical interval time code (VITC) type, which means that this information was stored in the vertical blanking interval portion of the video signal. The time code reader was a VITC reader with an RS-232C interface to the Amiga computer. The time code reader read the time codes from the tape and transmitted this data to the computer via the serial link.

The key component of this system was the Amiga computer which has computer video that is electrically similar to the composite video signal used by the on-board video system in the test truck. Hence, it was possible to combine computer generated graphics with the recorded video to develop the data reduction system. The video genlock was a device that accepted inputs from two video sources (i.e., the Amiga Computer and the video recorded during the run), superimposed the two images on one another and output a single video image to the display device.

Custom software was developed to control the system. The three primary functions of the software were to provide a screen-based interface to the data reducer, obtain the time code data from the time code reader and store information regarding each glance made by the participant in a database for subsequent analysis. The operating screen when viewed by the data reducer presented the driver's face in the background. In the foreground appeared onscreen controls (i.e., buttons) and menus. The controls allowed the data reducer to read the time codes, store data and terminate a data reduction session. The menus permitted the data reducer to select new values for data that changed within a session. For example, menus were provided to allow the selection of the glance location, road type, light level, etc. The software also allowed the data reducer to view the driver's face in a full screen mode (without the superimposed menus and controls) to aid in isolating the break points between glances.

To operate the system, the data reducer played back the video tape using the controls on the VCR. At the beginning of a new glance the data reducer activated an on-screen control using the computer's mouse. The computer read the beginning time code and displayed this value on the screen. The data reducer then moved the tape to the end of the glance. The data reducer made a menu selection to identify the glance location and a control activation to record the glance ending time code. The computer subsequently calculated the glance duration and stored the information as a record in the database. This process was repeated for each glance in the task or driving maneuver being reduced.

In reducing data, a glance was defined as the interval of time beginning with the frame when the participant's eyes first started to move away from the road scene to a specified location and ending when the eyes either returned to the road scene or to another specified location. Glance locations were classified into the following categories: 
1. Left side mirror

2. Right side mirror

3. Instrument panel

4. $\mathrm{AM} / \mathrm{FM}$ stereo radio

5. CB radio

5. Road scene

6. Other off-road locations combined (e.g., side window to observe traffic passing on the left)

7. Off Camera (i.e., participant momentarily out of view).

\subsubsection{Engineering Data Capture System}

A suite of sensors was used to capture driver in-cab behavior, speed and headway maintenance, and lanekeeping performance. The measures were taken at a sampling rate equal to the video frame rate of 30 samples per second. Given the recording of the time stamp provided by the time code generator, this sampling rate allowed for correlation of the video data and the engineering data. The sensor suite used in the vehicle is provided in Table 2-1.

Data reduction involved filtering by means of custom software developed by the NHTSA Vehicle Research and Test Center (VRTC) in East Liberty, OH. After all data channels to be analyzed had been filtered as deemed appropriate by VRTC personnel, data reduction moved to extracting those portions of the data stream correlated with the units of observation to be analyzed. This process used the begin and end time codes provided from the video data reduction process. For example, if the unit of observation was 60 seconds of open road driving for a given test participant, the begin time code and the end time code were provided from the video data reduction. Since those codes were recorded as part of the engineering data stream, this allowed for accurate extraction of the relevant portion of the data stream for analysis purposes.

\subsection{Test Route}

To achieve the objectives of the study, a fixed route of 285 miles through central Ohio was used. The route was divided into eight segments entailing approximately 45 minutes of driving each (at the posted speed limit). The route segments are identified below.

1. Depart truck terminal at Columbus, I-71 south to Ohio SR 72

2. Ohio SR 72 north to I-70 at Springfield

3. I-70 east to I-71 at Columbus

4. I-71 north to US 36 at Delaware

5. I-71 south to I-70 at Columbus 
Table 2-1. Engineering Data Capture Instrumentation for Measures Used in Task 6 Baseline Study

\begin{tabular}{|c|c|}
\hline Fundamental Measurement & Instrumentation \\
\hline Steering Wheel Angle & $\begin{array}{l}\text { String potentiometer in the engine } \\
\text { compartment attached to the pitman arm and } \\
\text { a redundant potentiometer mounted under } \\
\text { the dash board inside the cab. }\end{array}$ \\
\hline Steering Wheel Velocity & $\begin{array}{l}\text { A tachometer (DC motor) attached to the } \\
\text { steering wheel position string potentiometer. }\end{array}$ \\
\hline Accelerator Position & $\begin{array}{l}\text { Potentiometer calibrated to generate } 0 \% \text { to } \\
100 \% \text { of throw. }\end{array}$ \\
\hline Brake Activation & $\begin{array}{l}\text { A switch that activated when the heavy } \\
\text { vehicle brake lights came on. }\end{array}$ \\
\hline Travel Speed & $\begin{array}{l}\text { A 5th wheel tachometer. Also a redundant } \\
\text { channel available in car following situations } \\
\text { from a forward-looking radar processing } \\
\text { system. }\end{array}$ \\
\hline Acceleration (lateral, longitudinal, yaw rate) & $\begin{array}{l}\text { Lateral, longitudinal, and yaw rate } \\
\text { accelerometers mounted near the center of } \\
\text { gravity of the cab. }\end{array}$ \\
\hline Headway Distance & $\begin{array}{l}\text { Infrared laser range finder system with } \\
\text { maximum range of } 250 \text { meters. }\end{array}$ \\
\hline Headway Relative Velocity & Forward looking Doppler radar system. \\
\hline Lane position & $\begin{array}{l}\text { Optical lane tracker that sensed the } \\
\text { luminance difference between a lane line and } \\
\text { the surrounding pavement. Auxiliary } \\
\text { lighting of the lane tracker field-of-view was } \\
\text { used for night driving segments. }\end{array}$ \\
\hline Data Acquisition System & $\begin{array}{l}\text { 182-channel data acquisition and storage } \\
\text { system. For every sample, the time stamp } \\
\text { generated by the time code generator was } \\
\text { recorded both on the video image and as a } \\
\text { channel of the data acquisition system. All } \\
\text { engineering data stored on a high-density } \\
\text { tape cartridge. }\end{array}$ \\
\hline
\end{tabular}


6. I-70 west to SR 72 at Springfield

7. $\quad$ Ohio SR 72 south to I-71

8. I-71 north to truck terminal at Columbus.

Departure time was three (3) hours before sunset so that segments 1-4 were conducted in daylight and segments 5-8 were conducted at night. A lunch break was taken between segments 4 and 5 to give the participant a rest and to allow ample opportunity for the sun to set. The road type and lighting characteristics of each segment are as shown in Table 2-2 along with the types of tasks and driving maneuvers performed on each. Driving scenarios and requested tasks are described below.

\subsection{Driving Scenarios and Requested Tasks}

\subsubsection{Driving Scenarios}

For most of all segments, the participant drivers were able to select lane position, speed and headway as dictated by traffic conditions. This resulted in open road driving for most of the run segment until the urban freeway was encountered. Here traffic density presented car following opportunities. In this study, car following is defined as the condition when the participant followed a vehicle ahead in the same lane at a distance headway of 200 feet or less. At $55 \mathrm{mph}$ (the maximum speed limit for heavy trucks in Ohio), a distance headway of 200 feet represents a time headway of approximately 2.5 seconds. Both car following and open road driving were naturalistic maneuvers in the sense that the driver voluntarily engaged in these task in response to the traflic conditions. The ride-along experimenter did not prompt the drivers to engage in either open road driving or car following.

\subsubsection{Requested Tasks}

On each route segment, the ride-along experimenter asked the participant to perform twelve typical tasks found in normal, everyday truck driving. These are listed below. The "requested" tasks were introduced only when it was safe to do so. This means that the participants were not engaged in car following or other tasks that in the judgement of the ridealong experimenter could create a hazard during the execution of the requested task. Thus, for all requested tasks the headway was at least 200 feet.

The requested tasks were as follows:

1. Right mirror - detection

2. Right mirror - discrimination 
Table 2-2. Road Type and Lighting Characteristics by Driving Segment Along with the Types of Tasks and Driving Scenarios Performed on Each Segment

\begin{tabular}{|l|l|l|l|}
\hline Segment Number & Road Type & Lighting Condition & \multicolumn{1}{|c|}{$\begin{array}{c}\text { Tasks \& Driving } \\
\text { Scenarios }\end{array}$} \\
\hline Segment 1 & Rural Freeway & Day & $\begin{array}{l}\text { TruckFamiliarization-- } \\
\text { open road and requested } \\
\text { tasks }\end{array}$ \\
\hline Segment 2 & 2 lane Rural Road & Day & $\begin{array}{l}\text { Open road--requested } \\
\text { tasks }\end{array}$ \\
\hline Segment 3 & Rural Freeway & Day & $\begin{array}{l}\text { All driving scenarios and } \\
\text { tasks }\end{array}$ \\
\hline Segment 4 & Urban Freeway & Day & $\begin{array}{l}\text { All driving scenarios and } \\
\text { tasks }\end{array}$ \\
\hline LUNCH & BREAK & BREAK & BREAK \\
\hline Segment 5 & Urban Freeway & Night & $\begin{array}{l}\text { All driving scenarios and } \\
\text { tasks }\end{array}$ \\
\hline Segment 6 & Rural Freeway & Night & $\begin{array}{l}\text { All driving scenarios and } \\
\text { tasks }\end{array}$ \\
\hline Segment 7 & 2 lane Rural Road & Night & $\begin{array}{l}\text { Open road--requested } \\
\text { tasks }\end{array}$ \\
\hline Segment 8 & Rural Freeway & Night & $\begin{array}{l}\text { Open road--requested } \\
\text { tasks with time for } \\
\text { special tests at the end } \\
\text { of the segment. }\end{array}$ \\
\hline
\end{tabular}


3. Left mirror - detection

4. Left mirror - discrimination

5. Turn $\mathrm{CB}$ volume up/down

6. Change $\mathrm{CB}$ frequency

7. Manually tune AM/FM radio

8. Turn AM/FM radio volume up/down

9. Read clock

10. Read air pressure

11. Turn heater/AC temp up/down

12. Calculate available driving hours.

The order of these tasks were randomized for each segment and were part of a checklist for the ride-along experimenter.

\subsection{Experimental Procedure}

\subsection{Pre-Trip Procedure}

On arriving at the truck, the participants performed a walk-around safety inspection of the vehicle. The participants were given all instructions needed to participate in the study. The instructions consisted of a briefing on the purposes of the study and information needed to familiarize the participant with the layout of the cab. These instructions were recorded on an audio cassette and played back on the truck radio to ensure that all participants receive identical instructions. A transcription of the participant instructions is presented in Appendix B. The experimenter then answered any questions the participant had concerning the study. The participant also read and signed an "Informed Consent Form," a copy of which is provided in Appendix C.

Just prior to departing, the experimenter calibrated the participant's head and eye positions for glances to known locations in the cab and the road scene ahead. In this procedure the participant was asked to look at a specified location, while the participant's head and eye positions were recorded on videotape. The record of the head/eye positions by location served as a point of reference for the data reducer when determining the glance locations of the participant.

Recalibration was performed several times during the run to accommodate seat adjustments or major postural changes made by the driver within the run. 


\subsubsection{Over-the-Road Procedure}

The participant then drove the test truck on the fixed route while accompanied by the experimenter. The data for the experiment were recorded by the on-board instrumentation, the video system or on data forms by the experimenter. During the run, the experimenter marked the periods of car following and open road driving that occurred naturally in the traffic stream on the highway. These were later examined during the data reduction phase of the study. At an appropriate point on each route segment the experimenter asked the participant to execute the set of requested tasks (e.g., use of CB radio). See Appendix D for a sample checklist which includes the requested tasks.

During the run the participant was given a meal break at the midpoint of the run. Stops were also made during the third and sixth segments to change video tapes. In total, about six hours of driving was performed by the participant over an eight-hour period.

\subsubsection{Post-Run Participant Debriefing}

At the conclusion of the run, the participants were debriefed to obtain their views regarding driver workload (See Appendix E). Participant biographical data was also collected at this time.

\subsection{Statistical Analysis Approach}

This section provides a description of the general approach taken to prepare the data for analysis. The general analysis methodology is also described.

\subsubsection{Outliers and Transformations}

Prior to fitting models to any of the responses, plots of the raw and transformed data were examined to identify outliers and to determine an appropriate scale on which to perform the analyses. Very few outliers were identified (less than $0.5 \%$ for each response), and were attributed to instrumentation problems; no systematic pattern of data loss or outliers was found. A few responses were transformed for analysis--either by a logarithmic or square root transformation. However, most responses were analyzed on an untransformed scale. Transformations were used to achieve constant variance and/or better symmetry. 


\subsubsection{Standardization and Weighting}

In order make proper comparisons, certain responses were standardized by the duration of the observation period. For instance, the number of lane exceedences was standardized by dividing the lane exceedence count by the duration of the observation period for open road driving and close car following. This resulted in an estimate of the average number of lane exceedences per second. This and other "average" type responses were then given different weights in the analysis to reflect different levels of information.

Information based on better data was given more weight in the analysis. For instance, responses which represented the average or variance of a measure over an observation period, such as mean speed or lane position variance were weighted by the duration of the observation period. This weighting was applied only for open road driving and close car following, when the length of the observation period was not inherently dependent on the completion of a task.

\subsubsection{Statistical Model}

For open road driving and close car following, the following "complete" statistical model was considered for each response:

$$
Y=u+R+L+R * L+S+S * R+S * L+S * R * L+E
$$

where the following represent fixed effects

u represents the overall average,

$\mathrm{R}$ represents the effect of road type,

$\boldsymbol{L} \quad$ represents the effect of lighting,

$\boldsymbol{R}^{*} \boldsymbol{L} \quad$ represents the interaction effect of road type by lighting,

and the following represent random effects

S represents a random subject effect,

$S * \boldsymbol{R} \quad$ represents variability associated with different road types observed for the same subject,

$S^{*} L \quad$ represents variability associated with different lighting conditions observed for the same subject,

$S * R * L$ represents any additional condition-to-condition variability associated with individual subjects, and

E represents error, or replicate variability associated with the same test condition observed on the same subject. 
For every response, the random subject effect, $\mathrm{S}$, was included in the final model. However, the remaining random effects were selectively included in the final model depending on the observed significance of each factor. The significance of each of the remaining random effects (besides error) was tested using maximum likelihood methods (Searle, Casella, \& McCulloch, 1992) where possible. The only exception to this rule was when weighting was required. The software used for maximum likelihood estimation (SAS Institute, 1992) did not permit unequal weighting of the responses. Therefore, standard repeated measures ANOVA methods (Kirk, 1982) based on expected mean squares were applied. In deciding upon the significance of the different random effects, four groups of analyses were considered separately:

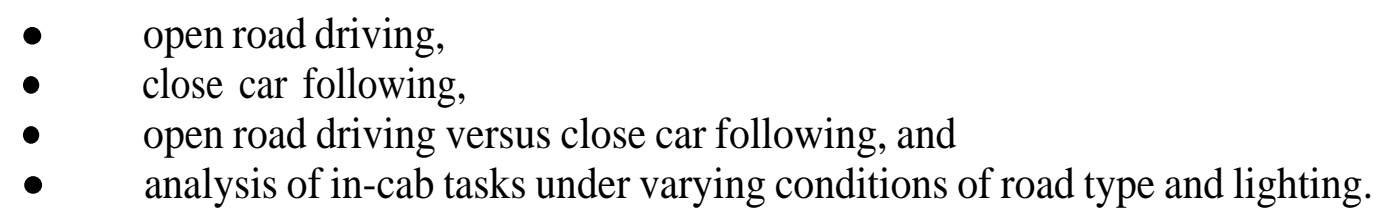

Within each of these groups, dependent measures or responses were considered separately. For instance, responses which required weighting were considered separately from those which did not.

After selection of the appropriate random effects using the procedure described above, a final model for each response was fitted based on standard repeated measures ANOVA methods, testing the significance of each factor using the appropriate linear combination of error terms. The composition of the ANOVA model used in each class of dependent measures will be indicated in the results sections. The 0.05 alpha level was used to judge statistical significance.

Differences in sample sizes will be noted. These resulted from occasional equipment problems, time constraints for task execution, or failure by the driver to exhibit certain behaviors or performances. For example, some drivers elected not to sample certain locations, like mirrors, on various segments. The ANOVA analyses made use of all available data by use of the General Linear Models (GLM) procedure in SAS ${ }^{\mathrm{TM}}$ (SAS Institute, 1992). Imbalance was dealt with by use of Type III Sums of Squares and Satterthwaite's approximation for error terms and associated degrees of freedom (Milliken and Johnson, 1984). It is for this reason that denominator degrees of freedom reported may vary. Fractional error degrees of freedom from Satterthwaite's approximation were rounded to the nearest integer value for reporting purposes.

\subsection{Dependent Measures}

A wide variety of dependent measures was taken in the following categories:

- Visual allocation,

- $\quad$ Driver steering, accelerator, and brake inputs,

- $\quad$ Speed and headway measures, and

- $\quad$ Lanekeeping measures. 
The motivation and rationale for including each category of measures and individual measures are provided in Tijerina et al. (1995). For convenience to the reader, the definitions of individual dependent measures in each measurement category are presented as an introduction to the results of the analyses for that measurement category. 


\subsection{RESULTS: VISUAL ALLOCATION DATA}

An estimated 90\% of the information required for driving is acquired through the driver's sense of vision (Rockwell, 1972). This point is intuitively reasonable and has also been demonstrated in on-the-road driving and simulator studies that indicate the driver can take eyes off the road scene for only a moment without the need to take another glance to update the driver's assessment of the driving situation. In particular, there is but one foveal resource and it must be moved about to gather detailed visual information (Wierwille, 1993). The deployment of this foveal resource by the driver is termed visual allocation. That is, visual allocation refers to where the driver is visually attending, based on where the driver is looking with central vision as opposed to peripheral vision. Driver visual allocation therefore plays an important role in driver human factors studies in general, and in-cab device workload assessment in particular.

\subsection{Visual Allocation Dependent Measures}

The dependent measures used to characterize heavy vehicle driver visual allocation are provided below. All times are given in seconds, fractions are given as proportions, and numbers of glances are given as counts.

- $\quad$ Mean time off-road (MTOR); this is the average single-glance duration spent looking away from the forward driving scene (i.e., straight ahead, forward left hand side, and forward right hand side viewing locations).

- $\quad$ Mean on-road time (MORT); this is the average single-glance duration spent in a single glance looking at the forward driving scene.

- Mean mirror glance duration to both side mirrors (MM); this is the average single-glance duration spent sampling the mirrors, averaged over both left and right mirrors.

- Mean left mirror glance duration (MLM); this is the average single-glance duration spent looking at the left mirror.

- Mean right mirror glance duration (MRM); this is the average single-glance duration spent looking at the right mirror.

- $\quad$ Mean instrument panel duration (MIP); this is the average single-glance duration spent head down in the cab of the heavy vehicle looking in the direction of the instrument panel.

- $\quad$ Fraction of time allocated to mirrors (FRACM); this is a proportion of the total measurement interval spent looking at the mirrors. It is the sum of the individual glance durations to the mirrors over the measurement interval of time.

- Device Average Glance Duration (DGLNCAV); this is the mean single glance dwell time to a particular device (radio, CB, mirror, etc.), associated with a requested task.

- Device number of glances (DGLNCNUM); this is the number of glances to a particular device to complete a requested task.

- Total Time to Device (DGLNCTOT); The total time spent looking at a particular device to complete a requested task. 
- $\quad$ Road glance average duration (RGLNCAV); the mean single-glance duration spent looking back at the road scene (i.e., scanning the road scene) while completing a particular requested task.

- $\quad$ Total requested task duration (TOTDUR); the total time to complete a requested task, measured from the first glance (in the case of visual-only tasks) or the first gesture (in the case of manual or visual-manual tasks), whichever came first.

During the car following and open road driving maneuvers and the requested tasks discussed below, drivers could make any number of glances to the specified locations examined in the study. That is, all looking behavior was elective. As a result, when glance durations were examined, the mean of the individual glances for a participant on a given route segment (by glance location) was used as the dependent measure. For example, during open road driving on the urban freeway segment at night, Participant 124 made 10 glances to the left mirror with a mean glance duration of 1.08 seconds. In comparison, Participant 128 made one glance to the left mirror on this same highway segment with a duration of 0.77 seconds. The responses for these two participants used in the left mirror analysis were 1.08 and 0.77 seconds, respectively.

\subsection{Results for Visual Allocation Measures in Open Road Driving}

For this analysis, the Subject and Subject $\mathrm{x}$ Light interaction were found to be significant random effects using the procedures described earlier. Thus, these random effects were included in the model and the Subject x Light term was used as the error term for the F-test for the Light main effect (Kirk, 1982). Based on the ANOVA results, the following effects were found:

\subsubsection{Road Type Effects on Visual Allocation in Open Road Driving}

Table 3.2.1 summarizes the main effects of Road Type on various visual allocation measures during open road driving. This table contains the means and standard deviations associated with each level of road type for a given dependent measure. Every visual allocation measure was affected. The general trend was for there to be significant differences between the 2-lane rural road condition and the urban and rural freeway conditions, but no substantial differences between the latter freeway conditions.

Various measures of mirror sampling behavior show a consistent pattern. MLM, MRM, and MM average glance durations for the 2-lane rural road are shorter than those exhibited for rural and urban freeways. This is in keeping with the observation that there is less concern for mirror sampling on 2-lane rural roads. The fact that FRACM is also less for the 2-lane rural road condition than for the urban and rural freeway road types is consistent with this expectation. Recall that these were not 'requested' looks to the mirrors, but elective. 


\section{Table 3.2.1 Means of Visual Allocation Measures that Significantly Differed as a Function of Road Type in Open Road Driving}

\begin{tabular}{|c|c|c|c|}
\hline \multirow[b]{2}{*}{ Dependent Measure } & \multicolumn{3}{|c|}{ Road Type } \\
\hline & Urban Freeway & Rural Freeway & Z-Lane Rural Road \\
\hline $\begin{array}{l}\text { MLM }^{\mathrm{a}} \text {, Left mirror average } \\
\text { duration, } \mathrm{s}\end{array}$ & $\begin{array}{l}1.00 \\
(0.06)^{*}\end{array}$ & $\begin{array}{c}1.01 \\
(0.07)\end{array}$ & $\begin{array}{c}0.87 \\
(0.05)\end{array}$ \\
\hline $\begin{array}{l}\mathrm{MRM}^{\mathrm{b}} \text {, Right mirror average } \\
\text { duration, } \mathrm{s}\end{array}$ & $\begin{array}{c}0.96 \\
(0.32)\end{array}$ & $\begin{array}{c}1.05 \\
(0.34)\end{array}$ & $\begin{array}{c}0.90 \\
(0.37)\end{array}$ \\
\hline $\begin{array}{l}\mathrm{MlP}^{\mathrm{C}} \text {, Instrument panel } \\
\text { average duration, s }\end{array}$ & $\begin{array}{c}0.84 \\
(0.22)\end{array}$ & $\begin{array}{c}0.93 \\
(0.24)\end{array}$ & $\begin{array}{c}0.76 \\
(0.19)\end{array}$ \\
\hline $\begin{array}{l}\text { MTOR }{ }^{d} \text {, Off-road average } \\
\text { glance duration, s }\end{array}$ & $\begin{array}{c}0.97 \\
(0.20)\end{array}$ & $\begin{array}{c}1.01 \\
(0.20)\end{array}$ & $\begin{array}{c}0.87 \\
(0.18)\end{array}$ \\
\hline $\begin{array}{l}\text { MORT } \mathrm{T}^{\mathrm{e}} \text { On-road average } \\
\text { glance duration, s }\end{array}$ & $\begin{array}{c}2.64 \\
(2.22)\end{array}$ & $\begin{array}{c}2.43 \\
(1.74)\end{array}$ & $\begin{array}{c}5.27 \\
(9.98)\end{array}$ \\
\hline $\begin{array}{l}\mathrm{MM}^{\mathrm{f}}, \text { mean mirror glance } \\
\text { duration, } \mathrm{s}\end{array}$ & $\begin{array}{c}1.02 \\
(0.27)\end{array}$ & $\begin{array}{c}1.04 \\
(0.26)\end{array}$ & $\begin{array}{c}0.89 \\
(0.28)\end{array}$ \\
\hline $\begin{array}{l}\text { FRACMg, fraction of tune } \\
\text { spent mirror sampling }\end{array}$ & $\begin{array}{c}0.083 \\
(0.064)\end{array}$ & $\begin{array}{c}0.092 \\
(0.069)\end{array}$ & $\begin{array}{c}0.047 \\
(0.053)\end{array}$ \\
\hline
\end{tabular}

Notes:

Corresponding F-values, and p-values are provided below.
a. $\quad \mathrm{F}(2,300)=8.92, \mathrm{p}=.0002$
b. $\quad \mathrm{F}(2,184)=6.01, \mathrm{p}=.0030$
c.. $\quad \mathrm{F}(2,301)=19.73, \mathrm{p}=.0001$
d. $\quad \mathrm{F}(2,335)=42.55, \mathrm{p}=.000 \mathrm{l}$
e. $\quad \mathrm{F}(2,336)=12.32, \mathrm{p}=.0001$
f. $\quad \mathrm{F}(2,313)=15.27, \mathrm{p}=.0001$
g. $\quad \mathrm{F}(2,336)=26.72, \mathrm{p}=.000 \mathrm{l}$

* Numbers in parentheses are respective standard deviations associated with each mean value. 
MIP average durations are shortest for the Z-lane rural road and next shortest for the Urban freeway; the rural freeway had the longest average mirror duration mean. The driver's sampling of the instrument panel may be modified by less need on the 2-lane rural road when compared to the competing visual attention needed for path control. On the other hand, the urban and rural freeway conditions may have allowed somewhat more visual attention to be spent on instrument panel checks. Furthermore, the need to check the instrument panel might have been tempered with greater traffic and/or speed limit concerns. Drivers did note during post-session interviews that the speedometer is the most frequently checked instrument panel device. The reason why the rural freeway had the longest instrument panel mean glance durations may reflect the fact that the traffic density and/or speed limit enforcement might demand less attention to the road scene than the other two conditions.

MTOR averaged 0.96 seconds across all conditions. Note for MTOR, there was a road type effect with the IL-lane rural road having the shortest "off road" duration at 0.87 seconds and the rural freeway having the longest at 1.01 seconds. The differences, while slight, are in the expected direction. Given the undivided nature of the roadway and relatively greater path control demand, drivers reasonably spent less time away from the road.

MORT for the 2-lane road was 5.27 seconds vs. about 2.43 and 2.64 seconds for the rural and urban freeways, respectively. This dramatic difference most likely stems from the relatively greater visual demands of path control to negotiate horizontal curves and the less concern for mirror sampling on the rural highways compared to freeways.

In summary, for the driving scenario or task of open road driving, road type had a consistent pattern of effects to which visual allocation measures were sensitive. Generally, the 2lane rural road was substantially different from the urban or rural freeway conditions which, in turn, did not substantially differ from each other. This suggests that visual demand of the driving task is substantially different as a function of road type. Workload assessments should therefore stipulate the road types being used in the assessment since this will likely substantially affect normal visual allocations.

\subsubsection{Lighting Effects on Visual Allocation in Open Road Driving}

Table 3.2.2 indicates that ambient lighting influenced instrument panel average glance duration (MIP), on-road glance duration means (MORT), and the fraction of time spent on mirror sampling (FRACM) The difference in means for Day and Night conditions on MIP was small and may reflect additional time needed by the driver to visually adapt to the lighted instrument panel when moving from the dark driving scene. The time course of light adaptation is generally very fast for low intensity light sources (Hood and Finkelstein, 1986), consistent with the $80 \mathrm{~ms}$ difference in means. MORT values indicate that drivers spent substantially longer average glance periods on the road at night. This may reflect the driver's awareness that object and event detection at night are less than during the day; this awareness may have prompted longer visual 
Table 3.2.2 Means of Visual Allocation Measures that Significantly Differed as a Function of Light Level in Open Road Driving

\begin{tabular}{|lcc|}
\hline \multicolumn{1}{|c|}{ Dependent Measure } & \multicolumn{2}{|c|}{ Light Level } \\
\cline { 2 - 3 } & Day & Night \\
\hline MIP $^{\mathrm{a}}$, Instrument panel average glance duration, s & 0.83 & 0.91 \\
& $(0.21)^{*}$ & $(0.25)$ \\
MORT $^{\mathrm{b}}$, On-road average glance duration, s & 2.35 & 4.00 \\
& $(1.67)$ & $(7.27)$ \\
FRACM $^{\mathrm{c}}$, fraction of time spent mirror sampling, & 0.090 & 0.067 \\
proportion & $(0.066)$ & $(0.065)$ \\
\hline
\end{tabular}

Notes:
a. $\quad \mathrm{F}(2,48)=9.50, \boldsymbol{p}=.0034$
b. $\quad \mathrm{F}(2,40)=10.37, \mathrm{p}=.0025$
c. $\quad F(2,37)=9.34, p=.0041$

* Numbers in parentheses are respective standard deviations associated with each mean value. 
scanning per glance to the road scene, on average. Finally, FRACM is slightly less during night driving than during day driving and this probably reflects the lower traffic density at night.

In general, then, ambient lighting had a smaller, though reliably measurable effect on driver visual allocation than did road type. The direction of effects is consistent with common sense and may be explained by driver visual processes as well as driver assessment of driving conditions (e.g., reduced traffic density). One implication of these outcomes is that visual allocation measures may be affected by night vs. daylight driving conditions, but the magnitude and breadth of such effects are likely to be smaller than that for road type differences.

\subsubsection{Interaction of Road Type and Light on Visual Allocation in Open Road Driving}

Table 3.2.3 indicates a significant interaction between Road Type and Light on Mean OnRoad Time (MORT) in open road driving $\boldsymbol{F}(2,235)=3.17, \mathbf{p}=.0111$. Inspection of the mean values in the table indicates that the interaction lies in the substantially longer MORT mean value associated with open road driving on a 2-lane rural highway under Night lighting conditions.

While Urban and Rural Freeway mean MORT values also increased under night driving conditions, the magnitude of increase was substantially smaller. This is not unexpected given the generally greater path control demand and perhaps lower artificial lighting associated with the 2lane rural roadway. This is taken as additional evidence that the 2-lane rural highway will have a significant impact on visual allocation measures in workload assessment when compared to urban or rural freeways.

No other significant main effects or interactions were found. It should be noted that special tests were made to evaluate replication effects, i.e., the first minute of open road driving vs. the second minute. No statistical or practical differences were observed. This was encouraging and supported the idea that one minute was as good as two minutes for understanding visual allocation by the participant over a given road segment.

\subsection{Results for Visual Allocation in Car Following}

Car following was not observed with the drivers on the 2-lane rural road in this study. Thus, the Road Type variable for the car following analysis had only two levels: Urban and Rural Freeway. Otherwise, the same model and analysis were applied to the car following data as that described for the Open Road Driving analysis. The statistically significant effects are reported in the following subsections. 
Table 3.2.3 Interaction of Road Type and Light Level in Terms of Mean On-road Glance Duration (MORT)

\begin{tabular}{|l|ccc|}
\hline \multirow{2}{*}{ Light Level } & \multicolumn{3}{|c|}{ Road Type } \\
\cline { 3 - 5 } Day & Urban Freeway & Rural Freeway & 2-Lane Rural Road \\
\cline { 3 - 5 } & 2.52 & 2.02 & 2.84 \\
& $(2.02)^{*}$ & $(1.16)$ & $(2.01)$ \\
Night & & & 7.81 \\
& 2.77 & 2.81 & $(13.73)$ \\
\hline
\end{tabular}

* Numbers in parentheses are respective standard deviations associated with each mean value. 


\subsubsection{Road Type Effects on Visual Allocation in Car Following}

Table 3.3.1 presents the dependent variables that varied significantly as a function of road type in the car following driving scenario. Though not all dependent measures were affected, the results closely parallel those found for the open road driving scenario. Generally, there are longer glances away from the driving scene under rural freeway conditions than under urban freeway conditions. However, the effects are quite small and appear to be of no practical significance. This pattern of results suggests that urban and rural freeway car following should yield results for driver workload assessment that, for practical purposes, are equivalent.

\subsubsection{Lighting Effects on Visual Allocation Measures During Car Following}

Light levels (day versus night) had statistically significant effects on Mean Instrument Panel glance durations (MIP), Mean Time Off Road (MT.OR), and mean on-road glance durations (MORT) and mean as indicated in Table 3.3.2. Night driving in a car following scenario led to relatively longer durations away from the road scene to check the instrument panel. An explanation for this effect in terms of driver visual processes has already been presented. However, the observed differences in mean values are small and appear to be of no practical significance. MTOR values follow a similar direction of effects; again, the light variable appears to have only a small impact on visual allocation away from the road scene, even under car following conditions. Finally, the MORT averages indicate that under night driving conditions of car following, drivers did spend longer periods of time looking at the road scene between glances away from the road scene. This is reasonable given the presence of a lead vehicle and the driver's awareness that night driving reduces object and event detection, a deficit drivers appear to compensate for by spending more time monitoring the road scene ahead. Based on these data, it appears that light effects are small for the car following scenario except for MORT values, which are longer for night driving.

No other significant main effects and no significant interactions were found in the car following data. In general, those Road Type and Light effects that were statistically significant are small and appear to be of little practical importance. On the other hand, mean on-road glance durations (MORT) are substantially longer for the nighttime car following situation than for daylight car following conditions. Thus, with this possible exception, it appears that light effects should have relatively small effects on driver visual allocation under car following situations.

\subsection{Results of a Comparison of Open Road Driving and Car Following Scenario Effects on Visual Allocation}

It is important to more directly assess the impact of driving scenario (open road driving versus car following) on visual allocation measures. To accomplish this, the data from the 
Table 3.3.1 Significant Road Type Effects on Visual Allocation Measures During Car Following

\begin{tabular}{|c|c|c|}
\hline \multirow[b]{2}{*}{ Dependent Measure } & \multicolumn{2}{|c|}{ Road Type } \\
\hline & Urban Freeway & Rural Freeway \\
\hline $\mathbf{M L M}^{\mathrm{a}}$ & $\begin{array}{l}0.91 \\
(0.28)^{*}\end{array}$ & $\begin{array}{c}1.01 \\
(0.29)\end{array}$ \\
\hline MIPb & $\begin{array}{c}0.76 \\
(0.22)\end{array}$ & $\begin{array}{c}0.84 \\
(0.21)\end{array}$ \\
\hline $\mathrm{MTOR}^{\mathrm{c}}$ & $\begin{array}{c}0.85 \\
(0.19)\end{array}$ & $\begin{array}{c}0.92 \\
(0.22)\end{array}$ \\
\hline MM $^{d}$ & $\begin{array}{c}0.93 \\
(0.26)\end{array}$ & $\begin{array}{c}0.98 \\
(0.29)\end{array}$ \\
\hline
\end{tabular}

Notes:
a. $\quad F(1,193)=11.44, p=.0009$
b. $\quad F(1,185)=9.36, p=.0025$
c. $\quad F(1,227)=14.65, p=.0002$
d. $\quad F(1,200)=4.54, p=.0344$

* Numbers in parentheses are respective standard deviations associated with each mean value. 
Table 3.3.2 Visual Allocation Measures that Significantly Differed by Lighting During Car Following

\begin{tabular}{|c|c|c|}
\hline \multirow[b]{2}{*}{ Dependent Measure } & \multicolumn{2}{|c|}{ Light Level } \\
\hline & Day & Night \\
\hline $\mathbf{M I P}^{\mathrm{a}}$ & $\begin{array}{c}0.77 \\
(0.21)^{*}\end{array}$ & $\begin{array}{c}0.84 \\
(0.22)\end{array}$ \\
\hline MTOR $^{b}$ & $\begin{array}{c}0.86 \\
(0.20)\end{array}$ & $\begin{array}{c}0.90 \\
(0.21)\end{array}$ \\
\hline MORT $^{c}$ & $\begin{array}{c}2.28 \\
(1.66)\end{array}$ & $\begin{array}{c}3.08 \\
(2.35)\end{array}$ \\
\hline
\end{tabular}

Notes:
a. $\mathrm{F}(1,41)=6.58, \boldsymbol{p}=.0141$
b. $\mathrm{F}(1,36)=5.13, p=.0295$
c. $\mathrm{F}(1,33)=9.53, \boldsymbol{p}=.0041$

* Numbers in parentheses are respective standard deviations associated with each mean value. 
previous two analyses were combined and an analysis of variance was carried out with a new model. Since car following was not observed on the 2-lane rural road type, these data were omitted from the analysis. The model included Driving Scenario (open road driving versus car following), Road Type (urban freeway versus rural freeway), Light (day versus night), and their two-way interactions as fixed effects. Subjects and Subjects x Light random effects were included in the model based on evaluations described earlier. Because the main effects of and interactions between Road Type and Light were previously reported, the following subsections report only those main effects of Driving Scenario and interactions that involve Driving Scenario.

\subsubsection{Driving Scenario (Open Road Driving versus Car Following) Effects on Visual Allocation Measures}

Statistically significant effects for the main effect of scenario are provided in Table 3.4.1. Note that the differences in mean values for the Open Road and Car Following scenarios are uniformly small and below those differences judged to be of practical significance. From these data, it appears that there are no practical differences between open road driving and car following scenarios like those observed elsewhere in this study.

\subsubsection{Results of the Interaction between Road Type $x$ Driving Scenario on Visual Allocation Measures}

Driving Scenario interacted with Road Type for only two visual allocation measures: MRM and MLM. As indicated in Table 3.4.2, the interaction is of no practical significance for the average dwell time to the left mirror (MLM). The MRM means are longer under open road driving conditions on the rural freeway than under car following conditions on the rural freeway; there are no significant driving scenario differences on the urban freeway. The direction of differences is such that less time is spent on glancing at the right mirror, on average, when car following. This is in line with expectations. No other interactions involving Driving Scenario were found. In general, the effects of Driving Scenario interacting with Road type appear to be of no practical significance.

\subsection{Results of Requested Task Execution During Open-Road Driving on Visual Allocation Requested}

During preliminary data organization and reduction, it appeared that some of the tasks were redundant in the sense that the mean glance durations and/or mean number of glances were not, on average, substantially different from others. Thus, a decision was made to include only the following 7 requested tasks in the analysis:

- $\quad$ Adjust radio volume

- $\quad$ Right Mirror Detect 
Table 3.4.1 Driving Scenario (Open Road Driving Versus Car Following) Effects on Visual Allocation

\begin{tabular}{|l|cc|}
\hline \multirow{2}{*}{ Dependent Measure } & \multicolumn{2}{|c|}{ Driving Scenario } \\
\cline { 2 - 3 } & Open Roadway & Car Following \\
\hline FRACM $^{\mathbf{a}}$ & 0.089 & 0.104 \\
& $(0.067)^{*}$ & $(0.079)$ \\
MM $^{\mathbf{b}}$ & 1.03 & \\
& $(0.26)$ & 0.96 \\
MTOR $^{\mathrm{c}}$ & 1.00 & $(0.28)$ \\
& $(0.20)$ & 0.88 \\
MIPd & 0.90 & $(0.21)$ \\
& $(0.24)$ & 0.80 \\
& & $(0.22)$ \\
MRM $^{\mathbf{e}}$ & 1.01 & 0.92 \\
& $(0.33)$ & $(0.311)$ \\
\hline
\end{tabular}

Notes:

Corresponding F-values, and p-values are provided below.

a. $\quad \mathrm{F}(1,526)=12.60, \mathrm{p}=.0004$

b. $\quad F(1,486)=7.13, \mathrm{p}=.0078$

c. $\quad \mathrm{F}(1,526)=47.58, \mathrm{p}=.0001$

d. $\quad \mathrm{F}(1,462)=15.71, \mathrm{p}=.0001$

e. $\quad F(1,291)=5.60, p=.0183$

* Numbers in parentheses are respective standard deviations associated with each mean value. 
Table 3.4.2 Significant Interaction Effects of Road Type x Driving Scenario (Open Road Driving Versus Car Following) on Visual Allocation Measures

\begin{tabular}{|c|c|c|c|}
\hline \multirow{2}{*}{$\begin{array}{c}\text { Dependent } \\
\text { Measure }\end{array}$} & \multirow[b]{2}{*}{ Driving Scenario } & \multicolumn{2}{|c|}{ Road Type } \\
\hline & & Urban Freeway & Rural Freeway \\
\hline \multirow[t]{3}{*}{$\mathrm{MRM}^{\mathrm{a}}$, s: } & & & \\
\hline & Open road driving & $\begin{array}{c}\mathbf{0 . 9 6} \\
(\mathbf{0 . 3 2})\end{array}$ & $\begin{array}{c}1.05 \\
(0.34)\end{array}$ \\
\hline & Car following & $\begin{array}{c}0.95 \\
(0.29)\end{array}$ & $\begin{array}{c}0.90 \\
(\mathbf{0 . 3 3})\end{array}$ \\
\hline \multirow[t]{3}{*}{$\mathbf{M L M}^{\mathbf{b}}, \mathrm{s:}$} & & & \\
\hline & Open road driving & $\begin{array}{r}1.00 \\
\mathbf{( 0 . 2 8 )}\end{array}$ & $\begin{array}{c}1.01 \\
\mathbf{( 0 . 3 0 )}\end{array}$ \\
\hline & Car following & $\begin{array}{c}0.91 \\
(\mathbf{0 . 2 8})\end{array}$ & $\begin{array}{c}1.01 \\
(\mathbf{0 . 3 0})\end{array}$ \\
\hline
\end{tabular}

Notes:

Corresponding F-values, and p-values are provided below.

a. $\quad \mathbf{F}(1,291)=5.40, p=.0208$

b. $\quad F(1,470)=7.70, p=.0057$

*Numbers in parentheses are standard deviations. 


$\begin{array}{ll}\text { - } & \text { Read Air Pressure } \\ \text { - } & \text { Tune Radio (Manually) } \\ \text { - } & \text { Change CB Frequency } \\ \text { - } & \text { Left Mirror Detect. }\end{array}$

These seven represent practical tasks commonly executed in driving and provide a range of visual allocation effects. The ANOVA model involved fixed main effects of requested Task (the 7 tasks just presented), Road Type (Urban freeway, Rural freeway, 2-lane rural road), and Lighting (day, night), as well as their two-way interactions. Subject and Subject x Requested Task random effects were found to be significant using procedures introduced earlier in this report. These random effects were included in the ANOVA model and the Subject x Requested Task interaction was used to assess Requested Task main effects. All data were collected under the Open Road Driving scenario. No data were collected under conditions of car following due to a human-use review panel stipulation that tasks not be requested if the heavy vehicle was within approximately 61 meters (200 feet) of the lead vehicle.

\subsubsection{Effects of Requested Task on Visual Allocation Measures}

Statistically significant effects of requested tasks on visual allocation are provided in Table 3.5.1. As indicated, the average device glance duration to the associated device (e.g,. radio, mirror, air pressure gauge, etc.), varied from 0.76 seconds for the radio volume adjustment task to 1.57 seconds for reading the air pressure gauge. This variation reflects the per-glance visual workload imposed by a particular device. For example, reaching for the radio volume control is interpreted to be a less-demanding visual task than visually acquiring and interpreting the air pressure gauge. Of all the requested tasks, "read air pressure" had the highest mean glance duration, 1.57 seconds but note it was completed in 1.16 glances. Participants apparently tried to get all the information in one long glance because this task could not be readily broken into two or more glances. Manually tuning the radio averaged over five glances with an average of 1.22 seconds each.

If average glance duration reflects the difficulty of a single task component, the number of glances to complete a task reflect task complexity as a whole, i.e., the number of task components (Kurokawa and Wierwille, 1990).

The mean number of glances to a device location in order to complete a requested task averaged from an about 1 glance for reading the clock, radio volume adjustment, and mirror sampling to over 5 glances for manually tuning an AM/FM radio. This variation reflects the visual demand of the task as well as the ability of the driver to break up or "chunk" the requested task. 
Table 3.51 Effects of Requested Task on Visual Allocation Measures in Open Road Driving

\begin{tabular}{|c|c|c|c|c|c|c|c|}
\hline \multirow[b]{2}{*}{$\begin{array}{c}\text { Dependent } \\
\text { Measure }\end{array}$} & \multicolumn{7}{|c|}{ Requested Task } \\
\hline & $\begin{array}{c}\text { Adjust } \\
\text { Radio } \\
\text { Volume }\end{array}$ & $\begin{array}{c}\text { Right } \\
\text { Mirror } \\
\text { Detect }\end{array}$ & $\begin{array}{l}\text { Read Air } \\
\text { Pressure }\end{array}$ & $\begin{array}{l}\text { Tune } \\
\text { Radio }\end{array}$ & Tune CB & $\begin{array}{l}\text { Read } \\
\text { Clock }\end{array}$ & $\begin{array}{c}\text { Left } \\
\text { Mirror } \\
\text { Detect } \\
\end{array}$ \\
\hline $\begin{array}{l}\text { DGLNCAV }^{\mathrm{a}} \text {, } \\
\text { device glance } \\
\text { duration, } \mathrm{s}\end{array}$ & $\begin{array}{l}0.76 \\
(0.401)^{*}\end{array}$ & $\begin{array}{c}1.37 \\
(0.59)\end{array}$ & $\begin{array}{c}1.57 \\
(0.71)\end{array}$ & $\begin{array}{c}1.22 \\
(0.41)\end{array}$ & $\begin{array}{c}0.95 \\
(0.341)\end{array}$ & $\begin{array}{c}1.20 \\
(0.43)\end{array}$ & $\begin{array}{r}1.21 \\
(0.55)\end{array}$ \\
\hline $\begin{array}{l}\text { DGLNCNUM }{ }^{b} \text {, } \\
\text { number of } \\
\text { glances to device }\end{array}$ & $\begin{array}{c}1.10 \\
(0.54)\end{array}$ & $\begin{array}{c}1.05 \\
(0.22)\end{array}$ & $\begin{array}{c}1.16 \\
(0.46)\end{array}$ & $\begin{array}{c}5.61 \\
(3.15)\end{array}$ & $\begin{array}{c}3.23 \\
(1.33)\end{array}$ & $\begin{array}{l}1.03 \\
(0.17)\end{array}$ & $\begin{array}{c}1.05 \\
(0.28)\end{array}$ \\
\hline $\begin{array}{l}\text { DGLNCTOT }^{\mathrm{c}} \text {, } \\
\text { device glance } \\
\text { time, s }\end{array}$ & $\begin{array}{c}0.90 \\
(0.62)\end{array}$ & $\begin{array}{c}1.43 \\
(0.62)\end{array}$ & $\begin{array}{c}1.80 \\
(0.99)\end{array}$ & $\begin{array}{c}6.75 \\
(4.40)\end{array}$ & $\begin{array}{c}2.99 \\
(1.42)\end{array}$ & $\begin{array}{l}1.23 \\
(0.46)\end{array}$ & $\begin{array}{c}1.27 \\
(0.63)\end{array}$ \\
\hline $\begin{array}{l}\text { RGLNCAV }^{\mathrm{d}} \text {, } \\
\text { road glance } \\
\text { duration, } \mathrm{s}\end{array}$ & $\begin{array}{c}1.65 \\
(1.47)\end{array}$ & $\begin{array}{c}0.64 \\
(0.40)\end{array}$ & $\begin{array}{c}0.61 \\
(0.70)\end{array}$ & $\begin{array}{c}0.89 \\
(0.45)\end{array}$ & $\begin{array}{c}1.04 \\
(0.65)\end{array}$ & $\begin{array}{l}0.66 \\
(0.49)\end{array}$ & $\begin{array}{c}0.69 \\
(0.37)\end{array}$ \\
\hline $\begin{array}{l}\text { TOTDUR }^{\mathrm{e}}, \text { task } \\
\text { total duration, s }\end{array}$ & $\begin{array}{c}1.94 \\
(1.78)\end{array}$ & $\begin{array}{c}1.69 \\
(0.83)\end{array}$ & $\begin{array}{c}1.98 \\
(1.32)\end{array}$ & $\begin{array}{l}11.74 \\
(7.59)\end{array}$ & $\begin{array}{c}5.79 \\
(3.73)\end{array}$ & $\begin{array}{l}1.37 \\
(0.61)\end{array}$ & $\begin{array}{c}1.42 \\
(0.79)\end{array}$ \\
\hline
\end{tabular}

Notes:

Corresponding F-values, and p-values are provided below.
a. $\quad \mathrm{F}(6,195)=34.59, \mathrm{p}=.0001$
b. $\quad \mathrm{F}(6,189)=159.99, \mathrm{p}=.0001$
c. $\quad \mathrm{F}(6,193)=237.39, \mathrm{p}=.000 \mathrm{l}$
d. $\quad F(6,157)=8.69, p=.0001$
e. $\quad F(6,189)=243.9, p=.0001$

* Numbers in parentheses are respective standard deviations associated with each mean value. 
The average total device glance time, a measure of the total time the driver's eyes were off the road scene while completing the requested task, varied roughly consistently with the product of average glance duration and mean number of glances. The total device glance time, on average, varied from 0.90 seconds to 6.75 seconds. These values represent the average total time that the driver is not visually attending to the road scene with foveal vision.

A fourth measure of potential interest is the average glance duration back to the road scene during the completion of the requested task. If a task imposes cognitive demand on the driver, e.g., displayed information must be kept in memory, then it is possible that the driver will shorten visual scanning to the road scene ahead to ease that memory burden and finish the task. The average road scene visual glance duration associated with adjusting radio volume is spuriously large because of the nature of the task. Once the volume knob is visually acquired and the hand is placed on it, the task is manual only or aural-manual in nature (Wierwille et al., 1992); no further visual allocation is required. In this task, several drivers acquired the volume knob without a single glance and most completed the volume adjustment while looking at the road scene. This is what is reflected in the associated on-road glance duration.

On the other hand, short road scene average glance durations associated with left and right mirror sampling, and reading the clock or air pressure gauge may reflect the effects of memory load. Note the higher mean glance duration to the left and right mirrors under urban and rural freeway driving, 1.25 seconds to 1.39 seconds, respectively. These are considerably longer than natural mirror glances in open road or car following reported earlier ( 0.91 seconds to 1.05 seconds, on average). This is probably due to the artifact of the requested task question "Is there traffic in your mirror?" The task has some discrimination in it compared to simple qualitative mirror checks for natural driving (which were observed, not requested). Also, many task requests were issued where there was no traffic to be seen in the mirror. Subject drivers may have tried to find traffic that wasn't there and this might account for the higher mean glance durations. They also wanted to give a correct answer. It is plausible that the drivers may have scanned the mirror display and, when more than one glance was used, attempted to keep in memory the mirror area that had been previously scanned to more accurately complete the requested task.

The radio tuning and $\mathrm{CB}$ tuning tasks had relatively longer average glance durations back to the road scene. Given that the driver was asked to tune to a specific channel, the memory load was minor. The radios each displayed the current radio frequency and this could be readily compared to the desired radio frequency. Thus, longer glances back to scan the road scene may have been feasible because little information from a device glance had to be kept in the driver's working memory. Further research should be directed to clarify this tentative interpretation of mean glance durations back to the road scene during task execution.

Total task duration means also varied significantly with tasks. While most tasks were completed in under 2 seconds, radio tuning and CB tuning took substantially longer (means of 11.74 seconds and 5.79 seconds, respectively). The difference between total task duration and total device glance time reflects time spent glancing back to the road scene during task execution. 
The importance of these data is that they represent a range of in-vehicle task demand on visual attention. As such, these data may serve as benchmarks with which to assess new hightechnology in-cab devices.

\subsubsection{Effects of Road Type on Visual Allocation Measures During Requested Device Use in Open Road Driving}

Table 3.5.2 indicates that only two visual allocation measures were statistically significant: average device glance durations and total device glance time. A consistent pattern is that the amount of time drivers took, either in a single glance to a device on average or the total time spent looking at a device to complete a requested task, was significantly shorter for open road driving on a 2-lane rural road. The results suggest drivers devoted slightly longer times away from the road scene in rural as opposed to urban freeways, probably because of greater traffic density in the urban setting. However, observed differences between Urban and Rural freeways on average device glance duration and mean total device glance time were small and do not appear to be of practical importance. Thus, these data suggest that drivers shorten their glance durations to devices, on average, when the road type demands it. However, the visual demands of the driving scene for urban and rural freeways, consistent with other analyses already presented, have little differential impact. Finally, small but reliable differences were found in average total task duration; drivers spent slightly less time completing tasks, on average, on the 2-lane rural road setting.

\subsubsection{Effects of Requested Task x Road Type Interactions on Visual Allocation Measures in Open Road Driving}

Table 3.5.3 provides the means associated with the statistically significant Requested Task $x$ Road Type interactions in open road driving. Average device glance durations, mean number of glances, total device glance times, and total task durations follow the same pattern of variation as found with the main effects of Requested Task. Similarly, the general trend across Road Types is consistent with the main effects of Road Type previously presented. The variations in patterns of effects that account for the interaction are small in magnitude and appear to be of no practical significance. For example, in general, the main effects of Road Type indicate that average glance durations will be slightly longer for Rural Freeways as compared to Urban Freeways. However, an opposite (but small) pattern appears for the in-cab task "adjust radio volume", "left mirror detect", or "read clock".

Consider next the mean number of glances to a device needed to complete a requested task. For a given requested task, differences among means as a function of road type are generally of no practical significance even though they may be statistically reliable. One notable difference is the mean number of glances to tune the $\mathrm{CB}$ under urban freeway (A4 $=3.68$ glances) versus rural freeway $(\mathrm{M}=3.01)$ driving. The reason for this particular difference is unknown. 
Table 3.5.2 Effects of Road Type on Visual Allocation Measures During Requested Task Execution in Open Road Driving

\begin{tabular}{|c|c|c|c|}
\hline \multirow[b]{2}{*}{ Dependent Measure } & \multicolumn{3}{|c|}{ Road Type } \\
\hline & Urban Freeway & Rural Freeway & 2-Lane Highway \\
\hline $\begin{array}{l}\text { DGLNCAV }{ }^{\mathrm{a}} \text { device } \\
\text { glance duration, } \mathrm{s}\end{array}$ & $\begin{array}{l}1.22 \\
(0.55)^{*}\end{array}$ & $\begin{array}{c}1.26 \\
(0.61)\end{array}$ & $\begin{array}{c}1.00 \\
(0.40)\end{array}$ \\
\hline $\begin{array}{l}\text { DGLNCTOT }^{\mathrm{b}} \text { device } \\
\text { glance time, } \mathrm{s}\end{array}$ & $\begin{array}{l}2.29 \\
(2.41)\end{array}$ & $\begin{array}{l}2.47 \\
(2.88)\end{array}$ & $\begin{array}{l}2.08 \\
(2.27)\end{array}$ \\
\hline $\begin{array}{l}\text { TOTDUR }^{\mathrm{c}} \text {, task total } \\
\text { duration. } \mathrm{s}\end{array}$ & $\begin{array}{c}3.71 \\
(4.58)\end{array}$ & $\begin{array}{c}3.70 \\
(4.69)\end{array}$ & $\begin{array}{c}3.64 \\
(5.53)\end{array}$ \\
\hline
\end{tabular}

Notes:

Corresponding F-values, and p-values are provided below.

a. $\quad \boldsymbol{F}(2,1374)=54.07, \boldsymbol{p}=.0001$

b. $\quad F(2,1374)=21.52, \mathrm{p}=.0001$

c. $\quad \boldsymbol{F}(2,1374)=8.45, \boldsymbol{p}=.0002$

* Numbers in parentheses are respective standard deviations associated with each mean value. 
Table 3.5.3 Effects of Requested Task $x$ Road Interactions on Visual Allocation Measures During Open Road Driving

\begin{tabular}{|c|c|c|c|c|c|c|c|c|}
\hline \multirow[b]{2}{*}{$\begin{array}{l}\text { Dependent } \\
\text { Measure }\end{array}$} & \multirow[b]{2}{*}{$\begin{array}{l}\text { Road } \\
\text { Type }\end{array}$} & \multicolumn{7}{|c|}{ Requested Task } \\
\hline & & $\begin{array}{c}\text { Adjust } \\
\text { Radio } \\
\text { Volume }\end{array}$ & $\begin{array}{c}\text { Right } \\
\text { Mirror } \\
\text { Detect } \\
\end{array}$ & $\begin{array}{l}\text { Read Air } \\
\text { Pressure }\end{array}$ & $\begin{array}{l}\text { Tune } \\
\text { Radio }\end{array}$ & Tune CB & $\begin{array}{l}\text { Read } \\
\text { Clock }\end{array}$ & $\begin{array}{c}\text { Left } \\
\text { Mirror } \\
\text { Detect }\end{array}$ \\
\hline \multirow[t]{3}{*}{$\begin{array}{l}\text { DGLNCAV, Average } \\
\text { Device Glance Duration, s: }\end{array}$} & Urban Freeway & $\begin{array}{l}0.82 \\
(0.34)^{*}\end{array}$ & $\begin{array}{l}1.39 \\
(0.48)\end{array}$ & $\begin{array}{c}1.69 \\
(0.66)\end{array}$ & $\begin{array}{l}1.15 \\
(0.46)\end{array}$ & $\begin{array}{c}0.93 \\
(0.45)\end{array}$ & $\begin{array}{l}1.20 \\
(0.97)\end{array}$ & $\begin{array}{c}1.34 \\
(0.47)\end{array}$ \\
\hline & Rural Freeway & $\begin{array}{c}0.80 \\
(0.39)\end{array}$ & $\begin{array}{l}1.50 \\
(0.67)\end{array}$ & $\begin{array}{c}1.68 \\
(0.77)\end{array}$ & $\begin{array}{c}1.31 \\
(0.41)\end{array}$ & $\begin{array}{c}1.01 \\
(0.34)\end{array}$ & $\begin{array}{c}1.26 \\
(0.44)\end{array}$ & $\begin{array}{c}1.25 \\
(0.63)\end{array}$ \\
\hline & $\begin{array}{l}\text { 2-Lane Rural } \\
\text { Road }\end{array}$ & $\begin{array}{c}0.65 \\
(0.46)\end{array}$ & $\begin{array}{l}1.07 \\
(0.36)\end{array}$ & $\begin{array}{c}1.23 \\
(0.47)\end{array}$ & $\begin{array}{c}1.09 \\
(0.30)\end{array}$ & $\begin{array}{c}0.86 \\
(0.23)\end{array}$ & $\begin{array}{c}1.09 \\
(0.35)\end{array}$ & $\begin{array}{c}1.00 \\
(0.35)\end{array}$ \\
\hline \multirow[t]{3}{*}{$\begin{array}{l}\text { DGLNCNUM }{ }^{b} \text {, Mean } \\
\text { Number of Glances: }\end{array}$} & Urban Freeway & $\begin{array}{l}1.09 \\
(0.34)\end{array}$ & $\begin{array}{l}1.03 \\
(0.18)\end{array}$ & $\begin{array}{l}1.07 \\
(0.26)\end{array}$ & $\begin{array}{c}5.32 \\
(2.52)\end{array}$ & $\begin{array}{c}3.68 \\
(1.89)\end{array}$ & $\begin{array}{l}1.00 \\
(0.00)\end{array}$ & $\begin{array}{c}1.04 \\
(0.20)\end{array}$ \\
\hline & Rural Freeway & $\begin{array}{c}1.11 \\
(0.63)\end{array}$ & $\begin{array}{l}1.08 \\
(0.28)\end{array}$ & $\begin{array}{c}1.14 \\
(0.41)\end{array}$ & $\begin{array}{c}5.70 \\
(3.50)\end{array}$ & $\begin{array}{c}3.01 \\
(1.03)\end{array}$ & $\begin{array}{c}1.03 \\
(0.18)\end{array}$ & $\begin{array}{l}1.05 \\
(0.35)\end{array}$ \\
\hline & $\begin{array}{l}\text { 2-Lane Rural } \\
\text { Road }\end{array}$ & $\begin{array}{r}1.07 \\
(0.52)\end{array}$ & $\begin{array}{l}1.00 \\
(0.00)\end{array}$ & $\begin{array}{r}1.35 \\
(0.65)\end{array}$ & $\begin{array}{c}5.72 \\
(2.91)\end{array}$ & $\begin{array}{l}3.24 \\
(1.12)\end{array}$ & $\begin{array}{c}1.05 \\
(0.22)\end{array}$ & $\begin{array}{l}1.03 \\
(0.19)\end{array}$ \\
\hline \multirow[t]{3}{*}{$\begin{array}{l}\text { DGLNCTOT }^{\mathrm{c}} \text {, Total } \\
\text { Device Glance Time, s: }\end{array}$} & Urban Freeway & $\begin{array}{c}0.92 \\
(0.51)\end{array}$ & $\begin{array}{c}1.44 \\
(0.53)\end{array}$ & $\begin{array}{c}1.78 \\
(0.74)\end{array}$ & $\begin{array}{c}6.27 \\
(3.95)\end{array}$ & $\begin{array}{c}3.28 \\
(1.87)\end{array}$ & $\begin{array}{c}1.20 \\
(0.47)\end{array}$ & $\begin{array}{c}1.39 \\
(0.53)\end{array}$ \\
\hline & Rural Freeway & $\begin{array}{c}0.96 \\
(0.68)\end{array}$ & $\begin{array}{c}1.59 \\
(0.69)\end{array}$ & $\begin{array}{c}1.91 \\
(1.10)\end{array}$ & $\begin{array}{c}7.27 \\
(5.01)\end{array}$ & $\begin{array}{c}2.93 \\
(1.06)\end{array}$ & $\begin{array}{c}1.30 \\
(0.49)\end{array}$ & $\begin{array}{c}1.32 \\
(0.71)\end{array}$ \\
\hline & $\begin{array}{l}\text { 2-Lane Rural } \\
\text { Road }\end{array}$ & $\begin{array}{c}0.76 \\
(0.59)\end{array}$ & $\begin{array}{c}1.07 \\
(0.36)\end{array}$ & $\begin{array}{c}1.57 \\
(0.93)\end{array}$ & $\begin{array}{l}6.11 \\
(3.22)\end{array}$ & $\begin{array}{c}2.82 \\
(1.55)\end{array}$ & $\begin{array}{c}1.12 \\
(0.35)\end{array}$ & $\begin{array}{c}1.06 \\
(0.48)\end{array}$ \\
\hline
\end{tabular}


Table 3.5.3 Effects of Requested Task x Road Interactions on Visual Allocation Measures During Open Road Driving (Continued)

\begin{tabular}{|c|c|c|c|c|c|c|c|c|}
\hline \multirow[b]{2}{*}{$\begin{array}{c}\text { Dependent } \\
\text { Measure }\end{array}$} & \multirow[b]{2}{*}{$\begin{array}{l}\text { Road } \\
\text { Type } \\
\end{array}$} & \multicolumn{7}{|c|}{ Requested Task } \\
\hline & & $\begin{array}{c}\text { Adjust } \\
\text { Radio } \\
\text { Volume }\end{array}$ & $\begin{array}{l}\text { Right } \\
\text { Mirror } \\
\text { Detect }\end{array}$ & $\begin{array}{l}\text { Read Air } \\
\text { Pressure }\end{array}$ & $\begin{array}{c}\text { Tune } \\
\text { Radio }\end{array}$ & Tune CB & $\begin{array}{l}\text { Read } \\
\text { Clock }\end{array}$ & $\begin{array}{l}\text { Left } \\
\text { Mirror } \\
\text { Detect }\end{array}$ \\
\hline \multirow[t]{3}{*}{$\begin{array}{l}\text { TOTDUR, Total Task } \\
\text { Duration }\end{array}$} & Urban Freeway & $\begin{array}{c}1.91 \\
(1.72)\end{array}$ & $\begin{array}{c}1.64 \\
(0.83)\end{array}$ & $\begin{array}{c}1.85 \\
(0.79)\end{array}$ & $\begin{array}{l}11.10 \\
(5.78)\end{array}$ & $\begin{array}{c}6.94 \\
(5.18)\end{array}$ & $\begin{array}{c}1.32 \\
(0.57)\end{array}$ & $\begin{array}{c}1.63 \\
(0.68)\end{array}$ \\
\hline & Rural Freeway & $\begin{array}{c}1.99 \\
(1.82)\end{array}$ & $\begin{array}{c}1.91 \\
(0.86)\end{array}$ & $\begin{array}{c}2.06 \\
(1.26)\end{array}$ & $\begin{array}{l}11.69 \\
(1.38)\end{array}$ & $\begin{array}{c}5.33 \\
(2.65)\end{array}$ & $\begin{array}{c}1.45 \\
(0.64)\end{array}$ & $\begin{array}{c}1.49 \\
(0.89)\end{array}$ \\
\hline & $\begin{array}{l}\text { 2-Lane Rural } \\
\text { Road }\end{array}$ & $\begin{array}{c}1.88 \\
(1.79)\end{array}$ & $\begin{array}{c}1.24 \\
(0.49)\end{array}$ & $\begin{array}{c}1.92 \\
(1.78)\end{array}$ & $\begin{array}{l}12.42 \\
(9.40)\end{array}$ & $\begin{array}{c}5.62 \\
(3.83)\end{array}$ & $\begin{array}{c}1.26 \\
(0.57)\end{array}$ & $\begin{array}{c}1.09 \\
(0.55)\end{array}$ \\
\hline
\end{tabular}

Notes:

Corresponding F-values, and p-values are provided below.

$\begin{array}{ll}\text { a. } & \mathrm{F}(12,1374)=2.76, \mathrm{p}=.0010 \\ \text { b. } & \mathrm{F}(12,1374)=1.83, \mathrm{p}=.0393 \\ \text { c. } & \mathrm{F}(12,1374)=\mathbf{1 . 8 7}, \mathrm{p}=.0339 \\ \text { d. } & \mathrm{F}(12,1374)=2.47, \mathrm{p}=.0033\end{array}$

* Numbers in parentheses are respective standard deviations associated with each mean value. 
From an interpretive standpoint, the number of glances required to complete an in-cab task is driven largely by the device and the driver's ability to "chunk" the task (Tijerina, et al., 1995). Accordingly, there is no logical reason to expect interactive effects with driving conditions like road type or lighting. The statistically significant interactions reported here may reflect the effects of statistical power (given the large number of observations included in the analysis), rather than practical differences.

No other main effects or interactions were found.

\subsection{Discussion}

The purpose of this analysis effort was to provide baseline data on how drivers allocate visual capacity during routine truck driving. Different highway segments were introduced and time of departure was varied so that road type, light level and traffic factors could be studied as to how they might influence allocation patterns. Car following was compared to open road driving. In preparation for use of in-cab devices in Task 7 of this program of research, requested driving tasks were introduced to see what normal shifts in visual allocation occur.

The total number of glances observed and measured in this task was over 32,000, covering the 30 volunteer drivers over all test conditions. Table 36.1 summarizes the statistical properties of allocations to the primary glance locations. First, note that the number of glances is equal to or greater than the number of observations. This is because a single observation, e.g., a driver manually tuning the $\mathrm{CB}$, sometimes consisted of multiple glances. Second, this table shows that glance frequency averages between about 1.0 and 1.2 glances for all off-road glances except radio tuning and CB tuning. Third, drivers return to the road in about 0.8 to 1.60 seconds regardless of the glance location. Even for those tasks which require extended time to complete, e.g., radio tuning, the drivers use multiple glances of short duration to the radio with a mean of 1.22 seconds.

For environmental factors, the influence of road type on glance durations showed a reduction in MTOR for 2-lane roads vs. freeways. Lighting becomes significant in few instances. For open road driving, MORT is considerably higher for night driving than daytime driving. This suggests that necessary visual cues for object and event detection with foveal vision are harder to discriminate at night.

One finding that was unexpected was the fact that car following visual allocation differs only slightly from open road visual allocation. While there was statistical significance for MTOR, mirror glance durations, and instrument panel glance durations, these differences had no practical significance, e.g., duration differences were less than 0.15 seconds.

The subject drivers adapted well to environmentally induced increased workload for road type, lighting and traffic (car following). First they allocated 90 percent of their visual resources 
Table 3.6.1 Visual Allocation of Heavy Vehicle Drivers by Location

\begin{tabular}{|c|c|c|c|c|}
\hline \multicolumn{5}{|c|}{ Glance Duration } \\
\hline Glance Location & $\begin{array}{c}\mathrm{N} \\
\text { Glances }\end{array}$ & $\begin{array}{c}\mathbf{N} \\
\text { Obser- } \\
\text { vations }\end{array}$ & $\begin{array}{c}\text { Mean Glance } \\
\text { Duration (s) }\end{array}$ & $\begin{array}{l}\text { Glance } \\
\text { Duration } \\
\text { SD (s) }\end{array}$ \\
\hline Road scene-natural & 14,907 & 689 & 2.83 & 2.43 \\
\hline Off road-natural & 9,149 & 689 & 0.93 & 0.21 \\
\hline $\begin{array}{l}\text { Left mirror } \\
\text { Natural } \\
\text { "Requested" (left mirror detect) }\end{array}$ & $\begin{array}{c}2,306 \\
218\end{array}$ & $\begin{array}{l}618 \\
217\end{array}$ & $\begin{array}{l}0.97 \\
1.21\end{array}$ & $\begin{array}{l}0.29 \\
0.55\end{array}$ \\
\hline $\begin{array}{l}\text { Right mirror } \\
\text { Natural } \\
\text { "Requested" (right mirror detect) }\end{array}$ & 1,090 & $\begin{array}{l}403 \\
230\end{array}$ & $\begin{array}{l}0.96 \\
1.37\end{array}$ & $\begin{array}{l}0.33 \\
0.59\end{array}$ \\
\hline $\begin{array}{l}\text { Inst.Panel } \\
\text { General }\end{array}$ & 2,877 & 610 & 0.84 & 0.23 \\
\hline Digital Clock* & 234 & 231 & 1.20 & 0.43 \\
\hline Air Pressure Gauge* & 269 & 238 & 1.57 & 0.71 \\
\hline $\begin{array}{l}\text { Radio* } \\
\text { Tune Radio } \\
\text { Adjust Volume } \\
\text { Tune CB* }\end{array}$ & $\begin{array}{l}1,281 \\
252 \\
751\end{array}$ & $\begin{array}{l}228 \\
239 \\
233\end{array}$ & $\begin{array}{l}1.22 \\
0.77 \\
0.96\end{array}$ & $\begin{array}{l}0.41 \\
0.40 \\
0.34\end{array}$ \\
\hline \multicolumn{5}{|c|}{ Number of Glances to Complete "Requested" Tasks } \\
\hline Requested Task & $\begin{array}{c}\mathbf{N} \\
\text { Glances }\end{array}$ & $\begin{array}{c}\mathrm{N} \\
\text { Obser- } \\
\text { vations }\end{array}$ & $\begin{array}{l}\text { Mean Number } \\
\text { of Glances }\end{array}$ & $\begin{array}{l}\text { Glance } \\
\text { Number } \\
\text { SD }\end{array}$ \\
\hline Read Digital Clock & 234 & 231 & 1.03 & 0.17 \\
\hline Read Air Pressure & 269 & 238 & 1.16 & 0.46 \\
\hline Adj . Radio Volume & 252 & 239 & 1.10 & 0.54 \\
\hline Tune Radio & 1,281 & 228 & 5.62 & 3.15 \\
\hline Left Mirror-Detect & 218 & 217 & 1.05 & 0.28 \\
\hline Right Mirror-Detect & 235 & 230 & 1.05 & 0.22 \\
\hline Tune CB & 751 & 233 & 3.23 & 1.33 \\
\hline
\end{tabular}

*Requested task. 
to road sampling for night 2-lane highways vs. 70 to 75 percent for day 4-lane rural expressways. Second, when required to sample for information off the roadway, e.g., mirrors and gauges, they limited their average time off the roadway (MTOR) to between 0.85 and 1.03 seconds. The drivers showed a tendency to use quickened values of MTOR for 2-lane roads vs. the freeways. Conversely, mean "on road" glance durations (MORT) showed a sensitivity to road segment and lighting with longer MORTS for 2-lane roads and night operation.

When asked to perform "off road" information sampling (requested tasks), the same general effects noted above were found. Single glance duration to a device averaged between about 0.65 seconds and 1.70 seconds, depending on task and driving conditions. Drivers again quickened their glance times when on 2-lane rural roads versus freeways. Most requested tasks were completed, on average, in one or two glances. (Some tasks, like adjusting radio volume, were occasionally done without any glance to the device at all.) Two notable exceptions were radio tuning and $\mathrm{CB}$ tuning to requested channels or frequencies. These two tasks averaged about 5.6 glances and 3.2 glances to completion, respectively. Multiple glances were associated with time sharing between the requested task and the driving task as the driver alternatively visually sampled between the road scene and the device. Average glance duration back to the road scene also appeared to vary such that longer device glance durations were associated with shorter road scene glances. This was interpreted to mean that greater attentional demand, as reflected in longer device glances, prompted drivers to reduce time spent scanning the road scene ahead.

In summary, visual allocation measures proved to be sensitive to road type and requested task effects, with smaller differences noted for light effects and very little difference between open road driving and car following scenarios. All effects were in the expected direction and the variability of the individual measures was generally tight about the mean value. Given these results and the primary of vision for safe driving visual allocation measures have much to recommend them for workload assessment. 


\subsection{RESULTS: STEERING, ACCELERATOR, AND BRAKE MEASURES}

The driver depends predominantly on visual information to safely control the vehicle. Thus, visual allocation measures are important for driver workload assessment. However, vehicle control takes place through driver inputs to the vehicle controls, i.e., the steering wheel, accelerator pedal, brake pedal and (less often) transmission. It is plausible that in-vehicle device use can disrupt driver control activities (Tijerina et al., 1995). Measures related to these inputs can potentially serve a useful role in driver workload assessment and as indicators of driver attentional state. Such measures are also safety-relevant to the extent that driver control inputs, mediated through vehicle dynamics and driving condition factors, affect driver-vehicle performance measures of lanekeeping, speed maintenance, and car following.

\subsection{Steering, Accelerator, and Brake Dependent Measures}

The following dependent measures were collected and analyzed to capture steering inputs:

- $\quad$ Steering Wheel

Position Variance (STPVAR), degrees ${ }^{2}$; The sample variance of steering wheel angle over a given sample time interval

- $\quad$ Steering Wheel Velocity

Variance(STVELVAR), [degrees/s] ${ }^{2}$;

The sample variance of steering velocity over a sample time interval

- $\quad$ Steering Holds count (STERHLD) or count per second;

A steering hold was defined to occur when the steering wheel velocity was zero for a minimum of $400 \mathrm{~ms}$.

- $\quad$ Steering Reversals count (STERRFV) or count per second;

A steering reversal was defined to begin when the steering velocity left a zerovelocity dead band and ended when the steering velocity entered a zero-velocity dead band such that the magnitude of the reversals was 2 degrees or greater. brake inputs:

The following dependent measures were collected and analyzed to capture accelerator and 
- $\quad$ Accelerator Pedal (\%-throw $)^{2}$

Position Variance (ACLVAR);

- $\quad$ Accelerator Pedal Velocity

Variance, $\left(\%\right.$-throw/s) ${ }^{2}$ (ACLWAR);

Accelerator Holds count (ACCLHLD)

or count per second (ACCLHLDS);
The sample variance of accelerator pedal percent of throw ( 0 for pedal released to 100 percent for pedal to the floor) over a given sample time interval

The sample variance of accelerator pedal velocity over a sample time interval

An accelerator hold was defined to occur when the accelerator pedal velocity was zero for a minimum of $400 \mathrm{~ms}$.

An accelerator release was defined to occur when the accelerator pedal was in the null (zero percent) position for a minimum of 400 ms.

The number of times the brake pedal was depressed sufficient to activate the brake lights

\subsection{Results: Steering, Accelerator, and Brake Effects in Open Road Driving}

\subsubsection{Effects of Road Type on Steering, Accelerator, and Brake Measures in Open Road Driving}

Table 4.2.1 presents the statistically significant effects of Road Type on various steering, accelerator, and brake measures during open road driving. Note that counts presented have been normalized to counts per second. Several trends are apparent in these data. The most noticeable is that steering, accelerator and brake activity are greatest for the 2-lane rural road, followed by the urban freeway; the rural freeway has the lowest level of activity. This may be explained by the greater path control demanded by the 2-lane rural road and the perhaps greater traffic density present in the urban freeway setting than in the rural freeway setting. A second noticeable trend is 
Table 4.2.1 Significant Effects of Road Type on Steering, Accelerator, and Brake Measures in Open Road Driving

\begin{tabular}{|c|c|c|c|}
\hline \multirow[b]{2}{*}{ Dependent Measure } & \multicolumn{3}{|c|}{ Road Type } \\
\hline & Urban Freeway & Rural Freeway & 2-Lane Highway \\
\hline $\begin{array}{l}\text { Steering Position } \\
\text { Variance }^{\mathrm{a}} \text {, degrees' }\end{array}$ & $\begin{array}{l}47.9 \\
(68.1) ”\end{array}$ & $\begin{array}{c}23.3 \\
(41.4)\end{array}$ & $\begin{array}{c}176.5 \\
(184.4)\end{array}$ \\
\hline $\begin{array}{l}\text { Steering Velocity } \\
\text { Variance }^{b}{\text { [degrees } / \mathrm{s}]^{2}}^{2}\end{array}$ & $\begin{array}{l}210.0 \\
(201.9)\end{array}$ & $\begin{array}{c}139.9 \\
(141.0)\end{array}$ & $\begin{array}{c}347.9 \\
(253.3)\end{array}$ \\
\hline $\begin{array}{l}\text { Number of Steering } \\
\text { Holds } \text { c, per second }\end{array}$ & $\begin{array}{c}0.17 \\
(0.14)\end{array}$ & $\begin{array}{c}0.23 \\
(0.15)\end{array}$ & $\begin{array}{c}0.14 \\
(0.10)\end{array}$ \\
\hline $\begin{array}{l}\text { Number of Steering } \\
\text { Reversals } \mathrm{d} \text {, per second }\end{array}$ & $\begin{array}{c}0.78 \\
(0.23)\end{array}$ & $\begin{array}{c}0.69 \\
(0.29)\end{array}$ & $\begin{array}{c}0.90 \\
(0.20)\end{array}$ \\
\hline $\begin{array}{l}\text { Accelerator Position } \\
\text { valiance }^{\mathrm{e}}, \% \text { throw }\end{array}$ & $\begin{array}{c}263.2 \\
(254.9)\end{array}$ & $\begin{array}{c}187.2 \\
(269.6)\end{array}$ & $\begin{array}{c}565.0 \\
(401.4)\end{array}$ \\
\hline $\begin{array}{l}\text { Accelerator Velocity } \\
\text { Variance }^{\mathrm{f}},[\% \text {-throw/s] }\end{array}$ & $\begin{array}{l}253.5 \\
(306.2)\end{array}$ & $\begin{array}{r}310.4 \\
(512.0)\end{array}$ & $\begin{array}{r}584.1 \\
(553.6)\end{array}$ \\
\hline $\begin{array}{l}\text { Number of Accelerator } \\
\text { Releases } \mathrm{g} \text {, per second }\end{array}$ & $\begin{array}{c}0.05 \\
(0.11)\end{array}$ & $\begin{array}{c}0.02 \\
(0.07)\end{array}$ & $\begin{array}{c}0.09 \\
(0.12)\end{array}$ \\
\hline $\begin{array}{l}\text { Number of Brake } \\
\text { Applications } \text {, per second }\end{array}$ & $\begin{array}{c}0.001 \\
(0.005)\end{array}$ & $\begin{array}{r}0.0001 \\
(0.005)\end{array}$ & $\begin{array}{l}0.01 \\
(0,014)\end{array}$ \\
\hline
\end{tabular}

Notes: Corresponding F-values, and p-values are provided below.
a. $\quad \mathrm{F}(2,61)=82.95, \mathrm{p}=.000 \mathrm{l}$
b. $\quad \mathrm{F}(2,63)=86.43, \mathrm{p}=.0001$
c. $\quad \mathrm{F}(2,61)=19.98, \mathrm{p}=.0001$
d. $\quad \mathrm{F}(2,59)=19.70, \mathrm{p}=.0001$
e. $\quad F(2,62)=59.76, p=.0001$
f. $\quad \mathrm{F}(2,63)=44.25, \mathrm{p}=.0001$
g. $\quad \mathrm{F}(2,60)=19.03, \mathrm{p}=.0001$
h. $\quad F(2,61)=46.05, p=.0001$

\footnotetext{
* Numbers in parentheses are respective standard deviations associated with each mean value.
} 
that brake applications are very infrequent regardless of road type. The 2-lane rural road setting is different in its effects on steering, acceleration, and brake activity than urban or rural freeway settings.

\subsubsection{Effects of Light on Steering, Accelerator and Brake Measures in Open Road Driving}

Table 4.2.2 contains the steering, accelerator, and brake measures found to be statistically significantly different as a function of Light level. Steering measures were not affected at all. This lack of significant differences might be explained by Liebowitz' (1988) duplex theory of vision. Liebowitz argues that in night driving, the driver uses the peripheral retina or "ambient mode of vision" to maintain lateral control. This mode is about as good under reduced lighting conditions as it is under daylight. Therefore, lighting effects on steering measures are not expected. On the other hand, accelerator velocity variance and accelerator releases per second were significantly different. Under night lighting, there is more accelerator activity and slightly fewer releases. This might also be explained by Liebowitz' duplex theory. The foveal retina or "focal mode of vision" is primarily used for object and event detection. It is degraded by reduced ambient lighting relative to daylighting. While most drivers do not substantially reduce their travel speed at night, it is possible that truck drivers, given their training and extensive experience, exhibit greater control activities in speed control, This explanation merits further investigation. No other main effects or interactions were significant.

\subsection{Results: Steering, Accelerator, and Brake Measures in Car Following}

An analysis was carried out on steering, accelerator, and brake measures during car following. The ANOVA model included fixed effects of Road Type (urban freeway, rural freeway), Light (day, night), and the Road Type x Light interaction. The following random effects were evaluated using maximum likelihood procedures and were included in the model: Subject, Subject x Light, Subject x Road Type x Light. Appropriate random effects were used to assess fixed effects, e.g., the Road Type $x$ Light interaction was assessed using the Subject $x$ Road Type x Light random effect as an error term (Kirk, 1982). Statistically significant effects are reported below.

\subsubsection{Effects of Road Type on Steering, Accelerator, and Brake Measures in Car Following}

Table 4.3.1 indicates those dependent measures that were statistically significantly different as a function of road type. In general there is more steering, accelerator, and brake activity on the urban freeway than on the rural freeway. For example, steering holds and accelerator holds are less frequent while brake applications are more frequent. Steering reversals 
Table 4.2.2 Significant Effects of Light on Steering, Accelerator, and Brake Measures in Open Road Driving

\begin{tabular}{|c|cc|}
\hline \multirow{2}{*}{ Dependent Measure } & \multicolumn{2}{|c|}{ Light Level } \\
\cline { 2 - 3 } & Day & Night \\
\hline Accelerator Velocity Variance $^{\mathrm{a}}$, [\%-throw/s] ${ }^{2}$ & $\mathbf{3 0 6 . 2}$ & 419.7 \\
& $(413.4)^{\prime}$ & $\mathbf{( 5 6 0 . 7 )}$ \\
& & \\
Number of Accelerator Releases $^{\mathrm{b}}$, per second & 0.05 & 0.04 \\
& $(0.11)$ & $\mathbf{( 0 . 0 9 )}$ \\
\hline
\end{tabular}

Notes:

a. $\quad \mathrm{F}(1,109)=\mathbf{5 . 0 4 , p}=.0268$

b. $\quad F(1,99)=3.94, p=.0499$

* Numbers in parentheses are respective standard deviations associated with each mean value. 
Table 4.3.1 Significant Effects of Road Type on Steering, Accelerator, and Brake Measures in Car Following

\begin{tabular}{|c|c|c|}
\hline \multirow[b]{2}{*}{ Dependent Measure } & \multicolumn{2}{|c|}{ Road Type } \\
\hline & Urban Freeway & Rural Freeway \\
\hline Steering Position Variance ${ }^{\mathrm{a}}$, degrees ${ }^{2}$ & $\begin{array}{l}49.7 \\
(64.0)^{*}\end{array}$ & $\begin{array}{c}22.3 \\
(22.3)\end{array}$ \\
\hline Steering Velocity Variance ${ }^{\mathrm{b}}$, [degrees/s $^{2}$ & $\begin{array}{c}231.7 \\
(219.8)\end{array}$ & $\begin{array}{c}154.7 \\
(154.1)\end{array}$ \\
\hline Number of Steering Holds per second ${ }^{c}$ & $\begin{array}{c}0.15 \\
(0.13)\end{array}$ & $\begin{array}{c}0.20 \\
(0.14)\end{array}$ \\
\hline Number of Steering Reversals per second ${ }^{d}$ & $\begin{array}{c}0.51 \\
(0.12)\end{array}$ & $\begin{array}{c}0.55 \\
(0.12)\end{array}$ \\
\hline Accelerator Position Variance (\%-throw $)^{2}$ & $\begin{array}{c}317.2 \\
(307.7)\end{array}$ & $\begin{array}{c}248.6 \\
(356.3)\end{array}$ \\
\hline Number of Accelerator Holds per second ${ }^{f}$ & $\begin{array}{c}0.25 \\
(0.13)\end{array}$ & $\begin{array}{c}0.29 \\
(0.13)\end{array}$ \\
\hline Number of Brake Applications per secondg & $\begin{array}{c}0.005 \\
(0.013)\end{array}$ & $\begin{array}{c}0.001 \\
(0.007)\end{array}$ \\
\hline
\end{tabular}

Notes:
a. $\quad \mathrm{F}(1,33)=33.71, \mathrm{p}=.0001$
b. $\quad \mathrm{F}(1,32)=24.88, \mathrm{p}=.0001$
c. $\quad \mathrm{F}(1,32)=8.38, \mathrm{p}=.0068$
d. $\quad \mathrm{F}(1,34)=14.94, \mathrm{p}=.0005$
e. $\quad \mathrm{F}(1,71)=7.41, \mathrm{p}=.0082$
f. $\quad F(1,69)=68.71, p=.0439$
g. $\quad F(1,71)=14.56, p=.0003$

* Numbers in parentheses are respective standard deviations associated with each mean value. 
are slightly greater for the rural freeway. Steering reversals, according to Macdonald and Hoffmann (1980), are indicative of primary task workload in the absence of an in-cab task. In general, the greater the driving task demand, the greater the incidence of steering reversals. However, the magnitude of differences is generally small. Thus, road type has some effects on such dependent measures, though they are small. From an interpretive standpoint, these data indicate that interpretation of such measures to assessment in-cab device or task workload must be tempered by the fact that many other factors, like road type, can also affect such measures.

\subsubsection{Effects of Light on Steering, Accelerator and Brake Measures in Car Following}

Table 4.3.2 indicates those dependent measures that reliably varied as a function of ambient light level. Note that only steering measures were reliably affected. Steering activity was somewhat greater and steering holds were less frequently in daylight conditions rather than night conditions. Furthermore, the incidence of steering reversals was slightly greater in daylight conditions than in night driving conditions. Given the theory that lanekeeping is generally less affected by low ambient illumination when driving, one would expect that no differences should be significant. One possibility, then, is that traffic density may be less under the night lighting conditions than day and it is this that is affecting the outcomes of the study.

No other significant main effects or two-factor interactions were found.

\subsection{Results: Steering, Accelerator, and Brake Measures in Comparison of Driving Scenarios (Open Road Driving versus Car Following)}

In order to directly compare the open driving and car following scenarios, the data from the two were combined for further analysis. However, since car following was not observed on 2-lane rural roads, these data were omitted from the combined data set. For all measures, then, the fixed effects consisted of Road Type (urban freeway, rural freeway), Light (day, night), Driving Scenario (open road driving, car following), and their various two-factor interactions. For steering measures, only the Subject random effect was included in the ANOVA model. For accelerator and brake measures, the following random effects were included in the ANOVA model and used as appropriate for F-tests of the associated fixed effects: Subject, Subject $\mathrm{x}$ Driving Scenario, Subject x Road Type x Light, Subject x Light x Driving Scenario, and Subject x Road Type. Since the effects of Road Type, Light, and their interaction have already been reported, only statistically significant results of Driving Scenario or interactions involving Driving Scenario are reported below. 
Table 4.3.2 Significant Effects of Light on Steering, Accelerator, and Brake Measures in Car Following

\begin{tabular}{|l|c|c|}
\hline \multirow{2}{*}{ Dependent Measure } & \multicolumn{2}{|c|}{ Light Level } \\
\cline { 2 - 3 } & Day & Night \\
\hline Steering Velocity Variance $^{\mathrm{a}}$, degrees $^{2}$ & 211.3 & 181.3 \\
& $(195.0)^{*}$ & $(195.2)$ \\
& & \\
Number of Steering Holds per second $^{\mathrm{b}}$ & 0.16 & 0.19 \\
& $(0.13)$ & $(0.14)$ \\
Number of Steering Reversals per second $^{\mathrm{c}}$ & & \\
& 0.80 & 0.75 \\
& $(0.26)$ & $(0.29)$ \\
\hline
\end{tabular}

Notes:
a. $\quad \mathrm{F}(1,67)=5.11, \mathrm{p}=.0271$
b. $\quad \mathrm{F}(1,70)=12.80, \mathrm{p}=.0006$
c. $\quad \mathrm{F}(1,67)=5.57, \mathrm{p}=.0211$

* Numbers in parentheses are respective standard deviations associated with each mean value. 


\subsubsection{Effects of Driving Scenario on Steering, Accelerator, and Brake Measures}

Driving Scenario had a statistically significant effect on only two measures: accelerator pedal velocity variance and number of brake applications (see Table 4.4.1). Each of these measures plausibly varies according to what one would expect. That is, when car following, there is more accelerator pedal activity and a greater incidence of brake applications. These effects appear small, however, and may have a negligible effect on workload assessments.

\subsubsection{Effects of Driving Scenario x Road Type Interactions on Steering, Accelerator, and Brake Measures}

Driving Scenario and Road Type interacted to yield reliable differences among the means of the dependent measures in Table 4.4.2. For the accelerator holds per second, there was no difference between driving scenarios on urban freeways but slightly more accelerator holds occurred while car following than in open road driving on rural freeways. The differences appear small, are somewhat counterintuitive, and may be little practical importance. Brake applications per second show no difference as a function of driving scenario while on rural freeways but are greater when car following on an urban freeway. The incidence of brake applications was quite small, however, and so no further interpretation of these results is provided.

\subsubsection{Effects of Driving Scenario x Light Interaction on Steering, Accelerator, and Brake Measures}

The statistically significant Driving Scenario x Light interactions are provided in Table 4.4.3. There is more steering in car following than in open road driving, as evidenced by greater steering velocity variance and fewer steering holds. However, the magnitude of the difference is greater in day than in night driving. This may be due to an effect of different traflic density effects; no explanation in terms of lighting effects is readily apparent. For accelerator releases/second, the magnitude of the difference is such that the magnitude of the difference in means is smaller in day as opposed to night driving. Again, no clear explanation for this pattern of results is apparent.

No other significant main effects or two-factor interactions were found. In total, it appears that effects of driving scenario, as observed in this study, are reliable but generally small in magnitude. The impact of factors such as lighting is such that there may have also been an effect of traffic density present that could also account for the observed differences in means. This suggests that study designs that explicitly separate traffic density and light level may be worthwhile to better understand their differential effects. 
Table 4.4.1 Significant Effects of Driving Scenario on Steering, Accelerator, and Brake Measures in Car Following

\begin{tabular}{|lcc|}
\hline \multirow{2}{*}{ Dependent Measure } & \multicolumn{2}{|c|}{ Driving Scenario } \\
\cline { 2 - 3 } & Open Roadway & Car Following \\
\hline Accelerator Velocity $^{2}$ & 291.4 & 361.5 \\
Variance $^{\mathrm{a}}$ (\%-throw) & $(454.8)^{*}$ & $(578.9)$ \\
& & \\
Number of Brake $_{\text {Applications per second }} \mathrm{b}$ & 0.001 & 0.003 \\
\hline
\end{tabular}

Notes:

Corresponding F-values, and p-values are provided below.

b. $\quad F(1,34) \quad 3 \mathrm{~F}(1,1)==4.73,12.9, \mathrm{p}=0.0374,0.0010$

* Numbers in parentheses are respective standard deviations associated with each mean value. 
Table 4.4.2 Significant Effects of Driving Scenario x Road Type Interaction on Steering, Accelerator, and Brake Measures

\begin{tabular}{|c|c|c|c|}
\hline \multirow[b]{2}{*}{ Dependent Measure } & \multirow[b]{2}{*}{ Road Type } & \multicolumn{2}{|c|}{ Driving Scenario } \\
\hline & & Open Roadway & Car Following \\
\hline \multicolumn{4}{|l|}{$\begin{array}{l}\text { Number of Accelerator Holds } \\
\text { per second' }\end{array}$} \\
\hline & Urban Freeway & $\begin{array}{l}0.25 \\
(0.12)^{*}\end{array}$ & $\begin{array}{c}0.25 \\
(0.13)\end{array}$ \\
\hline & Rural Freeway & $\begin{array}{c}0.23 \\
(0.13)\end{array}$ & $\begin{array}{l}0.29 \\
(0.13)\end{array}$ \\
\hline \multicolumn{4}{|l|}{$\begin{array}{l}\text { Number of Brake } \\
\text { Applications per second } b\end{array}$} \\
\hline & Urban Freeway & $\begin{array}{c}0.001 \\
(\mathbf{0 . 0 0 5})\end{array}$ & $\begin{array}{c}0.005 \\
(0.013)\end{array}$ \\
\hline & Rural Freeway & $\begin{array}{c}0.001 \\
(0.005)\end{array}$ & $\begin{array}{c}0.001 \\
(0.007)\end{array}$ \\
\hline
\end{tabular}

\section{Notes:}

Corresponding F-values, and p-values are provided below.
a. $\quad F(1,407)=10.88, p=.0011$
b. $\quad F(1,407)=6.56, p=.0108$

* Numbers in parentheses are respective standard deviations associated with each mean value. 
Table 4.4.3 Effects of Driving Scenario x Light Interaction on Steering, Accelerator, and Brake Measures

\begin{tabular}{|c|c|c|c|}
\hline \multirow[b]{2}{*}{ Dependent Measure } & \multirow[b]{2}{*}{ Light Level } & \multicolumn{2}{|c|}{ Driving Scenario } \\
\hline & & Open Roadway & Car Following \\
\hline \multirow[t]{2}{*}{$\begin{array}{l}\text { Steering Velocity Variance', } \\
{[\text { degrees } / /]^{2}}\end{array}$} & Day & $\begin{array}{c}160.4 \\
(168.1)^{*}\end{array}$ & $\begin{array}{l}211.3 \\
(195.0)\end{array}$ \\
\hline & Night & $\begin{array}{c}165.7 \\
(166.1)\end{array}$ & $\begin{array}{c}181.3 \\
(195.2)\end{array}$ \\
\hline \multirow[t]{2}{*}{$\begin{array}{l}\text { Number of Steering Holds per } \\
\text { second } b\end{array}$} & Day & $\begin{array}{c}0.21 \\
(0.15)\end{array}$ & $\begin{array}{c}0.16 \\
(0.13)\end{array}$ \\
\hline & Night & $\begin{array}{c}0.21 \\
(0.14)\end{array}$ & $\begin{array}{c}0.19 \\
(0.14)\end{array}$ \\
\hline \multirow[t]{2}{*}{$\begin{array}{l}\text { Number of Accelerator Releases } \\
\text { per second" }\end{array}$} & Day & $\begin{array}{c}0.039 \\
(0.096)\end{array}$ & $\begin{array}{c}0.050 \\
(0.112)\end{array}$ \\
\hline & Night & $\begin{array}{c}0.022 \\
(0.075)\end{array}$ & $\begin{array}{c}0.074 \\
(0.133)\end{array}$ \\
\hline
\end{tabular}

Notes:

Corresponding F-values, and p-values are provided below.
a. $\quad \mathrm{F}(1,541)=4.22, \mathrm{p}=.0403$
b. $\quad \mathrm{F}(1,517)=4.40, \mathrm{p}=.0363$
c.. $\quad \mathrm{F}(1,32)=4.93, \mathrm{p}=0.335$

* Numbers in parentheses are respective standard deviations associated with each mean value. 


\subsection{Results: Steering, Accelerator, and Brake Measures During Requested Task Execution}

Analyses were carried out on steering, accelerator, and brake measures during requested task execution. The statistical model included Road Type (urban freeway, rural freeway), Light (day, night), Requested Task (the 7 requested tasks previously introduced), and their various 2factor interactions. For both the open road driving scenario and car following scenario, random effects included in the models were Subject, Subject x Road Type, and Subject x Road Type x Light. For the combined data, Subject was the only random effect for the steering measures, while for the accelerator and brake measures the random effects included Subject, Subject $\mathrm{x}$ Light, and Subject $x$ Road Type $x$ Light. For analysis of requested tasks, random effects included in the model were Subject, Subject x Task, and Subject x Roadtype for the steering measures, as well as the additional random effects of Subject x Light x Task and Subject x Road Type x Light for accelerator and brake measures. Statistically significant results are reported below.

\subsubsection{Effects of Road Type on Steering, Accelerator, and Brake Measures During Requested Task Execution}

The general pattern of steering, accelerator, and brake activity as a function of road type found in open road driving remains during requested task execution (see Table 4.5.1). The 2-lane rural road is associated with the most steering activity, followed by the urban freeway and then the rural fieeway road types. Similar findings apply to accelerator position variance and the number of brake applications.

\subsubsection{Effects of Light on Steering, Accelerator, and Brake Measures During Requested Task Execution}

The effects of ambient Light level on steering measures are listed in Table 4.5.2. Night driving is associated with slightly more steering activity during requested task execution (as evidenced by steering position and velocity variance means). Also, the number of steering holds, on average, is quite small and even lower for night driving conditions. Accelerator velocity variance is greater during night driving but the number of steering holds per second is slightly larger during night driving. Why driver control activities should increase with night driving relative to day driving during requested task execution is unknown.

\subsubsection{Effects of Requested Task on Steering, Accelerator, and Brake Measures During In-cab Task Execution}

Table 4.5.3 presents the statistically significant effects of different requested tasks. The effects of Request Task are somewhat consistent across the various measures. The requested 
Table 4.5.1 Significant Effects of Road Type on Steering, Accelerator, and Brake Measures During Requested Task Execution

\begin{tabular}{|c|c|c|c|}
\hline \multirow[b]{2}{*}{ Dependent Measure } & \multicolumn{3}{|c|}{ Road Type } \\
\hline & $\begin{array}{l}\text { Urban } \\
\text { Freeway }\end{array}$ & Rural Freeway & 2-Lane Rural Road \\
\hline Steering Position Variance & $\begin{array}{l}14.20 \\
(22.90) "\end{array}$ & $\begin{array}{c}22.94 \\
(384.26)\end{array}$ & $\begin{array}{c}24.67 \\
(45.92)\end{array}$ \\
\hline Steering Velocity Variance & $\begin{array}{c}194.06 \\
(297.38)\end{array}$ & $\begin{array}{c}155.05 \\
(1083.74)\end{array}$ & $\begin{array}{l}260.76 \\
(358.60)\end{array}$ \\
\hline $\begin{array}{l}\text { Number of Steering } \\
\text { Holds }^{\mathrm{c}} \text {, count }\end{array}$ & $\begin{array}{c}0.75 \\
(1.36)\end{array}$ & $\begin{array}{c}0.96 \\
(1.53)\end{array}$ & $\begin{array}{c}0.53 \\
(1.13)\end{array}$ \\
\hline $\begin{array}{l}\text { Number of Steering } \\
\text { Reversals }{ }^{\mathrm{d}} \text {, count }\end{array}$ & $\begin{array}{l}2.88 \\
(4.57)\end{array}$ & $\begin{array}{c}2.50 \\
(4.41)\end{array}$ & $\begin{array}{c}3.40 \\
(5.72)\end{array}$ \\
\hline $\begin{array}{l}\text { Accelerator Position } \\
\text { Variance }^{\mathrm{e}}\end{array}$ & $\begin{array}{c}33.70 \\
(176.45)\end{array}$ & $\begin{array}{c}28.81 \\
(105.26)\end{array}$ & $\begin{array}{c}49.44 \\
(150.21)\end{array}$ \\
\hline $\begin{array}{l}\text { Number of Brake } \\
\text { Applications }{ }^{f} \text {, count }\end{array}$ & $\begin{array}{c}0.002 \\
(0.051)\end{array}$ & $\begin{array}{c}0.007 \\
(0.149)\end{array}$ & $\begin{array}{c}0.031 \\
(0.224)\end{array}$ \\
\hline $\begin{array}{l}\text { Number of Steering } \\
\text { Holds/second } \mathrm{g}\end{array}$ & $\begin{array}{c}0.21 \\
(0.33)\end{array}$ & $\begin{array}{c}0.27 \\
(0.34)\end{array}$ & $\begin{array}{c}0.16 \\
(0.32)\end{array}$ \\
\hline $\begin{array}{l}\text { Number of Steering } \\
\text { Reversals/second }\end{array}$ & $\begin{array}{l}0.66 \\
(0.58)\end{array}$ & $\begin{array}{c}0.55 \\
(0.51)\end{array}$ & $\begin{array}{c}0.82 \\
(0.58)\end{array}$ \\
\hline
\end{tabular}

\section{Notes:}

Corresponding F-values, and p-values are provided below.
a. $\quad \mathrm{F}(2,61)=44.50, \mathrm{p}=.0001$
b. $\quad \mathrm{F}(2,60)=46.05, \mathrm{p}=.0001$
c. $\quad \mathrm{F}(2,61)=18.91, \mathrm{p}=.0001$
d. $\quad \mathrm{F}(2,68)=9.63, \mathrm{p}=.0002$
e. $\quad F(2,60)=9.40, p=.0003$
f. $\quad \mathrm{F}(2,61)=4.77, \mathrm{p}=.0119$
g. $\quad \mathrm{F}(2,59)=9.64, \mathrm{p}=.0009$
h: $\quad F(2,63)=20.78, p=.0001$

* Numbers in parentheses are respective standard deviations associated with each mean value. 
Table 4.5.2 Significant Effects of Light on Steering, Accelerator, and Brake Measures During Requested Task Execution

\begin{tabular}{|c|c|c|}
\hline \multirow[b]{2}{*}{ Dependent Measure } & \multicolumn{2}{|c|}{ Light Level } \\
\hline & Day & Night \\
\hline Steering Position Variance, ${ }^{\mathrm{a}}$, degrees ${ }^{2}$ & $\begin{array}{c}0.83 \\
(0.21)^{*}\end{array}$ & $\begin{array}{c}0.91 \\
(0.25)\end{array}$ \\
\hline Steering Velocity Variance ${ }^{\mathrm{b}},{\text { (degrees/second })^{2}}^{2}$ & $\begin{array}{c}2.35 \\
(1.67)\end{array}$ & $\begin{array}{c}4.00 \\
(7.27)\end{array}$ \\
\hline Number of Steering Holds ${ }^{\mathrm{c}}$, count & $\begin{array}{c}0.090 \\
(0.066)\end{array}$ & $\begin{array}{c}0.067 \\
(0.065)\end{array}$ \\
\hline Accelerator Velocity Variance $^{\mathrm{d}},(\% \text {-throw/second })^{2}$ & $\begin{array}{c}171.87 \\
(523.33)\end{array}$ & $\begin{array}{c}255.19 \\
(729.18)\end{array}$ \\
\hline Number of Steering Holds/second" & $\begin{array}{r}0.189 \\
(0.312)\end{array}$ & $\begin{array}{r}0.265 \\
(0.359)\end{array}$ \\
\hline
\end{tabular}

Notes:

Corresponding F-values, and p-values are provided below.
a. $\quad \mathrm{F}(1,1267)=13.57, \mathrm{p}=.0001$
b. $\quad \mathrm{F}(1,1271)=42.44, \mathrm{p}=.0001$
c. $\quad \mathrm{F}(1,1214)=9.40, \mathrm{p}=.0022$
d. $\quad \mathrm{F}(1, \quad 51)=5.63, \mathrm{p}=.0214$
e. $\quad \mathrm{F}(1,1214)=18.80, \mathrm{p}=.0001$

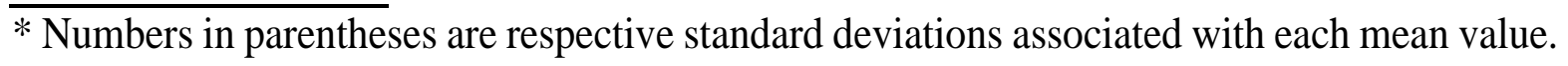


Table 4.5.3 Significant Effects of Requested Task on Steering, Accelerator, and Brake Measures During Requested Task Execution

\begin{tabular}{|c|c|c|c|c|c|c|c|}
\hline \multirow[b]{2}{*}{ Dependent Measure } & \multicolumn{7}{|c|}{ Requested Task } \\
\hline & $\begin{array}{l}\text { Adjust } \\
\text { Radio } \\
\text { Volume }\end{array}$ & $\begin{array}{l}\text { Right } \\
\text { M i i r } \\
\text { Detect }\end{array}$ & $\begin{array}{l}\text { Requested Task } \\
\text { Read Air } \\
\text { Pressure }\end{array}$ & $\begin{array}{l}\text { Tune } \\
\text { Radio }\end{array}$ & Tune CB & $\begin{array}{l}\text { Read } \\
\text { Clock }\end{array}$ & $\begin{array}{c}\text { Left } \\
\text { Mirror } \\
\text { Detect }\end{array}$ \\
\hline $\begin{array}{l}\text { Steering Position } \\
\text { Variance, }{ }^{\mathrm{a}}\end{array}$ & $\begin{array}{l}12.4 \\
(26.3)^{*}\end{array}$ & $\begin{array}{r}6.76 \\
(13.10)\end{array}$ & $\begin{array}{l}11.7 \\
(29.4)\end{array}$ & $\begin{array}{c}28.8 \\
(41.6)\end{array}$ & $\begin{array}{r}73.6 \\
(722.4)\end{array}$ & $\begin{array}{c}8.3 \\
(16.4)\end{array}$ & $\begin{array}{c}6.3 \\
(13.8)\end{array}$ \\
\hline $\begin{array}{l}\text { Steering Velocity } \\
\text { Variance }^{\mathrm{b}} \text {, }\end{array}$ & $\begin{array}{l}132.8 \\
(268.14)\end{array}$ & $\begin{array}{c}116.6 \\
(184.2)\end{array}$ & $\begin{array}{c}191.8 \\
(295.4)\end{array}$ & $\begin{array}{l}236.4 \\
(289.7)\end{array}$ & $\begin{array}{c}374.4 \\
(2026.9)\end{array}$ & $\begin{array}{l}164.0 \\
(295.9)\end{array}$ & $\begin{array}{l}112.8 \\
(179.4)\end{array}$ \\
\hline $\begin{array}{l}\text { Number of Steering } \\
\text { Holds c, count }\end{array}$ & $\begin{array}{c}0.498 \\
(0.760)\end{array}$ & $\begin{array}{c}0.398 \\
(0.627)\end{array}$ & $\begin{array}{c}0.408 \\
(0.636)\end{array}$ & $\begin{array}{l}2.40 \\
(2.32)\end{array}$ & $\begin{array}{c}1.31 \\
(1.72)\end{array}$ & $\begin{array}{c}0.37 \\
(0.58)\end{array}$ & $\begin{array}{c}0.28 \\
(0.50)\end{array}$ \\
\hline $\begin{array}{l}\text { Number of Steering } \\
\text { Reversals }{ }^{\mathrm{d}} \text {, count }\end{array}$ & $\begin{array}{l}1.28 \\
(1.956)\end{array}$ & $\begin{array}{c}1.03 \\
(1.14)\end{array}$ & $\begin{array}{c}1.43 \\
(1.62)\end{array}$ & $\begin{array}{c}9.82 \\
(8.52)\end{array}$ & $\begin{array}{l}4.55 \\
(4.11)\end{array}$ & $\begin{array}{c}0.89 \\
(0.88)\end{array}$ & $\begin{array}{c}0.96 \\
(1.17)\end{array}$ \\
\hline Accelerator ${ }^{\mathrm{e}}$ Position Var. & $\begin{array}{c}19.8 \\
(75.0)\end{array}$ & $\begin{array}{l}21.4 \\
(69.0)\end{array}$ & $\begin{array}{r}34.3 \\
(114.4)\end{array}$ & $\begin{array}{c}85.5 \\
(247.4)\end{array}$ & $\begin{array}{c}36.4 \\
(117.2)\end{array}$ & $\begin{array}{l}30.63 \\
(164.4)\end{array}$ & $\begin{array}{l}17.1 \\
(60.0)\end{array}$ \\
\hline Accelerator ${ }^{f}$ Velocity Var. & $\begin{array}{c}170.5 \\
(576.5)\end{array}$ & $\begin{array}{c}241.9 \\
(854.6)\end{array}$ & $\begin{array}{l}211.7 \\
(655.6)\end{array}$ & $\begin{array}{l}273.9 \\
(609.5)\end{array}$ & $\begin{array}{c}199.6 \\
(553.4)\end{array}$ & $\begin{array}{l}203.8 \\
(661.5)\end{array}$ & $\begin{array}{l}195.0 \\
(469.0)\end{array}$ \\
\hline $\begin{array}{l}\text { Number of Accelerator } \\
\text { Holds } \mathrm{g} \text {, count }\end{array}$ & $\begin{array}{c}0.88 \\
(0.77)\end{array}$ & $\begin{aligned} 1.61 \\
(11.83)\end{aligned}$ & $\begin{array}{c}0.83 \\
(0.73)\end{array}$ & $\begin{array}{l}12.79 \\
(2.67)\end{array}$ & $\begin{array}{l}1.61 \\
(1.38)\end{array}$ & $\begin{array}{c}0.73 \\
(0.53)\end{array}$ & $\begin{array}{c}0.76 \\
(0.59)\end{array}$ \\
\hline Steering Holds/second ${ }^{h}$ & $\begin{array}{c}0.301 \\
(0.445)\end{array}$ & $\begin{array}{c}0.225 \\
(0.364)\end{array}$ & $\begin{array}{c}0.203 \\
(0.332)\end{array}$ & $\begin{array}{c}0.211 \\
(0.200)\end{array}$ & $\begin{array}{c}0.226 \\
(0.248)\end{array}$ & $\begin{array}{c}0.235 \\
(0.359)\end{array}$ & $\begin{array}{c}0.193 \\
(0.356)\end{array}$ \\
\hline $\begin{array}{l}\text { Number Steering } \\
\text { Reversals/second }\end{array}$ & $\begin{array}{c}0.493 \\
(0.575)\end{array}$ & $\begin{array}{c}0.623 \\
(0.633)\end{array}$ & $\begin{array}{c}0.682 \\
(0.577)\end{array}$ & $\begin{array}{c}0.753 \\
(0.334)\end{array}$ & $\begin{array}{c}0.709 \\
(0.394)\end{array}$ & $\begin{array}{c}0.630 \\
(0.629)\end{array}$ & $\begin{array}{c}0.633 \\
(0.625)\end{array}$ \\
\hline $\begin{array}{l}\text { Number Accelelrator } \\
\text { Holds/second }\end{array}$ & $\begin{array}{c}0.521 \\
(0.480)\end{array}$ & $\begin{array}{c}0.529 \\
(0.436)\end{array}$ & $\begin{array}{c}0.437 \\
(0.372)\end{array}$ & $\begin{array}{c}0.239 \\
(0.188)\end{array}$ & $\begin{array}{c}0.283 \\
(0.001)\end{array}$ & $\begin{array}{c}0.563 \\
(0.433)\end{array}$ & $\begin{array}{c}0.588 \\
(0.494)\end{array}$ \\
\hline $\begin{array}{l}\text { Number Brake } \\
\text { Applications/second }\end{array}$ & $\begin{array}{c}0.003 \\
(0.037)\end{array}$ & $\begin{array}{c}0.000 \\
(0.000)\end{array}$ & $\begin{array}{c}0.009 \\
(0.089)\end{array}$ & $\begin{array}{l}0.002 \\
(0.020)\end{array}$ & $\begin{array}{l}0.001 \\
(0.016)\end{array}$ & $\begin{array}{c}0.000 \\
(0.000)\end{array}$ & $\begin{array}{c}0.000 \\
(0.000)\end{array}$ \\
\hline
\end{tabular}

Notes: Corresponding F-values, and pvalues arc provided below.
a. $\quad \mathrm{F}(6,213)=65.33, \mathrm{p}=.0001$
g. $\quad \mathrm{F}(6,211)=4.00, \mathrm{p}=-0008$
b. $\quad \mathrm{F}(6,219)=24.10, \quad \mathrm{p}=.0001$
h. $\quad \mathrm{F}(6,245)=2.82, \mathrm{p}=.0113$
c. $\quad \mathrm{F}(6,199)=37.43, \mathrm{p}=.0001$
i $\quad \mathrm{F}(6,226)=5.27, \mathrm{p}=.0001$
d. $\quad \mathrm{F}(6,196)=84.00, \mathrm{p}=.0001$
j. $\quad \mathrm{F}(2,199)=17.81, \mathrm{p}=.0001$
e. $\quad \mathrm{F}(6,208)=16.84, \mathrm{p}=.0001$
f $\quad F(6,220)=227, \quad p=.0378$
k. $\quad \mathrm{F}(2,222)=2.76, \mathrm{p}=.0131$

\footnotetext{
* Numbers in parentheses are respective standard deviations associated with each mean value.
} 
tasks of "tune radio" and "tune CB" (which were also the longest duration tasks, on average), are associated with the greatest magnitude of most of the steering measures listed. This consistency is somewhat confusing from a workload assessment perspective. For example, high requested task demand is expected to be associated with an increase in steering holds and a decrease in steering reversals, yet both sets of means are greatest for the longest-duration tasks. Normalizing to a per-second rate, the magnitude of these variables changes and becomes more homogenous across the different tasks. This normalization essentially puts tasks on a similar time base. This pattern in the data is evidence that many factors influence steering measures and their interpretation must be approached with caution.

The trends noted above do not necessarily hold for accelerator or brake measures. The "tune radio" task is still associated with the most accelerator holds and largest accelerator position and velocity variance magnitudes. However, the "tune $\mathrm{CB}$ " task is not associated with the next largest mean values for these dependent measures, like those measures associated with steering. Like steering measures, many factors besides requested task demand are likely to influence accelerator and brake measures during on-the-road studies.

\subsubsection{Effects of Road Type $x$ Requested Task Interaction on Steering, Accelerator, and Brake Measures During Requested Task Execution}

Table 4.5.4 presents the means of dependent measures that are statistically significantly diierent due to the interaction between Requested Task and Road Type. Across requested tasks, steering position variance, steering velocity variance, and steering hold measures show a general trend across road types toward greater steering activity on the 2-lane rural road, followed by the urban freeway, then the rural freeway. The locus of the interaction is contained in reversals to this trend such as that for the "tune CB" task on steering position variance.

\subsubsection{Effects of Road Type x Light Interaction on Steering, Accelerator, and Brake Measures During Requested Task Execution}

Table 4.5.5 indicates that the interaction between Road Type and Light had statistically significant impacts on dependent measures dealiig with steering variability and brake applications. Consider first the steering responses. While 2-lane rural roads were generally associated with the greatest steering position and velocity variances as well as the greatest steering reversal rates relative to urban and rural freeways, there were some deviations from this trend noted in the table. The reasons for these changes are not known but the changes appear to be small in magnitude. Finally, there is an interaction between Road Type and Light that shows greater braking activity on the 2-lane rural road under night driving conditions, but about equivalent braking activity in daylight driving conditions relative to the rural freeway. This effect is also considered of no practical significance and should be interpreted with the caution that brake applications were 
Table 4.5.4 Significant Effects of the Interaction Between Requested Task and Road Type on Steering, Accelerator, and Brake Measures During Requested Task Execution (Continued)

\begin{tabular}{|c|c|c|c|c|c|c|c|c|}
\hline \multirow[b]{2}{*}{ Dependent Measure } & \multirow[b]{2}{*}{ Road Type } & \multicolumn{7}{|c|}{ Requested Task } \\
\hline & & $\begin{array}{l}\text { Adjust Radio } \\
\text { Volume }\end{array}$ & $\begin{array}{l}\text { Right Mirror } \\
\text { Detect }\end{array}$ & $\begin{array}{l}\text { Read Air } \\
\text { Pressure }\end{array}$ & Tune Radio & Tune CB & Read Clock & $\begin{array}{l}\text { Left Mirror } \\
\text { Detect }\end{array}$ \\
\hline \multirow[t]{4}{*}{$\begin{array}{l}\text { Steering Position } \\
\text { variance a }\end{array}$} & Urban Freeway & $\begin{array}{l}11.07 \\
(24.84)\end{array}$ & $\begin{array}{c}7.66 \\
(12.49)\end{array}$ & $\begin{array}{c}9.94 \\
(11.40)\end{array}$ & $\begin{array}{c}28.76 \\
(31.73)\end{array}$ & $\begin{array}{c}25.74 \\
(27.89)\end{array}$ & $\begin{array}{c}9.69 \\
(19.79)\end{array}$ & $\begin{array}{c}7.05 \\
(13.09)\end{array}$ \\
\hline & Rural Freeway & $\begin{array}{c}9.11 \\
(19.23)\end{array}$ & $\begin{array}{c}5.38 \\
(10.00)\end{array}$ & $\begin{array}{c}6.76 \\
(12.39)\end{array}$ & $\begin{array}{c}17.86 \\
(18.85)\end{array}$ & $\begin{array}{c}110.11 \\
(1010.35)\end{array}$ & $\begin{array}{c}5.28 \\
(8.23)\end{array}$ & $\begin{array}{l}4.79 \\
(9.57)\end{array}$ \\
\hline & 2-Lane Rural & 20.66 & 8.78 & 23.53 & 51.61 & 45.34 & 13.12 & 8.52 \\
\hline & Road & $(37.21)$ & $(18.40)$ & $(53.97)$ & $(67.59)$ & $(53.68)$ & $(23.10)$ & $(19.98)$ \\
\hline \multirow{6}{*}{$\begin{array}{l}\text { Number of Steering } \\
\text { Holds b }\end{array}$} & Urban Freeway & 0.47 & 0.40 & 0.26 & 2.00 & 1.58 & 0.30 & 0.33 \\
\hline & & $(0.74)$ & $(0.63)$ & $(0.56)$ & $(1.87)$ & $(2.19)$ & $(0.50)$ & $(0.63)$ \\
\hline & Rural Freeway & 0.55 & 0.47 & 0.57 & 2.89 & 1.46 & 0.48 & 0.28 \\
\hline & & $(0.74)$ & $(0.63)$ & $(0.70)$ & $(2.53)$ & $(1.66)$ & $(0.66)$ & $(0.47)$ \\
\hline & 2-Lane Rural & 0.40 & 0.24 & 0.20 & 1.77 & 0.69 & 0.23 & 0.21 \\
\hline & Road & $(0.95)$ & $(0.60)$ & $(0.45)$ & $(2.02)$ & $(1.06)$ & $(0.42)$ & $(0.41)$ \\
\hline \multirow{6}{*}{$\begin{array}{c}\text { Number of Steering } \\
\text { Reversals c }\end{array}$} & Urban Freeway & 1.18 & 1.18 & 1.39 & 9.66 & 5.43 & 0.91 & 1.06 \\
\hline & & $(1.80)$ & (1.43) & $(1.20)$ & (7.04) & $(5.27)$ & $(0.87)$ & $(1.25)$ \\
\hline & Rural Freeway & 1.28 & 0.96 & 1.25 & 8.58 & 3.62 & 0.77 & 1.01 \\
\hline & & $(2.13)$ & (1.08) & $(1.55)$ & $(8.29)$ & $(3.02)$ & $(0.88)$ & $(1.32)$ \\
\hline & 2-Lane Rural & 1.36 & 1.00 & & 12.60 & 5.62 & 1.09 & 0.79 \\
\hline & Road & $(1.76)$ & $(0.91)$ & $(2.04)$ & $(9.74)$ & $(4.39)$ & $(0.84)$ & $(0.67)$ \\
\hline
\end{tabular}


Table 4.5.4 Significant Effects of the Interaction Between Requested Task and Road Type on Steering, Accelerator, and Brake Measures During Requested Task Execution

\begin{tabular}{|c|c|c|c|c|c|c|c|c|}
\hline \multirow[b]{2}{*}{ Dependent Measure } & \multirow[b]{2}{*}{ Road Type } & \multicolumn{7}{|c|}{ Requested Task } \\
\hline & & $\begin{array}{l}\text { Adjust Radio } \\
\text { Volume }\end{array}$ & $\begin{array}{l}\text { Right Mirror } \\
\text { Detect }\end{array}$ & $\begin{array}{l}\text { Read Air } \\
\text { Pressure }\end{array}$ & Tune Radio & Tune CB & Read Clock & $\begin{array}{l}\text { Left Mirror } \\
\text { Detect }\end{array}$ \\
\hline \multirow[t]{5}{*}{$\begin{array}{l}\text { Steering Position } \\
\text { variance a }\end{array}$} & Urban Freeway & $\begin{array}{c}16.68 \\
(37.34)\end{array}$ & $\begin{array}{c}9.32 \\
(14.11)\end{array}$ & $\begin{array}{c}16.18 \\
(42.51)\end{array}$ & $\begin{array}{c}90.95 \\
(3334.84)\end{array}$ & $\begin{array}{c}22.21 \\
(48.47)\end{array}$ & $\begin{array}{c}53.34 \\
(300.95)\end{array}$ & $\begin{array}{c}31.10 \\
(108.28)\end{array}$ \\
\hline & Rural Freeway & 14.39 & 28.68 & 27.76 & 62.39 & 34.00 & 21.26 & 12.60 \\
\hline & & $(55.37)$ & $(87.93)$ & $(94.50)$ & (189.86) & (116.04) & (77.69) & $(28.31)$ \\
\hline & 2-Lane Rural & 34.64 & 18.78 & 65.79 & 128.39 & 55.45 & 27.17 & 13.00 \\
\hline & Road & $(12.79)$ & $(55.49)$ & (178.68) & $(254.80)$ & $(159.93)$ & $(85.01)$ & $(30.74)$ \\
\hline \multirow{6}{*}{$\begin{array}{l}\text { Number of Steering } \\
\text { Holds b }\end{array}$} & Urban Freeway & 0.00 & 0.00 & 0.017 & 0.00 & 0.00 & 0.00 & 0.00 \\
\hline & & $(0.00)$ & $(0.00)$ & $(0.132)$ & $(0.00)$ & $(0.00)$ & $(0.00)$ & $(0.00)$ \\
\hline & Rural Freeway & 0.008 & 0.035 & 0.00 & 0.00 & 0.008 & 0.00 & 0.00 \\
\hline & & $(0.091)$ & $(0.373)$ & $(0.00)$ & $(0.00)$ & $(0.092)$ & $(0.00)$ & $(0.00)$ \\
\hline & 2-Lane Rural & 0.017 & 0.00 & 0.034 & 0.125 & 0.036 & 0.00 & 0.00 \\
\hline & Road & $(0.132)$ & $(0.00)$ & $(0.184)$ & $(0.469)$ & $(0.267)$ & $(0.00)$ & $(0.00)$ \\
\hline \multirow{6}{*}{$\begin{array}{c}\text { Number of Steering } \\
\text { Reversals c }\end{array}$} & Urban Freeway & 0.00 & 0.00 & 0.008 & 0.00 & 0.00 & 0.00 & 0.00 \\
\hline & & $(0.00)$ & $(0.00)$ & $(0.001)$ & $(0.00)$ & $(0.00)$ & $(0.00)$ & $(0.00)$ \\
\hline & Rural Freeway & 0.003 & 0.00 & 0.00 & 0.00 & 0.002 & 0.00 & 0.00 \\
\hline & & $(0.037)$ & $(0.00)$ & $(0.00)$ & $(0.00)$ & $(0.021)$ & $(0.00)$ & $(0.00)$ \\
\hline & 2-Lane Rural & 0.007 & 0.00 & 0.003 & 0.009 & 0.001 & 0.00 & 0.00 \\
\hline & Road & $(0.052)$ & 0.00 & $(0.168)$ & $(0.039)$ & $(0.010)$ & $(0.00)$ & $(0.00)$ \\
\hline
\end{tabular}

Notes: Corresponding F-values, and p-values are provided below.
a. $\mathrm{F}(12,1267)=3.90, \mathrm{p}=0.001$
c. $\mathrm{F} 9(12,1235)=4.05, \mathrm{p}=0.001$
e. $F(12,1032)=1.98, p=0.0224$
b. $\mathrm{f}(12,1214)=3.32, \mathrm{p}=0.001$
d. $\mathrm{F}(12,1029)=1.82, \quad \mathrm{p}=0.0413$

* Numbers in parentheses ace respective standard deviations associated with each mean value 
Table 4.5.5 Significant Effects of the Interaction Between Road Type and Light on Steering, Accelerator, and Brake Measures During Requested Task Execution

\begin{tabular}{|c|c|c|c|c|}
\hline \multirow{2}{*}{$\begin{array}{c}\text { Dependent } \\
\text { Measure }\end{array}$} & \multirow{2}{*}{$\begin{array}{l}\text { Light } \\
\text { Level }\end{array}$} & \multicolumn{3}{|c|}{ Road Type } \\
\hline & & Urban Freeway & Rural Freeway & 2-Lane Rural Road \\
\hline \multirow[t]{2}{*}{$\begin{array}{l}\text { Steering Position } \\
\text { Variance }\end{array}$} & Day & $\begin{array}{l}18.15 \\
(28.15)^{*}\end{array}$ & $\begin{array}{c}36.97 \\
(542.84)\end{array}$ & $\begin{array}{l}25.04 \\
(36.16)\end{array}$ \\
\hline & Night & $\begin{array}{c}10.63 \\
(16.09)\end{array}$ & $\begin{array}{c}8.87 \\
(15.67)\end{array}$ & $\begin{array}{c}24.31 \\
(53.67)\end{array}$ \\
\hline \multirow[t]{2}{*}{$\begin{array}{l}\text { Steering Velocity } \\
\text { Variance }^{\mathrm{b}}\end{array}$} & Day & $\begin{array}{l}253.70 \\
(370.86)\end{array}$ & $\begin{array}{c}201.92 \\
(1520.29)\end{array}$ & $\begin{array}{c}317.64 \\
(426.19)\end{array}$ \\
\hline & Night & $\begin{array}{c}140.36 \\
(196.40)\end{array}$ & $\begin{array}{c}108.06 \\
(182.67)\end{array}$ & $\begin{array}{l}206.78 \\
(269.96)\end{array}$ \\
\hline \multirow[t]{2}{*}{$\begin{array}{l}\text { Number of Brake } \\
\text { Applications }{ }^{c}\end{array}$} & Day & $\begin{array}{c}0.005 \\
(0.073)\end{array}$ & $\begin{array}{c}0.012 \\
(0.202)\end{array}$ & $\begin{array}{c}0.010 \\
(0.101)\end{array}$ \\
\hline & Night & $\begin{array}{c}0.00 \\
(0.00)\end{array}$ & $\begin{array}{c}0.002 \\
(0.050)\end{array}$ & $\begin{array}{c}0.051 \\
(0.299)\end{array}$ \\
\hline \multirow{2}{*}{$\begin{array}{l}\text { Number of } \\
\text { Steering } \\
\text { Reversals/second }\end{array}$} & Day & $\begin{array}{c}0.745 \\
(0.562)\end{array}$ & $\begin{array}{c}0.541 \\
(0.500)\end{array}$ & $\begin{array}{c}0.829 \\
(0.564)\end{array}$ \\
\hline & Night & $\begin{array}{c}0.589 \\
(0.580)\end{array}$ & $\begin{array}{c}0.564 \\
(0.520)\end{array}$ & $\begin{array}{c}0.805 \\
(0.594)\end{array}$ \\
\hline
\end{tabular}

Notes:

Corresponding F-values, and p-values are provided below.
a. $\mathrm{F}(2,1267)=4.33, \mathrm{p}=.0133$
b. $\mathrm{F}(2,1271)=8.85, \mathrm{p}=.0002$
c. $\mathrm{F}(2,58)=3.18, \mathrm{p}=.0490$
d. $\mathrm{F}(2,1214)=3.25, \mathrm{p}=.0035$

* Numbers in parentheses are respective standard deviations associated with each mean value. 
generally infrequent, as indicated by the mean values in the table. No other statistically significant effects were found.

\section{0iscussion}

This section reported on the results of steering, accelerator, and brake inputs by the driver under various driving scenarios, driving conditions (road type and lighting), and requested task execution. By and large, the effects noted were consistent with intuition and prior research. Steering position variance and steering velocity variance appear to be largely redundant. Steering holds were least and steering reversals were greatest on the 2-lane rural road. Given the relatively greater path control demands of such roads relative to freeways, this is as expected. No effects of ambient lighting were found for steering measures. Accelerator and brake inputs also tended to show greatest activity on the 2-lane rural road. There was also more accelerator activity during night driving as opposed to day driving. Car following data followed these trends as well and the differences between open road driving and car following scenarios were generally small. Brake applications were infrequent but their occurrence was in the correct direction, e.g., greater applications on the 2-lane rural road.

The requested tasks also had effects on steering, accelerator, and brake measures. Longer-duration tasks like radio tuning or $\mathrm{CB}$ tuning were associated with larger values for such measures. An attempt to use occurrence rates, e.g., steering holds per second, generally led to inconsistencies in results. For example, noticeable differences in steering reversals were eliminated when the number of reversals was divided by the requested task duration for a given observation. This is thought to be due to the fact that number of occurrences and the duration of a given occurrence interact in complex ways over the short-durations observed with requested tasks. This suggests that such rate measures should not be used in workload assessment unless they can be collected over a relatively longer sample interval of time.

Steering, accelerator, and brake dependent measures (e.g., steering and accelerator holds, accelerator or releases, brake applications, etc.) are influenced by a number of factors besides attentional demand. For example, accelerator variance may be high because the driver was shifting gears just prior to execution of a requested task. Steering inputs are affected largely by horizontal roadway geometry that demands a steering response from the driver, e.g., curve negotiation. Braking and accelerator inputs are affected by road grade and surface effects, wind gusts, and road curvature, among other factors. There are also some interpretive difficulties associated with operational definitions of certain measures. For example, an accelerator pedal release is also an accelerator pedal hold but not vice versa. That is, an accelerator release can be considered to occur when the accelerator is "held" in the 0\%of-throw position for 0.40 seconds or longer. Finally, the effects of steering and pedal inputs are modulated by vehicle dynamics and driving conditions and this precludes a simple relationship between, say, a steering input and some performance measure like lane position, 
even though a (complex) relationship exists. This makes clean interpretation of in-cab driver control inputs difficult.

In summary, steering, accelerator, and brake measures showed some sensitivity to road type, lighting, driving scenario, and requested task effects. These effects were generally small and many were of no apparent practical significance. Given prior research that suggests a workload interpretation might be applied to steering holds, steering reversals, these measures might be included in future workload assessments. Accelerator holds and releases may also be of some value as indicators of driver attention to the driving task. However, given the many sources of variation to which such measures may be subjected, these measures must be considered of lower priority than visual allocation measures. Driver-vehicle performance measures are considered in subsequent sections. 


\subsection{RESULTS: SPEED AND HEADWAY DATA}

This section provides a description of the dependent measures associated with longitudinal control, the analysis approach used, and the results obtained. Longitudinal control was captured by means of speed measures and car following measures such as time headway, following distances, and closing velocities.

\subsection{Longitudinal Control Dependent Measures}

The following dependent measures were collected and analyzed:

- $\quad$ Mean Speed (MEANSPEED): The arithmetic average travel speed for a particular sample interval of time, $\mathrm{m} / \mathrm{s}$

- $\quad$ Speed Variance (SPEEDVAR): The sample variance of travel speed computed for a particular sample interval of time, $[\mathrm{m} / \mathrm{s}]^{2}$

- Mean Following Distance in car following (FOLDISTM), the arithmetic average distance between the lead vehicle and the truck or heavy vehicle, $m$

- $\quad$ Following Distance Variance in car following (FOLDISTV), i.e., the sample variance of following distance computed for a particular sample interval of time, $\mathrm{m}^{2}$

- Mean Closing Velocity in car following (CLOSVMN), the arithmetic average relative velocity of the heavy vehicle relative to the lead vehicle, $\mathrm{m} / \mathrm{s}$

- $\quad$ Closing Velocity Variance in car following (VARCLOSV), defined as the sample variance of closing velocity computed for a given sample interval of time, $[\mathrm{m} / \mathrm{s}]^{2}$

- $\quad$ Mean Time Headway (MHEADWAY). Time headway is defined as the instantaneous following distance divided by the instantaneous travel speed per sample. The average of time headway over a sample interval of time is mean time headway, in seconds.

- $\quad$ Time Headway Variance (VHEADWAY), defined as the sample variance of time headway values computed for a given sample interval of time, seconds*.

Recall that car following behavior was observed on urban and rural freeways but was not observed on the 2-lane rural road and that drivers did not complete requested tasks under car following situations due to Human Subjects Committee restrictions. Thus, analyses of car following measures were carried out on car following scenarios only.

\subsection{Results for Speed Measures During Open Road Driving}

ANOVA analyses were carried out on the open road driving data to assess the fixed effects of Road Type, Light and their interaction on mean speed and speed variance. A Subject random factor was included in the repeated measures model. Statistically significant 
results are reported below. Recall that open road driving was defined as driving in the absence of car following. Thus, headway or car following measures were not collected in open road driving.

There was a significant effect of Road Type on both, mean speed and speed variance, as indicated in Table 5.2.1. For both urban and rural freeways, the travel speed averaged approximately $24 \mathrm{~m} / \mathrm{s}$ or about 54-55 $\mathrm{mph}$. For the 2-lane rural highway, travel speed averaged $20 \mathrm{~m} / \mathrm{s}$ or about $45 \mathrm{mph}$. This difference reflects the greater path control demands of the 2-lane rural road as well as differences in posted speed limits. These results indicate that, for this study, participant drivers drove at or below the posted speed limit on average. It further indicates that Road Type can significantly influence mean speeds observed during workload assessments.

There was also a significant Road Type effect on speed variance. The values for urban and rural freeway road types were comparable. The variance values were 0.36 and 0.39 $[\mathrm{m} / \mathrm{s}]^{2}$; these correspond roughly to a speed standard deviation of about $1.35 \mathrm{mph}$. This difference in travel speed variability does not appear to be of practical importance. The travel speed variance averaged $3.91[\mathrm{~m} / \mathrm{s}]^{2}$ for the 2-lane rural highway. This corresponds to a speed standard deviation of approximately $2.0 \mathrm{~m} / \mathrm{s}$ or $4.43 \mathrm{mph}$. This increased variation is likely due to the greater variation in horizontal roadway geometry on the 2-lane rural road.

There were no significant effects of Light or significant interactions between Road Type and Light Factors on travel speed or travel speed variance. Liebowitz and Owens (1986) noted from other data that travel speeds do not significantly change from day to night driving, despite that fact that people suffer from impaired foveal vision. Thus, these data suggest that the 2-lane rural road condition may provide a somewhat lower mean travel speed and substantially greater variation in travel speed. On the other hand, the urban and rural freeways are largely equivalent in their effects on mean travel speed and variation in travel speed. This suggests that the effects of workload assessments conducted on 2-lane rural roads may yield different results than those conducted on urban or rural freeways due to road type differences.

\subsection{Results for Speed and Headway Measures in Car Following}

ANOVA analyses were carried out on the car following driving scenario data to assess the fixed effects of Road Type (urban freeway, rural freeway), Light (day, night) and their interaction on the speed and headway control measures. A Subject random factor was included in the repeated measures model. Statistically significant results are reported below.

The analysis of longitudinal control measures during the car following scenario yielded no significant effects of Road Type, Light, or the Road Type x Light interaction for either mean speed or speed variance. The presence of a lead vehicle did not prompt drivers to 


\begin{tabular}{|c|c|c|c|}
\hline \multirow[b]{2}{*}{ Dependent Measure } & \multicolumn{3}{|c|}{ Road Type } \\
\hline & Urban Freeway & Rural Freeway & 2-Lane Highway \\
\hline Mean Speed ${ }^{\mathrm{a}}, \mathrm{m} / \mathrm{s}$ & $\begin{array}{l}24.00 \\
(1.30)^{*}\end{array}$ & $\begin{array}{l}24.36 \\
(1.60)\end{array}$ & $\begin{array}{l}20.02 \\
(2.78)\end{array}$ \\
\hline Speed Variance $^{\mathrm{b}},[\mathrm{m} / \mathrm{s}]^{2}$ & $\begin{array}{c}0.36 \\
(0.49)\end{array}$ & $\begin{array}{c}0.39 \\
(1.46)\end{array}$ & $\begin{array}{c}3.91 \\
(4.25)\end{array}$ \\
\hline $\begin{array}{l}\text { Speed Standard } \\
\text { Deviation }^{\mathrm{c}}, \mathrm{m} / \mathrm{s}\end{array}$ & $\begin{array}{l}0.00 \\
(0.70)\end{array}$ & $\begin{array}{l}0.62 \\
(1.21)\end{array}$ & $\begin{array}{l}1.97 \\
(2.06)\end{array}$ \\
\hline
\end{tabular}

Notes:

Corresponding F-values, and p-values are provided below.

a. $\quad \mathrm{F}(2,63)=194.68, \mathrm{p}=.0001$

b. $\quad \mathrm{F}(2,60)=51.19, \mathrm{p}=.0001$

C. The Speed Standard Deviation is included for reader convenience. Values are square roots of the Speed Variance values presented.

* Numbers in parentheses are respective standard deviations associated with each mean value. 
adopt different travel speed control strategies regardless of driving condition factors such as road type or light level.

More insights into driver-vehicle performance during car following can be found by examination of statistically significant headway measures. Table 5.3.1 presents the significant effects of Road Type on headway measures. Mean following distance and mean time headway were reliably different as a function of Road Type. The Rural freeway was associated with slightly greater mean following distances for those periods where a lead vehicle was within the range of the headway sensor on the instrumented vehicle. The difference in means is roughly one car length (4.83 meters or about 16 feet). This may be attributable to the fact that the rural freeway had less traffic overall and so may have afforded somewhat greater following distances, on average. Similarly the average time headways were slightly greater for the rural freeway than for the urban freeway. Interestingly, both means were close to 2.0 seconds, a value for time headway generally considered safe. It appears that the urban and rural freeways yield similar headway measures and that drivers adopted what are generally considered safe car following behaviors under the study conditions used in this research.

Table 5.3.2 indicates the statistically reliable differences in headway measures as a function of Light level. The dependent measures that were affected were mean following distance, mean closing velocity, and mean time headway. In general, mean following distance is slightly greater at night than during daylight conditions. This probably reflects the driver's desire for an extra margin of safety coupled with lower traffic density under night conditions. Interestingly, mean closing velocities are negative. This provides some quantitative support for the observation that heavy vehicle drivers do not like to engage in car following behavior and tend to "fall back" when possible. The light level differences, however, are small and appear to be of no practical concern. Finally, the time headway means again average about 2.0 seconds with slightly longer time headways associated with night lighting conditions. This indicates that drivers, on average, maintained what is considered a safe time headway under car following conditions regardless of ambient Light level.

No other statistically significant effects, either main effects or interactions, were found. In total, the effects of urban versus rural freeway Road Type and Lighting under car following conditions appear to be slight. This indicates that these factors will likely have negligible impacts on driver workload assessments.

\subsection{Results of Comparison of Open Road Driving and Car Following Driving Scenario Effects on Speed Measures}

Recall that the distinction between the open road driving scenario and the car following scenarios was that the latter involved the presence of a lead vehicle within the range of the headway detection equipment on the instrument heavy vehicle. Furthermore, recall that due to 
Table 5.3.1 Headway Measures that Significantly Differed by Road Type (Urban Versus Rural Freeway) Under Car Following Conditions

\begin{tabular}{|c|cc|}
\hline \multirow{2}{*}{ Dependent Measure } & \multicolumn{2}{|c|}{ Road Type } \\
\cline { 2 - 3 } & Urban Freeway & Rural Freeway \\
\hline Mean Following Distance ${ }^{\mathrm{a}}, \mathrm{m}$ & 44.90 & 49.73 \\
& $(1.94)$ & $(2.06)$ \\
& & \\
Mean Time Headway $\mathrm{b}, \mathrm{s}$ & 1.93 & 2.06 \\
& $(0.37)$ & $(0.40)$ \\
\hline
\end{tabular}

Notes:

a. $\quad \mathrm{F}(1,205)=18.87, \mathrm{p}=.0001$

b. $\quad \mathrm{F}(1,205)=9.98, \mathrm{p}=.0018$

* Numbers in parentheses are respective standard deviations associated with each mean value. 
Table 5.3.2 Headway Measures that Significantly Differed by Light Level (Day Versus Night) Under Car Following Conditions

\begin{tabular}{|c|c|c|}
\hline \multirow[b]{2}{*}{ Dependent Measure } & \multicolumn{2}{|c|}{ Light Level } \\
\hline & Day & Night \\
\hline Mean Following Distance ${ }^{\mathrm{a}}$, m & $\begin{array}{l}46.22 \\
(9.73)^{\prime \prime}\end{array}$ & $\begin{array}{l}48.30 \\
(8.47)\end{array}$ \\
\hline Mean Closing Velocity $\mathrm{b}, \mathrm{m} / \mathrm{s}$ & $\begin{array}{l}-0.95 \\
(0.91)\end{array}$ & $\begin{array}{l}-0.71 \\
(0.75)\end{array}$ \\
\hline Mean Time Headwayc ${ }^{\mathrm{c}}$, & $\begin{array}{c}1.94 \\
(0.39)\end{array}$ & $\begin{array}{c}2.05 \\
(0.37)\end{array}$ \\
\hline
\end{tabular}

Notes:

a. $\mathrm{F}(1,205)=4.44, \mathrm{p}=.0362$

b. $\mathrm{F}(1,180=12.66, \mathrm{p}=.0005$

c. $\mathrm{F}(1,205)=8.06, \mathrm{p}=.0050$

* Numbers in parentheses are respective standard deviations associated with each mean value. 
Human Subjects Committee requirements, no requested tasks were conducted during car following. Thus, headway measures are not available for comparison of open road driving and car following.

To assess the effects of Driving Scenario on speed measures, an ANOVA was conducted for each speed measure. The model included tied effects of Driving Scenario (open road driving versus car following), Road Type (urban freeway, rural freeway), Light (day, night), and their various two-factor interactions. In addition, preliminary analysis indicated that the following random effects should be included in the model: Subject, Subject x Light x Driving Scenario, Subject x Road Type x Driving Scenario, Subject x Light, Subject x Driving Scenario, Subject x Road Type, Subject x Road Type x Light, Subject x Road Type $x$ Light $x$ Driving Scenario. Appropriate interactions between fixed effects factors and subjects were used as the error terms for the associated fixed effects F-Tests. Because the factors of Road Type and Light under each driving scenario have already been presented and discussed, only the results of Driving Scenario Effects and interactions that involve driving scenarios will be presented.

ANOVA results indicated a statistically significant effect of Driving Scenario on Mean Speed, $\mathrm{F}(1,31)=5.08 . \boldsymbol{p}=-0314$. The mean speed, on average, during open road driving was $23.64 \mathrm{~m} / \mathrm{s}$ or approximately $53 \mathrm{mph}$. During car following, the mean travel speed averaged $24.23 \mathrm{~m} / \mathrm{s}$ or approximately $54 \mathrm{mph}$. This difference, though statistically reliable, appears to be of no practical significance. Thus, the effects of car following and open road driving are likely to be similar, on average, under driving conditions like those observed in this study.

No other significant effects were found. In general, driving scenario effects on longitudinal control measures appear minimal.

\subsection{Effects on Requested Task Execution During Open Road Driving on Speed Measures}

An analysis was conducted on the mean speed and speed variance observed during incab task execution. The same seven requested tasks as were analyzed in the visual allocation section were also analyzed here. The ANOVA consisted of fixed effects of Requested Task, Road Type (urban freeway, rural freeway, 2-lane rural road), Light (day, night), and their various two-factor interactions. The Subject, and Subject x Road Type x Requested Task random effects were also included in the model. The latter term was used as the error term for the Road Type x Requested Task interaction F-Tests.

There was a statistically significant main effect of Road Type on mean speed during requested task execution, $F(2,1485)=164.81, \mathbf{p}=.0001$. The results closely resemble those presented earlier for open road driving and car following. Urban freeways were 
associated with a mean travel speed, on average, of $23.97 \mathrm{~m} / \mathrm{s}$ or about $54 \mathrm{mph}$. Rural freeways were associated with a mean travel speed that averaged $24.31 \mathrm{~m} / \mathrm{s}$ or about $55 \mathrm{mph}$, about the same as on the urban freeway. On the other hand, 2-lane rural highway driving was associated with a mean speed of $21.92 \mathrm{~m} / \mathrm{s}$ or approximately $49 \mathrm{mph}$. Thus, the 2-lane rural road was significantly different from the urban or rural freeway road types in terms of mean speed.

There was a statistically significant interaction between Requested Task and Light for speed variance, $\mathrm{F}(6,943)=3.01, \mathbf{p}<.0001$. The mean values are presented in Table 5.5.1. Note that while the general trend is for night lighting conditions to be associated with less speed variance, the reverse is true for the requested tasks of "read air pressure gauge", "tune radio", and "tune CB". The differences in mean speed variance are small, however, and do not appear to be of practical significance. Therefore, no further comment on these results will be made.

No other main effects or interactions were found to be statistically significant.

\subsection{Discussion}

A number of speed and headway measures were analyzed to determine the effects of road type, lighting, driving scenario, and requested task execution. For the drivers and conditions employed in this study, only road-type had substantive effects on travel speed. The 2-lane rural road was associated with a lower mean speed and greater speed variability than found with urban or rural freeways. This suggests that 2-lane rural road settings are likely to lead to different speed results in workload assessments as compared to freeways due to the relatively greater path control demands of 2-lane rural roads.

The absence of substantive effects of most of the independent variables on speed and headway measures must be tempered by several constraints associated with this study. First, headway measures could not be collected during requested task execution due to safety concerns. This leaves open the issue of requested or in-cab task effects on car following performance. Second, the speed and headway effects that were noted could change with different levels of traffic density. While the urban freeway was associated with greater traffic density than the rural freeway in this study, this difference may not have been as great as the difference that might arise in other driving conditions or circumstances. Third, the fact that the drivers were driving an unfamiliar heavy vehicle and had a ride-along observer present could plausibly have affected their driving performance. Evidence to support this contention comes in comments made by several drivers during the post-run debrief that the presence of the on-board experimenter probably caused them to drive more safely than if driving alone.

In summary, the following points can be made on the use of speed and headway measures based on the results reported here. Speed measures can be sensitive to road type but 
Table 5.5.1 The Interaction Between Requested Task and Light on Speed Variance in Open Road Driving

\begin{tabular}{|c|c|c|c|c|c|c|c|}
\hline & \multicolumn{7}{|c|}{ Requested Task } \\
\cline { 2 - 8 } & $\begin{array}{c}\text { Adjust } \\
\text { Radio } \\
\text { Volume }\end{array}$ & $\begin{array}{c}\text { Right } \\
\text { Mirror } \\
\text { Detect }\end{array}$ & $\begin{array}{c}\text { Read Air } \\
\text { Pressure }\end{array}$ & $\begin{array}{c}\text { Tune } \\
\text { Radio }\end{array}$ & Tune CB & $\begin{array}{c}\text { Read } \\
\text { Clock }\end{array}$ & $\begin{array}{c}\text { Left } \\
\text { Mirror } \\
\text { Detect }\end{array}$ \\
\hline Day & 0.005 & 0.298 & 0.002 & 0.073 & 0.026 & 0.001 & 0.006 \\
& $(0.015)^{*}$ & $(3.099)$ & $(0.004)$ & $(0.151)$ & $(0.067)$ & $(0.003)$ & $(0.006)$ \\
& & & & & & & \\
Night & 0.003 & 0.001 & 0.003 & 0.091 & 0.032 & 0.001 & 0.001 \\
& $(0.0061)$ & $(0.001)$ & $(0.006)$ & $(0.225)$ & $(0.134)$ & $(0.002)$ & $(0.003)$ \\
\hline
\end{tabular}

* Numbers in parentheses are respective standard deviations associated with each mean value. 
are not likely to be affected by lighting difference. Furthermore, the kinematics of heavy vehicle operation may be taken as an indication that speed measures are unlikely to change substantially over short-duration "requested" or "in-cab" tasks. On the other hand, Dingus and his associates have recently reported that mean speed and speed variance were sensitive to navigation conditions that included various route guidance display configurations when assessed over drives that averaged about 20 to 24 minutes in duration (Dingus, Hulse, Fleischman, McGehee, and Manakkal, in press).

The headway measures collected in this study, for the conditions studied, showed negligible effects. While statistically significant differences were in the direction one might expect from intuition or prior research, the small magnitudes of these differences might suggest headway measures are not worthwhile. This conclusion is not put forth here because the car following scenarios were infrequent and were not even observed during requested task execution due to procedural constraints. Given the safety-relevance of such measures, it is recommended that they be considered for inclusion in future workload assessments. 


\subsection{RESULTS: ANALYSIS OF LANEKEEPING MEASURES}

This section provides a description of the dependent measures associated with lanekeeping or lateral control, the analysis approach used, and the results obtained. Lanekeeping or lateral control performance was captured by means of lane position, lane position variance, and lane exceedence measures. Such measures are safety-relevant because uncontrolled or inappropriate lane excursions are the precursor to a great many crashes each year, including lane change crashes (Chovan, Tijerina, Alexander, and Hendricks, 1994), opposite-direction crashes (Chovan, Everson, Hendricks, and Pierowicz, 1994), and single vehicle roadway departures (Hendricks, Allen, Tijerina, Everson, Knipling, and Wilson, 1992; Mironer and Hendricks, 1994). There is evidence that various lane keeping measures have demonstrated sensitivity to workload demand, both primary driving task demand and in-vehicle distraction, as well as value as part of a set of indicators of driver fatigue or incapacitation (e.g., Wierwille, 1994). The dependent measures used in this analysis are provided next.

\subsection{Lanekeeping Dependent Measures}

The following dependent measures were collected and analyzed:

- $\quad$ Mean Lane Position (LANEPOSM), meters from lane center; The arithmetic average of lane position with respect to lane center over a sample interval of time. Lane position left of lane center is positive in sign and lane position right of lane center is negative in sign.

- $\quad$ Lane position variance

(LANEPVAR), $\mathrm{m}^{2}$;

The sample variance computed for all lane position values in a sample interval of time.

- $\quad$ Lane exceedences, count (LANEXC)

or Lane exceedences per second

(LANEXS) ;

A lane exceedence occurred whenever any portion of the heavy vehicle exceeded a lane boundary line.

\subsection{Results of Lanekeeping Measures during Open Road Driving}

For this analysis, fixed effects of Road Type (urban freeway, rural freeway, 2-lane rural road), Light (day, night), and their interaction were assessed. The Subject, Subject $x$ Light, Subject x Road Type, and Subject x Light x Road Type random effects were found to be significant by the maximum likelihood procedures referenced earlier and were included in 
the ANOVA model and used as appropriate in a repeated-measures analysis of variance. Significant results are presented below.

Table 6.2.1 presents significant differences as a function of Road Type in open road driving. As indicated, the number of lane exceedences per second was greater on the 2-lane highway than either the urban freeway or rural freeway. This may be attributed to the characteristics of the 2-lane rural road, e.g., undivided roadway and generally greater path control demands than on freeways.

Table 6.2.2 presents significant differences as a function of Light in open road driving. Lane position variance was somewhat greater during daylight conditions than during night driving. The reasons for this are unclear but may be attributable to greater care taken by drivers to maintain proper tracking of the heavy vehicle under night driving conditions.

No other main effects or two-factor interactions were statistically significant in the open road driving scenario analysis.

\subsection{Results of Lanekeeping Measures during Car Following}

Table 6.3.1 presents significant effects of Road Type during car following. Mean lane position was slightly closer to lane center for the urban freeway road type than for the rural freeway road type. In addition, the number of lane exceedences per second was slightly greater in the rural freeway setting than in the urban freeway setting. Together, these results suggest that the urban freeway road type was associated with greater lanekeeping precision than the rural freeway setting.

Table 6.3.2 presents significant effects of Light during car following. As indicated by mean lane position and lane position variance average values, night driving was associated with driving closer to lane center and with slightly less lane position variation. Table 6.3.3 presents significant effects of Road Type x Light interaction during car following. Only lane position variance was significantly different as a function of this interaction. Greater lanekeeping variability was found, on average, with rural freeway settings than with urban freeway settings during daylight driving. However, no road type differences were noted during night driving, though the variability was less when compared to daylight driving. Taken together, this set of results suggests that night driving prompted more careful lanekeeping on the part of drivers in this study.

No other main effects or two-factor interactions were statistically significant. 
Table 6.2.1 Significant Effects of Road Type on Lanekeeping Measures in Open Road Driving

\begin{tabular}{|c|c|c|c|}
\hline \multirow[b]{2}{*}{ Dependent Measure } & \multicolumn{3}{|c|}{ Road Type } \\
\hline & Urban Freeway & Rural Freeway & \%-Lane Highway \\
\hline $\begin{array}{l}\text { LANEXS, Number of } \\
\text { Lane Exceedences/sec }\end{array}$ & $\begin{array}{c}0.009 \\
(0.015)^{*}\end{array}$ & $\begin{array}{c}0.007 \\
(0.015)\end{array}$ & $\begin{array}{l}0.04 \\
(0.029)\end{array}$ \\
\hline
\end{tabular}

Notes:

Corresponding F-values, and p-values are provided below.

a. $\mathbf{F}(\mathbf{2}, \mathbf{5 8})=\mathbf{7 2 . 2 ,} \mathbf{p}=.0001$

* Numbers in parentheses are respective standard deviations associated with each mean value. 
Table 6.2.2 Significant Effects of Light on Lanekeeping Measures in Open Road Driving

\begin{tabular}{|c|c|c|}
\hline \multirow{2}{*}{ Dependent Measure } & \multicolumn{2}{|c|}{ Light Level } \\
\cline { 2 - 3 } & Day & Night \\
\hline LANEPVAR, Lane Position Variance ${ }^{\mathrm{a}}, \mathrm{m}^{2}$ & $\begin{array}{c}0.037 \\
(0.052) *\end{array}$ & $\begin{array}{c}0.022 \\
(0.014)\end{array}$ \\
\hline
\end{tabular}

Notes:

a. $\mathrm{F}(1,26)=9.42, \mathrm{p}=.0049$

* Numbers in parentheses are respective standard deviations associated with each mean value. 
Table 6.3.1 Significant Effects of Road Type on Lanekeeping Measures During Car Following

\begin{tabular}{|c|c|c|}
\hline \multirow[b]{2}{*}{ Dependent Measure } & \multicolumn{2}{|c|}{ Road Type } \\
\hline & Urban Freeway & Rural Freeway \\
\hline $\begin{array}{l}\text { LANEPOSM, Mean Lane Position } \\
\text { from Lane Centef, } m\end{array}$ & $\begin{array}{l}0.059 \\
(0.246)^{*}\end{array}$ & $\begin{array}{c}0.128 \\
(0.192)\end{array}$ \\
\hline $\begin{array}{l}\text { LANEXS, Number Lane } \\
\text { Exceedences/sec }{ }^{b}\end{array}$ & $\begin{array}{c}0.008 \\
(0.018)\end{array}$ & $\begin{array}{c}0.010 \\
(0.020)\end{array}$ \\
\hline
\end{tabular}

Notes:

a. $\mathrm{F}(1,47.7)=27.7, \mathrm{p}=.0001$

b. $\quad \mathrm{F}(1,33)=5.0, \mathrm{p}=.0324$

* Numbers in parentheses are respective standard deviations associated with each mean value. 
Table 6.3.2 Significant Effects of Light on Lanekeeping Measures in Car Following

\begin{tabular}{|l|c|c|}
\hline \multirow{2}{*}{ Dependent Measure } & \multicolumn{2}{|c|}{ Light Level } \\
\cline { 2 - 3 } & Day & Night \\
\hline LANEPOSM, Mean Lane Position from Lane & 0.076 & 0.015 \\
Center $^{\mathrm{a}}, \mathrm{m}$ & $(0.248) ”$ & $(0.187)$ \\
& & \\
LANEPVAR, Lane Position Variance $^{\mathrm{b}}$ & 0.032 & 0.021 \\
& $(0.043)$ & $(0.017)$ \\
\hline
\end{tabular}

Notes:

a. $\mathrm{F}(1,31)=4.5, \mathrm{p}=.0416$

b. $\quad \mathrm{F}(1,38)=5.0, \mathrm{p}=.0318$

* Numbers in parentheses are respective standard deviations associated with each mean value. 
Table 6.3.3 Significant Effects of Road Type x Light Interaction on Lanekeeping Measures During Car Following

\begin{tabular}{|l|c|c|c|}
\hline & \multirow{2}{*}{ Dependent Measure } & Light Level & \multicolumn{2}{|c|}{ Road Type } \\
\cline { 3 - 4 } & \multirow{2}{*}{ Urban Freeway } & Rural Freeway \\
\hline LANEPVAR, Lane & Day & 0.028 & 0.036 \\
Position Variance, $\mathrm{m}^{2}$ & & $(0.029)^{*}$ & $(0.053)$ \\
& \multirow{2}{*}{ Night } & 0.021 & \\
& & $(0.012)$ & 0.021 \\
& & & \\
\hline
\end{tabular}

Notes:

a. $\quad \mathrm{F}(1,32)=4.2, \mathrm{p}=.0482$

* Numbers in parentheses are respective standard deviations associated with each mean value. 


\subsection{Results of Comparison between Driving Scenarios (Open Road Driving, Car Following) on Lanekeeping Measures}

To more directly compare differences between Driving Scenarios (open road driving and car following), the previous two data sets were combined for comparative analysis. Because the effects of Road Type and Light have already been discussed in previous sections, this section presents only the statistically significant effects of Driving Scenario or interactions that involve Driver Scenario.

There were no significant main effects of Driving Scenario on the lanekeeping measures. However, Table 6.4.1 presents statistically significant effects of Road Type $x$ Driving Scenario interactions on lanekeeping. Mean lane position and lane exceedences per second were both significantly affected by the interaction. Consider the mean lane position results. The trend is for the driver to keep closer to lane center under urban freeway than rural freeway conditions, held for both open road driving and car following scenarios. However, in car following on the urban freeway, the drivers kept even closer to lane center, while on the rural freeway, the car following scenario was associated with the greatest mean lane position offset. For lane exceedences per second, the means were greatest in the car following scenario, with a slight increase for rural freeways. This pattern was reversed for open road driving. The reasons for this pattern are unclear. No other statistically significant effects were found.

\subsection{Results of Lanekeeping Measures during Requested Task Execution}

Table 6.5.1 presents the significant effects of Requested Task on lanekeeping measures during open road driving. As indicated, only lane position variance and lane exceedences per second were affected by requested task. Lane position variance, on average, was greatest during manual radio tuning and $\mathrm{CB}$ tuning tasks. These were also the longest tasks to complete (see Table 3.5.1). On the other hand, no consistent pattern appears when looking at the averages for lane exceedences per second. Now it appears as if the less demanding tasks were associated with more lane exceedences per second. The reason for this apparent inconsistency may arise because exceedences per second is a complex measure that both hides and accentuates effects. Tijerina et al. (1995) point out that counts (e.g., of exceedences) and duration of the events counted (e.g., exceedence duration) may trade off such that, for a fixed interval, several shorter events or only one or two longer events occur. Both are of importance, perhaps, but the rate variable of counts/unit time will appear discrepant. This trade off between counts of events and event durations may be affecting the counts per second.

Table 6.5.2 presents the significant effects of Road Type on lanekeeping measures during requested task execution. In keeping with previous results for open road driving and car following scenarios, drivers kept closest to the lane center on the urban freeway, deviated 
Table 6.4.1 Significant Effects of Road Type $x$ Driving Scenario Interactions on Lanekeeping Measures

\begin{tabular}{|l|l|c|c|}
\hline & & \multicolumn{2}{|c|}{ Road Type } \\
\cline { 3 - 4 } \multicolumn{1}{|c|}{ Dependent Measure } & Driving Scenario & Urban Freeway & Rural Freeway \\
\hline $\begin{array}{l}\text { LANEPOSM, Mean Lane } \\
\text { Position from Lane }\end{array}$ & Open road driving & 0.077 & 0.109 \\
Centera ${ }^{\mathrm{a}}$, m: & & $(0.268)^{*}$ & $(0.198)$ \\
& & & \\
& Car following & 0.059 & 0.128 \\
& & $(0.246)$ & $(0.192)$ \\
\hline LANEXS, Number of & Open road driving & 0.009 & 0.007 \\
Lane Exceedences/sec $\mathrm{b}:$ & & $(0.015)$ & $0.015)$ \\
& & 0.009 & 0.010 \\
& Car following & $(0.018)$ & $(0.020)$ \\
\hline
\end{tabular}

Notes:

Corresponding F-values, and p-values are provided below.

a. $\quad \mathrm{F}(1,487)=5.40, \mathrm{p}=.0204$

b. $\quad \mathrm{F}(1,487)=4.90, \mathrm{p}=.0267$

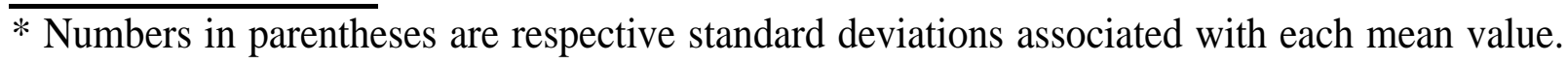


Table 6.5.1 Statistically Significant Effects of Requested Task on Lanekeeping Measures in Open Road Driving

\begin{tabular}{|c|c|c|c|c|c|c|c|}
\hline \multirow[b]{2}{*}{ Dependent Measure } & \multicolumn{7}{|c|}{ Requested Task } \\
\hline & $\begin{array}{l}\text { Adjust } \\
\text { Radio } \\
\text { Volume }\end{array}$ & $\begin{array}{l}\text { Right } \\
\text { Mirror } \\
\text { Detect }\end{array}$ & $\begin{array}{l}\text { Read Air } \\
\text { Pressure }\end{array}$ & $\begin{array}{l}\text { Tune } \\
\text { Radio }\end{array}$ & $\begin{array}{l}\text { Tune } \\
\text { CB }\end{array}$ & $\begin{array}{l}\text { Read } \\
\text { Clock }\end{array}$ & $\begin{array}{c}\text { Left } \\
\text { Mirror } \\
\text { Detect }\end{array}$ \\
\hline $\begin{array}{l}\text { LANEPVAR, Lane } \\
\text { Position Variance }^{\mathrm{a}} \text {, m2 }\end{array}$ & $\begin{array}{l}0.002 \\
(0.006) *\end{array}$ & $\begin{array}{l}0.002 \\
(0.006)^{*}\end{array}$ & $\begin{array}{l}0.002 \\
(0.004)\end{array}$ & $\begin{array}{c}0.019 \\
(0.036)\end{array}$ & $\begin{array}{c}0.012 \\
(0.033)\end{array}$ & $\begin{array}{c}0.001 \\
(0.002)\end{array}$ & $\begin{array}{c}0.001 \\
(0.003)\end{array}$ \\
\hline $\begin{array}{l}\text { Number of Lane } \\
\text { Exceedences } \mathrm{b} / \text { second }\end{array}$ & $\begin{array}{c}0.131 \\
(0.392)\end{array}$ & $\begin{array}{c}0.125 \\
(0.322)\end{array}$ & $\begin{array}{l}0.116 \\
(0.261)\end{array}$ & $\begin{array}{c}0.033 \\
(0.099)\end{array}$ & $\begin{array}{c}0.044 \\
(0.147)\end{array}$ & $\begin{array}{c}0.147 \\
(0.322)\end{array}$ & $\begin{array}{c}0.165 \\
(0.383)\end{array}$ \\
\hline
\end{tabular}

Notes:

$\begin{array}{ll}\text { a. } & F(6,355)=7.4, p=.0001 \\ \text { b } & F(6,247)=10.35, p=.0001\end{array}$

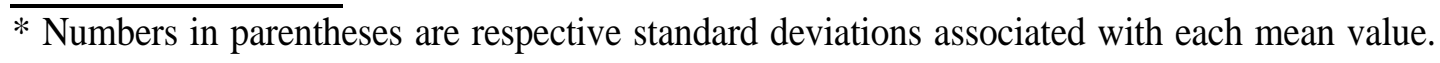


Table 6.5.2 Significant Effects of Road Type on Lanekeeping Measures During Requested Task Execution

\begin{tabular}{|l|c|c|c|}
\hline & \multicolumn{3}{|c|}{ Road Type } \\
\hline \multicolumn{1}{|c|}{ Dependent Measure } & Urban Freeway & Rural Freeway & 2-Lane Rural Road \\
\hline LANEPOSM, Mean Lane & -0.003 & 0.085 & 0.105 \\
Position from Lane Center ${ }^{\mathrm{a}}, \mathrm{m}$ & $(0.275)^{*}$ & $(0.253)$ & $(0.364)$ \\
LANEXC, Number of Lane & 0.077 & 0.083 & 0.638 \\
Exceedences ${ }^{\mathrm{b}}$, count & $(0.278)$ & $(0.356)$ & $(0.634)$ \\
LANEXS, Number of Lane $_{\text {Exceedences/second }}^{\mathrm{c}}$ & 0.028 & 0.031 & 0.353 \\
\hline
\end{tabular}

\section{Notes:}

Correspoding F-values, and p-values are provided below.

$\begin{array}{ll}\text { a. } & \mathbf{F}(2,62)=3.9, p=.0254 \\ \text { b. } & F(2,67)=17.3, p=.0001 \\ \text { c. } & F(2,59)=88.58, p=.0001\end{array}$

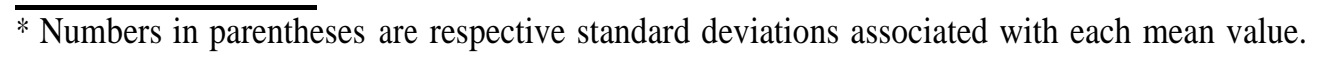


farthest from lane center on the 2-lane rural road, with rural freeway mean lane position next farthest from lane center. Lane exceedences were greatest for the 2-lane rural road, with substantially fewer lane exceedences associated with the urban and rural freeways. Lane exceedences per second followed the same pattern of magnitude as was found with the mean counts of lane exceedences. Interpretive comments about such results have previously been provided.

Table 6.5.3 presents the statistically significant effects of the interaction between Road Type and Requested Task on lanekeeping measures during open road driving. Consider first the lane exceedence count results. In general, the "tune radio" and "tune CB" requested tasks are associated with the highest number of lane exceedences, on average. However, the differences among tasks vary depending on road type. The 2-lane rural road is associated with the greatest number of lane exceedences when compared to the urban or rural freeway settings. The interaction effect comes from generally minor variations between the average exceedence counts associated with the urban and rural freeways. Mean lane exceedences per second, on the other hand, form an irregular pattern that does not readily lend itself to interpretation. The interplay between exceedence count and exceedence duration may account for the inconsistency.

No other main effects or interactions were statistically significant for lanekeeping dependent measures.

\subsection{Discussion}

Lanekeeping performance measures have been shown to be sensitive to road type, lighting, and requested task effects with heavy vehicle operators. In general, the effects of 2lane rural roads on lanekeeping measures were most pronounced relative to urban or rural freeways. This is attributable to the properties of the 2-lane rural road, e.g., they were undivided, narrower than freeways, and had more variation in terms of curves. These results generally held for both open road driving and car following scenarios.

Lighting had a smaller effect on lanekeeping performance. In general, night driving was associated with more precise lanekeeping. This might be attributed to the greater care truck drivers took to maintain proper tracking of the heavy vehicle under night driving conditions. Alternatively, it may be attributable to the effects of traffic density, there generally being greater traffic density under daylight conditions than under night driving conditions. This is speculative at this point and suggests that future research should attempt to discriminate between road type, lighting, and traffic density effects explicitly in the study design.

There were significant variations in lanekeeping that arose during requested task execution. Lane position variance, on average, was greatest for the longest duration requested 
Table 6.5.3 Statistically Significant Effects of Requested Task x Road Type Interactions on Lanekeeping Measures

\begin{tabular}{|c|c|c|c|c|c|c|c|c|}
\hline \multirow[b]{2}{*}{ Dependent Measure } & \multirow[b]{2}{*}{ Road Type } & \multicolumn{7}{|c|}{ Requested Task } \\
\hline & & $\begin{array}{c}\text { Adjust } \\
\text { Radio } \\
\text { Volume }\end{array}$ & $\begin{array}{l}\text { Right Mirror } \\
\text { Detect }\end{array}$ & $\begin{array}{l}\text { Read Air } \\
\text { Pressure }\end{array}$ & Tune Radio & Tune CB & Read Clock & $\begin{array}{l}\text { Left Mirror } \\
\text { Detect }\end{array}$ \\
\hline \multirow{6}{*}{$\begin{array}{l}\text { LANEXC, Lane } \\
\text { Exceedences, count }\end{array}$} & Urban Freeway & 0.06 & 0.04 & 0.06 & 0.23 & 0.06 & 0.02 & 0.09 \\
\hline & & $(0.235)$ & $(0.20)$ & $(0.24)$ & $(0.48)$ & $(0.24)$ & $(0.14)$ & $(0.28)$ \\
\hline & Rural Freeway & 0.06 & 0.10 & 0.08 & 0.11 & 0.11 & 0.05 & 0.05 \\
\hline & & $(0.25)$ & $(0.62)$ & $(0.28)$ & $(0.35)$ & $(0.37)$ & $(0.22)$ & $(0.23)$ \\
\hline & 2-Lane Rural & 0.48 & 0.55 & 0.60 & 0.98 & 0.70 & 0.64 & 0.50 \\
\hline & Road & $(0.54)$ & $(0.50)$ & $(0.49)$ & $(1.03)$ & $(0.58)$ & $(0.48)$ & $(0.50)$ \\
\hline \multirow{6}{*}{$\begin{array}{l}\text { LANEXS, Lane } \\
\text { Exceedences/second b }\end{array}$} & Urban Freeway & 0.045 & 0.010 & 0.022 & 0.396 & 0.012 & 0.012 & 0.058 \\
\hline & & $(0.216)$ & $(0.051)$ & $(0.091)$ & $(0.176)$ & $(0.063)$ & $(0.089)$ & $(0.192)$ \\
\hline & Rural Freeway & 0.051 & 0.022 & 0.043 & 0.009 & 0.012 & 0.035 & 0.044 \\
\hline & & $(0.238)$ & $(0.120)$ & $(0.154)$ & $(0.031)$ & $(0.039)$ & $(0.160)$ & $(0.196)$ \\
\hline & 2-Lane Rural & 0.395 & 0.488 & 0.365 & 0.075 & 0.143 & 0.510 & 0.517 \\
\hline & Road & $(0.625)$ & $(0.501)$ & $(0.377)$ & $(0.072)$ & $(0.133)$ & $(0.432)$ & $(0.562)$ \\
\hline
\end{tabular}

Notes:

a. $\mathrm{F}(12,1267)=3.90, \mathrm{p}=0.0001$

b. $\mathrm{F}(12,1084)=11.20, \mathrm{p}=0.0001$

* Numbers in parentheses ace respective standard deviations associated with each mean value 
tasks (radio tuning, CB tuning). On the other hand, lane exceedences per second yielded an inconsistent pattern. It is possible that this inconsistency arises because, over short durations, the exceedence rate measure is a complex combination of lane exceedence counts and durations. Road Type had a significant effect on mean lane position, with 2-lane rural road driving being associated with the greatest offset from lane center. The number of lane exceedences, on average, was greatest with two-lane rural road driving and lane exceedences per second followed a similar trend. This is evidence that the 2-lane rural highway road type is likely to have a substantial effect on driver workload assessments that are based on lanekeeping measures. Finally, an interaction between Road Type and Requested Task was found to be significant for number of lane exceedences and lane exceedences per second, on average. The interactions reside in generally small variations among the means of each requested task within a given road type. However, the mean number of lane exceedences was generally greatest for the 2-lane rural road setting and with the longest tasks (manually tuning the radio and tuning the $\mathrm{CB}$ ) being associated with greater lane exceedences.

From a safety perspective, lanekeeping performance is important to the avoidance of lane change, merge, opposite direction, and roadway departure crashes. For each of these crash types, the first event that leads to harm is unplanned or uncontrolled lane departure. Mean lane position was included in the analysis to determine if there is a tendency to drive left or right of lane center under a given driving circumstance. Such bias could predispose a driver toward a lane departure or exceedence. In general, the drivers appeared to drive slightly left of lane center (as indicated by the positive mean values).

Lane position variance, or its square root (lane position standard deviation), has been used in driver workload research repeatedly over the years. The safety relevance of specific lane position variances has been approached in the following manner by Zwahlen, Adams, and DeBald (1988) (See also Green, 1993). Consider that the greatest width of the heavy vehicle used in this study was 2.591 meters (102 inches). In a 3.650 meters-wide (12 foot) lane, this leaves (3.650 - 2.591 meters)/ 2 or a little over 0.5 meters (19.68 inches) on either side of a lane-centered vehicle before a lane exceedence occurs. For a 3.048 meter (10 foot) wide lane, the clearance on either side of a lane-centered vehicle is 0.228 meters (about 9 inches) on either side. Zwahlen and his associates assume that lane position is normally distributed. This allows one to use the standard normal tables to determine the probability of a lane exceedence. For example, lane position variance under daylight conditions was $0.037 \mathrm{~m}^{2}$, the square root of which corresponds to a lane position standard deviation of $0.19 \mathrm{~m}$. For the wider lanes normally associated with freeways, this corresponds to $\mathrm{z}=0.5 \mathrm{~m} / 0.19 \mathrm{~m}=2.63$. Referring to a table of standard normal deviates (e.g., Devore, 1982), a z-score of 2.63 corresponds to a probability of .0043 of exceeding a lane on one side. Twice that number, .0086, is the probability of exceeding a lane on either side. For the lo-foot wide lanes, the corresponding $\mathrm{z}$ score is $\mathrm{z}=0.228 / 0.19$ or 1.2 . This corresponds to a probability of 0.1151 of exceeding a lane on one side; twice that number, .2302 , is the probability of exceeding a lane on either side (about 23 percent). If such a lane exceedence is unplanned or uncontrolled, crash hazard exposure is marginally increased. 
Lane exceedences provide a direct safety-relevant measure of lanekeeping performance that does not depend on the assumptions just noted. For requested tasks, lane exceedence counts, on average, provide some measure of the degradation in lanekeeping performance associated with requested task execution. It was noted that longer-duration tasks are associated with a higher incidence of lane exceedences. Provided that task duration is intrinsic to the task itself and is not an experimental artifact, these differences can be interpreted directly to mean that longer-duration tasks which take the driver's eyes off the road or mind off the primary task of driving are worse from a safety perspective, to the extent that a greater incidence of lane exceedences is observed. Similarly, if, over a fixed sample interval of time, exceedence counts are tallied for various conditions, these two can be unambiguously interpreted. A more vexing interpretation problem stems with comparing exceedences for events or tasks of different durations, these durational differences being a result of experimental procedure. For example, it is not reasonable to compare the number of lane exceedences in 60 seconds of open road driving with the number of lane exceedences in 5 seconds of radio tuning. All else being equal, the former could be 12 times the latter without there being a significant difference. One approach to deal with this disparity was to compute exceedence rates in terms of lane exceedences per second. However, as was noted, the results are largely uninterpretable for short-duration requested tasks. The reason for this may lie in the fact that, over shortduration sample intervals, exceedence counts and exceedence durations may trade off. That is, longer duration exceedences may result in lower exceedence rates, even though the risk or hazard exposure remains the same. Attempts to further characterize exceedences, e.g., by exceedence duration, have indicated that mean exceedence duration is a largely insensitive measure (Green, 1993).

In summary, lanekeeping measures were significantly affected by Road Type, and Requested Task; smaller effects of Light on lanekeeping were also found. From a workload assessment perspective, 2-lane rural road settings are likely to yield significantly different lanekeeping results than urban or rural freeway settings. Requested tasks, particularly manual radio tuning or CB tuning tasks, will have the greatest effects on lanekeeping measures. Finally, more precise lanekeeping is to be expected under night driving conditions. Inclusion of lanekeeping measures for workload assessment appears warranted. 


\subsection{CORRELATION ANALYSIS}

In addition to the significance tests carried out and reported in previous sections, correlations were calculated between pairs of dependent measures under different test conditions. The purpose of the correlation analyses was to explore covariation among the response measures and determine which measures reliably covary. As such, correlations might serve as a check on the validity of the dependent measures as measures of attentional demand. Due to the large number of observations that contributed to the correlations, only relatively high correlations (i.e., correlations with an absolute value of 0.20 or greater) will be discussed. Significance levels will not be addressed specifically. However, all correlations with an absolute value of 0.20 or greater are also statistically significant at an alpha level of 0.05 or beyond. This approach closely follows that adopted by Dingus, Antin, Hulse, and Wienville (1986).

The previous sections have presented results in terms of categories of dependent measures:

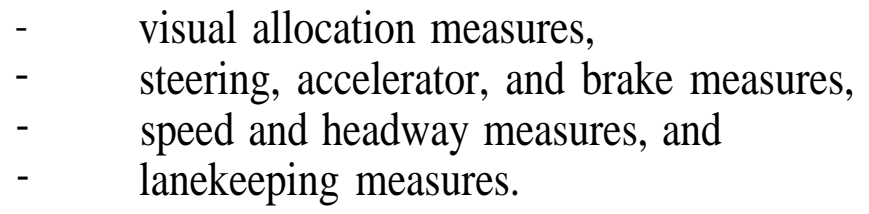

The presentation of a single correlation table for all the associated measures under these categories would be unwieldy. Therefore, the correlation table will be presented in sections. Visual allocation measures will be presented in conjunction with steering and other driver input measures, then with speed and headway measures, then with lanekeeping measures. Then, steering and other driver input measures will be correlated with speed and headway measures, and with lanekeeping measures. Finally, the speed and headway measures will be correlated with the lanekeeping measures. In this way, the entire correlational structure will be presented. A great many correlations will be presented for the sake of completeness. The accompanying narrative is used to focus on key results. All explanations put forth to account for the correlational results should be considered tentative given the exploratory nature of the research.

\subsection{Correlations: Open Road Driving}

The correlation matrix in Table 7.1.1 contains the visual allocation and steering, accelerator, and brake dependent measures collected in open road driving. Consider first the visual allocation measures. The pattern of correlations is consistent with the nature of the measures themselves. MTOR is negatively correlated with MORT but positively and highly correlated with mirror sampling (MLM, MRM, MM, and FRACM) measures and instrument 
Table 7.1.1 Correlations Among Visual Allocation Measures and Steering, Accelerator, and Brake Measures in Open Road Driving

Correlation Analysis

Pearson Correlation Coefficients / Number of observations

\begin{tabular}{|c|c|c|c|c|c|c|c|c|}
\hline & MTOR & MORT & $M$ & MLM & MRM & FRACM & MIP & STPVAR \\
\hline MTOR & 1.00000 & -0.23632 & 0.74502 & 0.63410 & 0.53440 & 0.34871 & 0.60360 & -0.29721 \\
\hline & 397 & 397 & 375 & 363 & 244 & 397 & 363 & 389 \\
\hline MORT & -0.23632 & 1.00000 & -0.27535 & -0.25488 & -0.13261 & -0.23877 & -0.09690 & 0.12161 \\
\hline & 397 & 398 & 375 & 363 & 244 & 398 & 363 & 390 \\
\hline MM & 0.74502 & -0.27535 & 1.00000 & 0.86753 & 0.69184 & 0.41338 & 0.29887 & -0.22834 \\
\hline & 375 & 375 & 375 & 363 & 244 & 375 & 346 & 367 \\
\hline MLM & 0.63410 & -0.25488 & 0.86753 & 1.00000 & 0.16442 & 0.34905 & 0.25103 & -0.20683 \\
\hline & 363 & 363 & 363 & 363 & 232 & 363 & 334 & 355 \\
\hline MRM & $\begin{array}{r}0.53440 \\
244\end{array}$ & $\begin{array}{r}-0.13261 \\
244\end{array}$ & $\begin{array}{r}0.69184 \\
244\end{array}$ & $\begin{array}{r}0.16442 \\
232\end{array}$ & $\begin{array}{r}1.00000 \\
244\end{array}$ & $\begin{array}{r}0.19567 \\
244\end{array}$ & $\begin{array}{r}0.25443 \\
229\end{array}$ & $\begin{array}{r}-0.13281 \\
236\end{array}$ \\
\hline FRACM & 0.34871 & -0.23877 & 0.41338 & 0.34905 & 0.19567 & 1.00000 & -0.00766 & -0.11327 \\
\hline p & 397 & 398 & 375 & 363 & 244 & 398 & 363 & 390 \\
\hline MIP & 0.60360 & -0.09690 & 0.29887 & 0.25103 & 0.25443 & -0.00766 & 1.00000 & $-0,25984$ \\
\hline & 363 & 363 & 346 & 334 & 229 & 363 & 363 & 356 \\
\hline STPVAR & -0.29721 & 0.12161 & -0.22834 & -0.20683 & -0.13281 & -0.11327 & -0.25984 & 1.00000 \\
\hline & 389 & 390 & 367 & 355 & 236 & 390 & 356 & 390 \\
\hline STVELVAR & -0.38737 & 0.22790 & -0.32110 & $-0,28903$ & -0.27318 & -0.12896 & -0.30431 & 0.66650 \\
\hline & 389 & 390 & 367 & 355 & 236 & 390 & 356 & 390 \\
\hline STERHLDS & 0.26122 & -0.12507 & 0.32580 & 0.26344 & 0.36350 & 0.10519 & 0.12288 & -0.14573 \\
\hline & 389 & 390 & 367 & 355 & 236 & 390 & 356 & 390 \\
\hline STERREVS & -0.35481 & 0.14280 & -0.36462 & -0.30458 & -0.38199 & -0.12325 & -0.23709 & 0.25848 \\
\hline & 389 & 390 & 367 & 355 & 236 & 390 & 356 & 390 \\
\hline ACLVAR & -0.19394 & 0.04211 & -0.13704 & -0.13768 & -0.05415 & -0.17790 & -0.12720 & 0.43322 \\
\hline & 397 & 398 & 375 & 363 & 244 & 398 & 363 & 390 \\
\hline ACLVVAR & -0.05833 & -0.03172 & -0.06220 & -0.06600 & 0.00803 & -0.16550 & -0.02211 & 0.13275 \\
\hline & 397 & 398 & 375 & 363 & 244 & 398 & 363 & 390 \\
\hline ACCLHLDS & -0.02252 & 0.11472 & -0.05092 & -0.04015 & -0.04119 & -0.01856 & 0.02597 & 0.05103 \\
\hline & 397 & 398 & 375 & 363 & 244 & 398 & 363 & 390 \\
\hline ACCLRELS & -0.28280 & 0.10089 & -0.22806 & -0.18088 & -0.21434 & -0.07454 & -0.23678 & 0.39702 \\
\hline & 397 & 398 & 375 & 363 & 244 & 398 & 363 & 390 \\
\hline BRKNUMS & -0.19171 & 0.09767 & -0.13288 & -0.12618 & -0.00772 & -0.08772 & -0.15873 & 0.51405 \\
\hline & 397 & 398 & 375 & 363 & 244 & 398 & 363 & 390 \\
\hline
\end{tabular}




\section{Table 7.1.1 (Continued)}

Correlation Analysis

Pearson Correlation Coefficients / Number of observations

\begin{tabular}{|c|c|c|c|c|c|c|c|c|}
\hline & \multirow[b]{2}{*}{ STVELVAR } & \multirow{2}{*}{ STERHLDS } & \multirow{2}{*}{ STERREVS } & \multirow{2}{*}{ ACLVAR } & & \multirow[b]{2}{*}{ BRKNUMS } \\
\hline & & & & & ACLVVAR & ACCLHLDS & ACCLRELS & \\
\hline MTOR & -0.38737 & 0.26122 & -0.35481 & -0.19394 & -0.05833 & -0.02252 & -0.28280 & -0.19171 \\
\hline & 389 & 389 & 389 & 397 & 397 & 397 & 397 & 397 \\
\hline MORT & 0.22790 & -0.12507 & 0.14280 & 0.04211 & -0.03172 & 0.11472 & 0.10089 & 0.09767 \\
\hline & 390 & 390 & 390 & 398 & 398 & 398 & 398 & 398 \\
\hline$M$ & -0.32110 & 0.32580 & -0.36462 & -0.13704 & -0.06220 & -0.05092 & -0.22806 & -0.13288 \\
\hline & 367 & 367 & 367 & 375 & 375 & 375 & 375 & 375 \\
\hline MLM & -0.28903 & 0.26344 & -0.30458 & -0.13768 & -0.06600 & -0.04015 & -0.18088 & -0.12618 \\
\hline & 355 & 355 & 355 & 363 & 363 & 363 & 363 & 363 \\
\hline MRM & -0.27318 & 0.36350 & -0.38199 & -0.05415 & 0.00803 & -0.04119 & -0.21434 & -0.00772 \\
\hline & & & & & & & & 244 \\
\hline FRACM & -0.12896 & 0.10519 & -0.12325 & -0.17790 & -0.16550 & -0.01856 & -0.07454 & -0.08772 \\
\hline & 390 & 390 & 390 & 398 & 398 & 398 & 398 & 398 \\
\hline MIP & -0.30431 & 0.12288 & -0.23709 & -0.12720 & -0.02211 & 0.02597 & -0.23678 & -0.15873 \\
\hline & 356 & 356 & 356 & 363 & 363 & 363 & 363 & 363 \\
\hline STPVAR & 0.66650 & -0.14573 & 0.25848 & 0.43322 & 0.13275 & 0.05103 & 0.39702 & 0.51405 \\
\hline & 330 & 390 & 390 & 390 & 390 & 390 & 390 & 390 \\
\hline STVELVAR & 1.00000 & -0.44415 & 0.59728 & 0.20907 & -0.04057 & 0.10752 & 0.51601 & 0.28725 \\
\hline & 390 & 390 & 390 & 390 & 390 & 390 & 390 & 390 \\
\hline STERHLDS & -0.44415 & 1.00000 & -0.85663 & -0.04132 & -0.02070 & -0.06141 & -0.19817 & -0.07156 \\
\hline & 300 & 390 & 390 & 390 & 390 & 390 & 390 & 390 \\
\hline STERREVS & 0.59728 & -0.85663 & 1.00000 & 0.10731 & 0.00900 & 0.02917 & 0.29924 & 0.15184 \\
\hline & 390 & 390 & 390 & 390 & 390 & 390 & 390 & 390 \\
\hline ACLVAR & 0.20907 & -0.04132 & 0.10731 & 1.00000 & 0.65640 & -0.05537 & 0.27413 & 0.47131 \\
\hline & 390 & 390 & 390 & 398 & 398 & 398 & 398 & 398 \\
\hline ACLVVAR & -0.04057 & -0.02070 & 0.00900 & 0.65640 & 1.00000 & -0.33470 & -0.03275 & 0.25902 \\
\hline & 390 & 390 & 390 & 398 & 398 & 398 & 398 & 398 \\
\hline ACCLHLDS & 0.10752 & -0.06141 & 0.02917 & -0.05537 & -0.33470 & 1.00000 & 0.10254 & -0.00701 \\
\hline & 390 & 390 & 390 & 398 & 398 & 398 & 398 & 398 \\
\hline ACCLRELS & 0.51601 & -0.19817 & 0.29924 & 0.27413 & -0.03275 & 0.10254 & 1.00000 & 0.26088 \\
\hline & 390 & 390 & 390 & 398 & 398 & 398 & 398 & 398 \\
\hline TMS & 0.28725 & -0.07156 & 0.15184 & 0.47131 & 0.25902 & -0.00701 & 0.26088 & 1.00000 \\
\hline & 390 & 390 & 390 & 398 & 398 & 398 & 398 & 398 \\
\hline
\end{tabular}


panel measures (MIP). This is reasonable because the mirrors and instrument panel largely represent the off-road areas that were visually sampled. The covariation between left mirror (LM) or right mirror (RM) average glance durations and MM arises because MM incorporates glance duration information from both mirrors into a single measure. FRACM correlations with MLM, MRM, and MM are lower, possibly due to range effects of the FRACM proportions. The narrower the range of a measure, the smaller the correlation it can have with another measure. The correlation between MLM and MRM values is somewhat low, indicating that drivers check the two mirrors independently. Finally, the MIP correlations with various mirror-related visual allocation measures are moderately positive. This might be interpreted to indicate that the driver strategy for controlling glance duration to the mirrors applies also to the instrument panel. That is, if the driver feels that taking the eyes off the road is risky, this is likely to translate into similar (shorter) visual sampling strategies across all off-road glance locations.

The correlation matrix also contains several substantial correlations between the visual allocation dependent measures and the steering, accelerator, and brake dependent measures. Mean time off road ( MT'OR) is negatively correlated with steering position variance (STPVAR), steering velocity variance (STVELVAR), and steering reversals (STERREVS) but positively correlated with steering holds (STERHLDS). MORT is only substantially correlated with STVELVAR, though the reason for this pattern may lie more in the demands of path control than in attentional demand. The correlations of steering measures with various mirror sampling and instrument panel sampling measures largely follows that reported for correlations between steering measures and MTOR. Taken as a whole, this pattern of correlations provides some validation for the hypothesis that when visual attention is directed away from the road scene, steering activity decreases and steering hold incidence increases.

Table 7.1.2 provides correlations among visual allocation measures and speed measures captured during open road driving (car following, by definition, was not part of open road driving and so headway measures are reserved for a later section). It was expected that when off-road attentional demand increases, mean speed would decrease or remain the same. Contrary to these expectations, there were positive correlations between MTOR and MIP measures and mean speed. This may have resulted from the fact that higher travel speeds were possible in urban and rural freeway driving, conditions that were also associated with lower driving demand (e.g., longer MTOR values). On the other hand, 2-lane rural road driving was associated with greater driving demand, lower or shorter off-road attentional deployment (e.g., shorter MTOR values) and also lower travel speeds and greater speed variance. This underscores the complex effects of road type on such measures. Also noteworthy is the high negative correlation between speed variance and mean speed. That is, lower mean speeds were associated with higher speed variation. This is likely the result of the effects of curve negotiation. In general, speed measures in open road driving appear to demand a more cautious interpretation with respect to driver workload assessment. Speed measures are substantially affected by driving demand in addition to any effects of attentional demand. 


\section{Table 7.1.2 Correlations Among Visual Allocation Measures and Speed Measures in Open Road Driving}

Correlation Analysis

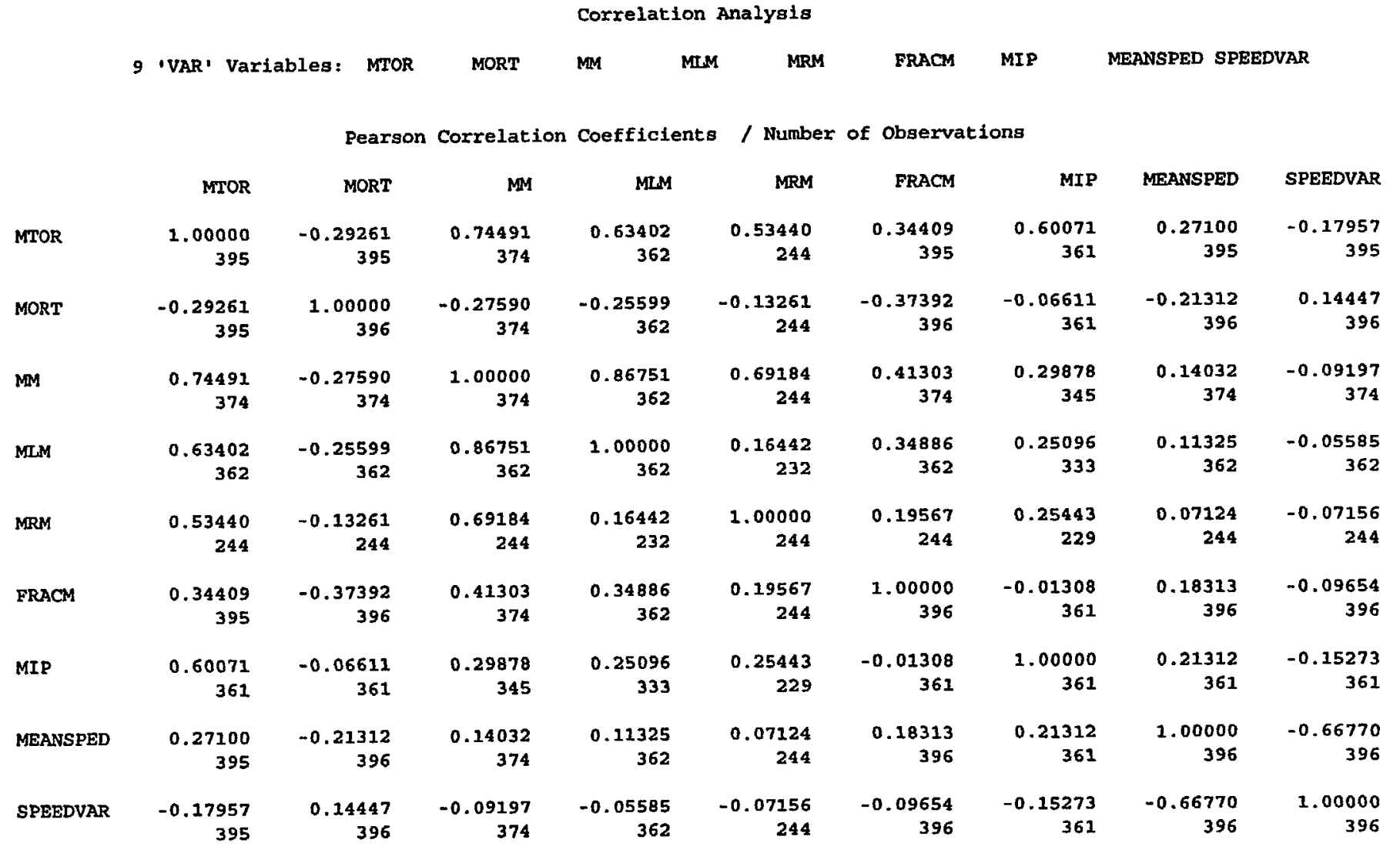


Table 7.1.3 presents the correlations among visual allocation measures and lanekeeping measures collected during open road driving. There are no significant correlations between visual allocation measures and lanekeeping measures under normal open road driving. The positive correlation between mean lane position (LANEPOSM) and lane exceedences per second (LANEXS) may be interpreted to reflect that the greater the heavy vehicle offset to the right of lane center, the greater the rate of lane exceedences (to the right). Given that drivers on freeways tended to stay in the rightmost lane and that 2-lane rural road driving demanded keeping away from driving left of center, this is a reasonable result.

Consider next the covariation among lanekeeping measures, steering, accelerator, and brake measures, and also speed measures. Table 7.1.4 presents the correlations among lanekeeping measures and steering, accelerator, and brake measures. The only correlations of note are between lane exceedences per second and accelerator position variance, and between lane exceedences per second and number of brake applications. The latter can be explained by a strategy whereby the driver exceeding the lane sometimes applies brakes to slow the lane departure. The reason for the former correlation is unknown. Table 7.1.5 shows the correlations between various lanekeeping measures and speed measures. Lane exceedence rate is negatively correlated with mean speed and positively correlated with speed variance. This pattern of results may be explained by the path control demands of the 2-lane rural road setting. The 2-lane rural road setting was associated with lower mean travel speed and greater speed variance ( this also explains the large negative correlation between these two speed measures), and also greater difficulty in maintaining path control. Finally, Table 7.1.6 presents the correlations between steering, accelerator, and brake measures and speed measures. There are numerous substantial correlations present. Many of these can be reasonably explained by considering the nature of vehicle dynamics and control. For example, a negative correlation between number of brake applications and mean speed is to be expected; the greater the number of brake applications, the lower the speed. Similarly, accelerator releases, which are positively correlated to brake applications, will also be expected to be negatively correlated with mean speed because of the normal pedal use associated with braking. Positive correlations between accelerator position variance and speed variance is also expected. The large negative correlation between steering position variance (STPVAR) and mean speed (MEANSPED) is expected under conditions of curve negotiation. In general, these correlations attest to the reasonableness of the measures taken.

The pattern of correlations generally supports their validity for use in workload assessment. However, driver-vehicle performance measures periodically show relatively poor correlations with off-road attentional demand (e.g., accelerator measures) and others show the complex interaction between driving demand and driver workload. To better understand the correlation structure among the dependent measures, the following sections will report the correlation analysis results for car following and requested task execution. 
Table 7.1.3 Correlations Among Visual Allocation Measures and Lanekeeping Measured Collected During Open Road Driving

\begin{tabular}{|c|c|c|c|c|c|c|c|c|c|c|c|}
\hline & & & & & Cors & lation Ana & lyais & & & & \\
\hline & 10 ' & 'VAR' Variabl & es: MTOR & MORT & MM & MR & FRACM & MIP & LANEPOSM & LANEPVAR I & NEXS \\
\hline & & & & Eson Corre & ation Coef & icients / & Number of 0 & observations & & & \\
\hline & & MTOR & MORT & MM & MLM & MRM & FRACM & MIP & LANEPOSM & LANEPVAR & LANEXS \\
\hline & MTOR & $\begin{array}{r}1.00000 \\
348\end{array}$ & $\begin{array}{r}-0.22689 \\
348\end{array}$ & $\begin{array}{r}0.75417 \\
327\end{array}$ & $\begin{array}{r}0.63546 \\
317\end{array}$ & $\begin{array}{r}0.55851 \\
206\end{array}$ & $\begin{array}{r}0.32877 \\
348\end{array}$ & $\begin{array}{r}0.58376 \\
314\end{array}$ & $\begin{array}{r}0.02728 \\
348\end{array}$ & $\begin{array}{r}0.03522 \\
348\end{array}$ & $\begin{array}{r}-0.19936 \\
348\end{array}$ \\
\hline & MORT & $\begin{array}{r}-0.22689 \\
348\end{array}$ & $\begin{array}{r}1.00000 \\
349\end{array}$ & $\begin{array}{r}-0.27670 \\
327\end{array}$ & $\begin{array}{r}-0.24967 \\
317\end{array}$ & $\begin{array}{r}-0.15090 \\
206\end{array}$ & $\begin{array}{r}-0.22476 \\
349\end{array}$ & $\begin{array}{r}-0.08904 \\
314\end{array}$ & $\begin{array}{r}0.01873 \\
349\end{array}$ & $\begin{array}{r}-0.01100 \\
349\end{array}$ & $\begin{array}{r}0.10386 \\
349\end{array}$ \\
\hline & MM & $\begin{array}{r}0.75417 \\
327\end{array}$ & $\begin{array}{r}-0.27670 \\
327\end{array}$ & $\begin{array}{r}1.00000 \\
327\end{array}$ & $\begin{array}{r}0.87602 \\
317\end{array}$ & $\begin{array}{r}0.66153 \\
206\end{array}$ & $\begin{array}{r}0.42081 \\
327\end{array}$ & $\begin{array}{r}0.28594 \\
298\end{array}$ & $\begin{array}{r}0.07142 \\
327\end{array}$ & $\begin{array}{r}0.05323 \\
327\end{array}$ & $\begin{array}{r}-0.14368 \\
327\end{array}$ \\
\hline & MLM & $\begin{array}{r}0.63546 \\
317\end{array}$ & $\begin{array}{r}-0.24967 \\
317\end{array}$ & $\begin{array}{r}0.87602 \\
317\end{array}$ & $\begin{array}{r}1.00000 \\
317\end{array}$ & $\begin{array}{r}0.13778 \\
196\end{array}$ & $\begin{array}{r}0.34200 \\
317\end{array}$ & $\begin{array}{r}0.23528 \\
288\end{array}$ & $\begin{array}{r}0.08248 \\
317\end{array}$ & $\begin{array}{r}0.08434 \\
317\end{array}$ & $\begin{array}{r}-0.10112 \\
317\end{array}$ \\
\hline On & MRM & $\begin{array}{r}0.55851 \\
206\end{array}$ & $\begin{array}{r}-0.15090 \\
206\end{array}$ & $\begin{array}{r}0.66153 \\
206\end{array}$ & $\begin{array}{r}0.13778 \\
196\end{array}$ & $\begin{array}{r}1.00000 \\
206\end{array}$ & $\begin{array}{r}0.23441 \\
206\end{array}$ & $\begin{array}{r}0.25435 \\
191\end{array}$ & $\begin{array}{r}0.02362 \\
206\end{array}$ & $\begin{array}{r}-0.01014 \\
206\end{array}$ & $\begin{array}{r}-0.13954 \\
206\end{array}$ \\
\hline & FRACM & $\begin{array}{r}0.32877 \\
348\end{array}$ & $\begin{array}{r}-0.22476 \\
349\end{array}$ & $\begin{array}{r}0.42081 \\
327\end{array}$ & $\begin{array}{r}0.34200 \\
317\end{array}$ & $\begin{array}{r}0.23441 \\
206\end{array}$ & $\begin{array}{r}1.00000 \\
349\end{array}$ & $\begin{array}{r}-0.03281 \\
314\end{array}$ & $\begin{array}{r}0.00250 \\
349\end{array}$ & $\begin{array}{r}0.00658 \\
349\end{array}$ & $\begin{array}{r}-0.15670 \\
349\end{array}$ \\
\hline & MIP & $\begin{array}{r}0.58376 \\
314\end{array}$ & $\begin{array}{r}-0.08904 \\
314\end{array}$ & $\begin{array}{r}0.28594 \\
298\end{array}$ & $\begin{array}{r}0.23528 \\
288\end{array}$ & $\begin{array}{r}0.25435 \\
191\end{array}$ & $\begin{array}{r}-0.03281 \\
314\end{array}$ & $\begin{array}{r}1.00000 \\
314\end{array}$ & $\begin{array}{r}0.07281 \\
314\end{array}$ & $\begin{array}{r}0.02428 \\
314\end{array}$ & $\begin{array}{r}-0.08177 \\
314\end{array}$ \\
\hline & WANEPOSM & $\begin{array}{r}0.02728 \\
348\end{array}$ & $\begin{array}{r}0.01873 \\
349\end{array}$ & $\begin{array}{r}0.07142 \\
327\end{array}$ & $\begin{array}{r}0.08248 \\
317\end{array}$ & $\begin{array}{r}0.02362 \\
206\end{array}$ & $\begin{array}{r}0.00250 \\
349\end{array}$ & $\begin{array}{r}0.07281 \\
314\end{array}$ & $\begin{array}{r}1.00000 \\
349\end{array}$ & $\begin{array}{r}-0.01385 \\
349\end{array}$ & $\begin{array}{r}0.39762 \\
349\end{array}$ \\
\hline & IAANEPVAR & $\begin{array}{r}0.03522 \\
348\end{array}$ & $\begin{array}{r}-0.01100 \\
349\end{array}$ & $\begin{array}{r}0.05323 \\
327\end{array}$ & $\begin{array}{r}0.08434 \\
317\end{array}$ & $\begin{array}{r}-0.01014 \\
206\end{array}$ & $\begin{array}{r}0.00658 \\
349\end{array}$ & $\begin{array}{r}0.02428 \\
314\end{array}$ & $\begin{array}{r}-0.02385 \\
349\end{array}$ & $\begin{array}{r}1.00000 \\
349\end{array}$ & $\begin{array}{r}0.14083 \\
349\end{array}$ \\
\hline & LANEXS & $\begin{array}{r}-0.19936 \\
348\end{array}$ & $\begin{array}{r}0.10386 \\
349\end{array}$ & $\begin{array}{r}-0.14368 \\
327\end{array}$ & $\begin{array}{r}-0.10112 \\
317\end{array}$ & $\begin{array}{r}-0.13954 \\
206\end{array}$ & $\begin{array}{r}-0.15670 \\
349\end{array}$ & $\begin{array}{r}-0.08177 \\
314\end{array}$ & $\begin{array}{r}0.39762 \\
349\end{array}$ & $\begin{array}{r}0.14083 \\
349\end{array}$ & $\begin{array}{r}1.00000 \\
349\end{array}$ \\
\hline
\end{tabular}


Table 7.1.4 Correlations Among Lanekeeping Measures and Steering, Accelerator, and Brake Measures

Correlation Analysis

Pearson Correlation Coefficients / Number of Observations

\begin{tabular}{|c|c|c|c|c|c|c|}
\hline & LANEPOSM & LANEPVAR & LANEXS & STPVAR & STVELVAR & STERHLDS \\
\hline \multirow[t]{2}{*}{ LANEPOSM } & 1.00000 & 0.00422 & 0.41030 & 0.01414 & -0.18716 & 0.14457 \\
\hline & 347 & 347 & 347 & 339 & 339 & 339 \\
\hline \multirow[t]{2}{*}{ LANEPVAR } & 0.00422 & 1.00000 & 0.13422 & 0.10870 & -0.00752 & 0.05640 \\
\hline & 347 & 347 & 347 & 339 & 339 & 339 \\
\hline \multirow[t]{2}{*}{ LANEXSS } & 0.41030 & 0.13422 & 1.00000 & 0.26506 & 0.12968 & -0.00867 \\
\hline & 347 & 347 & 347 & 339 & 339 & 339 \\
\hline \multirow[t]{2}{*}{ STPVAR } & 0.01414 & 0.10870 & 0.26506 & 1.00000 & 0.66254 & -0.25158 \\
\hline & 339 & 339 & 339 & 339 & 339 & 339 \\
\hline \multirow{2}{*}{ STVELVAR } & -0.18716 & -0.00752 & 0.12968 & 0.66254 & 1.00000 & -0.51923 \\
\hline & 339 & 339 & 339 & 339 & 339 & 339 \\
\hline \multirow[t]{2}{*}{ STERHLDS } & 0.14457 & 0.05640 & -0.00867 & -0.25158 & -0.51923 & 1.00000 \\
\hline & 339 & 339 & 339 & 339 & 339 & 339 \\
\hline \multirow[t]{2}{*}{ STERREVS } & -0.15787 & -0.07179 & 0.07455 & 0.32844 & 0.64034 & -0.84737 \\
\hline & 339 & 339 & 339 & 339 & 339 & 339 \\
\hline \multirow[t]{2}{*}{ ACLVAR } & 0.09169 & 0.00766 & 0.27747 & 0.43673 & 0.20301 & -0.09904 \\
\hline & 347 & 347 & 347 & 339 & 339 & 339 \\
\hline \multirow[t]{2}{*}{ ACLVVAR } & 0.05339 & -0.07461 & 0.10557 & 0.15660 & -0.04379 & -0.01730 \\
\hline & 347 & 347 & 347 & 339 & 339 & 339 \\
\hline \multirow[t]{2}{*}{ ACCLHLDS } & -0.02675 & 0.04796 & 0.03348 & 0.03462 & 0.07778 & 0.01140 \\
\hline & 347 & 347 & 347 & 339 & 339 & 339 \\
\hline \multirow[t]{2}{*}{ ACCLRELS } & -0.14852 & 0.08129 & 0.05587 & 0.35402 & 0.52009 & -0.32036 \\
\hline & 347 & 347 & 347 & 339 & 339 & 339 \\
\hline \multirow[t]{2}{*}{ BRKAUMS } & 0.14529 & 0.02181 & 0.33228 & 0.48826 & 0.27393 & -0.15699 \\
\hline & 347 & 347 & 347 & 339 & 339 & 339 \\
\hline
\end{tabular}


Table 7.1.4 (Continued)

Correlation Analygis

Pearson Correlation Coefficients / Number of Observations

\begin{tabular}{|c|c|c|c|c|c|c|}
\hline & STERREVS & ACLVAR & ACLVVAR & ACCLHLDS & ACCLRELS & BRKNUMS \\
\hline \multirow[t]{2}{*}{ LANEPOSM } & -0.25787 & 0.09169 & 0.05339 & -0.02675 & -0.14852 & 0.14529 \\
\hline & 339 & 347 & 347 & 347 & 347 & 347 \\
\hline \multirow[t]{2}{*}{ LANEPVAR } & -0.07179 & 0.00766 & -0.07461 & 0.04796 & 0.08129 & 0.02181 \\
\hline & 339 & 347 & 347 & 347 & 347 & 347 \\
\hline \multirow[t]{2}{*}{ L.ANEXS } & 0.07455 & 0.27747 & 0.10557 & 0.03348 & 0.05587 & 0.33228 \\
\hline & 339 & 347 & 347 & 347 & 347 & 347 \\
\hline \multirow[t]{2}{*}{ STPVAR } & 0.32844 & 0.43673 & 0.15660 & 0.03462 & 0.35402 & 0.48826 \\
\hline & 339 & 339 & 339 & 339 & 339 & 339 \\
\hline \multirow[t]{2}{*}{ STVELVAR } & 0.64034 & 0.20301 & -0.04379 & 0.07778 & 0.52009 & 0.27393 \\
\hline & 339 & 339 & 339 & 339 & 339 & 339 \\
\hline \multirow[t]{2}{*}{ STERHLDS } & -0.84737 & -0.09904 & -0.01730 & 0.01140 & -0.32036 & -0.15699 \\
\hline & 339 & 339 & 339 & 339 & 339 & 339 \\
\hline \multirow[t]{2}{*}{ STERREVS } & 1.00000 & 0.13515 & -0.00620 & -0.02754 & 0.37155 & 0.20730 \\
\hline & 339 & 339 & 339 & 339 & 339 & 339 \\
\hline \multirow[t]{2}{*}{ ACLVAR } & 0.13515 & 1.00000 & 0.64929 & -0.10084 & 0.24792 & 0.47248 \\
\hline & 339 & 347 & 347 & 347 & 347 & 347 \\
\hline \multirow[t]{2}{*}{ ACLVVAR } & -0.00620 & 0.64929 & 1.00000 & -0.39654 & -0.04169 & 0.28336 \\
\hline & 339 & 347 & 347 & 347 & 347 & 347 \\
\hline \multirow[t]{2}{*}{ ACCLHLDS } & -0.02754 & -0.10084 & -0.39654 & 1.00000 & 0.07209 & -0.03757 \\
\hline & 339 & 347 & 347 & 347 & 347 & 347 \\
\hline \multirow[t]{2}{*}{ ACCLRELS } & 0.37155 & 0.24792 & -0.04169 & 0.07209 & 1.00000 & 0.20098 \\
\hline & 339 & 347 & 347 & 347 & 347 & $\mathbf{3 4 7}$ \\
\hline \multirow[t]{2}{*}{ BRKNUMS } & 0.20730 & 0.47248 & 0.28336 & -0.03757 & 0.20098 & 1.00000 \\
\hline & 339 & 347 & 347 & 347 & 347 & 347 \\
\hline
\end{tabular}


Table 7.1.5 Correlations Among Various Lanekeeping Measures and Speed Measures in Open Road Driving

Correlation Analysis

5 'VAR' Variables: LANEPOSM LANEPVAR LANEXS MEANSPED SPEEDVAR

Pearson Correlation Coefficients / N $=345$

$\begin{array}{lccccc} & \text { LANEPOSM } & \text { LANEPVAR } & \text { LANEXS } & \text { MEANSPED } & \text { SPEEDVAR } \\ \text { LANEPOSM } & 1.00000 & 0.00488 & 0.40746 & -0.07874 & 0.09708 \\ \text { LANEPVAR } & 0.00488 & 1.00000 & 0.13574 & -0.08282 & 0.04232 \\ \text { LANEXS } & 0.40746 & 0.13574 & 1.00000 & -0.44224 & 0.34429 \\ \text { MEANSPED } & -0.07874 & -0.08282 & -0.44224 & 1.00000 & -0.64806 \\ \text { SPEEDVAR } & 0.09708 & 0.04232 & 0.34429 & -0.64806 & 1.00000\end{array}$

$\varnothing$ 
Table 7.1.6 Correlations Among Steering, Accelerator, and Brake Measures and Speed Measures

Correlation Analysis

11 'VAR' Variables: STPVAR STVELVAR STERHLDS STERREVS ACLVAR ACLVVAR ACCLHLDS ACCLRELS BRKNUMS MEANSPED SPEEDVAR

Pearson Correlation Coefficients / Number of observations

\begin{tabular}{|c|c|c|c|c|c|c|c|c|c|c|c|}
\hline & STPVAR & STVELVAR & STERHLDS & STERREVS & ACLVAR & ACLVVAR & ACCLHLDS & ACCLRELS & BRKNUMS & MEANSPED & SPEEDVAR \\
\hline TPVAR & $\begin{array}{r}.00000 \\
386\end{array}$ & $\begin{array}{r}0.66598 \\
386\end{array}$ & $\begin{array}{r}0.14327 \\
386\end{array}$ & $\begin{array}{r}0.25756 \\
386\end{array}$ & $\begin{array}{r}0.43368 \\
386\end{array}$ & $\begin{array}{r}0.13281 \\
386\end{array}$ & $\begin{array}{r}0.05271 \\
386\end{array}$ & $\begin{array}{r}0.39765 \\
386\end{array}$ & $\begin{array}{r}0.51490 \\
386\end{array}$ & $\begin{array}{r}-0.58704 \\
386\end{array}$ & $\begin{array}{r}0.50416 \\
386\end{array}$ \\
\hline TVELVAR & $\begin{array}{r}66598 \\
386\end{array}$ & $\begin{array}{r}.00000 \\
386\end{array}$ & $\begin{array}{r}-0.44484 \\
386\end{array}$ & $\begin{array}{r}0.59793 \\
386\end{array}$ & $\begin{array}{r}0.21046 \\
386\end{array}$ & $\begin{array}{r}0.03944 \\
386\end{array}$ & $\begin{array}{r}0.10865 \\
386\end{array}$ & $\begin{array}{r}0.51923 \\
386\end{array}$ & $\begin{array}{r}0.28940 \\
386\end{array}$ & $\begin{array}{r}-0.46065 \\
386\end{array}$ & $\begin{array}{r}.30816 \\
386\end{array}$ \\
\hline TERHLDS & $\begin{array}{r}0.14327 \\
386\end{array}$ & $\begin{array}{r}-0.44484 \\
386\end{array}$ & $\begin{array}{r}1.00000 \\
386\end{array}$ & $\begin{array}{r}0.85479 \\
386\end{array}$ & $\begin{array}{r}-0.04037 \\
386\end{array}$ & $\begin{array}{r}-0.01958 \\
386\end{array}$ & $\begin{array}{r}-0.07326 \\
386\end{array}$ & $\begin{array}{r}-0.19930 \\
386\end{array}$ & $\begin{array}{r}0.07059 \\
386\end{array}$ & $\begin{array}{r}.05596 \\
386\end{array}$ & $\begin{array}{r}0.03334 \\
386\end{array}$ \\
\hline CERREVS & $\begin{array}{r}0.25756 \\
386\end{array}$ & $\begin{array}{r}59793 \\
386\end{array}$ & $\begin{array}{r}-0.85479 \\
386\end{array}$ & $\begin{array}{r}00000 \\
386\end{array}$ & $\begin{array}{r}.0893 \\
3866\end{array}$ & $\begin{array}{r}00998 \\
386\end{array}$ & $\begin{array}{r}.03414 \\
386\end{array}$ & $\begin{array}{r}0.30191 \\
386\end{array}$ & $\begin{array}{r}.15305 \\
386\end{array}$ & $\begin{array}{r}-0.21147 \\
386\end{array}$ & $\begin{array}{r}.14312 \\
386\end{array}$ \\
\hline ELVAR & $\begin{array}{r}0.43368 \\
386\end{array}$ & $\begin{array}{r}21046 \\
386\end{array}$ & $\begin{array}{r}-0.04037 \\
386\end{array}$ & $\begin{array}{r}10893 \\
386\end{array}$ & $\begin{array}{r}1.00000 \\
394\end{array}$ & $\begin{array}{r}0.65540 \\
394\end{array}$ & $\begin{array}{r}-0.05026 \\
394\end{array}$ & $\begin{array}{r}0.27263 \\
394\end{array}$ & $\begin{array}{r}0.47033 \\
394\end{array}$ & $\begin{array}{r}-0.42032 \\
394\end{array}$ & $\begin{array}{r}.43541 \\
394\end{array}$ \\
\hline CLVVAR & $\begin{array}{r}13281 \\
386\end{array}$ & $\begin{array}{r}03944 \\
386\end{array}$ & $\begin{array}{r}-0.01958 \\
386\end{array}$ & $\begin{array}{r}0.00998 \\
386\end{array}$ & $\begin{array}{r}.65540 \\
394\end{array}$ & $\begin{array}{r}1.00000 \\
394\end{array}$ & $\begin{array}{r}-0.33159 \\
394\end{array}$ & $\begin{array}{r}-0.03535 \\
394\end{array}$ & $\begin{array}{r}.25729 \\
394\end{array}$ & $\begin{array}{r}-0.23059 \\
394\end{array}$ & $\begin{array}{r}28323 \\
394\end{array}$ \\
\hline CCLHLDS & $\begin{array}{r}0.05271 \\
386\end{array}$ & $\begin{array}{r}10865 \\
386\end{array}$ & $\begin{array}{r}-0.07326 \\
386\end{array}$ & $\begin{array}{r}.03414 \\
386\end{array}$ & $\begin{array}{r}0.05026 \\
394\end{array}$ & $\begin{array}{r}-0.33159 \\
394\end{array}$ & $\begin{array}{r}1.00000 \\
394\end{array}$ & $\begin{array}{r}10780 \\
394\end{array}$ & $\begin{array}{r}-0.00275 \\
394\end{array}$ & $\begin{array}{r}-0.04957 \\
394\end{array}$ & $\begin{array}{r}2271 \\
394\end{array}$ \\
\hline CCLREL & $\begin{array}{r}0.39765 \\
386\end{array}$ & $\begin{array}{r}51923 \\
386\end{array}$ & $\begin{array}{r}-0.19930 \\
386\end{array}$ & $\begin{array}{r}0.30191 \\
386\end{array}$ & $\begin{array}{r}0.27263 \\
394\end{array}$ & $\begin{array}{r}-0.03535 \\
394\end{array}$ & $\begin{array}{r}0.10780 \\
394\end{array}$ & $\begin{array}{r}00000 \\
394\end{array}$ & $\begin{array}{r}25960 \\
394\end{array}$ & $\begin{array}{r}-0.31262 \\
394\end{array}$ & $\begin{array}{r}2641 \\
394\end{array}$ \\
\hline BRKNUMS & $\begin{array}{r}0.51490 \\
386\end{array}$ & $\begin{array}{r}28940 \\
386\end{array}$ & $\begin{array}{r}-0.07059 \\
386\end{array}$ & $\begin{array}{r}.15305 \\
386\end{array}$ & $\begin{array}{r}0.47033 \\
394\end{array}$ & $\begin{array}{r}0.25729 \\
394\end{array}$ & $\begin{array}{r}-0.00275 \\
394\end{array}$ & $\begin{array}{r}25960 \\
394\end{array}$ & $\begin{array}{r}.00000 \\
394\end{array}$ & $\begin{array}{r}-0.54758 \\
394\end{array}$ & $\begin{array}{r}57205 \\
394\end{array}$ \\
\hline EANSPED & $\begin{array}{r}-0.58704 \\
386\end{array}$ & $\begin{array}{r}-0.46065 \\
386\end{array}$ & $\begin{array}{r}0.05596 \\
386\end{array}$ & $\begin{array}{r}-0.21147 \\
386\end{array}$ & $\begin{array}{r}-0.42032 \\
394\end{array}$ & $\begin{array}{r}-0.23059 \\
394\end{array}$ & $\begin{array}{r}-0.04957 \\
394\end{array}$ & $\begin{array}{r}-0.31262 \\
394\end{array}$ & $\begin{array}{r}-0.54758 \\
394\end{array}$ & $\begin{array}{r}1.00000 \\
394\end{array}$ & $\begin{array}{r}-0.66815 \\
394\end{array}$ \\
\hline gets & $\begin{array}{r}0.50416 \\
386\end{array}$ & $\begin{array}{r}30816 \\
386\end{array}$ & $\begin{array}{r}.03334 \\
386\end{array}$ & $\begin{array}{r}4312 \\
386\end{array}$ & $\begin{array}{r}3541 \\
394\end{array}$ & 394 & $\begin{array}{r}2271 \\
394\end{array}$ & $\begin{array}{r}2641 \\
394\end{array}$ & $\begin{array}{r}57205 \\
394\end{array}$ & $\begin{array}{r}-0.66815 \\
394\end{array}$ & $\begin{array}{r}1.00000 \\
394\end{array}$ \\
\hline
\end{tabular}




\subsection{Correlations: Car Foliowing}

The data collected during the car following driving scenario were also analyzed in terms of correlations. Table 7.2.1 presents the correlations between visual allocation measures and steering, accelerator, and brake application dependent measures. The correlations among the visual allocation measures often reflect the same strength of relationship as was found for open road driving. However, there is no longer a practically significant relationship between MTOR and MOTR measures, possibly because the off-road glance durations tended to be more constrained in their range. There is also no longer a significant correlation between MTOR and STPVAR. The reasons for such changes are unknown but may reflect the greater attention paid to the road scene and lead vehicle. Finally, the correlations among the steering, accelerator, and brake measures sometimes decrease in magnitude, perhaps because of a reduction in the range of certain driver control behaviors exhibited during car following. In general, however, the associations found in open road driving among these measures remains.

Table 7.2.2 presents the correlations among visual allocation, speed, and headway measures. The correlations among visual allocation measures and speed measures are not practically significant during car following. This may be due to the generally shorter sampling intervals measured for car following. Recall that car following was observed, not directed or manipulated. The intervals of time during which car following was observed were generally short compared with the period for open road driving and this may have served to reduce or eliminate some previously noteworthy correlations. Also, there appear to be no practically significant correlations among the visual allocation measures and various headway measures, possibly for the same reasons. This suggests that, in car following, these categories of measurement are assessing different aspects of the driving situation. Finally, the correlations among following distance measures reflect expected kinematic relationships. For example, it is reasonable to expect a high correlation between following distance variance and time headway variance or a high positive correlation between following distance mean and mean time headway.

Table 7.2.3 presents the correlations between visual allocation measures and lanekeeping measures during car following. In general, there are no substantial correlations between the two classes of measures. One exception is the positive correlation between MORT and LANEXS. The expectation was that they would be negatively correlated. The reason for this positive correlation is unknown but may reflect road type effects such that 2lane rural roads, with their greater path control demands, were associated with both greater MORT values as well as more lane exceedences.

The final tables represent correlations among various driver-vehicle performance measures. Table 7.2.4 presents the correlations between lanekeeping and steering, accelerator, and brake measures during car following. The pattern of correlations among these variables resembles that found in open road driving. Therefore, no further comments will be made. Table 7.2.5 presents the correlations among pairs of lanekeeping measures, speed measures, 


\section{Table 7.2.1 Correlations Among Visual Allocation Measures and Steering, Accelerator, and Brake Application Dependent Measures During Car Following}

Correlation Analysis

pearson Correlation Coefficients / Number of Observations

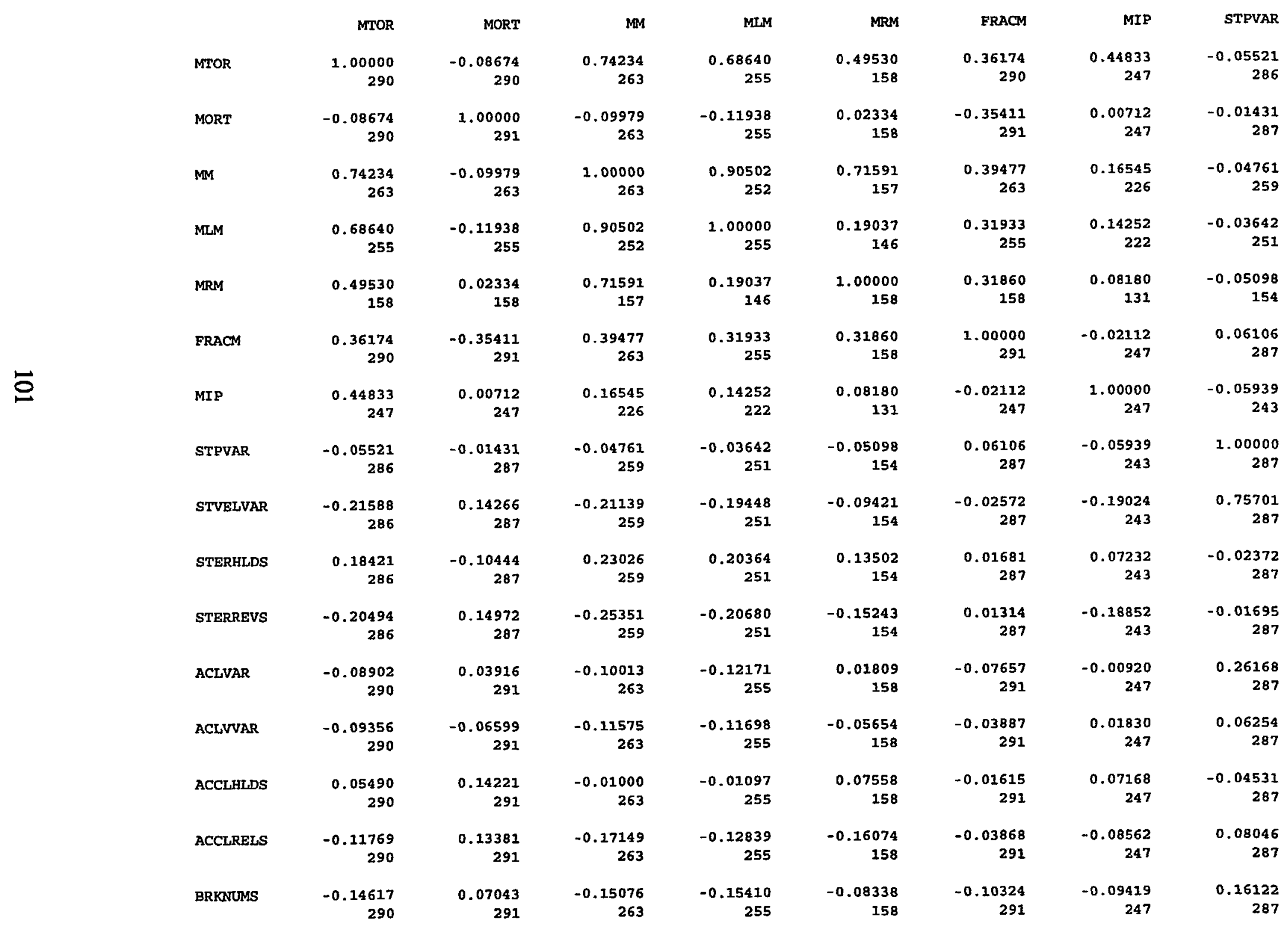


Table 7.2.1 (Continued)

Correlation Analysis

Pearson Correlation Coefficients / Number of observations

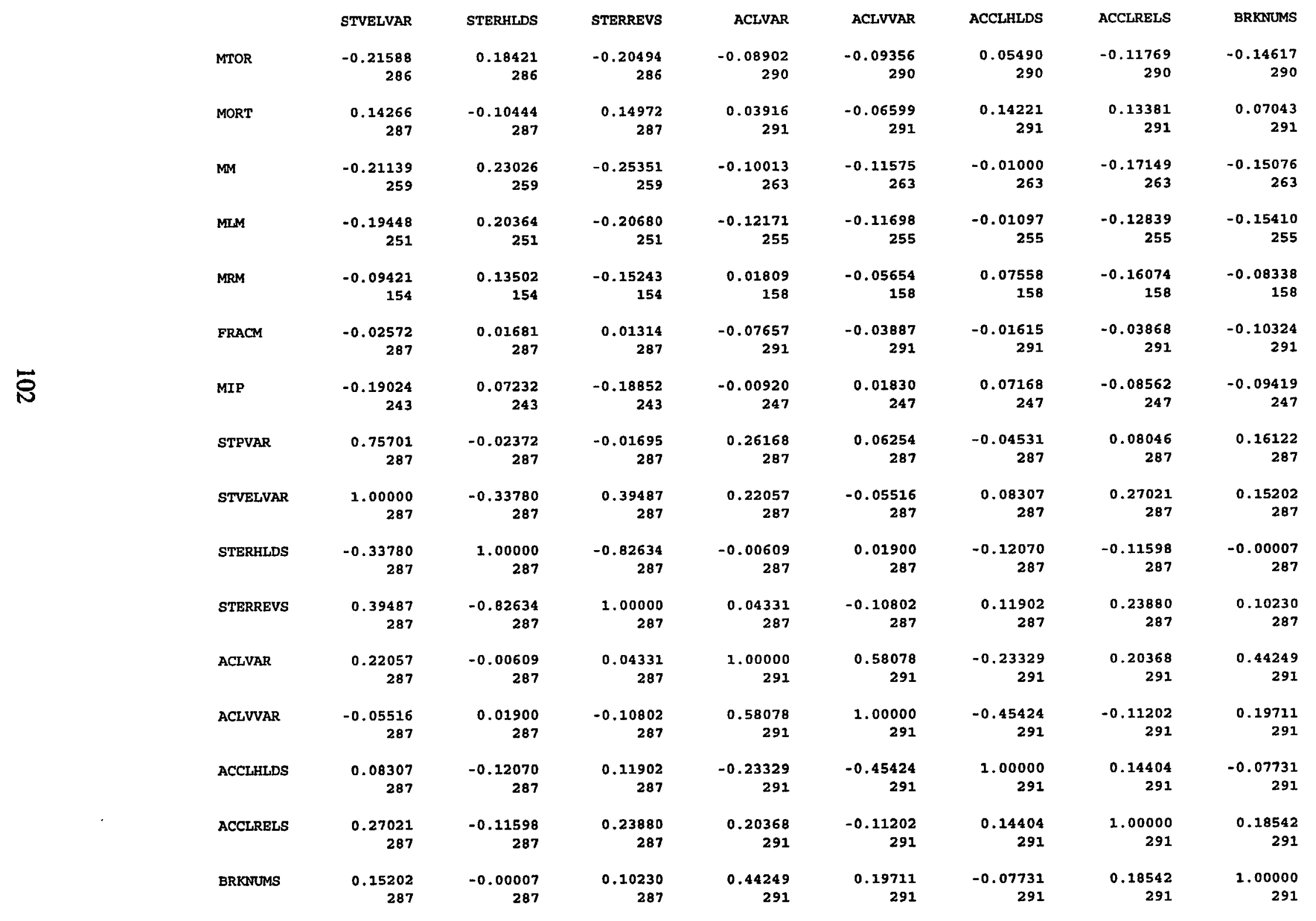


Table 7.2.2 Correlations Among Visual Allocation, Speed, and Headway Measuring During Car Following

Correlation Analysis

Pearson Correlation Coefficients / Number of Observations

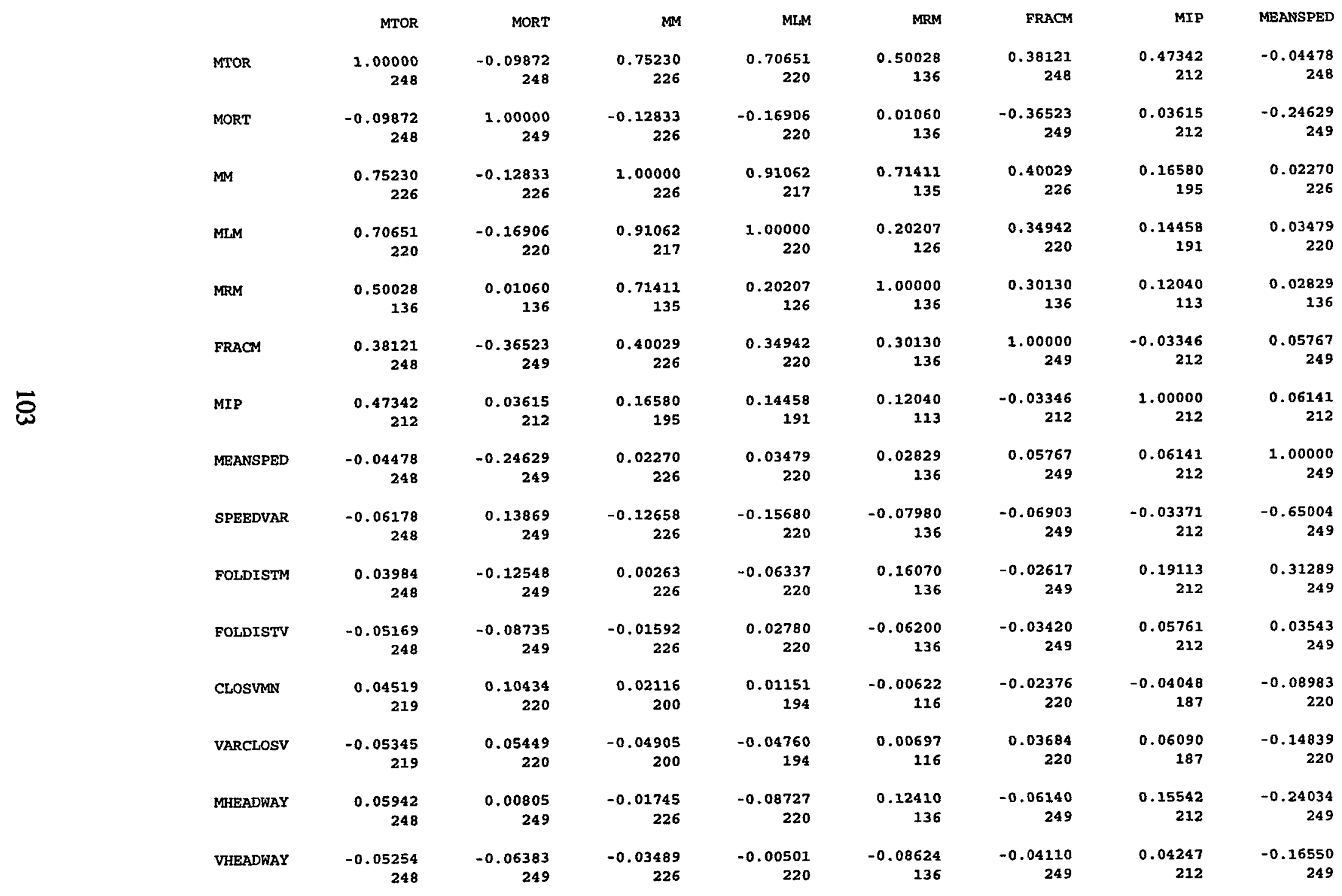




\section{Table 7.2.2 (Continued)}

Correlation Analysis

Pearson Correlation Coefficients / Number of Observations

\begin{tabular}{|c|c|c|c|c|c|c|c|}
\hline & SPEEDVAR & FOLDISTM & FOLDISTV & CLOSVMN & VARCLOSV & MHEADWAY & VHEADWAY \\
\hline \multirow[t]{2}{*}{ MTOR } & -0.06178 & 0.03984 & -0.05169 & 0.04519 & -0.05345 & 0.05942 & -0.05254 \\
\hline & 248 & 248 & 248 & 219 & 219 & 248 & 248 \\
\hline \multirow[t]{2}{*}{ MORT } & 0.13869 & -0.12548 & -0.08735 & 0.10434 & 0.05449 & 0.00805 & -0.06383 \\
\hline & 249 & 249 & 249 & 220 & 220 & 249 & 249 \\
\hline \multirow[t]{2}{*}{ MM } & -0.12658 & 0.00263 & -0.01592 & 0.02116 & -0.04905 & -0.01745 & -0.03489 \\
\hline & 226 & 226 & 226 & 200 & 200 & 226 & 226 \\
\hline \multirow[t]{2}{*}{ MLM } & -0.15680 & -0.06337 & 0.02780 & 0.01151 & -0.04760 & -0.08727 & -0.00501 \\
\hline & 220 & 220 & 220 & 194 & 194 & 220 & 220 \\
\hline \multirow{2}{*}{ MRM } & -0.07980 & 0.16070 & -0.06200 & -0.00622 & 0.00697 & 0.12410 & -0.08624 \\
\hline & & & 100 & 116 & 116 & 136 & 136 \\
\hline FRACM & -0.06903 & -0.02617 & -0.03420 & -0.02376 & 0.03684 & -0.06140 & -0.04110 \\
\hline \multirow{2}{*}{ MIP } & -0.03371 & 0.19113 & 0.05761 & -0.04048 & 0.06090 & 0.15542 & 0.04247 \\
\hline & 212 & 212 & 212 & 187 & 187 & 212 & 212 \\
\hline \multirow[t]{2}{*}{ MEANSPED } & -0.65004 & 0.31289 & 0.03543 & -0.08983 & -0.14839 & -0.24034 & -0.16550 \\
\hline & 249 & 249 & 249 & 220 & 220 & 249 & 249 \\
\hline \multirow[t]{2}{*}{ SPEEDVAR } & 1.00000 & -0.23962 & -0.12156 & 0.16822 & 0.19500 & 0.15169 & 0.05187 \\
\hline & 249 & 249 & 249 & 220 & 220 & 249 & 249 \\
\hline \multirow[t]{2}{*}{ FOLDISTM } & -0.23962 & 1.00000 & 0.21175 & -0.15994 & 0.07367 & 0.83058 & 0.16615 \\
\hline & 249 & 249 & 249 & 220 & 220 & 249 & 249 \\
\hline \multirow[t]{2}{*}{ FOLDISTV } & -0.12156 & 0.21175 & 1.00000 & -0.36343 & -0.11517 & 0.18324 & 0.95378 \\
\hline & 249 & 249 & 249 & 220 & 220 & 249 & 249 \\
\hline \multirow[t]{2}{*}{ CLOSVMN } & 0.16822 & -0.15994 & -0.36343 & 1.00000 & 0.01697 & -0.12053 & -0.32523 \\
\hline & 220 & 220 & 220 & 220 & 220 & 220 & 220 \\
\hline \multirow[t]{2}{*}{ VARCLOSV } & 0.19500 & 0.07367 & -0.11517 & 0.01697 & 1.00000 & 0.11377 & -0.09073 \\
\hline & 220 & 220 & 220 & 220 & 220 & 220 & 220 \\
\hline \multirow[t]{2}{*}{ MHEADWAY } & 0.15169 & 0.83058 & 0.18324 & -0.12053 & 0.11377 & 1.00000 & 0.27739 \\
\hline & 249 & 249 & 249 & 220 & 220 & 249 & 249 \\
\hline \multirow{2}{*}{ VHEADWAY } & 0.05187 & 0.16615 & 0.95378 & -0.32523 & -0.09073 & 0.27739 & 1.00000 \\
\hline & 249 & 249 & 249 & 220 & 220 & 249 & 249 \\
\hline
\end{tabular}


Table 7.2.3 Correlations Among Visual Allocation Measures and Lanekeeping Measures During Car Following Correlation Analysis

10 'VAR' Variables: MTOR MORT MM MLM MRM FRACM MIP LANEPOSM LANEPVAR LANEXS

Pearson Correlation Coefficients / Number of Observations

\begin{tabular}{|c|c|c|c|c|c|c|c|c|c|c|}
\hline & MTOR & MORT & MM & MLM & MRM & FRACM & MIP & LANEPOSM & LLANEPVAR & LANEXS \\
\hline MTOR & $\begin{array}{r}1.00000 \\
261\end{array}$ & $\begin{array}{r}-0.10204 \\
261\end{array}$ & $\begin{array}{r}0.76803 \\
234\end{array}$ & 0.69375 & $\begin{array}{r}0.52590 \\
137\end{array}$ & $\begin{array}{r}0.36151 \\
261\end{array}$ & $\begin{array}{r}0.43894 \\
221\end{array}$ & $\begin{array}{r}0.05707 \\
261\end{array}$ & $\begin{array}{r}0.19695 \\
261\end{array}$ & $\begin{array}{r}0.00157 \\
261\end{array}$ \\
\hline MORT & $\begin{array}{r}-0.10204 \\
261\end{array}$ & $\begin{array}{r}1.00000 \\
262\end{array}$ & $\begin{array}{r}-0.10942 \\
234\end{array}$ & $\begin{array}{r}-0.12368 \\
227\end{array}$ & $\begin{array}{r}-0.03116 \\
137\end{array}$ & $\begin{array}{r}-0.34922 \\
262\end{array}$ & $\begin{array}{r}0.01254 \\
221\end{array}$ & $\begin{array}{r}0.09849 \\
262\end{array}$ & $\begin{array}{r}0.02378 \\
262\end{array}$ & $\begin{array}{r}0.07506 \\
262\end{array}$ \\
\hline$M$ & $\begin{array}{r}0.76803 \\
234\end{array}$ & $\begin{array}{r}-0.10942 \\
234\end{array}$ & $\begin{array}{r}1.00000 \\
234\end{array}$ & $\begin{array}{r}0.90418 \\
224\end{array}$ & $\begin{array}{r}0.70985 \\
136\end{array}$ & $\begin{array}{r}0.38515 \\
234\end{array}$ & $\begin{array}{r}0.19887 \\
200\end{array}$ & $\begin{array}{r}0.12771 \\
234\end{array}$ & $\begin{array}{r}0.16694 \\
234\end{array}$ & $\begin{array}{r}-0.03109 \\
234\end{array}$ \\
\hline MLM & $\begin{array}{r}0.69375 \\
227\end{array}$ & $\begin{array}{r}-0.12368 \\
227\end{array}$ & $\begin{array}{r}0.90418 \\
224\end{array}$ & $\begin{array}{r}1.00000 \\
227\end{array}$ & $\begin{array}{r}0.15313 \\
126\end{array}$ & $\begin{array}{r}0.30086 \\
227\end{array}$ & $\begin{array}{r}0.15078 \\
197\end{array}$ & $\begin{array}{r}0.12291 \\
227\end{array}$ & $\begin{array}{r}0.09505 \\
227\end{array}$ & $\begin{array}{r}-0.00875 \\
227\end{array}$ \\
\hline MRM & $\begin{array}{r}0.52590 \\
137\end{array}$ & $\begin{array}{r}-0.03116 \\
137\end{array}$ & $\begin{array}{r}0.70985 \\
136\end{array}$ & $\begin{array}{r}0.15313 \\
126\end{array}$ & $\begin{array}{r}1.00000 \\
137\end{array}$ & $\begin{array}{r}0.34329 \\
137\end{array}$ & $\begin{array}{r}0.11497 \\
112\end{array}$ & $\begin{array}{r}0.15145 \\
137\end{array}$ & $\begin{array}{r}0.16925 \\
137\end{array}$ & $\begin{array}{r}0.02823 \\
137\end{array}$ \\
\hline FRACM & $\begin{array}{r}0.36151 \\
261\end{array}$ & $\begin{array}{r}-0.34922 \\
262\end{array}$ & $\begin{array}{r}0.38515 \\
234\end{array}$ & $\begin{array}{r}0.30086 \\
227\end{array}$ & $\begin{array}{r}0.34329 \\
137\end{array}$ & $\begin{array}{r}1.00000 \\
262\end{array}$ & $\begin{array}{r}-0.01585 \\
221\end{array}$ & $\begin{array}{r}-0.01618 \\
262\end{array}$ & $\begin{array}{r}0.08602 \\
262\end{array}$ & $\begin{array}{r}-0.02146 \\
262\end{array}$ \\
\hline MIP & $\begin{array}{r}0.43894 \\
221\end{array}$ & $\begin{array}{r}0.03254 \\
221\end{array}$ & $\begin{array}{r}0.19887 \\
200\end{array}$ & $\begin{array}{r}0.15078 \\
197\end{array}$ & $\begin{array}{r}0.11497 \\
122\end{array}$ & $\begin{array}{r}-0.01595 \\
221\end{array}$ & $\begin{array}{r}1.00000 \\
221\end{array}$ & $\begin{array}{r}0.13498 \\
221\end{array}$ & $\begin{array}{r}0.07107 \\
221\end{array}$ & $\begin{array}{r}0.06699 \\
221\end{array}$ \\
\hline LANEPOSM & $\begin{array}{r}0.05707 \\
261\end{array}$ & $\begin{array}{r}0.09849 \\
262\end{array}$ & $\begin{array}{r}0.12771 \\
234\end{array}$ & $\begin{array}{r}0.12291 \\
227\end{array}$ & $\begin{array}{r}0.15145 \\
137\end{array}$ & $\begin{array}{r}-0.01618 \\
262\end{array}$ & $\begin{array}{r}0.13498 \\
221\end{array}$ & $\begin{array}{r}1.00000 \\
262\end{array}$ & $\begin{array}{r}0.07990 \\
262\end{array}$ & $\begin{array}{r}0.43040 \\
262\end{array}$ \\
\hline LANEPVAR & $\begin{array}{r}0.19695 \\
261\end{array}$ & $\begin{array}{r}0.02378 \\
262\end{array}$ & $\begin{array}{r}0.16694 \\
234\end{array}$ & $\begin{array}{r}0.09505 \\
227\end{array}$ & $\begin{array}{r}16925 \\
137\end{array}$ & $\begin{array}{r}0.08602 \\
262\end{array}$ & $\begin{array}{r}0.07107 \\
221\end{array}$ & $\begin{array}{r}0.07990 \\
262\end{array}$ & $\begin{array}{r}1.00000 \\
262\end{array}$ & $\begin{array}{r}0.38718 \\
262\end{array}$ \\
\hline LANEXS & $\begin{array}{r}0.00157 \\
261\end{array}$ & $\begin{array}{r}0.07506 \\
262\end{array}$ & $\begin{array}{r}-0.03109 \\
234\end{array}$ & $\begin{array}{r}-0.00875 \\
227\end{array}$ & $\begin{array}{r}0.02823 \\
137\end{array}$ & $\begin{array}{r}-0.02146 \\
262\end{array}$ & $\begin{array}{r}0.06699 \\
221\end{array}$ & $\begin{array}{r}0.43040 \\
262\end{array}$ & $\begin{array}{r}0.38718 \\
262\end{array}$ & $\begin{array}{r}1.00000 \\
262\end{array}$ \\
\hline
\end{tabular}


Table 7.2.4 Correlations Among Lanekeeping and Steering, Accelerator, and Brake Measures During Car Following

Correlation Analysis

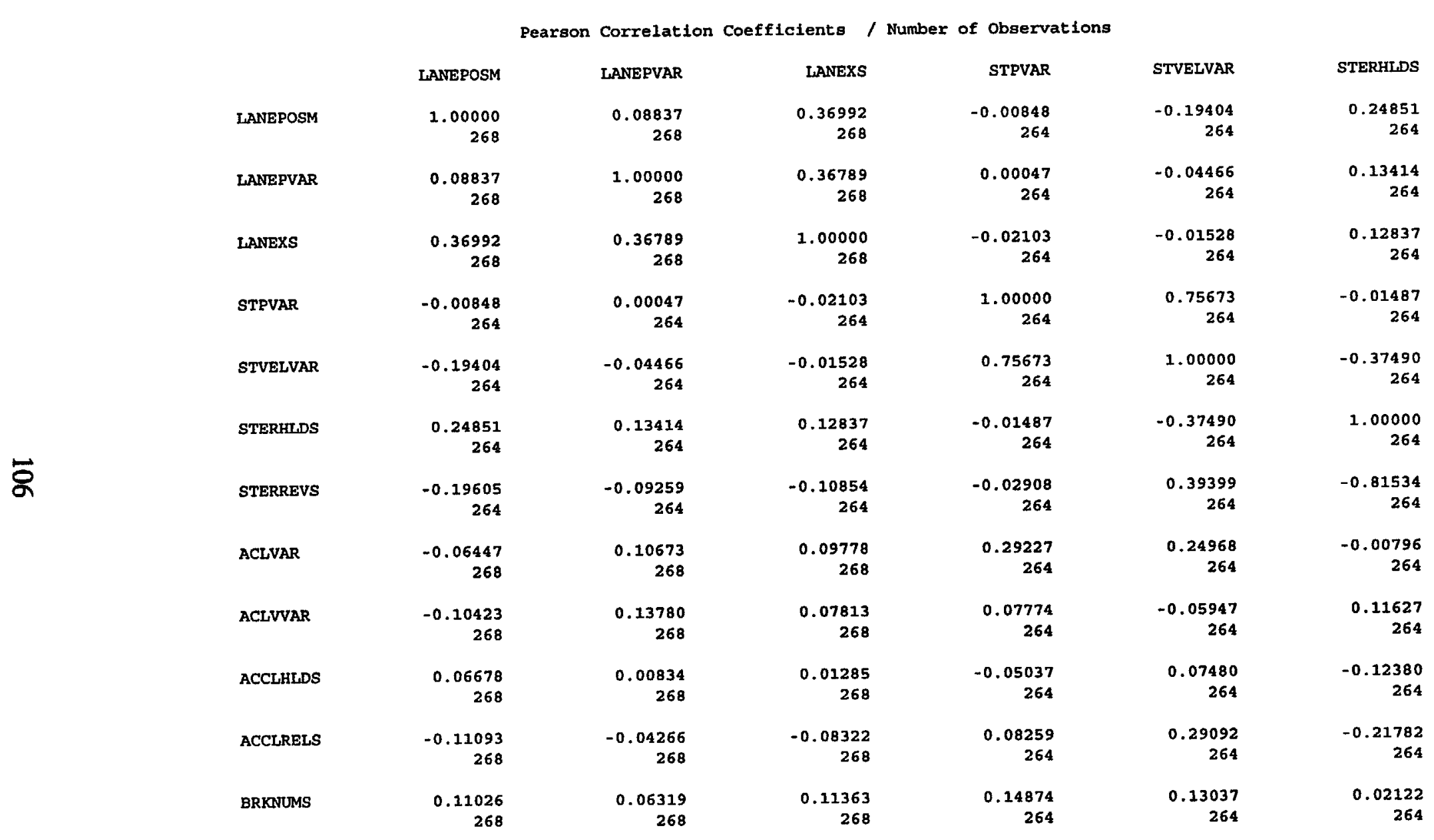




\section{Table 7.2.4 (Continued)}

Correlation Analysis

Pearson Correlation Coefflcients / Number of Observations

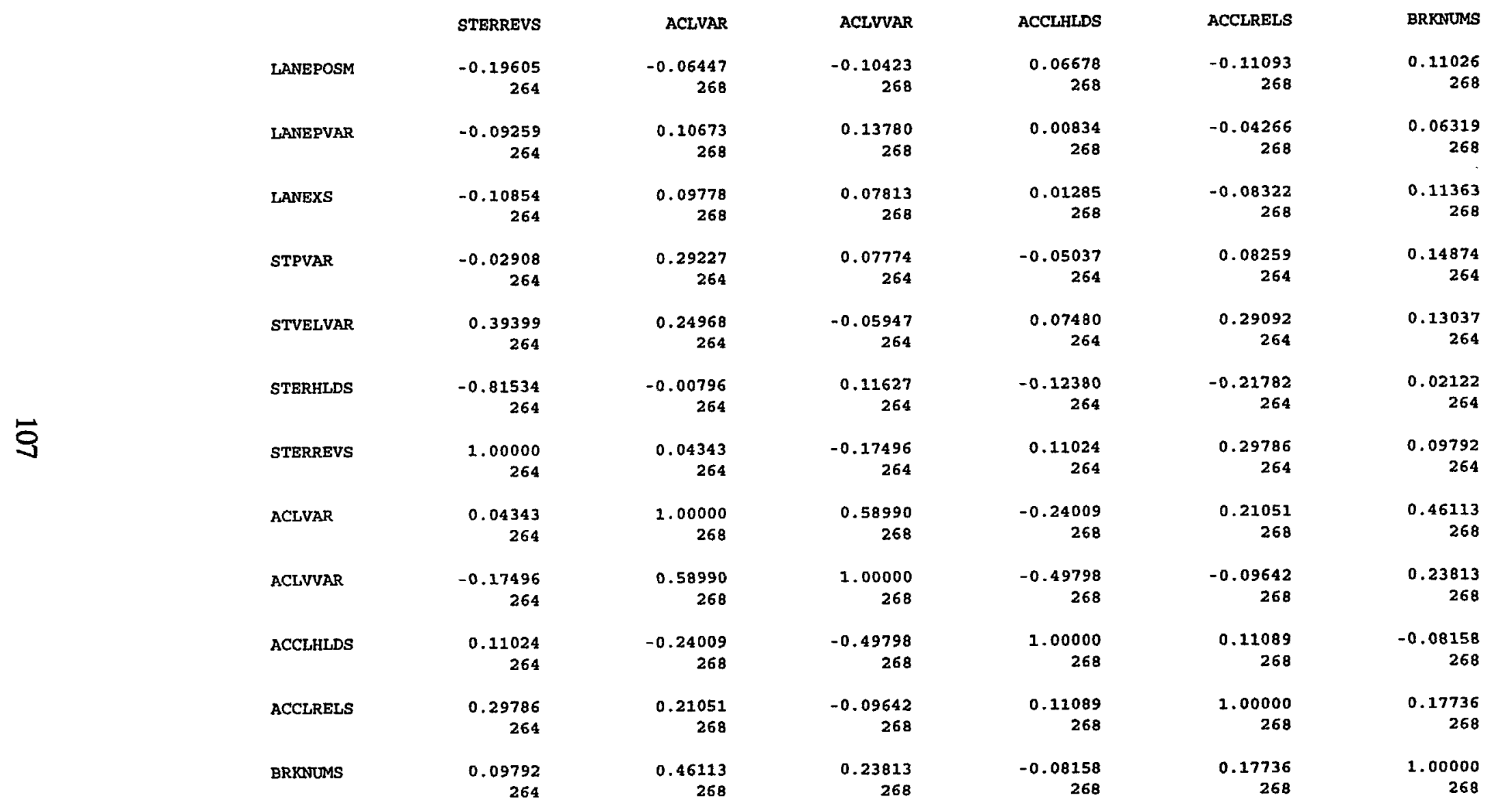




\section{Table 7.2.5 Correlations Among Pairs of Lanekeeping Measures, Speed Measures, and Headway Measures During Car Following}

Correlation Analysis 11 'VAR' Variables: LANEPOSM LANEPVAR LANEXS MEANSPED SPEEDVAR FOLDISTM FOLDISTV CLOSVMN VARCLOSV MHEADWAY

Pearson Correlation Coefficients / Number of Observations

LANEPOSM LANEPVAR LANEXS MEANSPED SPEEDVAR FOLDISTM FOLDISTV CLOSVMN VARCLOSV MHEADWAY VHEADWAY

\begin{tabular}{|c|c|c|c|c|c|c|c|c|c|c|c|}
\hline & LANEPOSM & LANEPVAR & LANEXS & MEANSPED & SPEEDVAR & FOLDISTM & FOLDISTV & CLOSVMN & VARCLOSV & MHEADWAY & VHEADWAY \\
\hline \multirow[t]{2}{*}{ LANEPOSM } & 1.00000 & 0.09947 & 0.42119 & -0.07457 & 0.01072 & 0.05245 & 0.06750 & .08132 & -0.06711 & 0.09307 & 0.09918 \\
\hline & 219 & 219 & 219 & 219 & 219 & 219 & 219 & 200 & 200 & 219 & 239 \\
\hline \multirow[t]{2}{*}{ LANEPVAR } & 0.09947 & 00000 & 0.38820 & -0.09484 & .11545 & 0.22317 & -0.07348 & .08028 & -0.03748 & -0.17203 & -0.05943 \\
\hline & 219 & 219 & 219 & 219 & 219 & 219 & 219 & 200 & 200 & 219 & 219 \\
\hline \multirow[t]{2}{*}{ LANEXS } & 42119 & 38820 & 00000 & -0.10414 & .07134 & 0.17847 & 0.03981 & .02303 & -0.03729 & -0.13116 & 0.01654 \\
\hline & 219 & 219 & 219 & 219 & 219 & 219 & 219 & 200 & 200 & 219 & 219 \\
\hline \multirow[t]{2}{*}{ MEANSPED } & .07457 & 1.09484 & .10414 & 1.00000 & .77481 & 4768 & 1634 & -0.09623 & -0.17900 & -0.25799 & $\begin{array}{r}-0.21299 \\
219\end{array}$ \\
\hline & 219 & 219 & 219 & 219 & 219 & 219 & 219 & 200 & 200 & 219 & 219 \\
\hline \multirow[t]{2}{*}{ SPEEDVAR } & 1072 & .1545 & 07134 & 7481 & 0000 & 6073 & 590 & 575 & 7987 & 6438 & 16674 \\
\hline & 219 & 219 & 219 & 219 & 219 & 219 & 219 & 200 & 200 & 219 & 219 \\
\hline \multirow[t]{2}{*}{ FOLDISTM } & 5245 & 22317 & 17847 & 4768 & 6073 & 000 & 812 & 7783 & 9159 & 15726 & 9596 \\
\hline & 219 & 219 & 219 & 219 & 219 & 219 & 219 & 200 & 200 & 219 & 219 \\
\hline \multirow[t]{2}{*}{ FOLDISTV } & 06750 & 07348 & .03981 & 1634 & 1590 & 812 & 0000 & -0.36774 & -0.09402 & 21742 & 95285 \\
\hline & 219 & 219 & 219 & 219 & 219 & 219 & 239 & 200 & 200 & 219 & 219 \\
\hline CLOSVMN & $\begin{array}{r}0.08132 \\
200\end{array}$ & $\begin{array}{r}0.08028 \\
200\end{array}$ & $\begin{array}{r}0.02303 \\
200\end{array}$ & $\begin{array}{r}-0.09623 \\
200\end{array}$ & $\begin{array}{r}18675 \\
200\end{array}$ & $\begin{array}{r}-0.17783 \\
200\end{array}$ & $\begin{array}{r}-0.36774 \\
200\end{array}$ & $\begin{array}{r}1.00000 \\
200\end{array}$ & $\begin{array}{r}0.02888 \\
200\end{array}$ & $\begin{array}{r}-0.13280 \\
200\end{array}$ & $\begin{array}{r}-0.33135 \\
200\end{array}$ \\
\hline \multirow[t]{2}{*}{ VARCLOSV } & -0.06711 & 0.03748 & -0.03729 & -0.17900 & 0.17987 & 0.09159 & -0.09402 & 0.02888 & 1.00000 & 0.14381 & -0.06304 \\
\hline & 200 & 200 & 200 & 200 & 200 & 200 & 200 & 200 & 200 & 200 & 200 \\
\hline \multirow[t]{2}{*}{ HEADWAY } & 0.09307 & -0.17203 & -0.13116 & -0.25799 & 6438 & 35726 & 0.21742 & -0.1 & 381 & 1.00000 & 0.31983 \\
\hline & 219 & 219 & 219 & 219 & 219 & 219 & 219 & 200 & 200 & 219 & 219 \\
\hline \multirow[t]{2}{*}{ IEADWAY } & 9918 & 5943 & .01654 & 1299 & 667 & 19596 & 5285 & -0 & -0.06304 & 83 & 000 \\
\hline & 219 & 219 & 219 & 219 & 219 & 219 & 219 & 200 & 200 & 219 & 219 \\
\hline
\end{tabular}


and headway measures during car following. Inspection of the data indicates that there are no substantial correlations across categories of dependent measures, though there are several correlations within categories that follow what one would expect given the kinematics involved. Table 7.2.6 presents the correlations between speed and headway measures and steering, accelerator and braking measures. The only substantial correlations are between steering position variance (STPVAR) and mean following distance (FOLDISTM). A negative correlation was found such that greater following distances were associated with lower steering position variation. This might be expected if the relative proximity of a lead vehicle prompted the heavy vehicle driver to steer more tightly, check for traffic ahead of the lead vehicle, or possibly change lanes. The other substantial correlation across measurement categories is a negative correlation between mean following distance and number of brake applications. This is reasonable if one considers that shorter following distances might require more brake applications. No other correlations appear noteworthy.

In summary, the car following scenario yielded a sometimes different pattern of correlations than did open road driving. This may reflect the driving scenario itself to a large extent. However, the relatively shorter intervals of time available to capture car following behavior and performance may also play a role in the generally lower degree of correlational structure found in this data set. Open road driving was measured for 60 to 90 seconds per observation. Car following, on the other hand, was often substantially less than that. The shorter time period for data analysis may have played in a role in reducing the range of variables, a result of which is smaller, insignificant correlations.

\subsection{Correlations: Requested Tasks}

The final correlational analysis carried out involved dependent measures taken during requested task execution. All requested tasks were executed in an open road driving situation, i.e., no tasks were requested during car following. With this in mind, the correlations will be presented.

Table 7.3.1 presents the visual allocation measures and steering, accelerator, and brake measures taken during requested task execution for the 7 tasks selected for analysis in this report. To begin, consider correlations among the five visual allocation variables: device single glance duration average (DGLNCAV), device glance number (DGLNCNUM) needed to complete a requested task, total glance duration to the device (DGLNCTOT), road scene single glance duration average (RGLNCAV), and total requested task duration (TOTDUR). The intercorrelations display several interesting results. First, there is no significant covariation between average device glance duration and number of glances to a device. This supports the interpretation that average glance duration represents the complexity of a single requested task component. On the other hand, the number of glances to complete a requested task represents the number of such components in which the requested task can be divided. Thus, the average glance duration represents component-specific visual demand, while the number of glances 
Table 7.2.6 Correlations Among Speed and Headway Measures and Steering, Accelerator and Steering Measures During Car Following

Correlation Analysis

Pearson Correlation Coefficients / Number of observations

\begin{tabular}{|c|c|c|c|c|c|c|c|c|c|}
\hline & STPVAR & STVELVAR & STERHLDS & STERREVS & ACLVAR & ACLVVAR & ACCLHLDS & ACCLRELS & BRKANUMS \\
\hline \multirow[t]{2}{*}{ STPVAR } & 1.00000 & 0.64739 & -0.26796 & 0.41563 & 0.25829 & 0.00870 & 0.07963 & 0.23610 & 0.37317 \\
\hline & 246 & 246 & 246 & 246 & 246 & 246 & 246 & 246 & 246 \\
\hline \multirow[t]{2}{*}{ STVELVAR } & 0.64739 & 1.00000 & -0.47224 & 0.61046 & 0.06829 & -0.13217 & 0.15232 & 0.30394 & 0.09910 \\
\hline & 246 & 246 & 246 & 246 & 246 & 246 & 246 & 246 & 246 \\
\hline \multirow[t]{2}{*}{ STERHLDS } & -0.26796 & -0.47224 & 1.00000 & -0.82171 & 0.00101 & 0.00155 & -0.08772 & -0.03623 & 0.00443 \\
\hline & 246 & 246 & 246 & 246 & 246 & 246 & 246 & 246 & 246 \\
\hline \multirow[t]{2}{*}{ STERREVS } & 0.41563 & 0.61046 & -0.82171 & 1.00000 & 0.05772 & -0.08346 & 0.08061 & 0.18576 & 0.11355 \\
\hline & 246 & 246 & 246 & 246 & 246 & 246 & 246 & 246 & 246 \\
\hline \multirow[t]{2}{*}{ ACLVAR } & 0.25829 & 0.06829 & 0.00101 & 0.05772 & 1.00000 & 0.59451 & -0.23624 & 0.16484 & 0.43295 \\
\hline & 246 & 246 & 246 & 246 & 246 & 246 & 246 & 246 & 246 \\
\hline \multirow[t]{2}{*}{ ACLVVAR } & 0.00870 & -0.13217 & 0.00155 & -0.08346 & 0.59451 & 1.00000 & -0.49450 & -0.11655 & 0.21844 \\
\hline & 246 & 246 & 246 & 246 & 246 & 246 & 246 & 246 & 246 \\
\hline \multirow[t]{2}{*}{ ACCLHLDS } & 0.07963 & 0.15232 & -0.08772 & 0.08061 & -0.23624 & -0.49450 & 1.00000 & 0.12810 & -0.08708 \\
\hline & 246 & 246 & 246 & 246 & 246 & 246 & 246 & 246 & 246 \\
\hline \multirow[t]{2}{*}{ ACCLRELS } & 0.23610 & 0.30394 & -0.03623 & 0.18576 & 0.16484 & -0.11655 & 0.12810 & 1.00000 & 0.28171 \\
\hline & 246 & 246 & 246 & 246 & 246 & 246 & 246 & 246 & 246 \\
\hline \multirow[t]{2}{*}{ BRKNOMS } & 0.37317 & 0.09910 & 0.00443 & 0.11355 & 0.43295 & 0.21844 & -0.08708 & 0.18171 & 1.00000 \\
\hline & 246 & 246 & 246 & 246 & 246 & 246 & 246 & 246 & 246 \\
\hline MEANSPED & -0.26018 & -0.11845 & 0.00651 & -0.14500 & -0.39590 & -0.08742 & 0.04209 & -0.12108 & -0.51246 \\
\hline \multirow{2}{*}{ SPEEDVAR } & & & & & & & 0399 & & 8000 \\
\hline & $\begin{array}{r}0.30161 \\
246\end{array}$ & $\begin{array}{r}0.06130 \\
246\end{array}$ & $\begin{array}{r}-0.01234 \\
246\end{array}$ & $\begin{array}{r}248 \\
246\end{array}$ & $\begin{array}{r}246 \\
\end{array}$ & $\begin{array}{r}246 \\
\end{array}$ & 246 & 246 & 246 \\
\hline \multirow[t]{2}{*}{ FOLDISTM } & -0.30364 & -0.20480 & 0.14349 & -0.19143 & -0.15168 & -0.00293 & 0.04962 & -0.07673 & -0.26773 \\
\hline & 246 & 246 & 246 & 246 & 246 & 246 & 246 & 246 & 246 \\
\hline \multirow[t]{2}{*}{ FOLDISTV } & -0.09358 & -0.08885 & 0.06035 & -0.07005 & -0.08486 & -0.04463 & 0.06523 & -0.08952 & -0.06799 \\
\hline & 246 & 246 & 246 & 246 & 246 & 246 & 246 & 246 & 246 \\
\hline \multirow[t]{2}{*}{ CLOSVMN } & -0.00774 & -0.19604 & 0.16635 & -0.19683 & 0.12872 & 0.07003 & -0.13734 & 0.13303 & 0.07491 \\
\hline & 217 & 217 & 217 & 217 & 217 & 217 & 217 & 217 & 217 \\
\hline \multirow[t]{2}{*}{ VARCLOSV } & 0.16274 & 0.10574 & -0.05493 & 0.05729 & 0.16383 & 0.11945 & 0.06660 & 0.11375 & 0.11990 \\
\hline & 217 & 217 & 217 & 217 & 217 & 217 & 217 & 217 & 217 \\
\hline \multirow[t]{2}{*}{ MHEADWAY } & -0.19481 & -0.16304 & 0.14660 & -0.11930 & 0.05061 & 0.03828 & 0.03579 & -0.02233 & 0.03034 \\
\hline & 246 & 246 & 246 & 246 & 246 & 246 & 246 & 246 & 246 \\
\hline \multirow[t]{2}{*}{ VHEADWAY } & -0.05100 & -0.06512 & 0.07222 & -0.05022 & 0.00727 & -0.04317 & 0.07003 & -0.06179 & 0.06756 \\
\hline & 246 & 246 & 246 & 246 & 246 & 246 & 246 & 246 & 246 \\
\hline
\end{tabular}


Table 7.2.6 (Continued)

Correlation Analysis

Pearson Correlation Coefficients / Number of Observations

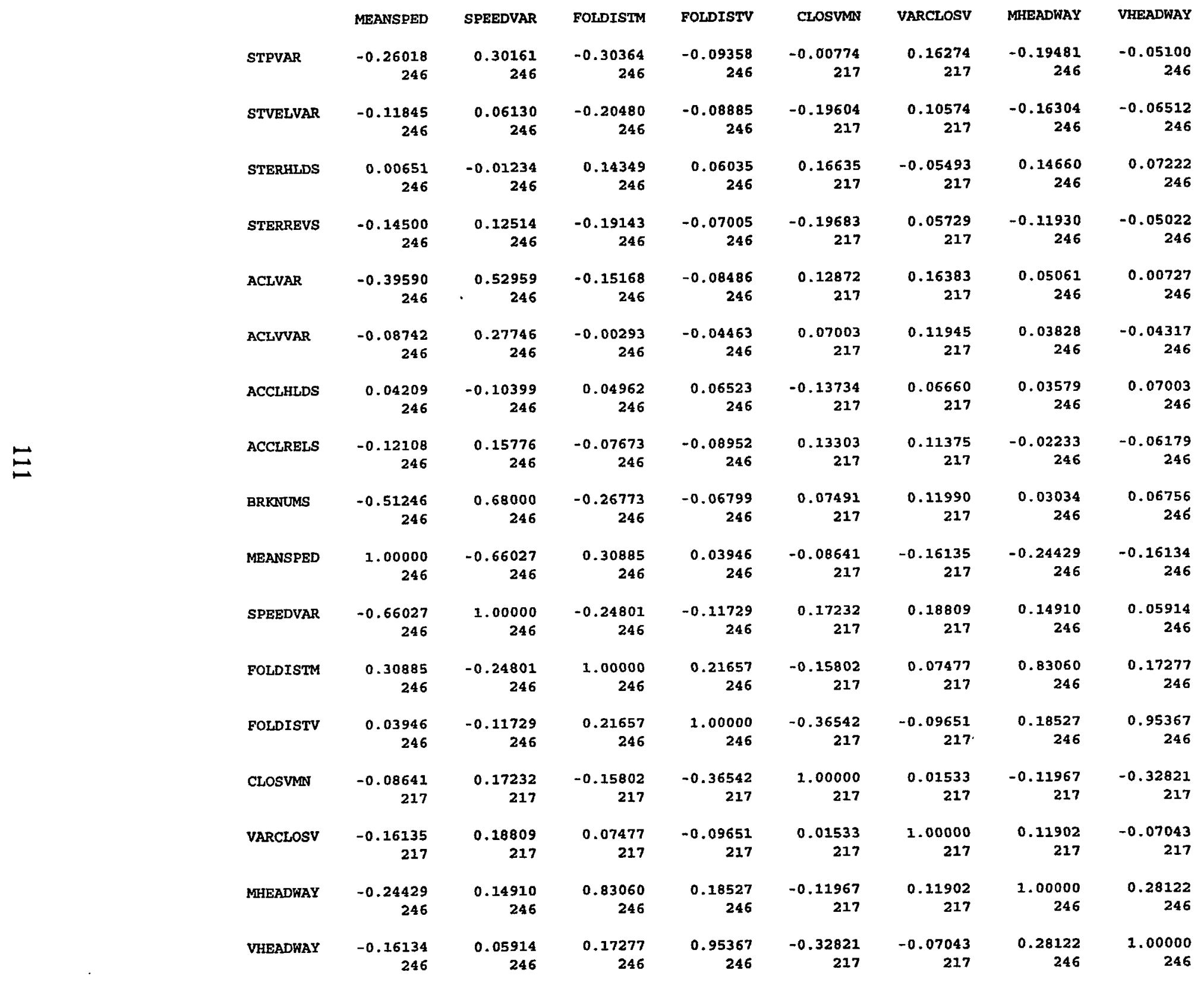


Table 7.3.1 Correlations Among the Visual Allocation Measures and Steering, Accelerator, and Brake Measures Taken During Requested Task Execution Correlation Analysis

Pearson Correlation Coefficients / Number of Observations

\begin{tabular}{|c|c|c|c|c|c|c|c|c|c|c|c|}
\hline & & DGLNCAV & DGLNCNUM & DGLNCTOT & RGLNCAV & TOTDUR & STPVAR & STVELVAR & STERHLD & STERHLDS & STERREV \\
\hline & DGLNCAV & 1.00000 & -0.06142 & 0.23535 & -0.35341 & -0.00101 & -0.00227 & -0.02219 & 0.03641 & 0.03371 & -0.04366 \\
\hline & & 1610 & 1610 & 1610 & 663 & 1582 & 1582 & 1582 & 1582 & 1582 & 1582 \\
\hline & DGLNCNUM & -0.06142 & 1.00000 & 0.91337 & -0.11970 & 0.93286 & 0.03712 & $\begin{array}{r}0.06471 \\
\end{array}$ & $\begin{array}{r}0.52380 \\
1582\end{array}$ & $\begin{array}{r}-0.05352 \\
1582\end{array}$ & $\begin{array}{r}0.84546 \\
1582\end{array}$ \\
\hline & DGLNCTOT & 0.23535 & 0.91337 & 1.00000 & -0.17475 & 0.88049 & 0.03149 & 0.04549 & 0.49805 & -0.03794 & 0.77807 \\
\hline & & 1610 & 1610 & 1610 & 663 & 1582 & 1582 & 1582 & 1582 & 1582 & 1582 \\
\hline & RGLNCAV & $\begin{array}{r}-0.35341 \\
663\end{array}$ & $\begin{array}{r}-0.11970 \\
663\end{array}$ & $\begin{array}{r}-0.17475 \\
663\end{array}$ & $\begin{array}{r}1.00000 \\
663\end{array}$ & $\begin{array}{r}0.10394 \\
655\end{array}$ & $\begin{array}{r}-0.01984 \\
655\end{array}$ & $\begin{array}{r}-0.03274 \\
655\end{array}$ & $\begin{array}{r}0.04533 \\
655\end{array}$ & $\begin{array}{r}-0.02613 \\
655\end{array}$ & $\begin{array}{r}0.10446 \\
655\end{array}$ \\
\hline & TOTDUR & $\begin{array}{r}-0.00101 \\
1582\end{array}$ & $\begin{array}{r}0.93286 \\
1582\end{array}$ & $\begin{array}{r}0.88049 \\
1582\end{array}$ & $\begin{array}{r}0.10394 \\
655\end{array}$ & $\begin{array}{r}1.00000 \\
1582\end{array}$ & $\begin{array}{r}0.04461 \\
1582\end{array}$ & $\begin{array}{r}0.06098 \\
1582\end{array}$ & $\begin{array}{r}0.54130 \\
1582\end{array}$ & $\begin{array}{r}-0.05782 \\
1582\end{array}$ & $\begin{array}{r}0.91339 \\
1582\end{array}$ \\
\hline & STPVAR & $\begin{array}{r}-0.00227 \\
1582\end{array}$ & $\begin{array}{r}0.03712 \\
1582\end{array}$ & $\begin{array}{r}0.03149 \\
1582\end{array}$ & $\begin{array}{r}-0.01984 \\
655\end{array}$ & $\begin{array}{r}0.04461 \\
1582\end{array}$ & $\begin{array}{r}1.00000 \\
1582\end{array}$ & $\begin{array}{r}0.95820 \\
1582\end{array}$ & $\begin{array}{r}0.05500 \\
1582\end{array}$ & $\begin{array}{r}0.02794 \\
1582\end{array}$ & $\begin{array}{r}0.03640 \\
1582\end{array}$ \\
\hline & STVELVAR & $\begin{array}{r}-0.02219 \\
1582\end{array}$ & $\begin{array}{r}0.06471 \\
1582\end{array}$ & $\begin{array}{r}0.04549 \\
1582\end{array}$ & $\begin{array}{r}-0.03274 \\
655\end{array}$ & $\begin{array}{r}0.06098 \\
1582\end{array}$ & $\begin{array}{r}0.95820 \\
1582\end{array}$ & $\begin{array}{r}1.00000 \\
1582\end{array}$ & $\begin{array}{r}-0.00155 \\
1582\end{array}$ & $\begin{array}{r}-0.05374 \\
1582\end{array}$ & $\begin{array}{r}0.08530 \\
1582\end{array}$ \\
\hline & STERHLD & $\begin{array}{r}0.03641 \\
1582\end{array}$ & $\begin{array}{r}0.52380 \\
1582\end{array}$ & $\begin{array}{r}0.49805 \\
1582\end{array}$ & $\begin{array}{r}0.04533 \\
655\end{array}$ & $\begin{array}{r}0.54130 \\
1582\end{array}$ & $\begin{array}{r}0.05500 \\
1582\end{array}$ & $\begin{array}{r}-0.00155 \\
1582\end{array}$ & $\begin{array}{r}1.00000 \\
1582\end{array}$ & $\begin{array}{r}0.50539 \\
1582\end{array}$ & $\begin{array}{r}0.26719 \\
1582\end{array}$ \\
\hline 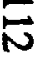 & STERHLDS & $\begin{array}{r}0.03371 \\
1582\end{array}$ & $\begin{array}{r}-0.05352 \\
1582\end{array}$ & $\begin{array}{r}-0.03794 \\
1582\end{array}$ & $\begin{array}{r}-0.02613 \\
655\end{array}$ & $\begin{array}{r}-0.05782 \\
1582\end{array}$ & $\begin{array}{r}0.02794 \\
1582\end{array}$ & $\begin{array}{r}-0.05374 \\
1582\end{array}$ & $\begin{array}{r}0.50539 \\
1582\end{array}$ & $\begin{array}{r}1.00000 \\
1582\end{array}$ & $\begin{array}{r}-0.19550 \\
1582\end{array}$ \\
\hline & STERREV & -0.04366 & 0.84546 & 0.77807 & 0.10446 & 0.91339 & 0.03640 & 0.08530 & 0.26719 & -0.19550 & 1.00000 \\
\hline & & 1582 & 1582 & 1582 & 655 & 1582 & 1582 & 1582 & 1582 & 1582 & 1582 \\
\hline & & $\begin{array}{r}-0.00509 \\
1582\end{array}$ & $\begin{array}{r}1582 \\
1581\end{array}$ & $\begin{array}{r}1582 \\
\end{array}$ & $\begin{array}{r}.05501 \\
655\end{array}$ & $\begin{array}{r}10894 \\
1582\end{array}$ & $\begin{array}{r}-0.00342 \\
1582\end{array}$ & $\begin{array}{r}0.08706 \\
1582\end{array}$ & $\begin{array}{r}-0.22729 \\
1582\end{array}$ & $\begin{array}{r}-0.44079 \\
1582\end{array}$ & $\begin{array}{r}0.34822 \\
1582\end{array}$ \\
\hline & ACLVAR & 0.04913 & 0.12274 & 0.13110 & 0.09330 & 0.16259 & 0.19286 & 0.17492 & 0.14760 & 0.01803 & 0.12159 \\
\hline & & 1610 & 1610 & 1610 & 663 & 1582 & 1582 & 1582 & 1582 & 1582 & 1582 \\
\hline & ACLVVAR & 0.08317 & -0.00196 & 0.03005 & 0.01113 & 0.01300 & 0.09560 & 0.07299 & 0.03844 & 0.01976 & -0.00753 \\
\hline & & 1610 & 1610 & $\begin{array}{r}1610 \\
\end{array}$ & 663 & 1582 & $\begin{array}{r}.00649 \\
1582\end{array}$ & $\begin{array}{r}0.01921 \\
1582\end{array}$ & $\begin{array}{r}0.08629 \\
1582\end{array}$ & $\begin{array}{r}-0.03302 \\
1582\end{array}$ & $\begin{array}{r}0.29825 \\
2582\end{array}$ \\
\hline & ACCLHLDS & -0.08899 & -0.24282 & -0.23526 & -0.07562 & -0.26122 & -0.03835 & -0.02901 & -0.18826 & 0.02585 & -0.20777 \\
\hline & & 1610 & 1610 & 1610 & 663 & 1582 & 1582 & 1582 & 1582 & 1582 & 1582 \\
\hline & ACCLREL & $\begin{array}{r}-0.01472 \\
1610\end{array}$ & $\begin{array}{r}0.00735 \\
1610\end{array}$ & $\begin{array}{r}-0.00027 \\
1610\end{array}$ & $\begin{array}{r}0.02746 \\
663\end{array}$ & $\begin{array}{r}-0.00309 \\
1582\end{array}$ & $\begin{array}{r}0.00306 \\
1582\end{array}$ & $\begin{array}{r}0.00737 \\
1582\end{array}$ & $\begin{array}{r}-0.01330 \\
1582\end{array}$ & $\begin{array}{r}-0.01958 \\
1582\end{array}$ & $\begin{array}{r}0.00569 \\
1582\end{array}$ \\
\hline & ACCLRELS & $\begin{array}{r}-0.04878 \\
1610\end{array}$ & $\begin{array}{r}-0.02136 \\
1610\end{array}$ & $\begin{array}{r}-0.03505 \\
1610\end{array}$ & $\begin{array}{r}0.05309 \\
663\end{array}$ & $\begin{array}{r}-0.02756 \\
1582\end{array}$ & $\begin{array}{r}-0.00005 \\
1582\end{array}$ & $\begin{array}{r}0.00162 \\
1582\end{array}$ & $\begin{array}{r}-0.03575 \\
1582\end{array}$ & $\begin{array}{r}-0.02187 \\
1582\end{array}$ & $\begin{array}{r}-0.01078 \\
1582\end{array}$ \\
\hline & BRKNUM & $\begin{array}{r}-0.02945 \\
1610\end{array}$ & $\begin{array}{r}0.06742 \\
1610\end{array}$ & $\begin{array}{r}0.03551 \\
1610\end{array}$ & $\begin{array}{r}0.14985 \\
663\end{array}$ & $\begin{array}{r}0.10514 \\
1582\end{array}$ & $\begin{array}{r}0.16905 \\
1582\end{array}$ & $\begin{array}{r}0.15899 \\
1582\end{array}$ & $\begin{array}{r}0.04740 \\
1582\end{array}$ & $\begin{array}{r}-0.01303 \\
1582\end{array}$ & $\begin{array}{r}0.11609 \\
1582\end{array}$ \\
\hline & BRKNUMS & -0.01218 & -0.00737 & -0.01229 & 0.05863 & -0.00155 & 0.15256 & 0.14332 & 0.00341 & 0.00084 & 0.00165 \\
\hline & & 1610 & 1610 & 1610 & 663 & 1582 & 1582 & 1582 & 1582 & 1582 & 1582 \\
\hline
\end{tabular}


Table 7.3.1 (Continued)

Correlation Analysis

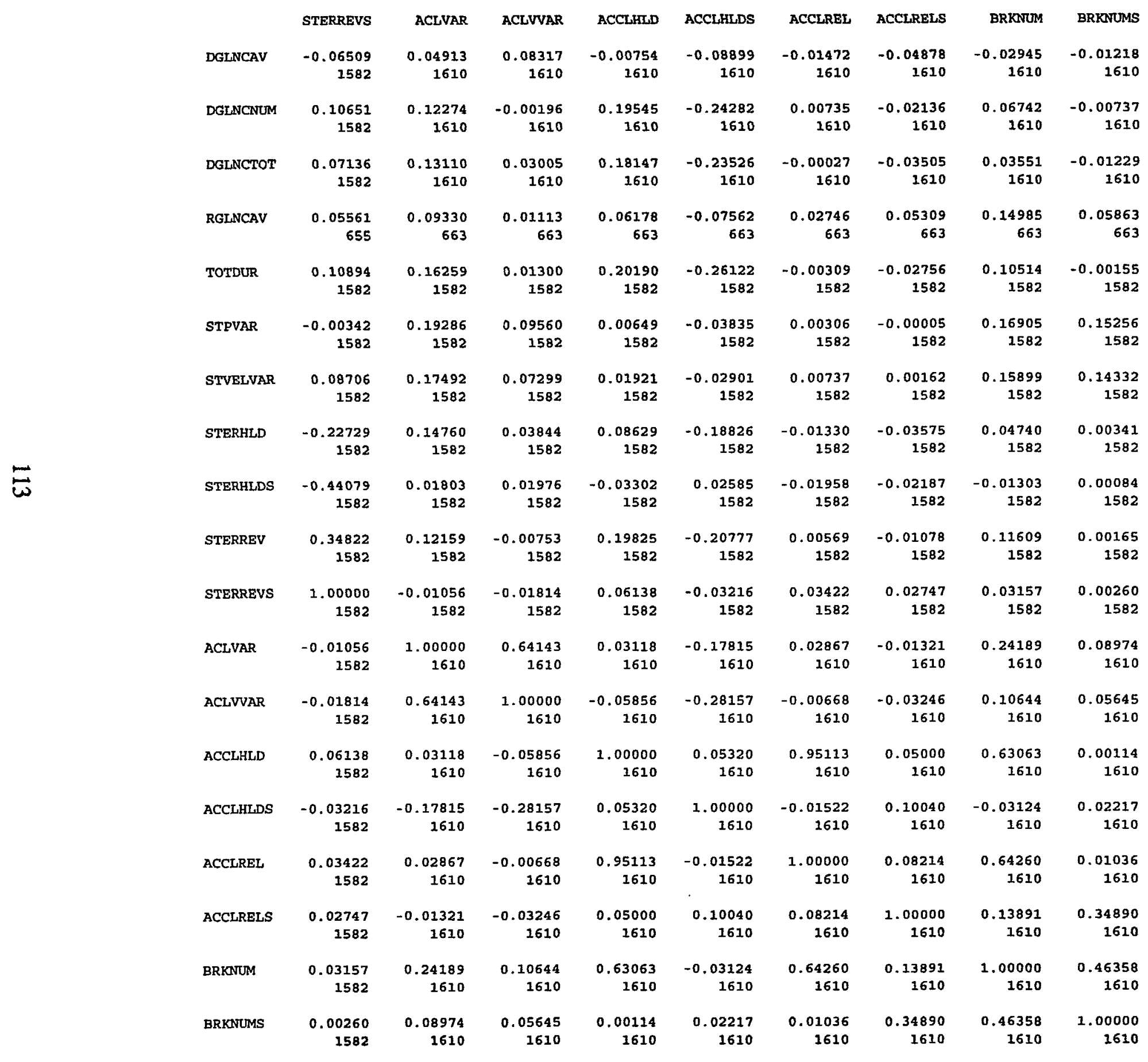


represents the overall task complexity and its divisibility. Second, note that there is a moderate negative correlation between average device glance duration and the average duration of glances back to the road scene. The negative correlation implies that longer device glance durations tend to be associated with shorter glances back to the road scene during task execution. If the hypothesis is true that task component complexity shortens glance time back to the road scene (to, for example, reduce memory burden), this is the pattern that would be expected. Third, notice the high correlations between both total device glance time and total task duration as related to number of glances to a device. This is the result of the fact that, to a first approximation, total device glance duration is average single-glance duration times the number of glances to complete a requested task.

The correlations among visual allocation measures and steering, accelerator, and brake measures are considered next. First note that there is generally a high correlation between variability measures like speed variance and total task duration. However, there are also several substantial correlations between visual allocation and steering measures. Notable among them are the high positive correlation between number of glances and number of steering holds (STERHLD). Similar high positive correlations hold between steering reversals and number of glances to device to complete a requested task and between the two steering measures just mentioned and total device glance duration. Dingus, Antin, Hulse, and Wierwille (1986) found similar high correlations associated with longer task completion times. They note that the relationship between steering and task time is probably the consequence of the relatively longer amount of time needed for a vehicle to drift off track on a straightaway.

In general, accelerator or brake measures covary less with visual allocation measures. Accelerator holds (ACCLHLD) are positively correlated with number of glance and total glance duration to a device, another indication that total requested task demand may be related to driver control inputs. On the other hand, there are negative correlations between these two visual allocation measures and accelerator holds per second (ACCLHLDS). This dissociation between hold counts and hold rates reflects the interplay between the hold incidence and hold duration within a small sample interval of time. Given the safety relevance of unplanned lane exceedences, the exceedence count would appear to be the more useful measure of task

demand. Correlations among steering measures collected during requested task execution are high for steering position variance and steering velocity variance and moderate between steering holds and steering reversals. This last positive correlation is contrary to expectation because more steering holds should be correlated to fewer reversals. The positive correlation may reflect the effects of longer task durations increasing the opportunity to see both types of steering behavior. Correlations involving accelerator or brake measures are generally low. Notable exceptions involve accelerator hold rates, but because of the difficulty of interpretation, these will not be discussed further.

Table 7.3.2 presents correlations among visual allocation and speed measures during requested task execution. There is a very high positive correlation between speed variance and total duration of a requested task. However, previously reported analyses indicate that 


\section{Table 7.3.2 Correlations Among Visual Allocation and Speed Measures During. Requested Task Execution}

Correlation Analysis

7 'VAR' Variables: DGLNCAV DGLNCNUM DGLNCTOT RGLNCAV TOTDUR MEANSPED SPEEDVAR

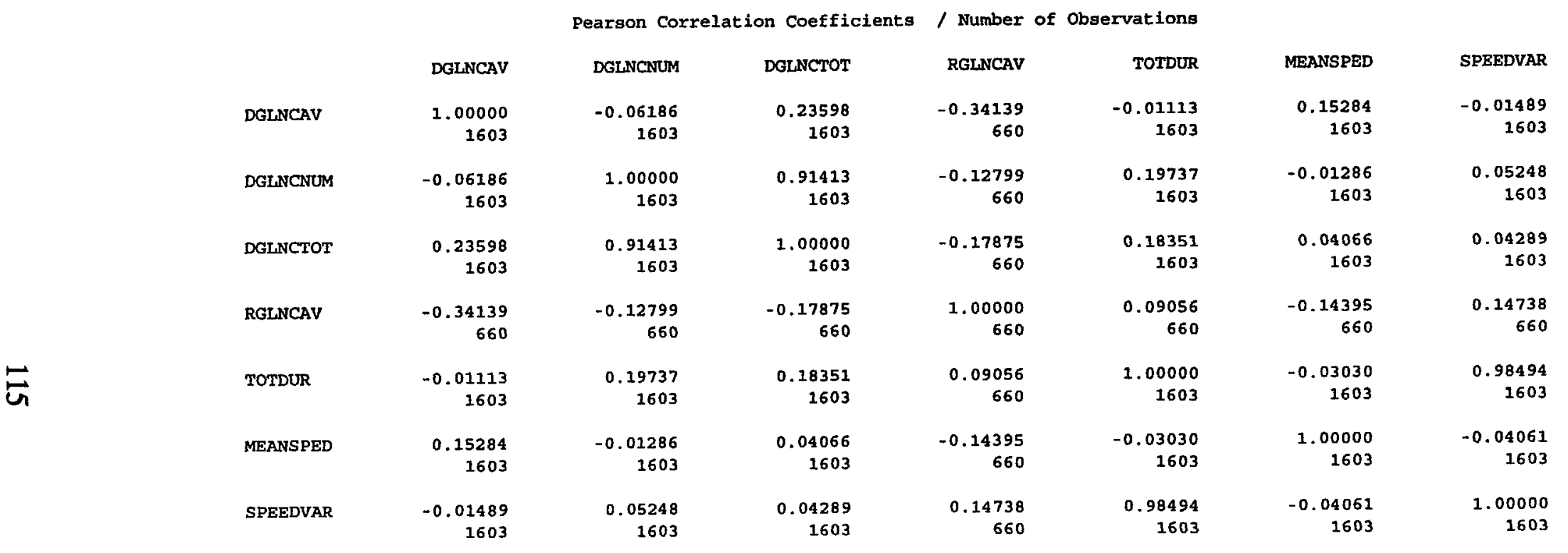


the effects of requested task execution on speed variance are small. Otherwise, no significant correlations beyond those already discussed are present.

Table 7.3.3 presents the correlations among visual allocation measures and lanekeeping measures during requested task execution. Substantial correlations exist between device glance number and lane position variance and lane exceedence count. There are also substantial correlations between total glance duration to the device and lane position variance and lane exceedence count. These are taken to provide some covalidation of the measures as indicators of driver workload (Dingus, Antin, Hulse, and Wierwille, 1986).

Table 7.3.4 presents the correlations among steering, accelerator, and brake measures and speed measures during requested task execution. Only correlations across the two categories of measures will be considered since comments have previously been made about correlations within a measurement category. There are moderate negative correlations between STPVAR and mean speed and also between STVELVAR and mean speed. This is taken to indicate greater steering activity at lower travel speeds, a pattern that might reflect curve negotiation effects. There were high positive correlations between speed variance and accelerator holds and accelerator releases. This may reflect the kinematic effects of speed control over road surfaces that varied somewhat in grade and also the gradual slowing of the heavy vehicle during an accelerator hold or release. Finally, there was a substantial positive correlation between brake applications and speed variance, a relationship that is self-evident.

Table 7.3.5 presents the correlations among lanekeeping measures and speed measure taken during requested task execution. As indicated in the table, there are substantial negative correlations between mean speed and lane exceedence counts and rates as well as a substantial positive correlation between lane exceedence counts and speed variance. These correlations are interpreted to reflect the effects of primarily 2-lane rural road driving. This road type was associated with greater numbers (and rates) of lane exceedences along slower mean travel speeds and greater speed variability.

Table 7.3.6 presents the final table of correlations between lanekeeping measures and steering, accelerator, and brake measures. There are several substantial correlations that are generally consistent with previously discussed results. For example, steering holds are substantially positively correlated with lane position variance and steering reversals are positively correlated with lane position variance and lane exceedence counts. Accelerator holds are positively correlated with lane exceedence counts, as are accelerator releases and number of brake applications. While such data should be interpreted with caution, these patterns suggest that lane exceedences tend to occur while other indicators of driver distraction are also present, indicators like accelerator holds and releases. 
Table 7.3.3 Correlations Among Visual Allocation Measures and Lanekeeping Measures During Requested Task Execution

Correlation Analysis

9 'VAR' Variables: DGLNCAV DGLNCNUM DGLWCTOT RGLNCAV TOTDUR LANEPOSM LANEPVAR LANEXC LANEXS

Pearson Correlation Coefficients / Number of observations

\begin{tabular}{|c|c|c|c|c|c|c|c|c|c|}
\hline & DGLNCAV & DGLNCNUM & DGLNCTOT & RGLNCAV & TOTDUR & LANEPOSM & LANEPVAR & LANEXC & LANEXS \\
\hline DGLNCAV & $\begin{array}{r}1.00000 \\
1421\end{array}$ & $\begin{array}{r}-0.05937 \\
1421\end{array}$ & $\begin{array}{r}0.23421 \\
1421\end{array}$ & $\begin{array}{r}-0.34715 \\
588\end{array}$ & $\begin{array}{r}-0.01282 \\
1421\end{array}$ & $\begin{array}{r}0.00201 \\
1421\end{array}$ & $\begin{array}{r}0.00616 \\
1421\end{array}$ & $\begin{array}{r}-0.07469 \\
1421\end{array}$ & $\begin{array}{r}-0.10307 \\
1421\end{array}$ \\
\hline DGLNCNUM & $\begin{array}{r}-0.05937 \\
1421\end{array}$ & $\begin{array}{r}1.00000 \\
1421\end{array}$ & $\begin{array}{r}0.91512 \\
1421\end{array}$ & $\begin{array}{r}-0.12117 \\
588\end{array}$ & $\begin{array}{r}0.19165 \\
1421\end{array}$ & $\begin{array}{r}-0.03363 \\
1421\end{array}$ & $\begin{array}{r}0.36349 \\
1421\end{array}$ & $\begin{array}{r}0.22651 \\
1421\end{array}$ & $\begin{array}{r}-0.11820 \\
1421\end{array}$ \\
\hline DGLNCTOT & $\begin{array}{r}0.23421 \\
1421\end{array}$ & $\begin{array}{r}0.91512 \\
1421\end{array}$ & $\begin{array}{r}1.00000 \\
1421\end{array}$ & $\begin{array}{r}-0.17482 \\
588\end{array}$ & $\begin{array}{r}0.17555 \\
1421\end{array}$ & $\begin{array}{r}-0.03868 \\
1421\end{array}$ & $\begin{array}{r}0.35375 \\
1421\end{array}$ & $\begin{array}{r}0.17921 \\
1421\end{array}$ & $\begin{array}{r}-0.12962 \\
1421\end{array}$ \\
\hline RGL.NCAV & $\begin{array}{r}-0.34715 \\
588\end{array}$ & $\begin{array}{r}-0.12117 \\
588\end{array}$ & $\begin{array}{r}-0.17482 \\
588\end{array}$ & $\begin{array}{r}1.00000 \\
588\end{array}$ & $\begin{array}{r}0.08392 \\
588\end{array}$ & $\begin{array}{r}0.06184 \\
588\end{array}$ & $\begin{array}{r}-0.01596 \\
588\end{array}$ & $\begin{array}{r}0.08961 \\
588\end{array}$ & $\begin{array}{r}0.01075 \\
588\end{array}$ \\
\hline TOTDUR & $\begin{array}{r}-0.01282 \\
1421\end{array}$ & $\begin{array}{r}0.19165 \\
1421\end{array}$ & $\begin{array}{r}0.17555 \\
1421\end{array}$ & $\begin{array}{r}0.08392 \\
588\end{array}$ & $\begin{array}{r}1.00000 \\
1421\end{array}$ & $\begin{array}{r}-0.03765 \\
1421\end{array}$ & $\begin{array}{r}0.12834 \\
1421\end{array}$ & $\begin{array}{r}0.36105 \\
1421\end{array}$ & $\begin{array}{r}-0.03708 \\
1421\end{array}$ \\
\hline LANEPOSM & $\begin{array}{r}0.00201 \\
1421\end{array}$ & $\begin{array}{r}-0.03363 \\
1421\end{array}$ & $\begin{array}{r}-0.03868 \\
1421\end{array}$ & $\begin{array}{r}0.06184 \\
588\end{array}$ & $\begin{array}{r}-0.03765 \\
1421\end{array}$ & $\begin{array}{r}1.00000 \\
1421\end{array}$ & $\begin{array}{r}-0.00903 \\
1421\end{array}$ & $\begin{array}{r}0.16558 \\
1421\end{array}$ & $\begin{array}{r}0.24241 \\
1421\end{array}$ \\
\hline LANEPVAR & $\begin{array}{r}0.00616 \\
1421\end{array}$ & $\begin{array}{r}0.36349 \\
1421\end{array}$ & $\begin{array}{r}0.35375 \\
1421\end{array}$ & $\begin{array}{r}-0.01596 \\
588\end{array}$ & $\begin{array}{r}0.12834 \\
1421\end{array}$ & $\begin{array}{r}-0.00903 \\
1421\end{array}$ & $\begin{array}{r}1.00000 \\
1421\end{array}$ & $\begin{array}{r}0.26705 \\
1421\end{array}$ & $\begin{array}{r}-0.03595 \\
1421\end{array}$ \\
\hline LANEXC & $\begin{array}{r}-0.07469 \\
1421\end{array}$ & $\begin{array}{r}0.22651 \\
1421\end{array}$ & $\begin{array}{r}0.17921 \\
1421\end{array}$ & $\begin{array}{r}0.08961 \\
588\end{array}$ & $\begin{array}{r}0.36105 \\
1421\end{array}$ & $\begin{array}{r}0.16558 \\
1421\end{array}$ & $\begin{array}{r}0.26705 \\
1421\end{array}$ & $\begin{array}{r}1.00000 \\
1421\end{array}$ & $\begin{array}{r}0.61221 \\
1421\end{array}$ \\
\hline LANEXS & $\begin{array}{r}-0.10307 \\
1421\end{array}$ & $\begin{array}{r}-0.11820 \\
1421\end{array}$ & $\begin{array}{r}-0.12962 \\
1421\end{array}$ & $\begin{array}{r}0.01075 \\
588\end{array}$ & $\begin{array}{r}-0.03708 \\
1421\end{array}$ & $\begin{array}{r}0.24241 \\
1421\end{array}$ & $\begin{array}{r}-0.03595 \\
1421\end{array}$ & $\begin{array}{r}0.61221 \\
1421\end{array}$ & $\begin{array}{r}1.00000 \\
1421\end{array}$ \\
\hline
\end{tabular}




\section{Table 7.3.4 Correlations Among Steering, Accelerator, and Brake Measures and Speed Measures During Requested}

Task Execution

Correlation Analysis

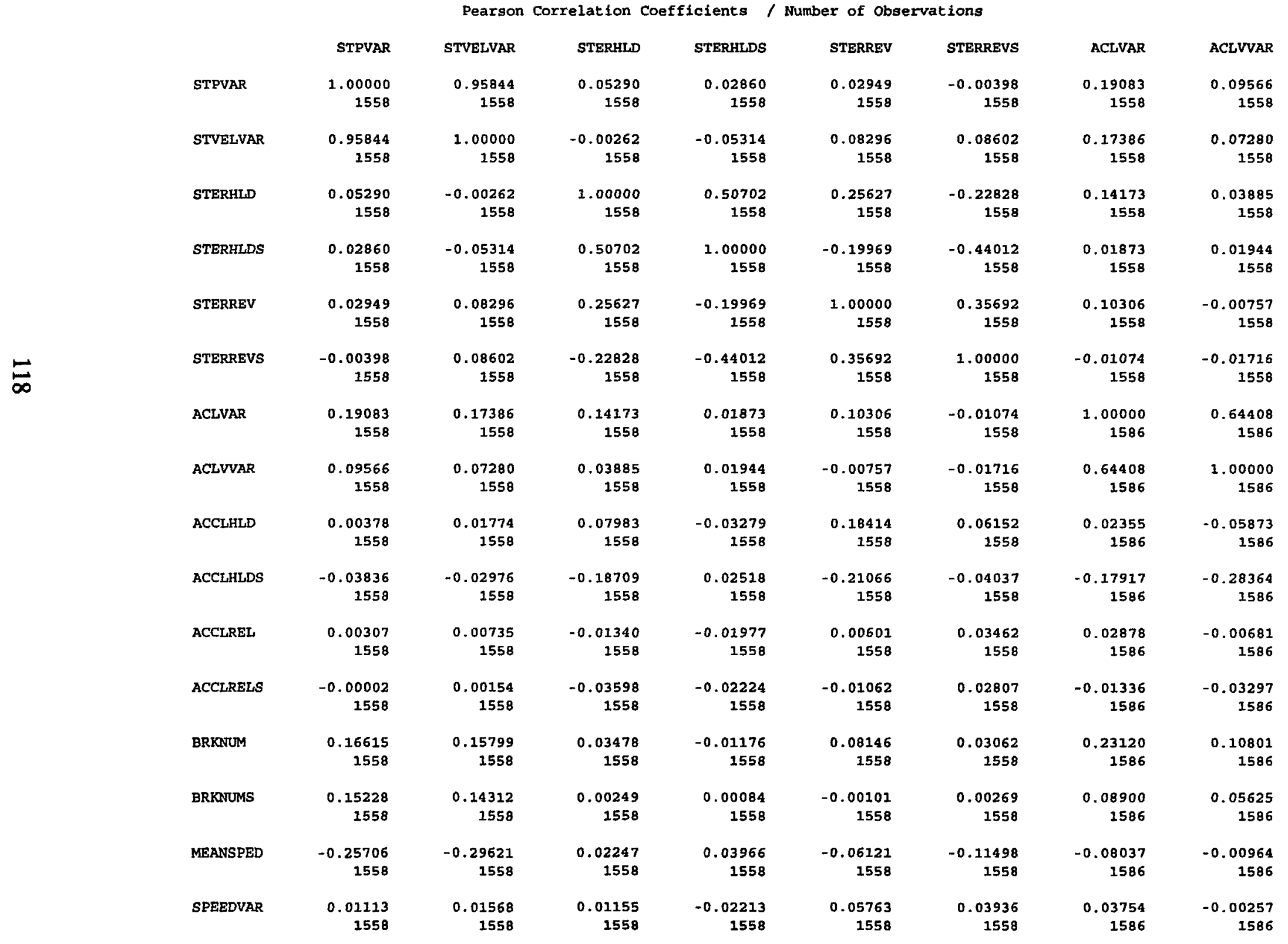




\section{Table 7.3.4 (Continued)}

Correlation Analysis

Pearson Correlation Coefficients / Number of Observations

\begin{tabular}{|c|c|c|c|c|c|c|c|c|}
\hline \multirow{3}{*}{ STPVAR } & ACCLHLD & -ACCLHLDS & ACCLREL & ACCLRELS & BRKNUM & BRKNUMS & MEANSPED & SPEEDVAR \\
\hline & 0.00378 & -0.03836 & 0.00307 & -0.00002 & 0.16615 & 0.15228 & -0.25706 & 0.01113 \\
\hline & 1558 & 1558 & 1558 & 1558 & 1558 & 1558 & 1558 & 1558 \\
\hline STVELVAR & 0.01774 & -0.02976 & 0.00735 & 0.00154 & 0.15799 & 0.14312 & -0.29621 & 0.01568 \\
\hline & 1558 & 1558 & 1558 & 1558 & 1558 & 1558 & 1558 & 1558 \\
\hline STERHLD & 0.07983 & -0.18709 & -0.01340 & -0.03598 & 0.03478 & 0.00249 & 0.02247 & 0.01155 \\
\hline & 1558 & 1558 & 1558 & 1558 & 1558 & 1558 & 1558 & 1558 \\
\hline STERHLDS & -0.03279 & 0.02518 & -0.01977 & -0.02224 & -0.01176 & 0.00084 & 0.03966 & -0.02213 \\
\hline & 1558 & 1558 & 1558 & 1558 & 1558 & 1558 & 1558 & 1558 \\
\hline STERREV & 0.18414 & -0.21066 & 0.00601 & -0.01062 & 0.08146 & -0.00101 & -0.06121 & 0.05763 \\
\hline & 1558 & 1558 & 1558 & 1558 & 1558 & 2558 & 1558 & 1558 \\
\hline STERREVS & 0.06152 & -0.04037 & 0.03462 & 0.02807 & 0.03062 & 0.00269 & -0.11498 & 0.03936 \\
\hline & 1558 & 1558 & 1558 & 1558 & 1558 & 1558 & 1558 & 1558 \\
\hline ACLVAR & 0.02355 & -0.17917 & 0.02878 & -0.01336 & 0.23320 & 0.08900 & -0.08037 & 0.03754 \\
\hline$\Rightarrow$ & 1586 & 1586 & 1586 & 1586 & 1586 & 1586 & 1586 & 1586 \\
\hline ACLVVAR & -0.05873 & -0.28364 & -0.00681 & -0.03297 & 0.10801 & 0.05625 & -0.00964 & -0.00257 \\
\hline & 1586 & 1586 & 1586 & 1586 & 1586 & 1586 & 1586 & 1586 \\
\hline ACCLHLD & 1.00000 & 0.05436 & 0.95479 & 0.05038 & 0.62752 & 0.00023 & -0.03732 & 0.96277 \\
\hline & 1586 & 1586 & 1586 & 1586 & 1586 & 1586 & 1586 & 1586 \\
\hline ACCLHLDS & 0.05436 & 1.00000 & -0.01525 & 0.10215 & -0.03030 & 0.02284 & -0.07631 & -0.02528 \\
\hline & 1586 & 1586 & 1586 & 1586 & 1586 & 1586 & 1586 & 1586 \\
\hline ACCLREL & 0.95479 & -0.01525 & 1.00000 & 0.08209 & 0.65097 & 0.01034 & -0.03086 & 0.99455 \\
\hline & 1586 & 1586 & 1586 & 1586 & 1586 & 1586 & 1586 & 1586 \\
\hline ACCLRELS & 0.05038 & 0.10215 & 0.08209 & 1.00000 & 0.14105 & 0.34889 & -0.05662 & 0.05214 \\
\hline & 1586 & 1586 & 1586 & 1586 & 1586 & 1586 & 1586 & 1586 \\
\hline BRKNUUM & 0.62752 & -0.03030 & 0.65097 & 0.14105 & 1.00000 & 0.46783 & -0.12001 & 0.66515 \\
\hline & 1586 & 1586 & 1586 & 1586 & 1586 & 1586 & 1586 & 1586 \\
\hline BRKNUMS & 0.00023 & 0.02284 & 0.01034 & 0.34889 & 0.46783 & 1.00000 & -0.09237 & 0.00520 \\
\hline & 1586 & 1586 & 1586 & 1586 & 1586 & 1586 & 1586 & 2586 \\
\hline MEANSPED & -0.03732 & -0.07631 & -0.03086 & -0.05662 & -0.12001 & -0.09237 & 1.00000 & -0.04053 \\
\hline & 1586 & 1586 & 1586 & 1586 & 1586 & 1586 & 1586 & 1586 \\
\hline SPEEDVAR & 0.96277 & -0.02528 & 0.99455 & 0.05214 & 0.66515 & 0.00520 & -0.04053 & 1.00000 \\
\hline & 1586 & 1586 & 1586 & 1586 & 1586 & 1586 & 1586 & 1586 \\
\hline
\end{tabular}


Table 7.3.5 Correlations Among Lanekeeping Measures and Speed Measure Taken During Requested Task Execution

Correlation Analysis

6 'VAR' Variables: LANEPOSM IANEPVAR IANEXC LANEXS MEANSPED SPEEDVAR

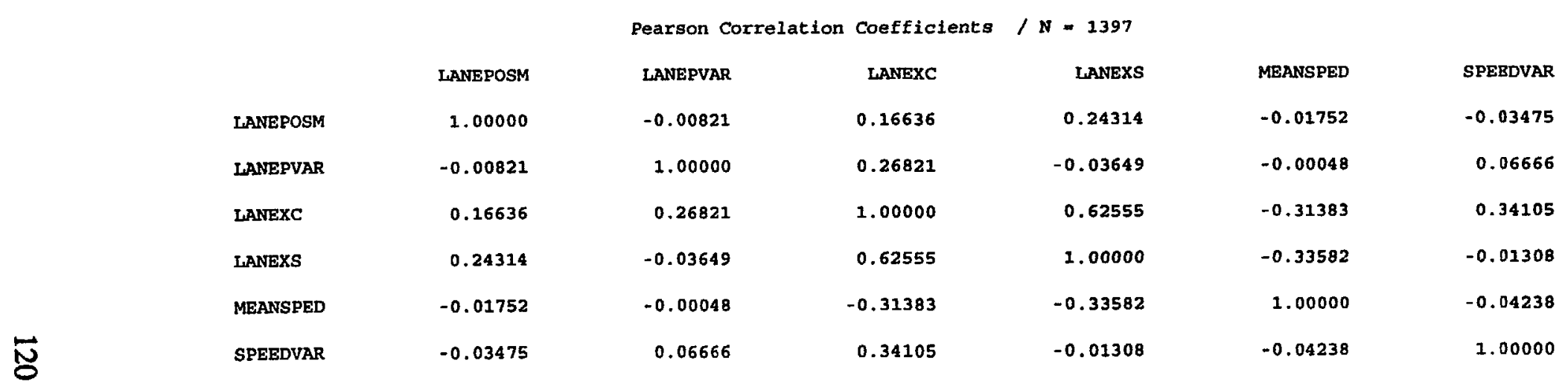


Table 7.3.6 Correlations Among Lanekeeping Measures and Steering, Accelerator, and Brake Measures During Requested Task Execution

Correlation Analysis

Pearson Correlation Coefficients / Number of observations

\begin{tabular}{|c|c|c|c|c|c|c|c|c|c|}
\hline & LANEPOSM & LANEPVAR & LANEXC & LANEXS & STPVAR & STVELVAR & STERHLD & STERHLDS & STERREV \\
\hline \multirow[t]{2}{*}{ LANEPOSM } & 1.00000 & -0.00805 & 0.16764 & 0.24349 & 0.01353 & -0.04163 & 0.07249 & 0.08771 & -0.06477 \\
\hline & 1404 & 1404 & 1404 & 1404 & 1376 & 1376 & 1376 & 1376 & 1376 \\
\hline \multirow[t]{2}{*}{ LANEPVAR } & -0.00805 & 1.00000 & 0.26526 & -0.03670 & 0.01240 & 0.01287 & 0.33524 & 0.01816 & 0.27707 \\
\hline & 1404 & 1404 & 1404 & 1404 & 1376 & 2376 & 1376 & 1376 & 1376 \\
\hline \multirow[t]{2}{*}{ IAANEXC } & 0.16764 & 0.26526 & 1.00000 & 0.61196 & 0.01565 & 0.03198 & 0.11222 & -0.07177 & 0.25389 \\
\hline & 1404 & 1404 & 1404 & 1404 & 1376 & 1376 & 1376 & 1376 & 1376 \\
\hline \multirow[t]{2}{*}{ LANEXS } & 0.24349 & -0.03670 & 0.61196 & 1.00000 & -0.01302 & -0.00930 & -0.12038 & -0.09317 & -0.10155 \\
\hline & 1404 & 1404 & 1404 & 1404 & 1376 & 1376 & 1376 & 1376 & 1376 \\
\hline \multirow[t]{2}{*}{ STPVAR } & 0.01353 & 0.02240 & 0.01565 & -0.01302 & 1.00000 & 0.95994 & 0.06576 & 0.03810 & 0.03378 \\
\hline & 1376 & 1376 & 1376 & 1376 & 1376 & 1376 & 1376 & 1376 & 1376 \\
\hline \multirow[t]{2}{*}{ STVELVAR } & -0.04163 & 0.01287 & 0.03198 & -0.00930 & 0.95994 & 1.00000 & 0.00847 & -0.04242 & 0.07735 \\
\hline & 1376 & 1376 & 1376 & 1376 & 1376 & 1376 & 1376 & 1376 & 1376 \\
\hline \multirow[t]{2}{*}{ STERHLD } & 0.07249 & 0.33524 & 0.11222 & -0.12038 & 0.06576 & 0.00847 & 1.00000 & 0.50306 & 0.29436 \\
\hline & 1376 & 1376 & 1376 & 1376 & 1376 & 1376 & 1376 & 1376 & 1376 \\
\hline \multirow[t]{2}{*}{ STERHLDS } & 0.08771 & 0.01816 & -0.07177 & -0.09317 & 0.03810 & -0.04242 & 0.50306 & 1.00000 & -0.17907 \\
\hline & 1376 & 1376 & 1376 & 1376 & 1376 & 1376 & 1376 & 1376 & 1376 \\
\hline \multirow[t]{2}{*}{ STERREV } & -0.06477 & 0.27707 & 0.25389 & -0.10155 & 0.03378 & 0.07735 & 0.29436 & -0.17907 & 1.00000 \\
\hline & 1376 & 1376 & 1376 & 1376 & 1376 & 1376 & 1376 & 1376 & 1376 \\
\hline \multirow[t]{2}{*}{ STERREVS } & -0.09443 & 0.01520 & 0.09549 & 0.04755 & -0.00707 & 0.08002 & -0.21540 & -0.41958 & 0.34152 \\
\hline & 1376 & 1376 & 1376 & 1376 & 1376 & 1376 & 1376 & 1376 & 1376 \\
\hline \multirow[t]{2}{*}{ ACLVAR } & 0.01491 & 0.05043 & 0.09190 & -0.02691 & 0.21081 & 0.18998 & 0.19238 & 0.05676 & 0.21771 \\
\hline & 1404 & 1404 & 1404 & 1404 & 1376 & 1376 & 1376 & 1376 & 1376 \\
\hline \multirow[t]{2}{*}{ ACLVVAR } & 0.03841 & 0.00161 & -0.01450 & -0.03027 & 0.11541 & 0.08783 & 0.07554 & 0.08450 & -0.02262 \\
\hline & 1404 & 1404 & 1404 & 1404 & 1376 & 1376 & 1376 & 1376 & 1376 \\
\hline \multirow[t]{2}{*}{ ACCLHLD } & -0.02941 & 0.13761 & 0.36693 & -0.03523 & 0.00565 & 0.01805 & 0.09129 & -0.03568 & 0.19994 \\
\hline & 1404 & 1404 & 1404 & 1404 & 1376 & 1376 & 1376 & 1376 & 1376 \\
\hline \multirow[t]{2}{*}{ ACCLHLDS } & 0.01635 & -0.09249 & -0.00532 & 0.11840 & -0.03840 & -0.02222 & -0.18393 & -0.03905 & -0.18414 \\
\hline & 1404 & 1404 & 1404 & 1404 & 1376 & 1376 & 1376 & 1376 & 2376 \\
\hline \multirow[t]{2}{*}{ ACCLREL } & -0.03214 & 0.05282 & 0.32302 & -0.00970 & 0.00287 & 0.00687 & -0.01372 & -0.02073 & 0.00570 \\
\hline & 1404 & 1404 & 1404 & 1404 & 1376 & 1376 & 1376 & 1376 & 1376 \\
\hline \multirow[t]{2}{*}{ ACCLRELS } & 0.00147 & -0.01278 & 0.02554 & 0.00628 & -0.00004 & -0.00161 & -0.04369 & -0.05506 & -0.00401 \\
\hline & 1404 & 1404 & 1404 & 1404 & 1376 & 1376 & 1376 & 1376 & 1376 \\
\hline \multirow[t]{2}{*}{ BRKRUOM } & -0.02972 & 0.04524 & 0.30343 & -0.01438 & 0.19535 & 0.18456 & 0.05290 & -0.01856 & 0.12038 \\
\hline & 1404 & 1404 & 1404 & 1404 & 1376 & 1376 & 1376 & 1376 & 1376 \\
\hline \multirow[t]{2}{*}{ BRRNUMS } & -0.01454 & -0.00821 & 0.00559 & -0.00929 & 0.17192 & 0.16077 & -0.00246 & -0.02111 & 0.00070 \\
\hline & 1404 & 1404 & 1404 & 1404 & 1376 & 1376 & 1376 & 1376 & 1376 \\
\hline
\end{tabular}




\section{Table 7.3.6 (Continued)}

Correlation Analyais

Pearson Correlation Coefficients / Number of Observations

\begin{tabular}{|c|c|c|c|c|c|c|c|c|c|}
\hline & STERREVS & ACLVAR & ACLVVAR & ACCLHLD & ACCLHLDS & ACCLREL & ACCLRELS & BRKNUM & BRKNUMS \\
\hline \multirow[t]{2}{*}{ LANEPOSM } & -0.09443 & 0.01491 & 0.03841 & -0.02941 & 0.01635 & -0.03214 & 0.00147 & -0.02972 & -0.01454 \\
\hline & 1376 & 1404 & 1404 & 1404 & 1404 & 1404 & 1404 & 1404 & 1404 \\
\hline \multirow[t]{2}{*}{ LANEPVAR } & 0.01520 & 0.05043 & 0.00161 & 0.13761 & -0.09249 & 0.05282 & -0.01278 & 0.04524 & -0.00821 \\
\hline & 1376 & 1404 & 1404 & 1404 & 1404 & 1404 & 1404 & 1404 & 1404 \\
\hline \multirow[t]{2}{*}{ LANEXC } & 0.09549 & 0.09190 & -0.01450 & 0.36693 & -0.00532 & 0.32302 & 0.02554 & 0.30343 & 0.00559 \\
\hline & 1376 & 1404 & 1404 & 1404 & 1404 & 1404 & 1404 & 1404 & 1404 \\
\hline \multirow[t]{2}{*}{ LANEXS } & 0.04755 & -0.02691 & -0.03027 & -0.03523 & 0.11840 & -0.00970 & 0.00628 & -0.01438 & -0.00929 \\
\hline & 1376 & 1404 & 1404 & 1404 & 1404 & 1404 & 1404 & 1404 & 1404 \\
\hline \multirow[t]{2}{*}{ STPVAR } & -0.00707 & 0.21081 & 0.11541 & 0.00565 & -0.03840 & 0.00287 & -0.00004 & 0.19535 & 0.17192 \\
\hline & 1376 & 1376 & 1376 & 1376 & 1376 & 1376 & 1376 & 1376 & 1376 \\
\hline \multirow[t]{2}{*}{ STVELVAR } & 0.08002 & 0.18998 & 0.08783 & 0.01805 & -0.02222 & 0.00687 & -0.00161 & 0.18456 & 0.16077 \\
\hline & 1376 & 1376 & 1376 & 1376 & 1376 & 1376 & 1376 & 1376 & 1376 \\
\hline \multirow[t]{2}{*}{ STERHLD } & -0.21540 & 0.19238 & 0.07554 & 0.09129 & -0.18393 & -0.01372 & -0.04369 & 0.05290 & -0.00246 \\
\hline & 1376 & 1376 & 1376 & 1376 & 1376 & 1376 & 1376 & 1376 & 1376 \\
\hline \multirow[t]{2}{*}{ STERHLDS } & -0.41958 & 0.05676 & 0.08450 & -0.03568 & -0.03905 & -0.02073 & -0.05506 & -0.01856 & -0.02111 \\
\hline & 1376 & 1376 & 1376 & 1376 & 1376 & 1376 & 1376 & 1376 & 1376 \\
\hline \multirow[t]{2}{*}{ STERREV } & 0.34152 & 0.11771 & -0.02262 & 0.19994 & -0.18414 & 0.00570 & -0.00401 & 0.12038 & 0.00070 \\
\hline & 1376 & 1376 & 1376 & 1376 & 1376 & 1376 & 1376 & 1376 & 1376 \\
\hline \multirow[t]{2}{*}{ STERREVS } & 1.00000 & -0.02356 & -0.05867 & 0.06609 & -0.00264 & 0.03613 & 0.04818 & 0.03665 & 0.01443 \\
\hline & 1376 & 1376 & 1376 & 1376 & 1376 & 1376 & 1376 & 1376 & 1376 \\
\hline \multirow[t]{2}{*}{ ACLVAR } & -0.02356 & 1.00000 & 0.65867 & 0.03693 & -0.17305 & 0.03166 & -0.01086 & 0.14333 & 0.05735 \\
\hline & 1376 & 1404 & 1404 & 1404 & 1404 & 1404 & 1404 & 1404 & 1404 \\
\hline \multirow[t]{2}{*}{ ACLVVAR } & -0.05867 & 0.65867 & 1.00000 & -0.06004 & -0.30008 & -0.00748 & -0.03404 & 0.06671 & 0.05285 \\
\hline & 1376 & 1404 & 1404 & 1404 & 1404 & 1404 & 1404 & 1404 & 1404 \\
\hline \multirow[t]{2}{*}{ ACCLHLD } & 0.06609 & 0.03693 & -0.06004 & 1.00000 & 0.05361 & 0.95369 & 0.05369 & 0.73401 & 0.00201 \\
\hline & 1376 & 1404 & 1404 & 1404 & 1404 & 1404 & 1404 & 1404 & 1404 \\
\hline \multirow[t]{2}{*}{ ACCLHLDS } & 0.00264 & -0.17305 & -0.30008 & 0.05361 & 1.00000 & -0.01592 & 0.10724 & -0.02622 & 0.02693 \\
\hline & 1376 & 1404 & 1404 & 1404 & 1404 & 1404 & 1404 & 1404 & 1404 \\
\hline \multirow[t]{2}{*}{ ACCLREL } & 0.03613 & 0.03166 & -0.00748 & 0.95369 & -0.01592 & 1.00000 & 0.08401 & 0.74444 & 0.00926 \\
\hline & 1376 & 1404 & 1404 & 1404 & 1404 & 1404 & 1404 & 1404 & 1404 \\
\hline \multirow[t]{2}{*}{ ACCLRELS } & 0.04818 & -0.01086 & -0.03404 & 0.05369 & 0.10724 & 0.08401 & 1.00000 & 0.13846 & 0.32884 \\
\hline & 1376 & 1404 & 1404 & 1404 & 1404 & 1404 & 1404 & 1404 & 1404 \\
\hline \multirow[t]{2}{*}{ BRKNUM } & 0.03665 & 0.14333 & 0.06671 & 0.73401 & -0.02622 & 0.74444 & 0.13846 & 1.00000 & 0.41024 \\
\hline & 1376 & 1404 & 1404 & 1404 & 1404 & 1404 & 1404 & 1404 & 1404 \\
\hline \multirow[t]{2}{*}{ BRKNUMS } & 443 & $\begin{array}{r}0.05735 \\
1404\end{array}$ & $\begin{array}{r}0.05285 \\
1404\end{array}$ & $\begin{array}{r}0.00201 \\
1404\end{array}$ & $\begin{array}{r}0.02693 \\
1404\end{array}$ & $\begin{array}{r}0.00926 \\
1404\end{array}$ & $\begin{array}{r}0.32884 \\
1404\end{array}$ & $\begin{array}{r}0.41024 \\
1404\end{array}$ & $\begin{array}{r}1.00000 \\
1404\end{array}$ \\
\hline & 1376 & 1404 & 1404 & 1404 & 1404 & 1404 & 1404 & 1404 & 1404 \\
\hline
\end{tabular}




\subsection{Discussion}

The correlation analysis provides general support for the workload assessment measures found to be sensitive in the ANOVA analyses. The correlations found during car following and requested task execution were generally lower than with open road driving. This is attributed to the fact that the sample time intervals during which data were gathered were substantially shorter than the 60 -second to 90 -second observation period for open road driving. Since the latter are of particular interest for in-cab device evaluation, some further discussion is warranted.

For short-duration observations (e.g., requested task execution), it appears that variables that consist of counts (e.g., exceedences) are generally more interpretable than variables that provide a rate of counts per unit time (e.g., exceedences per second). The latter variables are calculated by taking the counts in a particular observation and dividing by the total task duration for that observation to arrive at the counts per second metric. While this approach may have its uses, the interplay between incidence and duration per incidence makes the rate variables unstable for short duration tasks.

Based on the correlations found and the results presented in previous sections of this report, it appears that the preferred measures for driver workload assessment will include the following:

- $\quad$ Visual allocation measures (all)

- $\quad$ Steering holds, steering position variance, steering velocity variance, steering reversals

- $\quad$ Speed variance

- $\quad$ Lane position variance, lane exceedences.

In general, accelerator and brake measures do not appear to lend themselves well to interpretation. This is because, in the case of accelerator measures, many factors other than device workload affect how the driver uses the accelerator. For example, 2-lane rural road driving requires more accelerator movement because of substantial changes in sight distance, and perhaps uneven surfaces (Dingus et al., 1986). Furthermore, in the present study, the incidence of brake applications was generally quite low. 


\subsection{GENERAL DISCUSSION}

This study was conducted to establish baselines on heavy vehicle driver visual allocation; steering, accelerator, and brake inputs; speed and headway performance; and lanekeeping performance during real-world driving under various conditions of road type, lighting, driving scenario, and requested task. Such data are scarce in the literature. Thus, this report represents an original contribution to an understanding of heavy vehicle operation from a driver-oriented perspective.

The preceding sections presented the results obtained for each of several classes of candidate workload measures. The reader should refer to the appropriate section for details associated with specific measures. This discussion will attempt to present overall findings or trends that arose in the baseline study.

Visual allocation measures were sensitive to road type and requested task differences. In general, the 2-lane rural road prompted more visual attention to the road scene than urban or rural freeways. Requested task effects were noted in terms of average single glance duration and number of glances required to complete the requested task. The effects of ambient light level were smaller, but in the direction expected by intuition and prior research. At night, the driver spent more time looking at the road scene and took slightly longer glances to the instrument panel. There was a general lack of effects when comparing open road driving and car following. This probably resulted from the nature of the data collection run, i.e., the routes taken, the relatively low traffic density and procedures that did not allow for requested task execution during car following. The professional drivers who participated in the study allocated their visual attention in a generally safe manner based on the conditions in which they drove.

Steering, accelerator, and brake dependent measures showed some sensitivity to road type, lighting, driving scenario, and requested task effects. Differences in various conditions were consistent with expectations. For example, steering activity was greatest in the 2-lane rural road setting relative to the urban and rural freeway settings. Accelerator and brake inputs also tended to show the greatest activity on the 2-lane rural road. Outside of road effects, the differences in means were generally small and many appeared to be of no practical significance. It was noted that many factors influence driver control inputs besides workload. These include road grade, road curvature, wind gusts, and vehicle dynamics. This makes it difficult to draw clean interpretations of the these types of measures from a workload standpoint. However, at least some steering and pedal measures merit further investigation because they have been demonstrated to reflect driver attentional states such as drowsiness (Wierwille, 1994). However, the data collected and analyzed in this study relegate such measures to a lower priority than visual allocation measures. 
Speed and headway measures were also analyzed in this study. Drivers in this study maintained speeds very near the posted speed limits of the roads used in the data collection run and maintained headways that averaged very close to 2.0 seconds of time headway. They tended to fall back, generally by allowing another vehicle to pass and pull away. Speed measures were sensitive to road type differences but not to ambient lighting differences. Furthermore, for short-duration requested tasks, the kinematics of heavy vehicle operation makes it unlikely that there will be substantial changes in mean speed or speed variance during execution of such tasks. The relationship of speed and speed variance to highway safety, coupled with its sensitivity to task effects in other research (e.g., Dingus, Hulse, Fleischman, McGehee, and Manakkal, in press) suggests it be retained for further investigation and research. However, like steering, accelerator, and brake measures, the priority of speed measures is lower than that for visual allocation measures.

The headway measures collected in this study showed negligible effects in this study. This should not be taken as evidence that headway measures have no place in workload assessment. The lack of substantive effects is likely due to the relative infrequency of capturing such data, and procedural factors such as not pursuing requested tasks during car following. Under different driving conditions, e.g., rush hour traffic in a city with very heavy traffic, headway measures may provide telling information about in-cab device effects. At present, the use of headway measures should be considered tentative and of lower priority than visual allocation measures.

Lanekeeping measures were the last category of driver-vehicle performance measures reported in this study. The safety relevance of measures is drawn out from crash studies of lane change, opposite direction, and roadway departure crashes. In each of these crash types, the first significant event is an unplanned or uncontrolled lane departure. Lanekeeping measures were significantly affected by road type and requested task. The 2-lane rural road led to more lane exceedences and greater lane position variance, probably due to the greater path control demand associated with such roads. Longer requested tasks were significantly associated with greater numbers of lane exceedences and greater lane position variance. Analysis concluded that, for short-duration requested tasks, attempts to use rates of lane exceedences such as lane exceedences/second should be avoided. Relatively clear patterns that arise with lane exceedence counts become obscured when exceedences/second are used for analysis. In general, ambient lighting had a smaller effect on lanekeeping measures; drivers drove more precisely under night driving conditions. Given the safety relevance of this category of measures and the sensitivity shown by them to road type and requested task execution, lanekeeping measures should be included in future workload assessments. Furthermore, they should be considered second only to visual allocation measures in priority for a safety-relevant workload assessment.

The baseline study results are noteworthy for their consistency. In general, effects are in the right direction, i.e., the direction expected based on prior research or intuition. The 
variability of most of the measures is also relatively small considering the fact that this study was essentially a field study with many potential sources of variation.

The correlational analysis provided additional evidence that the measures taken and results obtained were valid. The correlational analysis indicated several substantial correlations among dependent measures that are coherent and follow expected trends. For example, mean time the eyes are off the road (MTOR) is negatively correlated with steering position variance and steering reversals but positively correlated with steering holds. This correlational pattern is consistent with the hypothesis that with increased attentional demand away from the road scene or driving task, steering activity decreases. Many kinematic relations are also upheld in the correlational analysis. For instance, correlations between brake application and each of mean speed and speed variance are expected to be negative and positive, respectively, and this is true.

The correlations among the measured variables generally decrease and become less stable when the data set consists of measures collected concurrently during relatively short time periods, i.e., car following and requested task execution. It is known that the magnitude of a correlation coefficient is significantly affected by the range of the variables; the more limited the range, the smaller the correlation. Shorter-durations imply range limitations for many measures, especially vehicle dynamics measures that change relatively slowly. Thus, this is a plausible explanation for the less stable correlational structure associated with requested task execution or car following. This effect also suggests that multivariate analysis to create a composite measure of short-duration task workload by analysis of the correlation matrix, e.g., principal components analysis, is unlikely to yield usable results.

Additional evidence that the results obtained from the measures used in this study are valid comes from the drivers themselves. Appendix E summarizes the results of the driver debriefings following a given run. Most drivers thought the run to be fairly typical of their normal runs. Eight believed that the presence of the ride-along experimenter caused them to be more careful. Most had no difficulty with the requested tasks. Several expressed concern about operation on 2lane highways. When asked to comment on the workload associated with the runs only two considered the workload to be higher than normal. Twenty-eight drivers reported the workload to be the same or lower than normal. When asked to rank the workload by road segment from 1 to 8 where 1 equaled the most workload, the mean rank for SR-72 day was 2.6 and for SR-72 at night it was 1.8. All other segments had easier workloads ranging from 4.8 to 5.7. When asked where they looked during a typical instrument panel search, the drivers cited the speedometer as most frequently sampled. Summarizing, drivers reported that the most demanding driving conditions were the 2-lane rural road at night, followed by the 2-lane rural road under daylight conditions. The other conditions were perceived to involve little workload. This parallels the objective measures and results obtained with them. 
Some comment on the realism of the data collection session must be made. Drivers often said they did not believe they had enough time to get accustomed to the truck. The research team anticipated this and did not use the data from the first segment (approximately 45 minutes long) in the analysis. However, the comments remain. Furthermore, several drivers stated that they thought the presence of an on-board experimenter probably caused them to drive more carefully. This suggests that the presence of an on- board experimenter influenced the drivers to some degree. Therefore, the baseline data may differ from other data that might be collected in less obtrusive ways. In future research or workload evaluation, it would be ideal to have drivers in their own vehicles with no ride-along observer present. However, the feasibility of this will depend largely on the ability to instrument the driver's own vehicle easily and monitor it unobtrusively. "Driver Assessment System for Crash Avoidance Research" (DASCAR) project, under the sponsorship of NHTSA, is attempting to develop a system that can meet these requirements.

The candidate workload measures collected in this baseline study generally show relatively tight variation. This is taken as an indication that the candidate workload measures as a whole represent a relatively clean measurement system.

From a logistical point of view, several instrumentation challenges were encountered during the study. The instrumentation used in the study was sometimes unreliable and this led to different levels of reliability in the data and results from those channels of data. The visual allocation measures, for instance, were extremely reliable because of the robustness of the video equipment used. Unfortunately, manual data reduction was time consuming and labor intensive. Speed measures were relatively robust and could be automatically recorded and subsequently reduced. The same is true of steering, accelerator, and brake inputs. The automatic lane tracker, on the other hand, was less reliable and this led to data loss. For example, there were problems with the auto-iris that arose gradually and the system would sometimes lose the lane line if the luminance difference between the painted lane line marker and the adjacent pavement was not sufficient. The laser headway sensor used in this study also had some problems associated with it. For instance, as a line-of-sight system, it would lose the lead vehicle when the road ahead curved beyond a certain degree. The system would also sometimes pick up stationary objects on the roadside. These examples are presented here to indicate that instrumentation reliability deserves high priority for a workload assessment project that attempts to gather measures like those presented in this report. It should also be noted that the kinds of instrumentation needed to collect the kinds of measures reported herein are also like those needed for ITS applications such as Collision Avoidance Systems (CAS) and driver alertness monitoring. There is a great deal of effort currently under way to develop sensors for ITS applications that will be suitable for driver workload assessment and attentional status monitoring as well. More specifically, the NHTSA DASCAR program is in the process of solving many of the problems encountered in this study. 
In conclusion, the following recommendations are made:

- Visual allocation measures should be high priority measurements to be collected in workload assessments. Such measures show sensitivity to factors related to driver workload. Furthermore, the primacy of vision in safe driving virtually dictates that such measures be examined. The manual data reduction methods in this study make use of visual allocation measures prohibitive without substantial time and dollar resources. It is recommended that efforts be directed toward determining automated means of data capture, data reduction, or both (see Tijerina et al., 1995 for a discussion of this issue). For example, image processing technology might be applied to visual allocation video data extraction.

- $\quad$ Lanekeeping measures are preferred due to their safety relevance and potential sensitivity to various factors associated with driver workload. Empirical and theoretical considerations indicate that lanekeeping measures like lane exceedences and lane position variability will be useful measures for assessing the demand of high-technology in-cab devices. There is a need to provide robust sensors for automatic lane tracking to support collection and analysis of lanekeeping performance. The instrumentation used in this study was sometimes unreliable and led to data loss. The need for lanetracking instrumentation is associated with many aspects of ITS (e.g., crash avoidance), and it is expected that evolving technologies will soon be brought to bear on this need.

- $\quad$ Optional measures that may be collected for workload are in-cab driver control inputs. This category of measures includes steering holds and steering reversals, accelerator holds and accelerator releases. Such measures can be influenced by a great many factors such as road grade, road curvature, vehicle dynamics, wind gust, and so forth. However, there is evidence that these measures can serve as indicators of driver attentional state and effort.

A final note on safety and traffic conflicts deserves mention. Some investigators have mentioned the importance of collecting traffic conflict data with which to assess new in-vehicle technologies (e.g., Dingus, 1995). This includes data on abrupt lateral maneuvers, hard braking, or observations of near-miss collision circumstances that might be associated with attentional demand away from the driving task. Data on high lateral or longitudinal accelerations were not analyzed in this report because no traffic conflicts were observed. The drivers in this study exhibited superb driving and over many hours on the road no safetyrelevant incident arose. This suggests that experienced heavy vehicle drivers may truly differ from the population of passenger car drivers in terms of their driving skills and judgement, factors that bode well for the safe introduction of advanced technology into the fleet. It remains to be seen if specific high-technology devices (e.g., text message systems, voice communication systems, route guidance systems) can inadvertently lure the driver's attention away from the road scene and increase the risk of a mishap. 


\section{REFERENCES}

Chovan, J. D., Everson, J. H., Hendricks, D. L., \& Pierowicz, J. (1994). Analysis of opposite direction crashes. (OMNI Task RA1039, Contract No. DTRS-57-89-D-00086). Cambridge, MA: Volpe National Transportation Systems Center.

Chovan, J. D., Tijerina, L., Alexander, G., \& Hendricks, D. L. (1994, March). Examination of lane change crashes and potential IVHS countermeasures (Report No. DOT HS 808 071/DOT-VNTSC-NHTSA-93-2). Cambridge, MA: U.S. Department of Transportation Volpe National Transportation Systems Center.

Chovan, J. D., Tijerina, L., Everson, J. H., Pierowicz, J. A., \& Hendricks, D. L. (1994, September). Examination of intersection, left turn across path crashes and potential IVHS countermeasures (Report No. DOT HS 808 154/DOT-VNTSC-NHTSA-94-4). Cambridge, MA: U.S. Department of Transportation Volpe National Transportation Systems Center.

Devore, J. L. (1982). Probability and statistics for engineering and the sciences. Monterey, CA: Brooks/Cole.

Dingus, T. A., Antin, J. F., Hulse, M. C., \& Wierwille, W. W. (1986, September). Human factors test and evaluation of an automobile moving-map navigation system Part I: Attentional demand requirements (IEOR Report No. 86-03). Blacksburg, VA: Vehicle Analysis and Simulation Laboratory, Virginia Polytechnic Institute and State University.

Dingus, T. A., Antin, J. F., Hulse, M. C., \& Wierwille, W. W. (1989). Attentional demand requirements of an automobile moving-map navigation system. Transportation Research, $23 \mathrm{~A}(4), 301-315$.

Dingus, T. A., \& Hulse, M. C. (1993, January). TravTek Evaluation: Task C3 camera car study final detailed test plan (Contract No. DTFH61-91-C-00106). Iowa City, IA: Performance and Safety Sciences, Inc.

Dingus, T. A. (1995). Moving from measures of performance (MOPs) to measures of effectiveness (MOEs) in the safety evaluation of ITS products or demonstrations. In D. Nelson (Ed.), Proceedings of ITS Safety Evaluation Workshop. Washington, DC: ITS America.

Dingus, T. A., Hulse, M. C., Fleischman, R. N., McGehee, D. V., \& Manakkal, N. (in press). The effects of age and navigation technique on driving with an Advanced Traveler Information System. Human Factors. 
Green, P. (1983, April). Measures and methods used to assess the safety and usability of driver information systems (Technical Report No. UMTRl-93-12). Ann Arbor, MI: University of Michigan Transportation Research Institute.

Hendricks, D., Allen, J., Tijerina, L., Everson, J., Knipling, R., \& Wilson, C. (July, 1992). VNTSC IVHS program Topical Report \#2: Single vehicle roadway departures (Volumes I and II) (Contract No. DTRS-57-89-D-00086). Columbus, OH: Battelle

Hood, D. C., \& Finlkestein, M. A. (1986). Sensitivity to light. In K. Boff, L. Kaufman, \& J. P. Thomas (Eds.), Handbook of perception and performance - Volume I: Sensory processes and perception (pp. 5-1 to 5-66). New York: John Wiley.

Kiger, S., Rockwell, T. H., Niswonger, S., Tijerina, L., Myers, L. B., \& Nygren, T. (1992, September). NHTSA heavy vehicle driver workload assessment Task 3 Interim Report: Task analysis data collection (Contract No. DTHN22-91-C-07003). Columbus, OH: Battelle.

Kirk, R. E. (1982). Experimental Design (Second Edition). Belmont, CA: Brooks/Cole Publishing.

Kurokawa, K., \& Wierwille, W. W. (1990). Validation of a driving simulation facility for instrument panel task performance. Proceedings of the Human Factors Society 34th Annual Meeting, 1299 - 1303.

Liebowitz, H. W. (1988). The human senses in flight. in E. L. Wiener and D. C. Nagel (Eds.), Human factors in aviation (pp. 83 - 110). San Diego, CA: Academic Press.

Liebowitz, H. W., \& Owens, D. A. (1986). We drive by night. Psychology Today, 20(1), 54 $-58$.

MacDonald, W. A., \& Hoffmann, E. R. (1980). Review of relationships between steering wheel reversal rate and driving task demand. Human Factors, 22(6), $733 \cdot 739$.

Milliken, G. A., \& Johnson, D. E. (1984). Analysis of Messy Data Volume I: Designed Experiments (pp. 251-262). New York: Van Nostrand Reinhold.

Mironer, M., \& Hendricks, D.L. (1994, August). Examination of single vehicle roadway departure crashes and potential IVHS countermeasures (Report No. DOT HS 808144 and DOT-VNTSC-NHTSA-94-3). Cambridge, MA: U.S. Department of Transportation John A. Volpe National Transportation Systems Center.

Rockwell, T. H. (1988). Spare visual capacity in driving- revisited: New empirical results for an old idea. In A. G. Gale et al. (Eds.), Vision in vehicles ZZ. Amsterdam, The Netherlands: Elsevier. 
Rockwell, T. H. (1972). Skills, judgement, and information acquisition in driving. In T. W. Forbes (EM .), Human factors in highway traffic safety research (pp. 133 - 164). New York: Wiley Interscience.

SAS Institute (1992). SAS'M user' s guide: Statistics (Version 6). Carey, NC: SAS Institute.

Searle, S. R., Casella, G., \& McCulloch, C. E. (1992). Variance Components (pp. 254-256). New York: John Wiley \& Sons.

Tijerina, L., Hendricks, D., Pierowicz, J., Everson, J., \& Kiger, S. (1993, September). Examination of backing crashes and potential IVHS countermeasures (Report No. DOT HS 808016 and DOT-VNTSC-NHTSA-93-1). Cambridge, MA: Volpe National Transportation Systems Center.

Tijerina, L., Kantowitz, B., H., Kiger, S., \& Rockwell, T. H. (1994, May). Driver workload assessment of in-cab high technology devices (Paper No. 94-S2-0-06). Paper presented at the XIVth International Technical Conference on Enhanced Safety of Vehicles, Munich, Germany, May 23 - 26, 1994.

Tijerina, L., Kiger, S. M., Rockwell, T. H., \& Wierwille, W. W. (1995, June). NHTSA heavy vehicle driver workload assessment Task 5 Interim Report: Workload Measurement Protocol Development Draft Driver Workload Assessment Protocol (Contract No. DTHN2291 -C-07003). Columbus, OH: Battelle.

Turanski, A., \& Tijerina, L. (January, 1992). NHTSA heavy vehicle driver w orkload assessment Task 2 Interim Report= Standard vehicle configuration/task specifications (Contract No. DTHN22-91-C-07003). Columbus, OH: Battelle.

Wierwille, W. W., Tijerina, L., Kiger, S. M., Rockwell, T. H., Lauber, E., \& Bittner, A. (September, 1992). NHTSA Heavy Vehicle Driver Workload Assessment Task 4 Interim Report= Review of Workload and Related Research and a Theoretical Basis for Safety Relevance of W orkload Measures (Contract No. DTHN22-91-C-07003). Columbus, OH: Battelle.

Wierwille, W. W. (1993). Visual and manual demands of in-car controls and displays. in B. Peacock and W. Karwowski (Eds.), Automotive ergonomics (pp. 299 - 320). London: Taylor and Francis.

Wierwille, W. W. (1994). Overview of research on driver drowsiness definition and driver drowsiness detection (Paper No. 94 S3 0 07). Paper presented at the XIVth International Technical Conference on the Enhanced Safety of Vehicles, Munich, Germany, May 23-26, 1994. 
Zwahlen, H., Adams, C. C., \& DeBald, D. P. (1988). Safety aspects of CRT touch panel controls in automobiles. In A. G. Gale et al (Eds.), vision in Vehicles II (pp. 335-344). Amsterdam: Elsevier. 
Appendix A: Subject Biographical Data Summary 
1. Gender: Male $27 \quad$ Female 3

2. Age: 38

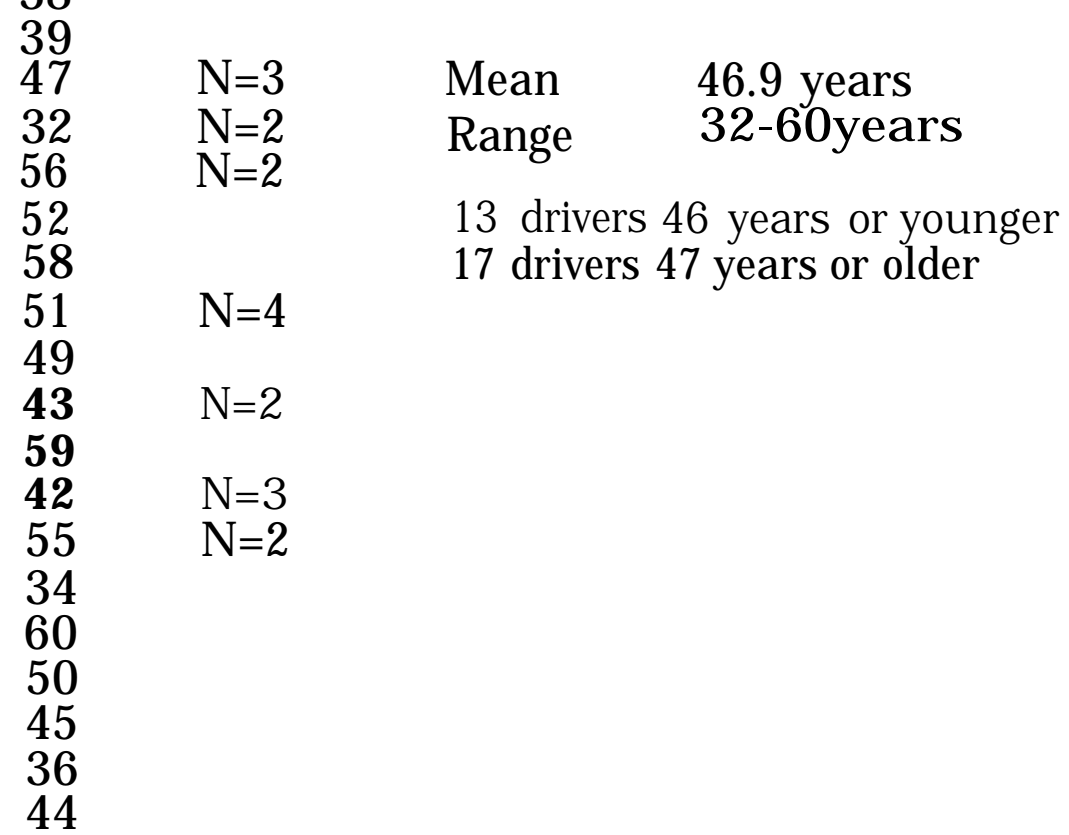

3. Years of Driving Experience: $\quad 5.5 \quad \mathrm{~N}=2$

$\begin{array}{rll}15.0 & & \\ 6.0 & & \\ 14.0 & & \text { Mean: } 21.6 \text { years } \\ 34.0 & & \text { Range: } 5.5-42 \text { years } \\ 20.0 & & \\ 30.0 & \mathrm{~N}=4 & \\ 26.0 & \mathrm{~N}=3 & \\ 9.5 & & \\ 35.0 & \mathrm{~N}=2 & \\ 24.0 & \mathrm{~N}=4 & \\ 11.0 & & \\ 16.0 & \mathrm{~N}=4 & \\ 27.0 & & \\ 10.0 & & \\ 21.0 & & \\ 42.0 & & \end{array}$


4. Years of Driving Experience with longtrailers*:

* (48 ft. and longer and/or multiple trailers)

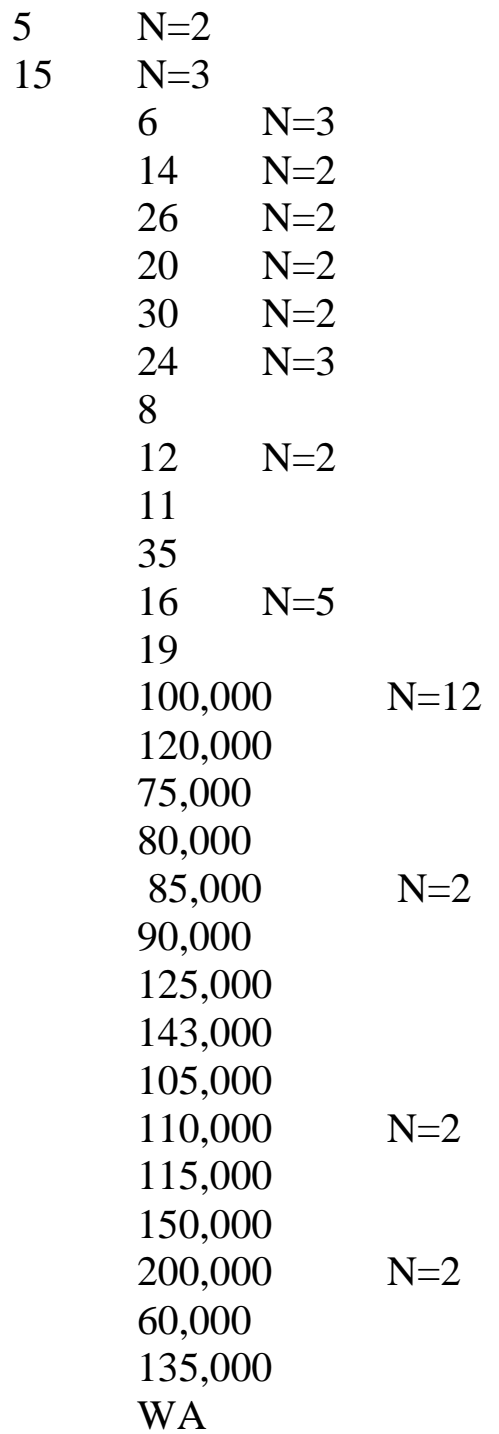

6. Corrective lenses worn? $\quad$ Yes $16 \quad$ No 14

Mean 109,931.0 miles

Range 60,000 - 200,000

WA

Type:

Near Vision

7. Height: 6'2" $\mathrm{N}=5$

6'3" $\mathrm{N}=2$

5'2" Mean 5'11"

5'11" N=5 Range 5'2" -6'4"

5,9 ' $\mathrm{N}=4$

6'0 $\mathrm{N}=5$

$5,10 \quad \mathrm{~N}=3$

6'4"

6'1"

5' 6 "

5,5 "

$5 " 8 "$
Glasses 16

Distance Vision 2 Both 9 
8. Dominant hand: left 5 right 25

9. Seated Eye Height (above floor) (inches) $48 \mathrm{~N}=7$

Mean 47.5 inches

Range 43 - 50 inches

10. Viewing Distance to Speedometer

Mean 30.8 inches

Range 28 - 34 inches
$49 \mathrm{~N}=5$

43

$47 \mathrm{~N}=8$

$46 \mathrm{~N}=4$

$50 \mathrm{~N}=3$

$45 \mathrm{~N}=2$

$31 \mathrm{~N}=5$

$33 \mathrm{~N}=5$

$29 \mathrm{~N}=9$

$32 \mathrm{~N}=5$

28

$30 \mathrm{~N}=4$

34

11. Viewing Distance to AM/FM Radio

Mean 33.6 inches

Range 3137 inches

$34 \mathrm{~N}=5$

$35 \mathrm{~N}=5$

$32 \mathrm{~N}=4$

$31 \quad N=5$

$33 \mathrm{~N}=6$

$36 \mathrm{~N}=3$

$37 \mathbf{N}=\mathbf{2}$

12. Viewing Distance to CB Radio

Mean 25.1 inches

Range 22 - 30 inches
$26 \mathrm{~N}=8$

$25 \mathrm{~N}=2$

$28 \mathrm{~N}=3$

$24 \mathrm{~N}=8$

$22 \mathrm{~N}=3$

$23 \mathrm{~N}=3$

$27 \quad N=2$

30

13. On a typical working run, do you normally use any of the following equipment?
a) $\mathrm{AM} / \mathrm{FM}$ radio
23
$76.7 \%$ of total
w/cassette player 19
$63.3 \%$ of total
w/CD player
b) $\mathrm{CB}$ radio
28
93.3\% of total
c) Cellular telephone 2
$6.7 \%$ of total 
Appendix B: Subject Instructions 


\section{APPENDIX B. Subject Instructions}

Thank you for agreeing to help us in this study. The major objective of the study is to better understand the various driving tasks truck drivers must perform and the effects of different highway, traffic and weather conditions on driving. One of the key questions of the study is identifying where drivers look while performing their tasks.

'To record data for the project, we have mounted several video cameras in the cab. One video camera is mounted on the dash and is focused on your face to record your glances. Other cameras are positioned to record where you reach and to record the road, traffic and the weather conditions on the trip.

"On our run today we will be going <insert general description of route used - e.g., South on I-71 to SR 72 . . . > As the trip progresses, I will remind you of upcoming route changes far enough in advance for you to make preparations for changing lanes or making a turn.

"During the run we will observe you as you naturally drive. We will also ask you to perform ordinary driving related tasks throughout the trip. For example. we will ask you to use your mirrors, read the speedometer or other engine gauges and operate your radio. Since we will frequently ask you to perform these tasks during the trip, we hope you will be patient with us.

"It is essential for you to understand that safe driving comes first. Drive the truck first and perform the other tasks only when it is safe and convenient for you to do so. Never blindly follow our instructions if you feel the safely of the trip would be jeopardized. Always obey the rules of the road.

"Once again, remember that this is an ordinary trip with the addition of a few driving related tasks. Safety comes first; execute the other tasks only when it is safe to do so,

You may stop the study at any time during the trip should you wish to do so. We plan to take periodic breaks during the trip so that you have an opportunity to rest. If you need to stop before one of the planned breaks, just let me know.

"As a token of our appreciation for your assistance, you will be paid $\$ 138.00$ for participation in the study. We also want to assure you that your name will remain anonymous - only our immediate project staff will know who you are.

"Do you have any questions?" 
Appendix C: Informed Consent Form 


\title{
APPENDIX C. Informed Consent Form
}

\author{
Title of Study: $\quad$ Heavy Vehicle Driver Workload Assessment Project
}

Study Descrintion: Many high technology in-cab devices are being proposed for use in heavy trucks (e.g.,route guidance systems, trip recorders, text displays, communications systems, etc.). These devices sometimes introduce additional tasks which might compete with the driver's primary job of safely controlling the vehicle at all tunes. Battelle is conducting a research project for the National Highway Traffic Safety Administration (NHTSA) to measure the effects on drivers of introducing high technology in-cab devices. We believe that this work will contribute significantly toward enhancing safety and promoting a driver-centered approach to the development of high technology in-cab devices.

As part of our work, Battelle (through our subcontractor R\&R Research, Inc.) must collect data from drivers under various normal driving conditions. The purpose of this data collection is to better understand the various driving tasks drivers must perform today, the driving conditions under which they work, and the driver behaviors, performance, and attitudes which may reflect driver workload.

As a voluntary participant, you will drive a US Government tractor-semitrailer through public roadways selected for the study. During testing, a ride-along experimenter will be in the vehicle with you on your assigned route. This observer will operate measurement equipment, give instructions to you about where to drive, and ask you to operate equipment commonly found in modem heavy vehicles. On-the-road data collection will observation of driving behaviors and tasks performed, vi\&o taping of the road scene and the driver's visual scanning patterns, and various measures of driving performance such as lane keeping, speed control, headway maintenance, and so forth. The ride-along experimenter will ask you to visually scan the west coast mirrors and selected gauges on the instrument panel or to manipulate knobs or switches when driving permit. The ride-along experimenter will ask you to answer questions about heavy vehicle driving.

\section{Yoll. the driver. are in control and will be the final judge on whether or when to respond to anv reagest. Do not blindly follow anv request. Follow our requests and answer our questions onlv when it is safe and convenient to do so.}

Risks: While driving for this study, you will be subject to all risks normally present during heavy truck driving. There are no known physical or psychological risks associated with participation in this study beyond those normally found in heavy truck driving. However, you must be aware that accidents can happen any time while driving.

You remain legally liable for your actions during this testing. You will not intentionally be asked to drive illegally. Should an action requested of you by the ride-along: experimenter seem illegal. vo are not to do it. Should yo receive a speeding ticket or some other legal penalty for your driving during this testing, you understand that neither Battelle, R\&R Research, Inc., nor the US Government will compensate you for any fines or otherwise assist you in resolving legal problems arising out of any illegal action.

Benefits: The results of this study will provide valuable guidance for the development of an evaluation method to determine the safety of high technology in-cab devices offered for use in heavy trucks.

By participating in this study, you will get some exposure to transportation research methods and will be lending your expertise and experience to support highway safety research regarding future use of in-cab devices. 
Confidentiality: We are gathering information on heavy vehicle driving. We are not testing you. If you agree to participate in this study, you name will not be released to anyone other than the principal investigator. Individual performance will not have the subject's name associated with it in any interim or final reports. This confidentiality will be maintained.

Principal Investigator: If you have any questions or comments in relation to this study, please contact the following person:

Louis Tijerina, Ph.D.

Battelle

505 King Avenue

Columbus, OH 43201

Phone: 614-424-5406

\section{Right to Withdraw: YOU HAVE THE OPTION OFWITHDRAWING AT ANY TIME DURING} THE COURSE OF THE STUDY.

Compensation: You will be paid a sum of $\$ 138.00$ to participate in this study for an estimated one full day of your time. You are entitled to this pay even if you elect to withdraw at any time during the course of the study.

Cautions: As mentioned earlier, there are no known risks associated with participation in this study beyond those normally found in heavy truck driving. You will be the final judge of when or whether to respond to a question or request by the ride-along experimenter. If new information becomes available which might reasonably be expected to affect your willingness to continue to participate in the study, you will be so informed.

Approximately thirty-five (35) drivers are expected to participate in this study.

It is not anticipated that you will be informed of the results of this study.

Tsposition oned Comsentator will retain a copy of this Informed Consent Form. A copy of this form will also be provided to you upon completion of participation in this study.

\section{INFORMED CONSENT:}

I, UNDERSTAND THE TERMS OF THIS

AGREEMENT AND CONSENT TO PARTICIPATE IN THIS STUDY.

Signature Date 
Appendix D: Checklist for Tasks and Naturally Occurring Maneuvers 
APPENDIX D. Checklist for Tasks and Naturally Occurring Maneuvers

Repeat list at least once for each segment. If possible, perform naturally occurring maneuvers first then commanded tasks.

NATURALLY OCCURRING MANEUVERS:

Segment 6

1. Right lane car follow

la Center lane car follow

2. Right lane open road driving

2a Center lane open road driving

3. Overtake and pass slower vehicle

4. Exit/enter freeway

\section{COMMANDED TASKS:}

10. Turn heater/AC temp up/down

1. Turn AM/FM radio volume up/down

3. Right mirror - detection

9. Read clock

11. Left mirror - detection

4. Turn CB volume up/down

2. How much more can you drive today before you are out of hours

8. Change CB frequency (3 or 19)

7. Left mirror - discrimination

6. Manually tune $\mathrm{AM} / \mathrm{FM}$ radio (96.3 or 105.7 )

12. Right mirror - discrimination

5. Read air pressure

Perform the commanded tasks in order listed. 
Appendix E: Summary of Subject Debriefing 
APPENDIX E.

Debriefing (Subjects 101-130)

Summary of Subject

1. Was this a typical run for you as a professional truck driver?

Shorter than normal

$\mathrm{N}=6$

Easier than typical day

Basically the same

$\mathbf{N}=\mathbf{2 0}$

More stops and lights than usual

No really close, he runs in the mountains of Pennsylvania

Somewhat, except for the presence of the 2-lane road and usually drive more hours

Had a little trouble getting used to the truck - OK at end

Did the presence of the experimenter affect your driving, e.g., were you more careful than when driving alone?

No

$\mathbf{N}=\mathbf{1 8}$

Yes

$\mathbf{N}=\mathbf{8}$

No, but kept him more aware and alert

$\mathbf{N}=\mathbf{2}$

Nervous at first - didn't know what I was checking on 
2. Did you have any difhulties during the run? (Probe for difficulties in driving the truck or in executing the tasks asked by the experimenter.)

No

Had trouble hearing question regarding mirror

Steering wheel poorly positioned

Difficulty reaching CB to make asked for adjustments

$\mathrm{N}=2$

Took a little while to get used to positioning of things

Tired at the end

Night driving on wet road made it difficult to see

Route 72 is dangerous

Had trouble with transmission and power steering $\quad \mathrm{N}=2$

Seat belt too tight

Turns were tricky on Rt. 72, downshifting and performing tasks

3. Compared to other Typical," normal runs you have made, do you think your driving workload today was higher, lower or about the same as in the other runs? Why? (Inquire by segment of run.)

Workload was lower - traffic was light

$\mathrm{N}=2$

About the same

$\mathrm{N}=15$

Workload lower (285 mi./7.25 hr.)-

typical day $(350-430 \mathrm{mi} / 8-10 \mathrm{hr}$.) $\quad \mathrm{N}=2$

Back roads with 1 trailer is tougher than with doubles

Workload lower - no comparison

Workload lower because schedule and fatigue were not factors

Lower than usual-solid run-carried more weight-design $\quad \mathrm{N}=2$ of truck make run easier (air ride, power steering)

Lower-not as many miles. He has other work to do in a normal run.

Great truck, reduced stress

Everything about the same - Route 72 more difficult $\quad \mathrm{N}=6$

Lower - no time constraints

Higher - not typical route, passenger present 
4. Below is a list of the eight segments of the run we just made. (Review the list with the driver.) How would you rank the segments in terms of the driving workload you experienced today? Use a " 1 " for the segment with the most workload and an ' 8 "' for the segment with the least workload.

\begin{tabular}{|c|c|c|c|}
\hline \multirow{2}{*}{$\frac{\text { Segment }}{1}$} & \multirow{2}{*}{$\frac{\text { Highways }}{\text { I-71 south to S.R } 72}$} & \multicolumn{2}{|l|}{$\underline{\text { Rank }}$} \\
\hline & & 3 & $\mathrm{~N}=2$ \\
\hline & & 8 & $\mathrm{~N}=6$ \\
\hline & & 7 & $\mathrm{~N}=4$ \\
\hline & & 5 & $\mathrm{~N}=3$ \\
\hline & & 4 & \\
\hline & & 6 & \\
\hline & & 2 & $\mathrm{~N}=2$ \\
\hline & S.R 7 north to I-70 & 1 & $\mathrm{~N}=5$ \\
\hline & & 2 & $\mathrm{~N}=5$ \\
\hline & & 5 & $\mathrm{~N}=2$ \\
\hline & & 4 & $\mathrm{~N}=2$ \\
\hline & & 3 & \\
\hline & & 6 & \\
\hline & I-70 east to I-71 & 6 & $\mathrm{~N}=5$ \\
\hline & & 8 & $\mathrm{~N}=3$ \\
\hline & & 7 & $\mathrm{~N}=4$ \\
\hline & & 3 & $\mathrm{~N}=4$ \\
\hline & I-71 north to U.S.36 & 4 & $\mathrm{~N}=9$ \\
\hline & & 3 & \\
\hline & & 8 & $\mathrm{~N}=3$ \\
\hline & & 6 & $\mathrm{~N}=2$ \\
\hline & & 5 & $\mathrm{~N}=3$ \\
\hline & & 2 & \\
\hline & I-71 south to I-70 (night) & 2 & $\mathrm{~N}=2$ \\
\hline & & 3 & $\mathrm{~N}=4$ \\
\hline & & 4 & $\mathrm{~N}=2$ \\
\hline & & 5 & $\mathrm{~N}=4$ \\
\hline & & 6 & $\mathrm{~N}=5$ \\
\hline & & 8 & \\
\hline & & 7 & \\
\hline & I-70 west to S.R 71 (night) & 7 & $\mathrm{~N}=4$ \\
\hline & & 5 & $\mathrm{~N}=6$ \\
\hline & & 6 & $\mathrm{~N}=2$ \\
\hline & & 1 & \\
\hline & & 3 & $\mathrm{~N}=3$ \\
\hline & & 4 & $\mathrm{~N}=2$ \\
\hline & & 8 & \\
\hline & S.R.7 south to I-71 (night) & 2 & $\mathrm{~N}=6$ \\
\hline & & 1 & $\mathrm{~N}=11$ \\
\hline & & 3 & \\
\hline & & 4 & \\
\hline & I-71 north to terminal (night) & 8 & $\mathrm{~N}=5$ \\
\hline & & 7 & $\mathrm{~N}=6$ \\
\hline & & 6 & $\mathrm{~N}=3$ \\
\hline & & 3 & $\mathrm{~N}=3$ \\
\hline & & 1 & $\mathrm{~N}=2$ \\
\hline
\end{tabular}

Sample size 11 less due to confusion of driver 
4a. What could be done within these run conditions that would increase driver workload?

No

Make it longer

$\mathrm{N}=2$

Make it later at night

Drivers tend to be uncomfortable with riders in cab

Use a less comfortable truck

Different time of departure (a.m. school buses, rush hr.) $\quad \mathrm{N}=2$

Make driver be at a given spot at a given time

4b.. When you look at the I.P. during ordinary driving, what instruments are you checking? Could you estimate the percent of time you look at each of the instruments you mentioned?

Speedometer

Air pressure

Voltage

Cruise control

$75 \% \quad \mathrm{~N}=6$

$20 \% \quad \mathrm{~N}=5$

$5 \% \quad \mathrm{~N}=5$

$25 \%$

5. How would you evaluate the time provided for you to get accustomed to the truck? Was the time provided enough, longer than needed, or not enough time?

Enough time

$$
\mathrm{N}=27
$$

Need better explanation of transmission

More than enough time

$\mathrm{N}=2$

Power steering took much more time

Never got used to transmission

Is there anything that could speed up familiarization with the truck?

No

$$
\mathrm{N}=10
$$


6. Do you have any other comments for us about our study?

No

Good idea, hope it works for the right purpose

Go over some hills

Adjust headlights up a little

I was only interested in the money

Some tasks not entirely clear, e.g., presence of traffic - how far next time unit uncoupled, check 5th wheel grease

Study is a great thing but you have only scratched the surface of what goes on in the average day of a trucker. I would like to talk to someone about other factors.

Fun trip, glad to help anytime

Real nice truck and researcher

I enjoyed the drive $\mathrm{N}=3$

Comfort clip for seatbelt

Truck handled nicely

I think these routes represent the correct challenge that a driver should have to operate this equipment

Test evaluator was very informative, helpful and professional

Would like headlights to come on automatically when windshield wipers are on - day or night

Need tilt steering wheel

Light on in bunk at night a hazard

What was objective?

I like the pulling power of the motor

Additional study pertaining to the importance of radial tires and front end alignment on uneven highways

Would like to see my tape - might help me correct some bad habits

Would like to see a study on the different speed limits for trucks and cars

Study on how to eliminate blind spots 
7. Do you have any suggestions on how we can recruit more drivers?

More information on the role of Battelle would cause local drivers to be more interested and possible more trusting.

Allow smoking - thats what we do when driving

I was interested in money

Bulletin board at union hall

Put up the signs in the drivers room at the terminal

8. We may be making another set of runs later this year, would you be interested in making another run for us?

Subject $121 \quad$ yes

Subject 122 yes

Subject 123 yes

Subject 124 yes

Subject 125 yes

Subject 126 yes

Subject 127 yes

Subject 128 yes

Subject 129 yes

Subject 130 yes 